\title{
Inflammatory bowel disease and nutrition
}

Citation for published version (APA):

Geerling, B. J. (1999). Inflammatory bowel disease and nutrition. [Doctoral Thesis, Maastricht University]. Universitaire Pers Maastricht. https://doi.org/10.26481/dis.19990625bg

Document status and date:

Published: 01/01/1999

DOI:

$10.26481 /$ dis. $19990625 \mathrm{bg}$

Document Version:

Publisher's PDF, also known as Version of record

\section{Please check the document version of this publication:}

- A submitted manuscript is the version of the article upon submission and before peer-review. There can be important differences between the submitted version and the official published version of record.

People interested in the research are advised to contact the author for the final version of the publication, or visit the DOI to the publisher's website.

- The final author version and the galley proof are versions of the publication after peer review.

- The final published version features the final layout of the paper including the volume, issue and page numbers.

Link to publication

\footnotetext{
General rights rights.

- You may freely distribute the URL identifying the publication in the public portal. please follow below link for the End User Agreement:

www.umlib.nl/taverne-license

Take down policy

If you believe that this document breaches copyright please contact us at:

repository@maastrichtuniversity.nl

providing details and we will investigate your claim.
}

Copyright and moral rights for the publications made accessible in the public portal are retained by the authors and/or other copyright owners and it is a condition of accessing publications that users recognise and abide by the legal requirements associated with these

- Users may download and print one copy of any publication from the public portal for the purpose of private study or research.

- You may not further distribute the material or use it for any profit-making activity or commercial gain

If the publication is distributed under the terms of Article $25 \mathrm{fa}$ of the Dutch Copyright Act, indicated by the "Taverne" license above, 


\title{
Inflammatory Bowel Disease
}

\author{
and
}

\author{
Nutrition
}


- Berendina Janna Geerling, Maastricht 1999

ISBN 90-9012745-3

Cover design: Ineke Brummer

Production: Datawyse | Universitaire Pers Maastricht.

The studies described in this thesis were supported by grants from Novartis Nutrition Ltd, Switzerland and by Yamanouchi BV, the Netherlands.

Printing of this thesis was financially supported by Novartis Nutrition Ltd, Yamanouchi BV, Ferring BV and Astra Pharmaceutica BV. 


\title{
Inflammatory Bowel Disease
}

\author{
and
}

\section{Nutrition}

\author{
PROEFSCHRIFT
}

ter verkrijging van de graad van doctor

aan de Universiteit Maastricht,

op gezag van de Rector Magnificus,

Prof Dr AC Nieuwenhuijzen Kruseman,

volgens het besluit van het College van Decanen,

in het openbaar te verdedigen

op vrijdag 25 juni 1999 om 12.00 uur

door

BJ Geerling

geboren op 14 augustus 1969 te Zwolle 


\section{Promotor}

Prof dr RW Stockbrügger

\section{Co-promotor}

Dr R-JM Brummer

\section{Beoordelingscommissie}

Prof dr ir WHM Saris (voorzitter)

Dr I Bosaeus (Universitet Göteborg, Sweden)

Prof dr MP van Dieijen-Visser

Prof dr SGM Meuwissen (Vrije Universiteit van Amsterdam)

Prof dr HP Sauerwein (Universiteit van Amsterdam)

Prof dr EFM Wouters 


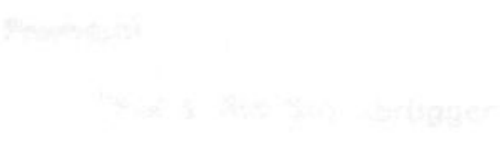




\section{Contents}

$\begin{array}{lll}\text { Chapter } 1 & \text { Introduction }\end{array}$

$\begin{array}{lll}\text { Chapter } 2 & \text { Nutrition and Inflammatory Bowel Disease: an update } & 17\end{array}$

Chapter 3 Diet as a risk factor for the development of ulcerative colitis

Chapter $4 \quad$ Comprehensive nutritional status in patients with long-standing Crohn's disease currently in remission

Chapter 5 Comprehensive nutritional status in recently diagnosed patients with Inflammatory Bowel Disease compared with population controls

Chapter 6 Gender specific alterations of body composition in patients with Inflammatory Bowel Disease compared with controls

Chapter 7 Fat intake and fatty acid profile in plasma phospholipids and adipose tissue in patients with Crohn's disease compared with controls

Chapter 8 The relation between antioxidant status and alterations in fatty acid profile in patients with Crohn's disease and controls

Chapter 9 Nutritional supplementation with $n-3$ fatty acids and antioxidants in patients with Crohn's disease in remission: effects on nutritional status and fatty acid profile

Chapter 10 General discussion

Chapter 11 Summary

Chapter 12 Samenvatting

Dankwoord

Publicaties 


\section{Introduction}




\section{Introduction}

Ulcerative colitis (UC) and Crohn's disease (CD) are chronic inflammatory disorders collectively referred to as Inflammatory Bowel Disease (IBD). The disease is characterized by alternating periods of flare ups (exacerbation) and quiescent disease (remission). The inflammation in UC is confined to the mucosal layer and affects the large bowel only, being usually superficial. $C D$ can affect any part of the gastrointestinal tract from mouth to anus, although the most common sites to be involved are the terminal ileum and coecum. Unlike $U C$, the inflammation in CD is not necessarily continuous and areas of ulceration may be interspersed by relatively normal mucosa. The inflammatory process can affect all layers of the gastrointestinal wall. In IBD patients, a wide spectrum of disease severity is observed, with respect to the site, nature and extent of intestinal involvement.

\section{Descriptive epidemiology}

In the United States and in Europe, IBD appears to be more common in northern than in southern areas ${ }^{1.3}$. A recent study conducted in the Netherlands showed incidence rates of 6.9 per 100,000 and year for $C D$, and 10.0 for UC, respectively ${ }^{4}$. These age- and sex-standardized incidence rates are high compared to studies in neighboring countries ${ }^{5}$. However, it should be kept in mind that comparing incidence rates between different countries can be misleading, because different diagnostic facilities and disease definitions may have been used. The age distribution in CD shows a peak incidence between 15 and 30 years, and the reported incidence rates of CD in this age group are higher in females than in males. ${ }^{4}$. On the other hand, UC is equally distributed between genders, although a male preponderance is frequently observed in the older age groups $\mathrm{s}^{4,6,7}$.

The number of newly-diagnosed $C D$ patients has increased over the last decades, while the incidence of UC has shown a more constant picture ${ }^{8}$.

\section{Pathogenesis}

The etiology of the chronic inflammatory process in IBD remains unknown. Family studies and genetic marker studies have supported the relevance of genes to disease predisposition in $\mathrm{IBD}^{9-11}$. However, the increased incidence since the $1950 \mathrm{~s}^{12,13}$ cannot be attributed to a change in genetic mapping in the relatively homogeneous populations over this period of time. Environmental factors have therefore been suggested as important etiological factors in the pathogenesis of IBD, probably through an as yet unclear interaction with multiple predisposing genes.

Environmental factors could comprise thrombogenic factors ${ }^{14-16}$ and microbiological agents ${ }^{17.18}$. As nutritional habits have clearly changed over the past decades, diet is an important environmental factor to be considered in the 
etiology of IBD. In a recent case-control study, some distinct nutritional factors were found to be associated with IBD, and the authors suggested that this could be the expression of a modern life-style ${ }^{19}$. However, at this moment there is still very little conclusive evidence regarding the role of specific dietary components in the pathogenesis of IBD. Unfortunately, most studies were subject to methodological limitations, and well designed studies are necessary to confirm the hypothesis that nutritional factors play a role in the development of IBD.

Fatty acid metabolism is involved in the immune response and inflammation processes in IBD patients, since polyunsaturated fatty acids are precursors of eicosanoids, which participate in the regulation of immunological and inflammatory responses ${ }^{20,21}$. Hence, fatty acid intake and metabolism may be important both in the pathophysiology of IBD and in the clinical course of the disease.

Under normal physiologic conditions, inflammatory reactions are an essential part of host defense, playing a critical role in the eradication of foreign agents. In healthy humans, reactive oxygen species are constantly generated, but antioxidant defenses may regulate this process by scavenging abundant radicals. In patients with active $C D$, an increased production of reactive oxygen species has been observed (oxidative stress) ${ }^{22-25}$. Furthermore, an imbalance between prooxidant and antioxidant mechanisms has been reported in IBD patients ${ }^{26}$. It is unknown whether this imbalance is a cause of inflammation in IBD or just its result. However, recent studies support the idea that antioxidants may be important in the pathogenesis of tissue injury in IBD 27.29 .

\section{Treatment}

Current therapy for IBD patients aims at local anti-inflammatory action, immunosuppresion, prevention of complications and general support. At present, medical therapy counteracts the inflammation rather than the underlying cause of the disease. The efficacy of preventive medical treatment during a phase of remission is unsatisfactory, especially in the case of CD. Another disadvantage of current medical treatment is the side-effects of systemically active immuno-suppresive agents. Surgical treatment is unavoidable in some circumstances and can cure UC. In CD patients, disease recurrence affects $50-90 \%$ of patients after surgery, depending on the definition used $^{30}$.

In $C D$ patients, the therapeutic value of selected enteral nutrition was observed more than two decades ago. Such enteral nutrition comprises either an elemental diet providing nutrients in their simplest form (with the aim of reducing the total antigenic load) or oligopeptide and polymeric formulae containing nitrogen sources in the form of di- and tripeptides and whole protein, respectively. In recent years, many excellent reviews $\mathrm{s}^{31-35}$ and meta-analyses ${ }^{36-38}$ have been published on the primary therapeutic role of selected enteral diets. Enteral nutrition is effective at inducing remission in active $C D$, although there is 
insufficient data to confirm that enteral nutrition may replace drug therapy. Enteral nutrition is especially recommended in specific subgroups, such as children with signs of growth impairment and patients with intolerable steroidassociated side effects. Several hypotheses have been proposed to explain the efficacy of enteral nutrition in $C D$, but none of these has achieved general acceptance $^{33}$. In UC, on the other hand, enteral diet seems to be less successful in inducing remission ${ }^{39-41}$.

Nutritional supplementation is indicated for repairing nutritional deficiencies, which are frequently reported in IBD patients ${ }^{42-52}$. Furthermore, specific immunomodulating nutrients can be administrated, such as antioxidants or fish oil, which may interact with the inflammatory process in IBD. Fish oil containing the n-3 fatty acids eicosapentaenoic acid and docosahexaenoic acid may exert antiinflammatory activity by modifying cell membrane structure and by altering eicosanoid metabolism in IBD patients ${ }^{53}$. A diminished antioxidant status has been reported in IBD patients ${ }^{44,45,49,54,55}$ and this justifies intervention trials to investigate the potential beneficial role of antioxidants in the clinical course of IBD.

\section{IBD and nutrition}

Nutrition strongly interacts with IBD, as was outlined above. Three main topics can be distinguished in the relation between IBD and nutrition: 1) the role of specific dietary components in the pathogenesis of IBD, 2) malnutrition as a result of the disease process, and 3) nutritional intervention to improve the nutritional status or to attenuate inflammatory activity.

It is known that the prevalence and severity of malnutrition are markedly influenced by the activity and extent of the disease, especially in CD. In many studies it is difficult to separate the effects of the disease, especially those caused by inflammation, from those of malnutrition per se. The association between IBD and malnutrition per se should therefore preferably be investigated in patients during remission of the disease.

This thesis attempts to provide further insights into the role of nutrition in IBD. The following aims are addressed:

1. Investigating the role of nutrition in the pathogenesis of IBD, with special reference to the role of fatty acids and antioxidants.

2. Determining a comprehensive nutritional status in various groups of IBD patients compared with controls in order to
a. study the association between $C D$ and malnutrition per se;
b. study the association between disease duration and malnutrition;
c. study the interrelation between the various dimensions of the nutritional status.

3. Studying the effects of n-3 fatty acids and antioxidant supplementation on the nutritional status in CD patients. 


\section{Outline of the thesis}

Chapter 2 reviews current knowledge on the relation between nutrition and IBD.

The role of nutrition in the pathogenesis of UC is described in Chapter 3 , based on a case-control study design. Recently diagnosed UC patients (within 6 months of diagnosis) and age- and sex-matched population controls were included in this study. Pre-illness diet was assessed by the cross-check dietary history method.

In Chapter 4 the association between $C D$ and malnutrition per se is discussed. A comprehensive nutritional status was assessed in patients with long-standing ( $>10$ years) $C D$, currently in remission, compared with population controls. The assessment of nutritional status comprised four different dimensions: 1) body composition, 2) dietary intake, 3) biochemical parameters of nutrition, 4) muscle strength.

A study investigating whether the nutritional status in IBD is already affected at the time of diagnosis is described in Chapter 5 . The comprehensive nutritional status of newly diagnosed IBD patients (within 6 months of diagnosis) is compared with that of population controls.

Chapter 6 discusses a detailed study on body composition in IBD, with special reference to the body water distribution. Malnutrition and inflammation may both affect body hydration by changing the size of the extracellular and intracellular water compartments, respectively. Measurement of body water distribution is an essential part of nutritional assessment and it may be helpful in understanding the reported metabolic alterations in IBD.

Fatty acid metabolism is involved in the immune response and inflammation processes in CD patients and, changes in the fatty acid profile may thus be relevant to the clinical course of the disease. In Chapter 7, a study is presented on qualitative and quantitative fat intake and the fatty acid profile of plasma phospholipids and adipose tissue in various groups of CD patients and controls.

The interrelation between two important aspects of the nutritional status, antioxidant defense (Chapters 4,5) and fatty acid profile (Chapter 7) in CD patients, is investigated in a study described in Chapter $\mathbf{8}$.

The results observed in the above studies led to a nutritional intervention trial in CD patients (Chapter 9). Antioxidants and n-3 fatty acids were supplemented for three months, in addition to the regular diet, to $C D$ patients currently in remission. We investigated the effects of this specific nutritional supplement primarily on nutritional status and fatty acid profile, and secundary on the quality of life and the course of the disease.

Finally, the results of the various studies in this thesis, in relation to each other and in the light of information from current literature, are discussed in Chapter 10. 


\section{References}

1. Sonnenberg A, McCarty DJ, Jacobsen SJ. Geographic variation of inflammatory bowel disease within the United States. Gastroenterology 1991; 100:143-9.

2. Binder V. Progress in epidemiology, quality of life and life expectancy in IBD. In: Tijtgat GJN, Bartelsman JFWM, Deventer van SJH, eds. Inflammatory Bowel Disease. Dordrecht, The Netherlands: Kluwer Academic Publishers 1995; 27-32.

3. Shivananda S, Lennard-Jones J, Logan R, Fear N, Price A, Carpenter L, Blankenstein van $M$ and the EC-IBD Study Group. Incidence of inflammatory bowel disease across Europe: is there a difference between north and south? Results of the European collaborative study on inflammatory bowel disease (ECIBD). Gut 1996; 39:690-7.

4. Russel MGVM, Dorant E, Volovics A, Brummer R-JM, Pop P, Muris JWM et al. High incidence of Inflammatory Bowel Diseae in The Netherlands: results of a prospective study. Dis Colon Rectum 1998;41:33-40.

5. Shivananda S, Mayberry JF. Epidemiology of inflammatory bowel disease. Inflammatory Bowel Disease Study Group, Royall Free Hospital 1993; 9:560-5.

6. Langholz E, Munkholm P, Nielsen $\mathrm{OH}$, Kreiner S, Binder V. Incidence and prevalence of ulcerative in Copenhagen country from 1962 to 1987 . Scand J Gastroenterol 1991; 26:1247-56.

7. Moum B, Vatn MH, Ekbom A, Aadland E, Fausa O, Lygren I, et al. Incidence of Crohn's disease in four counties in southeastern Norway, 1990-93. Scand J Gastroenterol 1996; 31:355-61.

8. Sandler RS. Epidemiology of inflammatory bowel disease. In: Targan SR, Shanahan F, eds. Inflammatory bowel disease; from bench to bedside. Baltimore, Maryland: Williams \& Wilkins $1994 ; 5-32$.

9. Satsangi J, Welsh KI, Bunce M, Julier C, Farrant JM, Bell JI, Jewell DP. Contribution of genes of the major histocompatibility complex to susceptibility and disease phenotype in inflammatory bowel disease. Lancet 1996; 347:1212-7.

10. Russel MGVM, Pastoor CJ, Janssen KMW, Deursen van CT, Muris JWM, Wijlick van WHJ, Stockbrügger RW and the South Limburg IBD Study Group. Familial aggregation of Inflammatory Bowel Disease: a population-based study in South Limburg, The Netherlands. Scand J Gastroenterol 1997; 32:88S-91S.

11. Fiocchi C. Inflammatory bowel disease: etiology and pathogenesis. Gastroenterology 1998; 115:182-205.

12. Calkins BM, Lilienfeld AM, Garland CF, Meneloff AI. Trends in incidence rates of ulcerative colitis and Crohn's disease. Dig Dis Sci 1984; 29:913-20.

13. Srivastava ED, Mayberry JF, Morris TJ, Smith PM, Williams GT, Roberts GM et al. Incidence of ulcerative colitis in Cardiff over 20 years: 1968-87. Gut 1992; 33:256-8.

14. Jick $\mathrm{H}$, Walker AM: Cigarette smoking and ulcerative colitis. N Eng J Med 1983; 308:261-3.

15. Persson PG, Ahlbom A, Hellers G: Inflammatory bowel disease and tobacco smoke-a case control study. Gut 1990; 31:1377-81.

16. Russel MGVM, Volovics A, Schoon EJ, van Wijlick EHJ, Logan RF, Shivananda S, et al. Inflammatory bowel disease: is there any relationship between smoking status and disease presentation? Inflammatory Bowel Dis 1998; 4:182-6.

17. Burnham WR, Lennard-Jones JE: Mycobacterial disease as a possible cause of IBD. Lancet 1978; 2693-6. 
18. Thompson NP, Montgomery SM, Pounder RE, Wakefield AJ. Is measles vaccination a risk factor for inflammatory bowel disease? Lancet 1995; 345:1071-4.

19. Russel MG, Engels LG, Muris JW, Limonard CB, Volovics A, Brummer R-JM, Stockbrügger RW. 'Modern life' in the epidemiology of inflammatory bowel disease: a case-control study with special emphasis on nutritonal factors. Eur $\mathrm{J}$ Gastroenterol 1998; 10:243-9.

20. Rask-Madsen J. Eicosanoids in inflammatory bowel disease: advances, pitfalls and therapeutic consequences. Eur J Gastroenterol Hepatol 1989; 1:133-165.

21. Lands WEM: Long-term fat intake and biomarkers. Am J Clin Nutr 1995; 61:721S-5S.

22. Grisham MB. Oxidants and free radicals in inflammatory bowel disease. Lancet 1994;344: 859-61.

23. Simmonds NJ, Rampton DS. Inflammatory bowel disease-a radical view. Gut 1993;34:865-8.

24. Gross V, Arndt H, Andus T, Palitzsch KD, Scholmerich J. Free radicals in inflammatory bowel diseases pathophysiology and therapeutic implications. Hep Gastroenterol 1994; 41:320-7.

25. Keshavarzian A, Sedghi S, Kanofsky J, List T, Robinson C, Ibrahim C, Winship D. Excessive production of reactive oxygen metabolites by inflamed colon: analysis by chemiluminescence probe. Gastroenterology 1992; 103:177-85.

26. Halliwell B. Free radical and antioxidants: a personal view. Nutr Rev 1994;52: 253-65.

27. Buffington GD, Doe WF. Altered ascorbic acid status in the mucosa from inflammatory bowel disease patients. Free Radic Res 1995; 40:131-43.

28. Millar AD, Rampton DS, Chander CL, Claxson AWD, Blades S, Coumbe A, et al. Evaluating the antioxidant potential of new treatments for inflammatory bowel disease using a rat model of colitis. Gut 1996; 39:407-15.

29. Reimund JM, Allison AC, Muller CD, Dumont S, Kenney JS, Baumann R, et al. Antioxidants inhibit the in vitro production of inflammatory cytokines in Crohn's disease and ulcerative colitis. Eur J Clin Invest 1998; 28:145-50.

30. Fazio VW. IBD: Postoperative recurrence. In: Rachmilewitz D, ed. Inflammatory bowel disease-1994. Lancester: MTP Press, 1994; 246-51.

31. Teahon K, Bjarnason I, Pearson M, Levi AJ. Ten years experience with elemental diet in the management of Crohn's disease. Gut 1190; 31:1133-7.

32. O'Morain CA, O'Sullivan MA. Nutritional support in Crohn's disease: current status and future directions. J Gastroenterol 1995; 30:102S-7S.

33. King TS, Woolner JT, Hunter JO. Review article: the dietary management of Crohn's disease. Aliment Pharmacol 1997; 11:17-31.

34. Stenson WF, Alpers DH. Nutritional therapy in inflammatory bowel disease: a historical overview. Current Opinion Gastroenterol 1997; 13:135-9.

35. O'Sullivan MA, O'Morain CA. Nutritional therapy in Crohn's disease. Inflammatory Bowel Dis 1998; 4:45-53.

36. Griffiths AM, Ohlsson A, Sherman PM, Sutherland LR. Meta-analysis of enteral nutrition as primary treatment of active Crohn's disease. Gastroenterology 1995; 108:1056-67.

37. Fernández-Bañares F, Cabre E, Esteve-Comas M, Gassull MA. How effective is enteral nutrition in inducing clinical remission in active Crohn's disease? A metaanalysis of the randomized clinical trials. J Parenter Enteral Nutr 1995; 19:356-64. 
38. Messori A. Trallori G, D'albasio G, Milla M, Vannozzi G, Pacini F. Defined-formula diets versus steroids in the treatment of active Crohn's disease: a meta-analysis. Scand J Gastroenterol 1996; 31:267-72.

39. Dickson RJ, Ashton MG, Axon ATR Smith RC, Yeuns CH, Hill GL. Controlled trial of intravenous hyperalimentation and total bowel rest: as an adjunct to the routine therapy of acute colitis. Gastroenterology 1980; 79:1199-1204.

40. Gonzalez-Huix F, Fernández-Bañares F, Esteve-Comas M, Abad-Lacruz, Cabre E, Acero D, et al. Enteral vs parenteral nutrition as adjunct therapy in ulcerative colitis. Am J Gastroenterol 1993; 88:227-32.

41. Mclntyre PB, Powell-Tuck J, Wood SR. Controlled trial of bowel rest in the treatment of severe acute colitis.Gut 1986; 27:481-5.

42. Zurita VF, Rawls DE, Dyck WP. Nutritional support in inflammatory bowel disease. Dig Dis 1995; 503;92-107.

43. Harries AD, Heatley RV. Nutritional disturbances in Crohn's disease. Postgraduate Med J 1983; 59:690-7.

44. Fernández-Bañares F, Abad-Lacruz A, Xiol X, Gine JJ, Dolz C, Cabré E, et al. Vitamin status in patients with inflammatory bowel disease. Am J Gastroenterol $1989 ; 84: 744-8$.

45. Fernández-Bañares $F$, Mingorance MD, Esteve M, Cabré E, Lachica M, AbadLacruz A, et al. Serum zinc, copper, and selenium levels in inflammatory bowel disease: effect of total enteral nutrition on trace element status. Am J Gastroenterol 1990; 85: 1584-9.

46. Cristie PM, Hill GL. Effect of intravenous nutrition on nutrition and function in acute attacks of inflammatory bowel disease. Gastroenterology 1990; 99:730-6.

47. Janczewska I, Bartnik W, Butruk E, Tomecki R, Kazik E, Ostrowski J. Metabolism of vitamin A in inflammatory bowel disease. Hepatogastroenterol 1991;38:391-5.

48. Stokes MA. Crohn's disease and nutrition. Br J Surg 1992; 79:391-4.

49. Kuroki F, lida M, Tominaga M, Matsumoto T, Hirakawa K, Sugiyama S, Fujishima M. Multiple vitamin status in Crohn's disease. Correlation with disease activity. Dig Dis Sci 1993; 38:1614-18.

50. Royall D, Greenberg GR, Allard JP, Baker JP, Jeejeebhoy KN. Total enteral nutrition support improves body composition of patients with active Crohn's disease. J Parenter Enteral Nutr 1995; 19:95-9.

51. Teahon K, Pearson M, Smith T, Bjarnason I. Alternations in nutritional status and disease activity during treatment of Crohn's disease with elemental diet. Scand J Gastroenterol 1995;30: 54-60.

52. Lanfranchi GA, Brignola C, Campieri M. Assessment of nutritional status in Crohn's disease in remission or low activity. Hepatogastroenterol 1984; 31:129-32.

53. Kinsella JR, Lokesh B, Broughton S, Whelan J. Dietary polyunsaturated fatty acids and eicosanoids: potential effects on the modulation of inflammatory and immune cells: an overview. Nutr 1990;6:24-44.

54. Sturniolo GC, Mestriner C, Lecis PE, D'Odorico A, Venturi C, Irato P, et al. Altered plasma and mucosal concentrations of trace elements and antioxidants in active ulcerative colitis. Scand J Gastroenterol 1998; 33:644-9.

55. Bhaskar L, Ramakrishna BS, Balasubramanian KA. Colonic mucosal antioxidant enzymes and lipid peroxide levels in normal subjects and patients with ulcerative colitis. J Gastroenterol \& Hepatol 1995; 10:140-3. 


\section{Nutrition and Inflammatory Bowel Disease: an update}

Geerling BJ, Stockbrügger RW, Brummer R-JM 


\section{Introduction}

Inflammatory Bowel Disease (IBD) is a chronic inflammatory process that involves the colon in ulcerative colitis (UC) and may involve any part of the entire gastrointestinal tract in Crohn's disease (CD). The etiology and pathogenesis of IBD are still unclear. Nutrition plays an important role in the pathogenesis as well as in the treatment. In the relation between nutrition and $\mathrm{IBD}$, three topics can be distinguished: the role of specific dietary components in the pathogenesis of IBD, malnutrition in the course of the disease, and nutritional therapy. This review evaluates dietary etiological factors, nutritional status and nutritional therapy in IBD.

\section{Diet and risk of IBD}

IBD incidence rates in various countries show wide variations ${ }^{1,2}$. Although the role of genetic factors in the pathogenesis of IBD has been established by twin and family studies as well as genetic linkage analysis ${ }^{3.4}$, the geographical variation in incidence suggests that environmental factors could also play a significant role $^{5}$. In addition, the incidence of $C D$ in urban populations in the developed countries has increased during the last decades ${ }^{2,6.7}$, whereas the genetic background of the population has remained stable. This indicates that environmental factors like diet may be important in the etiology of IBD.

In 1976, Martini \& Brandes $^{8}$ and Miller et $\mathrm{al}^{9}$ were the first to report that CD patients consumed an excess amount of sugar and sugar-containing products, and many studies on dietary habits of IBD patients have been conducted since. We will critically review studies on sugar, fiber, fruit, vegetables, fat and protein consumption which have been considered to play an role in the etiology of IBD.

\section{Consumption of sugars}

The most consistent finding in all studies has been the increased sugar consumption in $C D$ patients ${ }^{8-26}$. This was also shown in a few studies to be true for UC $\mathrm{C}^{22,25-28}$. Intakes of sugars vary considerably across countries with the highest intake in Israel $\left.\right|^{29,30}$. However, epidemiological studies have failed to find correlations between the rising incidence of IBD and marked change in sugar consumption over the last 50 years ${ }^{29}$.

In a recent large epidemiological study, a greater risk for the development of $C D$ or UC was found among those with a high consumption of chocolate, chewing gum and cola drinks (nutritional items share a high sugar content), whereas a decreased risk was observed with a high intake of citrus fruits ${ }^{5}$. The authors suggested that the nutritional items mentioned may be true risk factors or they just might be the expression of a modern life-style also involving other risk factors for the development of IBD. 
Since the possible role of sugar in the pathogenesis of IBD was postulated, several dietary intervention studies have investigated the effects of a low sugar, high fiber diet in $C D$ patients. In a large multi-center trial of Ritchi et al ${ }^{31}, 190$ $C D$ patients were randomized to low sucrose, high fiber diet and $162 \mathrm{CD}$ patients to the control diet. Dietary assessment by the recall method showed good compliance in both groups. However, no significant benefits in clinical course were demonstrated. In a small randomized double blind study of Alun Jones et $\mathrm{al}^{32}$, all of the $10 \mathrm{CD}$ patients randomized to the low sucrose, high fiber diet had relapsed by six months while 7 out of the 10 patients on the exclusion diet remained in remission. In a large study of Lorenz-Meyer et al, remission rates at 1 year in $C D$ patients were identical in the low carbohydrate and placebo group ${ }^{33}$. Thus, these carefully designed trials did not demonstrate any significant benefits from sucrose avoidance.

In a recent review of the association between $C D$ and sugar consumption however, Riordan et $\mathrm{al}^{29}$ showed that the relationship between sugars and the onset of CD was inconsistent. Many studies have been subject to important methodological limitations. Most of the studies investigated post-illness diet, although dietary habits may have changed since onset of the illness. This suggests that a high sugar intake is a consequence of the symptoms rather than a cause of the disease. Even if questionnaires referred to pre-illness diet, only a few studies investigated patients close to the time of diagnosis ${ }^{6,16.26}$. It is known that retrospectively recalled information dating from several years before the onset of illness has limited accurary ${ }^{34}$.

A problem in most studies is the quality of the data analysis. A comparison of the mean consumption of different foods/nutrients between patients and controls does not provide any information about the magnitude of the increase in disease risk associated with specific consumption. Instead, relative risk or odds ratios should be obtained. Another methodological shortcome of many of the studies is the representativeness of the control group as hospital controls were used in most studies. These controls all suffer from disease and it is possible that their disorders are associated with the dietary intake, in which case they do not constitute an appropriate controls series. Therefore, randomly chosen population controls are preferable ${ }^{25,26}$.

Several studies failed to conduct a dietary interview or questionnaire assessing the entire dietary intake. It is doubtful whether questions about the use of added sugar to cereals and drinks or about the consumption of sweet foods accurately reflect daily sugar intakes.

Abdominal pain or diarrhoea can affect appetite but most studies did not report data on disease activity. In the study by Brauer et $\mathrm{al}^{20}$, which found no change in current sugar intake of IBD patients compared with the general population, the majority of the patients were in remission.

In summary, although many studies have reported increased sugar consumption in $C D$ patients compared with controls, the methodological limitations of most studies mean that it remains questionable whether sugar 
consumption is really associated with the onset of IBD. Future well-designed studies may provide an answer to this question.

\section{Dietary fiber and consumption of fruit and vegetables}

Other nutrients which have frequently been studied are dietary fiber, fruit and vegetables. ${ }^{11,14,16,19,21,22,25,26,35}$. A decreased consumption of fruit, fruit juice or vegetables was found among both $C D$ and UC patients. The consumption of dietary fibers and especially the consumption of fibers from fruit was also found to be negatively associated with the risk of $\mathrm{IBD}^{22,25,26}$. Most studies have evaluated fruit and vegetables as food items, but Reif et $\mathrm{al}^{26}$ also studied selected micronutrients (mainly minerals and vitamins). They found that fruits and vegetables as food items were negatively associated with IBD risk. In addition, a decreased risk of IBD was found to be associated with increased consumption of water as well as potassium (in CD only), magnesium and vitamin C. They proposed, however, that the effects of these vitamins and minerals are not exclusively due to their presence in fruits and vegetables, because vitamin $A$ and various $B$ vitamins (present in vegetables and fruit) showed no clear association with IBD. In summary, keeping the above mentioned methodological limitations of the studies in mind, the consumption of fibre, fruit and vegetables seems to be a protective factor in the etiology of IBD.

\section{Fat consumption}

Guthy suggested that chemically processed hydrogenated fats, such as margarine, may be important in the etiology of $C^{36}$. This hypothesis was based on the association between the onset of margarine consumption and the first reports of granulomatous ileitis, as well as the similarities in their geographic distribution. The hypothesis has been investigated in a few studies. A Japanese study found that the use of margarine showed a significant positive association with the risk of $\mathrm{UC}^{37}$. By contrast, Chuah et $\mathrm{al}^{38}$ showed no significant differences in dietary oil consumption between Asian IBD patients and Asian controls. However, $C D$ patients were found to recycle their cooking oil significantly more often than controls. Furthermore, some studies have reported an increased relative risk of $C D$ and $U C$ associated with the consumption of fast foods ${ }^{5.25}$ which is in line with Guthy's hypothesis that chemically modified fat (margarine, frying or cooking fat) in fast foods may play a role in the etiology of $\mathrm{CD}^{39}$.

Some studies have investigated qualitative and quantitative overall fat intake as a risk factor for IBD. Tragnone et $\mathrm{al}^{6}$ found no differences in fat consumption (qualitative or quantitative) between IBD patients and controls. However, their reported mean daily nutrient consumption was not corrected for energy intake, and this methodological limitation could have biased the results. In a recent study by Reif et $\mathrm{al}^{26}$, increased fat consumption in the pre-illness period was found among IBD patients, especially those suffering from UC. This increased 
fat consumption was found to cover all types of fats (animal fat, vegetable fat, saturated as well as unsaturated fat, and cholesterol). Shoda et $\mathrm{al}^{40}$ reported in an epidemiological study the qualitative fat intake and found that the increased incidence of $C D$ was correlated with increased intake of dietary fat, especially $n-$ 6 fatty acids, combined with a relative decrease in the intake of $n-3$ fatty acids. This type of epidemiological study has some limitations because results could be influenced by the age of the data. The question is whether the CD incidence should be related to dietary consumption data from the same year or to data from 5-10 years before.

\section{Protein consumption}

Only a few studies have investigated protein intake as a risk factor for the development of IBD. Tragnone et $\mathrm{al}^{6}$ found that pre-illness total protein intake was significantly higher in UC, but not in CD. A Japanese study showed, however, that animal protein was related to an increased incidence of $C D^{40}$. Reif et $\mathrm{al}^{26}$ reported that protein consumption did not seem to play a role.

\section{Conclusion}

In summary, there is still very little conclusive evidence regarding the role of specific dietary components in the pathogenesis of IBD. One obvious reason could be that the dietary factors studied so far do not play a role as risk factors for $C D$ or UC. Another explanation is that the possible real differences in dietary intake between patients and controls are undetected. Most studies reviewed were subject to methodological limitations, which could have biased the results. The study by Reif et $\mathrm{al}^{26}$ was well designed, but more of such studies will be required to confirm the findings before dietary factors can be regarded as important in the development of IBD.

\section{Nutritional status in IBD}

As early as 1932, Crohn described regional enteritis as muscle wasting and loss of weight as common clinical signs of the disease ${ }^{41}$. Since that time, malnutrition has often been reported in IBD patients, especially in CD patients. The multiple factors involved in the development of malnutrition are outlined in Table 2.1. In most individual cases, more than one factor is responsible for malnutrition. Evaluation of malnutrition in IBD has, until recently, most frequently been performed using only anthropometric and biochemical techniques ${ }^{42-44}$. Weight loss has been regarded as a predominant feature; it occurs in approximately $80 \%$ of CD patients ${ }^{45}$ and in $18-62 \%$ in UC patients ${ }^{46}$. However, most studies on malnutrition and IBD have been performed among hospitalized patients and/or patients with active disease. In these patients, the metabolic disturbances associated with malnutrition may be caused by the 
malnutrition itself and/or by the inflammation, as it is known that the prevalence and degree of malnutrition are markedly influenced by the activity and the extent of the disease ${ }^{43,47}$.

What is nutritional status? One satisfactory definition has been given by Jeejeebhoy et $\mathrm{al}^{48}$, who described nutritional status as 'an equilibrium of the intake of a diet sufficient to meet or exceed the needs of the individual which will keep the composition and function of the otherwise healthy individuals within the normal range'. This equilibrium can be disturbed by decreased intake, increased requirements and altered metabolism. Obviously, nutritional status is influenced by several factors. Charney ${ }^{49}$ stated that individual parameters may reflect disease states rather than nutritional status.

In the following discussion, the assessment of nutritional status in IBD will be critically reviewed in terms of how the interpretation of the measurement may be affected by disease activity and how the markers used may be of value in assessing nutritional status.

Table 2.1: Factors involved in the development of malnutrition in IBD

$\begin{array}{ll}\text { Inadequate food intake } & \text { Anorexia (disease-induced), } \\ & \text { Fear of eating due to abdominal pain }\end{array}$

Malabsorption/maldigestion Decreased effective absorptive area due to extensive disease or extensive resection,

Bacterial overgrowth,

Drugs: corticosteroids (calcium), sulphasalazine (folate) cholestyramine (fat and fat soluble vitamins),

Small intestine bypass (fistulae)

Increased intestinal losses

Blood loss,

Protein-losing enteropathy,

Bile salt-losing enteropathy,

Electrolytes, minerals, trace elements

Increased requirements

Inflammation,

Fistula,

Increased intestinal cell turnover

Disease activity

Elimination of antioxidants due to oxidative stress

\section{Protein-energy malnutrition}

A common clinical manifestation of protein-energy malnutrition in IBD is weight loss ${ }^{42}$. Weight loss frequently occurs, however, in patients requiring hospital admission because of acute exacerbation ${ }^{50}$. Insufficient intake is often attributed to weight loss caused by the presence of chronic illness or fear of precipitating abdominal pain. In addition, increased energy expenditure should also be considered as a possible explanation for the reported weight loss ${ }^{51}$. However, Stokes and Hill ${ }^{52}$ showed that total energy expenditure was not raised in $C D$ patients.

Loss of body protein mass in IBD has been reported in active CD patients ${ }^{51,53}$, 
but is less common in patients in remission. Hypoalbuminemia, on the other hand, is a very common finding in IBD patients ${ }^{46,54}$. Low serum albumin concentrations are not necessarily related to protein undernutrition; reduced hepatic protein synthesis, malabsorption and anorexia all play an role, but hypoalbuminemia results predominantly from intestinal protein loss and increased catabolism. Serum albumin is a marker of disease activity rather than of nutritional status. Plasma concentrations of retinol binding protein and prealbumin fall rapidly in protein malnutrition. These proteins have a relatively short half-life and are more sensitive to protein or energy deprivation than albumin ${ }^{55}$.

\section{Vitamin deficiencies}

Several vitamin deficiencies have been reported in IBD patients, but many studies only assessed one single vitamin concentration. It is especially during the last decade that vitamins have been recognized as an important factor in IBD.

\section{Vitamin $A$}

Vitamin $A$ is a fat-soluble vitamin and reduced levels have been found in $\mid \mathrm{BD}^{56-60}$, but these are associated with disease activity. Janczewska et al $\left.\right|^{58}$ showed that serum retinol levels in patients with active IBD are secondary to the decreased retinol-binding protein concentrations, and probably depend on the increased protein catabolism. Plasma levels of circulating retinol are controlled by the level of retinol-binding protein, and as this is a negative acutephase protein, concentrations of plasma retinol will fall in disease ${ }^{61}$. Furthermore, a study of patients with long-standing $C D$, clinically in remission, found no difference in serum retinol concentrations between patients and controls $^{62}$. These results suggest that one should be cautious in interpreting vitamin A deficiency in IBD patients with active disease. Serum concentrations of $\beta$-carotene (pro-vitamin A) have been found to be reduced in active IBD patients ${ }^{59}$ and in inactive $C D$ patients ${ }^{62}$. Steatorrhoea resulting in the malabsorption of fat-soluble vitamins, like $\beta$-carotene, may contribute to the suboptimal status.

\section{Water- soluble $B$ vitamins}

A few studies have reported low serum concentrations of thiamine, riboflavin, and pyridoxine in IBD patients, most with active disease ${ }^{42,59,60}$. Kuroki et $\mathrm{al}^{60}$, however, failed to demonstrate an obvious difference in vitamin status between active and inactive $C D$ patients. Furthermore, there have been some rare case reports on deficiencies of water-soluble B vitamins producing syndromes resembling beriberi (thiamine), pellagra (niotinic acid), photophobia with dermatological changes (riboflavin) or dermatological and neurologic changes (pyridoxine) $)^{42,45}$.

The majority of the B-vitamins are present in the tissues in the form of co- 
enzymes ${ }^{61}$. The functions of these enzymes may be strongly influenced by disease, and it is obvious that requirements for these nutrients may be increased by the disease. There are no data on vitamin B concentrations in IBD patients with inactive disease. It is, however, plausible that no deficiencies of the water soluble B vitamins will be found in these patients.

Folate deficiency has often been described in IBD, and has been partly ascribed to long-term use of sulfasalazine, which causes competitive inhibition of folate absorption ${ }^{63}$. Decreased dietary intake, increased demand and malabsorption due to mucosal impairment are also associated with folate deficiency ${ }^{64}$. Furthermore, folate deficiency may be primary or secondary to vitamin B-12 deficiency ${ }^{65}$. Besides systemic deficiency, increased intestinal cell turnover due to epithelial inflammation, could also result in folate deficiency in patients with $\mathrm{UC}^{63}$. It has been shown that the risk of malignant transformation in UC patients is significantly affected by low folate status ${ }^{66}$.

Vitamin B-12 deficiency has frequently been found in CD patients, but rarely in UC ${ }^{45}$. Vitamin B-12 malabsorption is related to the affliction of the terminal ileum, but studies indicate that vitamin B-12 should also be seriously considered for any patient with $C D^{42,67}$.

Anemia is present in $25-85 \%$ of CD patients and in up to two thirds of UC patients. This may be due to the iron deficiency resulting from gastrointestinal blood loss, folate deficiency, or vitamin B-12 deficiency or may be a consequence of chronic inflammation ${ }^{45}$.

\section{Vitamin C}

A few studies have reported lower serum vitamin C concentrations in IBD patients compared with controls ${ }^{59.60}$. In addition, Buffinton and $D_{0} e^{68}$ showed that in non-inflamed mucosal biopsies from IBD patients, the proportion of reduced and total ascorbate present was very low. It has been suggested that these low levels are partly related to reduced dietary intake ${ }^{69}$. Furthermore, the ascorbate deficiency could be a factor in the pathogenesis of fistula formation because of the importance of ascorbate in collagen synthesis.

Studies have indicated that disease activity has a major impact on vitamin C in the blood ${ }^{61}$. It is known that vitamin $C$ is an pro-oxidant in the presence of $\mathrm{Fe}$. In healthy individuals, the amount of free Fe will be kept at a minimum, since there is adequate binding capacity in the plasma in the form of transferrin. During disease activity, however, the amount of free $\mathrm{Fe}$ will increase. Thurnham ${ }^{61}$ suggested that the decreased vitamin $C$ concentration is a response to increased disease activity.

\section{Vitamin D}

Vitamin $D$ deficiency is one of the most common nutritional deficits in CD patients, but has also been reported in UC ${ }^{45,70,71}$. Malabsorption and endogenous loss of $25(\mathrm{OH})$ vitamin D3 are probably involved ${ }^{72}$. Vitamin D metabolism is closely related to bone metabolism, and osteoporosis is indeed a relatively 
common complication of $\mathrm{CD}^{73}$. Although, the precise cause of the loss of bone mineral density is not known, it may be due to a combination of factors, including corticosteroids use, malabsorption, reduced dietary calcium intake, vitamin D deficiency, or even the direct effects of chronic inflammation and cytokine production on bone metabolism. Several studies have investigated the relation between vitamin $D$ status and bone mineral density, but results are contradictory ${ }^{74,75}$. Furthermore, different findings have been reported on biochemical markers of bone metabolism in patients with and without osteopenia ${ }^{74,76}$. However, it is clear that nutritional status and disease activity affect bone metabolism, and should be taken into account in future studies for osteoporosis in IBD ${ }^{77}$.

\section{Vitamin $E$}

Fat-soluble vitamin $E$ ( $a$-tocopherol) correlates with lipoproteins ${ }^{61}$. A few studies have found reduced serum concentrations of $a$-tocopherol in patients with active disease ${ }^{59,60}$. However, the ratio of serum vitamin $E$ to serum cholesterol or to total lipids did not differ significantly between patients and controls, suggesting that the decreased vitamin $E$ levels in $C D$ patients could be explained by the decreased serum concentrations of cholesterol and plasma total lipids. Furthermore, Kuroki et $\mathrm{al}^{78}$ assessed $a$-tocopherol in red blood cells and did not find a significant difference between $C D$ patients at the time of diagnosis and controls, suggesting that $a$-tocopherol is not actually depleted in CD patients.

\section{Trace element deficiencies}

Trace elements vary in their biologic function, e.g. some have antioxidant capacities. Deficiency of trace elements in IBD patients is often recognized and in addition, the relevance of an optimum antioxidant status in the pathogenesis of IBD and its influence in the clinical outcome of these patients has been the target of some studies. Specific trace elements deficiencies in IBD will be discussed below.

\section{Selenium}

Several studies have found decreased selenium concentrations in $C D$ patients with varying disease activity ${ }^{79-82}$. Three studies did not detect decreased selenium concentrations in $\mathrm{CD}$ or $\mathrm{UC}^{83}$ but two of these studies were performed in children with $\mathrm{IBD}^{84,85}$. In the study by Fernández-Bañares et $\mathrm{al}^{83}$, serum selenium values were found to show high dispersion rates compared with controls which could have influenced the statistical outcome of the study. Furthermore, Fernández-Bañares et $\mathrm{al}^{86}$ also reported low serum selenium concentrations in the healthy population resident in Catalunya and it was this population that was used as the control group. This may explain the lack of difference between the IBD patients and the controls in their study ${ }^{83}$. It has been suggested that low selenium concentrations are caused by the use of corticosteroids ${ }^{84}$, but also the length of resected bowel has been indicated as a 
cause of selenium deficiency ${ }^{82}$. Selenium is a component of glutathione peroxidase, a seleno-protein enzyme which is important in protecting against the development of lipid peroxides and free radicals, which can damage cell membranes. It is known that glutathione peroxidase activity is a sensitive indicator of selenium deficiency ${ }^{81}$. Formation of soap complexes due to steatorrhoea may occur in $C D$ patients ${ }^{87}$ and divalent cations such as magnesium, selenium or zinc may form unabsorbable subcomplexes with malabsorbed fat.

\section{Magnesium}

Magnesium deficiency is a common finding in $C D^{45,88-90}$. This deficiency can result from poor intake, increased intestinal losses, malabsorption, bacterial overgrowth or small bowel especially ileum resection ${ }^{90,91}$. There have been some case reports on hypomagnesemia in patients with $C D^{42}$, but most patients with magnesium deficiency do not develop these symptoms. Magnesium depletion may be the cause of persistent hypocalcemia despite adequate replacement of calcium and vitamin D. Serum magnesium levels are poor indicators of magnesium status because serum levels are kept constant by the human body and it is therefore possible that magnesium deficiency is highly underestimated in IBD patients. Muscle magnesium concentration is the best indicator of magnesium status, but urinary excretion is also thought to be a sensitive index of magnesium deficiency in $\mathrm{IBD}^{89}$.

\section{Zinc}

Zinc deficiency has often been reported in IBD, especially in $C D^{45,91-93}$. Increased losses of zinc are associated with diarrhoea/steatorrhoea and fistula drainage and a close correlation has been found between stool weights and zinc losses ${ }^{46}$. Whether decreased zinc absorption can be caused by malnutrition per se is controversial $^{94,95}$. Zinc status is usually assessed as serum concentration. However, acute inflammation and hypoalbuminemia may decrease serum zinc levels in spite of a normal total body zinc content. The zinc status of a patient remains difficult to assess, especially in the presence of inflammation, and no single method for measuring zinc status seems entirely satisfactory ${ }^{96}$. Alternatives to serum zinc level measurements include measurement of the activity of zinc-dependent enzymes ${ }^{97-99}$, hair and urinary zinc ${ }^{91}$, zinc content in blood cells ${ }^{100,101}$ or in vitro uptake of zinc by blood cells ${ }^{102}$. However, more research is necessary to find a valid and clinically practical method for the assessment of the true zinc status of IBD patients. It has been suggested that in a patient population with quiescent disease serum zinc levels may provide enough information about the zinc status, because circulating zinc reflects the metabolizable or exchangeable zinc that is delivered to the metabolically active tissues $^{103}$. 


\section{Antioxidants and IBD}

Nutritional deficiency can negatively affect immunocompetence ${ }^{104-106}$. Evidence is accumulating for the role of an imbalance between increased reactive oxidative species production and reduced antioxidant defenses with regard to

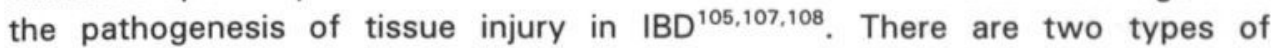
antioxidants in the body; antioxidant enzymes and antioxidant small molecules. The enzymes include superoxide dismutase which uses zinc as a co-factor, catalase which uses copper, and gluthatione peroxidase which needs selenium. The activities of the antioxidant enzymes depend on the nutritional availability of co-factors. The non-enzymatic antioxidants include the dietary exogenous vitamins $E$ and $C, \beta$-carotene, flavonoids and the endogenous substances glutathione, uric acid and taurine. Several studies have reported low concentrations of circulating antioxidant vitamins ${ }^{59,60}$ and antioxidant minerals ${ }^{80}$. 82,83 in $C D$ patients. Furthermore, some studies have found a deteriorated antioxidant status in patients with $\mathrm{IBD}^{84}$. Maintaining an adequate antioxidant status by antioxidant supplementation has been suggested as a useful approach in attenuating the cellular injury and dysfunction observed in IBD. Antioxidant defenses are highly interactive, for instance in coupled redox reactions, and it is therefore very important in future studies to determine the optimum amount of the individual antioxidants needed in IBD.

\section{Body composition}

As described above, weight loss is a common finding in IBD patients, but to quantify the magnitude of malnutrition, accurate assessment of body composition is required.

Only a few studies have described body composition of IBD patients, and these studies were predominantly performed in patients with high disease activity $^{51,109-113}$. Significant losses of fat, protein and water have been reported ${ }^{110,112}$, but the size of these compartments returned to normal after nutritional repletion ${ }^{51}$ or when patients went into remission ${ }^{110}$.

Increased resting energy expenditure has been proposed as a possible mechanism for the weight loss observed in active IBD patients. It has been suggested that the higher resting metabolic rate in underweight IBD patients is due to a proportionally greater decrease in fat with sparing of lean body mass ${ }^{51}$. However, Stokes and Hill ${ }^{52}$ showed that total energy expenditure was not raised in $C D$ patients.

Disturbed body hydration and body water distribution has been reported in children with active $C D^{113}$. This study showed an increased ratio of extracellular to intracellular water in $C D$ patients compared with controls. It is known that malnutrition can influence body hydration ${ }^{114}$. Furthermore, there is both clinical and experimental evidence that chronic inflammation may lead to an expansion of extra-cellular water ${ }^{115}$. 


\section{Muscle strength}

Lopes et al discovered that skeletal muscle function was a sensitive indicator of the nutritional status of patients ${ }^{116}$. They further showed that functional changes occurred before abnormalities in the values of conventional indices of malnutrition ${ }^{117}$. In a study by Brevinge et $\mathrm{al}^{118}$, exercise capacity assessed by cycle ergometry was significantly reduced in $C D$ patients undergoing proctocolectomy and small bowel resection. Skeletal muscle function can be evaluated by means of hand grip dynamometry ${ }^{119}$, by contraction of the adductor pollicis muscle in response to an electrical stimulus ${ }^{120}$, or by isokinetic dynamometry ${ }^{121}$. To our knowledge, muscle strength has not been assessed in IBD patients.

\section{Nutritional therapy in IBD}

The value of nutritional support in the correction and maintenance of nutritional status in $C D$ is widely accepted. The primary therapeutic effect of an enteral diet was observed more than 2 decades ago, but results remain somewhat controversial. In recent years, many excellent reviews $s^{122-126}$ and metaanalyses ${ }^{127-129}$ have been published on the primary role of enteral and parenteral nutrition. Enteral nutrition is effective at inducing remission in active $C D$, although there is insufficient data to suggest that enteral nutrition should replace drug therapy. Several trials have failed to show any significant difference in efficacy between elemental and polymeric diets ${ }^{124}$. Compliance should be improved with more palatable nutrition in future studies to confirm the effectiveness of enteral nutrition as a therapy for CD.

In this review we focus on nutritional supplements as an adjunctive therapy in IBD patients.

\section{Fish oil}

Eicosapentaenoic acid (EPA) and docosahexaenoic acid (DHA) are polyunsaturated acids derived from fish oil. They are $n-3$ fatty acids because the first double bond is three carbons removed from the terminal methyl group. EPA and DHA are incorporated into membrane phospholipids replacing arachidonic acid ( $n-6$ fatty acid). The latter acid is the substrate for the synthesis of leukotriene B4 (LTB4), thromboxane A2 and prostaglandin E2 (PGE2) with high inflammatory activity ${ }^{130}$. The $\mathrm{n}-3$ fatty acids competitively inhibit the formation of the prostaglandins and leukotrienes derived from arachidonic acid, while serving as a substrate for prostaglandins and leukotrienes with lower inflammatory activity (LTB5 and PGE3). n-3 Fatty acids have greater affinity with the cyclooxygenase and lipoxygenase enzymes than $n-6$ fatty acids. Fish oil reduces the production of LTB4 and tromboxane A2 while also inhibiting interleukin $1 \beta$ synthesis and tumor necrosis factor- $a$ (TNF- $\alpha$ ) secretion ${ }^{131}$. 
Fish oil has been reported to be beneficial in UC patients, but results are controversial $^{133-136}$. Three studies reported clinical improvement after fish oil supplementation, but only Stenson et $\mathrm{al}^{135}$ found a significant decrease in rectal dialysate LTB4 levels. Differences between the studies as regards dose, study design, composition of the supplement and assessment of clinical improvement may explain the conflicting results.

Another important aspect to be taken into account is the increase in lipid peroxidation after fish oil supplementation ${ }^{137}$. Concomitant antioxidant supplementation may be able to counteract this potentially adverse effect of n-3 supplementation. Most publications on fish oil supplementation fail to state the amount of concomitant antioxidant administration.

The most recent studies on fish oil supplementation have been conducted in $C D$ patients. Two studies examined the role of fish oil in the prevention of relapses in $C D$ patients who had gone into remission with steroids ${ }^{33,138}$. In the study by Belluzi et $\mathrm{al}^{138}, 78 \mathrm{CD}$ patients with a high risk of relapse were randomly assigned to receive enteric-coated fish oil capsules or placebo. After 1 year follow-up, $59 \%$ of patients in the fish oil group remained in remission compared with $26 \%$ in the placebo group. In the trial of Lorenz-Meyer et al $^{33}$, however, remission rates after 1 year follow -up were identical in the fish oil and placebo groups.

An experimental study revealed a different mechanism for the inhibitory action of $\mathrm{n}-3$ fatty acids on the immune system ${ }^{139}$. When monocytes were incubated in vitro with either EPA or DHA, the expression of major histocompatibility complex class II molecules (HLA-DR, HLA, DP, and HLA-DQ) and adhesion molecules (ICAM-1) was significantly reduced.

\section{Short chain fatty acids}

Short chain fatty acids (SCFA) are formed in the colon by bacterial fermentation of non-absorbed carbohydrates, such as resistant starches or soluble fiber. The major SCFAs in the human colon are acetate, propionate, and butyrate. Butyrate is the preferred fuel for colonocytes, accounting for $70 \%$ of total energy consumption. In the starved colon, the SCFAs cannot easily be replaced by endogenous nutrients. In contrast, during starvation in small epithelial cells, endogenous sources (glutamine and ketone bodies) can meet the energy requirements of enterocytes through the vascular bed. It has therefore been hypothesized that an energy-deficient state of the colonic mucosa may lead to mucosal atrophy, diminished absorption and, eventually, colitis ${ }^{140}$.

It was originally suggested that the production of SCFAs in UC patients might be reduced. In stools from active UC patients, reduced concentrations of SCFAs were found compared with those from healthy controls or $C D$ patients $^{141}$. As a result, intervention trials with SCFAs were conducted in UC patients, and initial reports were encouraging ${ }^{142}$. Recently, however, welldesigned placebo-controlled trials have shown no benefit of SCFAs in UC ${ }^{143-145}$. An alternative hypothesis, which may explain contradictory results, is the 
observation of a reduced capacity of colonocytes in UC patients to oxidize butyrate ${ }^{146}$. It has been suggested that reducing sulphur compounds produced by certain species of colonic bacteria may impair colonocyte nutrition ${ }^{147}$. High prevalence rates of sulphate-reducing bacteria, increased faecal sulphide concentration and a higher sulphite production by sulphate-reducing bacteria have been found in UC patients compared with controls ${ }^{147}$. Sulphate-reducing bacteria produce sulphide, which may impair mucosal butyrate oxidation and may lead to decreased energy availability.

\section{Glutamine}

Glutamine has been shown to be an essential nutrient for many of the rapidly proliferating cells in the intestinal mucosa. A number of studies have demonstrated that glutamine supplementation improves the structural integrity, function and repair of the intestine during catabolic conditions associated with gastrointestinal disease ${ }^{149.150}$. To our knowledge, no studies have so far been conducted on oral glutamine as a therapeutic agent in IBD. However, topical glutamine supplementation in patients with pouchitis has been examined ${ }^{151}$. After 21 days of glutamine supplementation, 6 of 10 patients had significantly benefited from the treatment.

\section{Conclusion}

This review has attempted to provide further insights into the relationship between nutrition and IBD. At the moment, there is very little conclusive evidence regarding the role of specific dietary components in the pathogenesis of IBD. Assessment of nutritional status in IBD is complex, as nutritional status is influenced by several factors and it is hard to discriminate between diseaseinduced and malnutrition-induced changes in nutritional parameters. Several nutritional and functional deficiencies have been reported in patients with IBD, especially those with $C D$. Improvement of nutritional status may decrease disease activity in IBD patients, but further studies are needed to confirm this hypothesis. There have been a number of important observations leading to new and interesting developments in the field of nutritional therapy in IBD. It has been suggested that treatment of certain species of colonic bacteria in the gastrointestinal tract with specific nutrition may have protective effects against IBD. Furthermore, studies indicate that immunonutrition with $n-3$ fatty acids and antioxidants may play an important role in the nutritional treatment of IBD. 


\section{References}

1. Shivananda S, Lennard-Jones J, Logan R, Fear N, Price A, Carpenter L, et al. Incidence of inflammatory bowel disease across Europe: is there a difference between north and south? Results of the European collaborative study on inflammatory bowel disease (EC-IBD). Gut 1996; 39:690-7.

2. Russel MGVM, Dorant E, Volovics A, Brummer R-JM, Pop P, Muris JWM, et al. High incidence of Inflammatory Bowel Diseae in The Netherlands: results of a prospective study. Dis Colon Rectum 1998; 41:33-40.

3. Tysk C, Lindberg C, Jarnerot G, Floderus-Myrhed B. Ulcerative colits and Crohn's disease in a unselected population of monozygotic and dizygotic twins. A study of heritability and the influence of smoking. Gut 1988; 29:990-6.

4. Nakajima A, Matsuhashi N, Kodama T, Nazaki Y, Takazoe M, Kimura A. HLA linked susceptibility and resistence gene in Crohn's disease. Gastroenterology 1995; 109:1462-7.

5. Russel MGVM, Engels LG, Muris JW, Limonard CB, Volovics A, Brummer R-JM, et al. 'Modern life' in the epidemiology of inflammatory bowel disease: a casecontrol study with special emphasis on nutritional factors. Eur J Gastroenterol Hepatol 1998; 10:243-9.

6. Tragnone A, Valpiani D, Miglio F, Elmi G, Bazzocchi G, Pipitone E, Lanfranchi GA. Dietary habits as risk factors for inflammatory bowel disease. Eur J Gastroenterol \& Hepatol 1995; 7:47-51.

7. Gilat T, Langman MJS, Rozen P. Environmental factors in inflammatory bowel disease. Front Gastrointest Res 1986; 11:158-76.

8. Martini GA, Brandes JW. Increased consumption of refined carbohydrates in patients with Crohn's disease. Klinische Wochenschrift 1976; 54:367-71.

9. Millar B, Fervers F, Rohbeck R, Strohmeyer G. Sugar consumption in patients with Crohn's disease (German). Verh Dtsch Ges Inn Med 1976; 82(Part 1):922-4.

10. Graham WB, Torrance B, Taylor TV. Breakfast and Crohn's disease (letter). Br Med J 1978; 2:768.

11. Mayberry JF, Rhodes J, Newcombe RG. Breakfast and dietary aspects of Crohn's disease. Br Med J 1978; 2:1401.

12. Mayberry JF, Rhodes J, Newcombe RG. Increased sugar consumption in Crohn's disease. Digestion 1980; 20:323-6.

13. Mayberry JF, Rhodes J, Allan R, Newcombe RG, Regan GM, Chamberlain LM, et al. Diet in Crohn's disease. Two studies of current and previous habits in newly diagnosed patients. Dig Dis Sci 1981; 26:444-8.

14. Rawcliffe PM, Truelove SC. Breakfast and Crohn's disease. Br Med J 1978; 2:539-40.

15. Kasper H, Sommer H. Dietary fibre and nutrient intake in Crohn's disease. Am J Clin Nutr 1979; 32:1898-1901.

16. Thornton JR, Emmet PM, Heaton KW. Diet and Crohn's disease: characteristics of the pre-illness diet. Br Med J 1979; 2:762-4.

17. Silkoff K, Hallak A, Yegena L, Rozen P, Mayberry JF, Rhodes J, et al. Consumption of refined carbohydrates by patients with Crohn's disease in TelAviv-Yafo. Postgrad Med J 1980; 56:842-6.

18. Jarnerot G, Jarnmark I, Nilsson K. Consumption of refined sugar by patients with Crohn's disease, ulcerative colitis or irritable bowel syndrome. Scand J Gastroenterol 1983; 18:999-1002.

19. Penny WJ, Mayberry JF, Aggett PJ, Gilbert JO, Newcombe RG, Rhodes J. Relationship between trace elements, sugar consumption, and taste in Crohn's disease. Gut 1983; 24:288-92. 
20. Brauer PM, Gee MI, Grace M Thomson ABR, Diet of women with Crohn's and other gastrointestinal diseases. Am Diet Ass 1983; 82:659-64.

21. Porro GB, Panza E. Smoking, sugar and inflammatory bowel disease. Br Med J 1985; 291:971-2.

22. Panza E, Franceschi S, La Vecchia C, Prazzini F, Petrillo M, Decarli A, et al. Dietary factors in the aetiology of inflammatory bowel disease. Ital $J$ Gastroenterol 1987; 19:205-9.

23. Katschinski B, Logan RFA, Edmond M, Langman MJS. Smoking and sugar intake are seperate but interactive risk factors in Crohn's disease. Gut 1988; 29:1202-6.

24. Matsui T, lida M, Fujishima M, Imai K, Yao T. Increased sugar consumption in Japanese patients with Crohn's disease. Gastroenterologia Japonica, 1990; 25:271.

25. Persson PG, Ahlbom A, Hellers G. Diet and inflammatory bowel disease: a case control study. Epidemiology 1992; 3:47-52.

26. Reif S, Klein I, Lubin F, Farbstein M, Hallak A, Gilat T. Pre-ilness dietary factors in inflammatory bowel disease. Gut 1997; 40:754-60.

27. Thornton JR, Emmet PM, Heaton KW. Diet and ulcerative colitis. Br Med J 1980; 2:293-4.

28. Thornton JR, Emmet PM, Heaton KW. Smoking, sugar and inflammatory bowel disease. Br Med J 1985; 290:1786-7.

29. Riordan AM, Ruxton CHS, Hunter JO. A review of associations between Crohn's disease and consumption of sugars. Eur J Clin Nutr 1998; 52:229-38.

30. Sonnenberg A. Geographic and temporal variations of sugar and margarine consumption in relation to Crohn's disease. Dig 1988; 41:161-71.

31. Ritchie JK, Wadsworth J, Lennard-Jones JE, Rogers E. Controlled multicentre therapeutic trial of an unrefined carbohydrate, fibre-rich diet in Crohn's disease. Br Med J Clin Res 1987; 295:517-20.

32. Alun Jones V, Dickinson RJ, Workman E, Wilson AJ, Freeman AH, Hunter JO. Crohn's disease: maintenance of remission by diet. Lancet 1985; ii:177-180.

33. Lorenz-Meyer H, Nicolay C, Schulz B, Purrmann J, Fleig WE, Scheurlen C, et al. Omega-3 fatty acids and low carbohydrate diet for maintenance of remission in Crohn's disease: a randomized controlled multicenter trial. Scand J Gastroenterol 1996; 31:778-85.

34. McKeown GE, Sing Yeung KA, Bright-See E. Assessment of past diet in epidemiologic studies. Am J Epidemiol 1986; 124:94-103.

35. Gilat T, Hacohen D, Lilos P, Langman MJS. Childhood factors in ulcerative colitis and Crohn's disease. An international co-operative study. Scand J Gastroenterol 1987; 22:1009-24.

36. Guthy E. Morbus Crohn und nahrungsfette. Hypothese zur aetiologie der enteritis regionalis. Dtsch Med Wschr 1982; 107:71-3.

37. Epidemiology group of the research committee of inflammatory bowel disease in Japan. Dietary and other risk factors of ulcerative colitis: a case control study in Japan. J Clin Gastroenterol 1994; 19:166-71.

38. Chuah SY, Jayanthi V, Lee CN, McDonald B, Probert CSJ, Mayberry JF. Dietary fats and inflammatory bowel disease in Asians. Ital J Gastroenterol 1992; 24:386-8.

39. Guthy E. Atiologie des Morbus Crohn. Was spricht fur Fette als mogliche Ursache. Drsch Med Wschr 1983; 108:1719-20. 
40. Shoda R, Matsueda K, Yamato S, Umeda N. Epidemiologic analysis of Crohn disease in Japan: increased dietary intake of n-6 polyunsaturated fatty acids and animal protein relates to the increased incidence of Crohn disease in Japan. Am J Clin Nutr 1996; 63:741-5.

41. Crohn BB, Ginzberg L, Oppenheimer GD. Regional ileitis, a pathologic and clinical entity. J Am Med Ass 1932; 99:1323.

42. Harries AD, Jones LA, Heatley RV, Rhodes J. Malnutrition in inflammatory bowel disease: an anthropometric study. Hum Nutr Clin Nutr 1982; 36C:307-13.

43. Lanfranchi GA, Brignola C, Campieri M. Assessment of nutritional status in Crohn's disease in remission or low activity. Hepatogastroenterol 1984; 31:129-32.

44. Gee MI, Grace MGA, Wensel RH, Sherbaniuk RW, Thompson ABR. Nutritional status of gastroenterology outpatients: comparison of inflammatory bowel disease with functional disorders. J Am Diet Ass 1985; 85:1591-9.

45. Zurita VF, Rawls DE, Dyck WP. Nutritional support in inflammatory bowel disease. Dig. Dis 1995; 503;92-107.

46. Fleming CR. Nutrition considerations in patients with Crohn's disease. Sem Colon Rectal Surg 1994; 5:167-173.

47. Weinsier RL, Heimburger DC. Distinguishing malnutrition from disease: the search goes on. Am J Clin Nutr 1997;66:1063-4.

48. Jeejeebhoy KN, Detsky AS, Baker JP. Assessment of nutritional status. J Parenter Enteral Nutr 1990; 14(Suppl):193-6.

49. Charney P. Nutrition assessment in the 1990s: where are we now? Nutr Clin Prac 1995; 10:131-9.

50. Silk DBA, Payne-James J. Inflammatory bowel disease: nutritional implications and treatment. Proc Nutr Soc 1989; 48:355-61.

51. Royall D, Greenberg GR, Allard JP, Baker JP, Jeejeebhoy KN. Total enteral nutrition support improves body composition of patients with active Crohn's disease. J Parenter Enteral Nutr 1995; 19:95-9.

52. Stokes MA, Hill GL. Total energy expenditure in patients with Crohn's disease: measurement by the combined body scan technique. J Parenter Enteral Nutr 1993; 17:3-7.

53. Jacobson S, Carlmark B. Total body potassium, fat and water using total parenteral nutrition in Crohn's disease. Clin Nutr 1990; 9:272-80.

54. Stokes MA. Crohn's disease and nutrition. Br J Surg 1992;79:391-4.

55. Shenkin A. Impact of disease on markers of macronutrient status. Proc Nutr Soc 1997; 56:433-41.

56. Main ANH, Mills PR, Russell RI, Bronte-Stewart J, Nelson LM, Mclelland A, et al. Vitamin A deficiency in Crohn's disease. Gut 1983;2 4:1169-75.

57. Schoelmerich J, Bechner MS, Hoppe-Seyler P, Matern S, Haessinger E, Loehle E, et al. Zinc and vitamin A deficiency in patients with Crohn's disease is correlated with activity but not with localization or extent of the disease. Hepatogastroenterol 1985; 32:34-8.

58. Janczewska I, Bartnik W, Butruk E, Tomecki R, Kazik E, Ostrowski J. Metabolism of vitamin A in inflammatory bowel disease. Hepatogastroenterol 1991; 38:391-5.

59. Fernández-Bañares F, Abad-Lacruz A, Xiol X, Gine JJ, Dolz C, Cabre E, et al. Vitamin status in patients with inflammatory bowel disease. Am J Gastroenterol $1989 ; 84: 744-8$.

60. Kuroki F, lida M, Tominaga M, Matsumoto T, Hirakawa K, Sugiyama S, et al. Multiple vitamin status in Crohn's disease. Correlation with disease activity. Dig Dis Sci 1993; 38:1614-8. 
61. Thurnham DI. Impact of disease on markers of micronutrient status. Proc Nutr Soc 1997; 56:421-31.

62. Imes S, Pinchbeck B, Dinwoodie A, Walker K, Thomson ABR. Vitamin A status in 137 patients with Crohn's disease. Dig 1987; 37:166-70.

63. Cravo M, Gloria L, Salazar de Sousa L, Chaves P, Dias Pereira A, Quina M, et al. Folate status, DNA methylation and colon cancer risk in inflammatory bowel disease. Clin Nutr 1995; 14:50-3.

64. Steger GG, Mader RM, Vogelsang H, Schöfl R, Lochs H, Ferenci P. Folate absorption in Crohn's disease. Dig 1994; 55:234-8.

65. Herbert V, Das KC. The role of vitamin B12 and folic acid metabolism:folic acid clearance studies. Vitam Horm 1976; 34:1-30.

66. Lashner BA. Red blood cell folate is associated with the development of dysplasia and cancer in ulcerative colitis. J Cancer Res Clin Oncol 1993; 119:549-54.

67. Behrend C, Jeppesen PB, Mortensen PB. Vitamin B12 absorption after ileorectal anastomosis for Crohn's disease: effect of ileal resection and time span after surgery. Eur J Gastroenterol Hepatol 1995; 7:397-400.

68. Buffinton GD, Doe WF. Altered ascorbic acid status in the mucosa from inflammatory bowel disease patients. Free Rad Res 1995; 22:131-43.

69. Imes S, Dinwoodie A, Walker K, Pinchbeck B, Thompson AB. Vitamin C status in 137 outpatients with Crohn's disease. Effect of diet counselling. J Clin Gastroenterol 1986; 8:443-6.

70. Leichtmann GA, Bengoa JM, Bolt MJG, Sitrin MD. Intestinal absorption of cholecalciferol and 25-hydroxycholecalciferol in patients with both Crohn's disease and intestinal resection. Am J Clin Nutr 1991; 54:548-52.

71. Nunen van $A B$, Schoon EJ, Russel MG, Stockbrügger RW, Brummer R-JM. Vitamin D deficiency and osteopenia in Crohn's disease. Eur J Gastroenterol Hepatol 1997; 9:A5.

72. Harries AD, Brown R, Heatley RV, Williams LA, Woodhead S, Rhodes J. Gut 1985; 26:1197-1203.

73. Schoon EJ, van Nunen AB, Heidendal G, Geerling BJ, Stockbrügger RW, Russel MGVM, et al. Low body fat and risk for osteoporosis in Crohn's disease. Gut 1996; 39(Suppl 3):A958.

74. Abitbol V, Roux C, Chaussade S, Guillemant S, Kolta S, Dougados M, et al. Metabolic bone assessment in patients with inflammatory bowel disease. Gastroenterology 1995; 108:417-22.

75. Silvennoinen J. Relationships between vitamin D, parathyroid hormone and bone mineral density in inflammatory bowel disease. J Intern Med 1996; 239:131-7.

76. Schoon EJ, Geerling BJ, Schurgers L, Vermeer C, Stockbrügger RW, Brummer R$\mathrm{JM}$. Bone formation is suppressed and bone resorption is normal in long-standing quiescent Crohn's disease. Gastroenterology 1998; 114:G4421.

77. Steinhart $A H$, Greenberg GR. Nutrition in inflammatory bowel disease. Current Opinion in Gastroenterol 1997; 13:140-5.

78. Kuroki $F$, lida M, Tominaga M, Matsumoto $T$, Kanamoto K, Fujishima M. Is vitamin $E$ depleted in Crohn's disease at initial diagnosis? Dig Dis 1994; 12:248-54.

79. Loeschke K, Konig A, Haeberlin ST. Low blood selenium concentrations in Crohn's disease. Ann Intern Med 1987; 106:908.

80. Hinks LJ, Inwards KD, Lloyd B, Clayton B. Reduced concentrations of selenium in mild Crohn's disease. J Clin Pathol 1988; 41:198-201.

81. Ringstad J, Kildebo S, Thomassen Y. Serum selenium, copper, and zinc concentrations in Crohn's disease and ulcerative colitis. Scand J Gastroenterol 1993; 28:605-8. 
82. Rannem T, Ladefoged K, Hylander E, Hegnhøj, Jarnym S. Selenium status in patients with Crohn's disease. Am J Clin Nutr 1992; 56:933-7.

83. Fernández-Bañares $F$, Mingorance MD, Esteve M, Cabre E, Lachica M, AbudLacruz A, et al. Serum zinc, copper, and selenium levels in inflammatory bowel disease: effect of total enteral nutrition on trace element status. Am $J$ Gastroenterol 1990; 85:1584-9.

84. Hoffenberg EJ, Deutsch J, Smith S, Sokol RJ. Circulating antioxidant concentrations in children with inflammatory bowel disease. Am J Clin Nutr 1997; 65:1482-8.

85. Thomas AG, Miller V, Shenkin A, Fell GS, Taylor F. Selenium and gluthatione peroxidase status in pediatric health and gastrointestinal disease. J Pediatr Gastroenterol Nutr 1994; 19:213-9.

86. Fernández-Bañares F, Dolz C, Mingorance MD. Low serum selenium concentrations in healthy population resident in Catalunya: A preliminary report. Eur J Clin Nutr 1990; 44:225-9.

87. Andersson H, Bosaeus I, Brummer R-J, Fasth S, Hultén L, Magnusson O, Strauss B. Nutritional and metabolic consequences of extensive bowel resection. Dig Dis 1986; 4:193-202.

88. Sjogren A, Floren $\mathrm{CH}$, Nilsson A. Evaluation of magnesium status in Crohn's disease as assessed by intracellular analysis and intravenous magnesium infusion. Scand J Gastroenterol 1981; 23:555-61.

89. Hessov I, Hasselblad C, Fasth S, Hulten L. Magnesium deficiency after ileal resection for Crohn's disease. Scand J Gastroenterol 1983; 18:643-649.

90. Galland L. Magnesium and inflammatory bowel disease. Magnesium 1988; 7:78-83.

91. Kelly DG, Fleming CR. Nutritional considerations in inflammatory bowel diseases. Gastroenterol Clin North Am 1995; 24:597-611.

92. Hendricks KM, Walker WA. Zinc deficiency in inflammatory bowel disease. Nutr Rev $1988 ; 46: 401-8$.

93. Naber THJ, Hamer van den CJA, Baadenhuysen H, Jansen JBMJ. The value of methods to determine zins deficiency in patients with Crohn's disease. Scand J Gastroenterol 1998; 33:514-23.

94. Valberg LS, Flanagan PR, Kertesz A, Dondy DC. Zinc absorption in inflammatory bowel disease. Dig Dis Sic 1986; 31:724-31.

95. Sandström B, Davidsson L, Bosaeus I, Eriksson R, Alpsten M. Selenium status and absorption of zinc $\left({ }^{65} \mathrm{Zn}\right)$, selenium $\left({ }^{75} \mathrm{Se}\right)$ and manganese $\left({ }^{54} \mathrm{Mn}\right)$ in patients with short bowel syndrome. Eur J Clin Nutr 1990; 44: 697-703.

96. Fleming CR, Huizenga KA, Mc Call JT, Gildea J, Dennis R. Zinc nutrition in Crohn's disease. Dig Dis Sci 1981; 26:865-70.

97. Mulder TPJ, Verspaget HW, Janssens AR, de Bruin PAF, Peña AS, Lamer CBHW. Decrease in two intestinal copper/zinc containing proteins with antioxidant function in inflammatory bowel disease. Gut $1991 ; 32: 1146-50$.

98. Goode HF. Inflammatory bowel disease, free radicals and zinc. J Gastroenterol Hepatol 1994; 9:519-20.

99. Naber THJ, Baadenhuysen H, Jansen JBMJ, Hamer van den CJA, Broek van den W. Serum alkaline phosphatase activity during zinc deficiency and long-term inflammatory stress. Clin Chim Acta 1996; 249:109-27.

100. Ainley CC, Cason J, Carlsson LK, Slavin BM, Thompson RPH. Zinc status in inflammatory bowel disease. Clin Sci 1988; 75:277-83.

101. Ainley CC, Cason J, Slavin BM, Wolstencroft RA, Thompson RPH. The influence of zinc status and malnutritin on immunological function in Crohn's disease. Gastroenterology 1991; 100:1616-25. 
102. Naber THJ, Heymer F, Hamer van den CJA, Broek WJM, Jansen JBMJ. The in vitro uptake of zinc by blood cells in rats with long term inflammatory stress. Clin Nutr 1994; 13:247-55.

103. Solomons NW. On the assessment of zinc anc copper nutriture in man. Am J Clin Nutr 1979; 32:856-71.

104. Harries AD, Danis VA, Heatley RV. Influence of nutritional status on immune functions in patients with Crohn's disease. Gut $1984 ; 25: 465-72$.

105. Grimble RF. Nutritional antioxidants and the modulation of inflammation: Theory and practice. New Horizons $1994 ; 32: 175-85$.

106. Wan JMF, Haw MP, Blackburn GL. Nutrition, immune function, and inflammation: an overview. Proc Nutr Soc 1989; 48:315-35.

107. Verspaget HW, Mulder TPJ, van der Sluys-Veer A, Peña AS, Lamers CBHW. Reactive oxygen metabolites and colitis; a disturbed balance between damage and protection. Scan J Gastroenterol 1991; 26:44S-51S.

108. Conner EM, Grisham MB. Inflammation, Free radicals, and antioxidants. Nutrition $1996 ; 12: 274-7$.

109. Öjerskog B, Andersson H, Bosaeus I, Brevinge H, Nilsson LO. Total body water and total body potassium in ileostomy patients before and after conversion to the continent ileostomy. Gut 1988; 29:1198-1201.

110. Christie PM, Graham MB, Hill L. Return to normal body composition after ileoanal $\mathrm{J}$-pouch anastomosis for ulcerative colitis. Dis Colon Rectum 1990; 33:584-6.

111. Christie PM, Knight GS, Hill GL. Metabolism of body water and electrolytes after surgery for ulcerative colitis: conventional ileostomy versus $\mathrm{J}$ pouch. $\mathrm{Br} \mathrm{J}$ Surg 1990; 77:149-51.

112. Royall D, Greenberg GR, Allard JP, Baker JP, Harrison JE, Jeejeebhoy KN. Critical assessment of body composition measurements in malnourished subjects with Crohn's disease: the role of bioelectric impedance analysis. Am J Clin Nutr 1994; 59:325-30.

113. Azcue M, Rashid M, Griffiths A, Pencharz PB. Energy expenditure and body composition in children with Crohn's disease: effect of enteral nutrition and treatment with prednisolone. Gut 1997; 41:203-8.

114. Streat SJ, Beddoe AH, Hill GL. Measurement of body fat and hydration of the fatfree body in health and disease. Metabolism 1985; 34:509-18.

115. Chrousos GP. The hyothalamic-pituitary-adrenal axis and immune-mediated inflammation. New Engl J Med 1995; 332:1351-62.

116. Lopes J, Russell DMcR, Whitwell J, Jeejeebhoy KN. Skeletal muscle function in malnutrition. Am J Clin Nutr 1982; 36:602-10.

117. Nishio ML, Jeejeebhoy KN. Effect of malnutrition on aerobic and anaerobic performance of fast- and slow-twitch muscles of rats. J Parenter Enteral Nutr $1992 ; 16: 219-25$.

118. Brevinge $H$, Berglund B, Bosaeus I, Tolli J, Nordgren S, Lundholm K. Exercise capacity in patients undergoing proctocolectomy and small bowel resection for Crohn's disease. Br J Surg 1995; 82:1040-5.

119. Kalfarentzos F, Spiliotis J, Velimezis G, Dougenis D, Androulakis J. Comparison of forearm muscle dynamometry with nutritional prognostic index, as a preoperative indicator in cancer patients. J Parenter Enteral Nutr 1989; 13:34-36.

120. Berkelhammer $\mathrm{CH}$, Leiter LA, Jeejeebhoy KN. Skeletal muscle function in chronic renal failure: an index of nutritional status. Am J Clin Nutr 1985; 42:845-54.

121. Gleeson NP, Mercer TH. The utility of isokinetic dynamometry in the assessment of human muscle function. Sports Med 1996; 21:18-34.

122. Teahon K, Bjarnason I, Pearson M, Levi AJ. Ten years experience with elemental diet in the management of Crohn's disease. Gut 1190; 31:1133-7. 
123. O'Morain CA, O'Sullivan MA. Nutritional support in Crohn's disease: current status and future directions. J Gastroenterol 1995; 30:102S-7S.

124. King TS, Woolner JT, Hunter JO. Review article: the dietary management of Crohn's disease. Aliment Pharmacol 1997; 11:17-31.

125. Stenson WF, Alpers DH. Nutritional therapy in inflammatory bowel disease: a historical overview. Current Opinion Gastroenterol 1997; 13:135-9.

126. O'Sullivan MA, O'Morain CA. Nutritional therapy in Crohn's disease. Inflammatory Bowel Dis 1998; 4:45-53.

127. Griffiths AM, Ohlsson A, Sherman PM, Sutherland LR. Meta-analysis of enteral nutrition as primary treatment of active Crohn's disease. Gastroenterology 1995; 108:1056-67.

128. Fernández-Bañares $F$, Cabre E, Esteve-Comas M, Gassull MA. How effective is enteral nutrition in inducing clinical remission in active Crohn's disease? A metaanalysis of the randomized clinical trials. J Parenter Enteral Nutr 1995; 19:356-64.

129. Messori A. Trallori G, D'albasio G, Milla M, Vannozzi G, Pacini F. Defined-formula diets versus steroids in the treatment of active Crohn's disease: a meta-analysis. Scand J Gastroenterol 1996; 31:267-72.

130. O'Morain C, Tobin A, Suzuki Y, McColl T, Collins R. Fish oil in the treatment of ulcerative colitis. Can J Gastroenterol 1990; 4:420-3.

131. Sanderson IR. Diet and gut inflammation. Current Opinion Gastroenterol 1997; 13:518-24.

132. Lorenz R, Weber PC, Szimnau P, Heldwein W, Strasser T, Loeschke K. Supplementation with $\mathrm{n}-3$ fatty acids from fish oil in chronic inflammatory bowel disease- a randomized, placebo-controlled, double-blind cross-over trial. J Int Med $1989 ; 225: 225$ S-32S.

133. McCall TB, O'Leary D, Bloomfield J, O'Morain CA. Therapeutic potential of fish oil in the treatment of ulcerative colitis. Aliment Pharmacol Therap 1989; 3:415-24.

134. Aslan A, Triadafilopoulos G. Fish oil fatty acid supplementation in acitive ulcerative colitis: a double blind, placebo-controlled, crossover study. Am J Gastroenterol 1992; 87:432-7.

135. Stenson WF, Cort DC, Rodgers J, Burakoff R, DeSchryver-Keeskemeti K, Gramlich TL, Becken W. Dietary supplementation with fish oil in ulcerative colitis. Ann Int Med 1992; 116:609-14.

136. Hawthorne AB, Daneshmend TK, Hawkey CJ, Belluzi A, Everitt SJ, Holmes GKT, et al. Treatment of ulcerative colitis with fish oil supplementation: a prospective 12 month randomised controlled trial. Gut 1992; 33:922-8.

137. Girelli D, Olivieri O, Stanzial AM, Guarini P, Trevisan MT, Bassi A, Corrocher R. Factors affecting the thiobarbituric acid test as index of red blood cell susceptibility to lipid peroxidation: a multivariate analysis. Clin Chim Acta 1994; 227:45-57.

138. Belluzi A, Brignola C, Campieri M, Pera A, Boschi S, Migliolo M. Effect of an enteric-coated fish-oil preparation on relapses in Crohn's disease. N Eng J Med 1996; 334:1557-60.

139. Hughes DA, Southon S, Pinder AC. N-3 polyunsaturated fatty acids modulate the expression of functionally associated molecules on human monocytes in vitro. $\mathrm{J}$ Nutr 1996; 126:603-10.

140. Roediger WEW. The starved colon-diminished mucosal nutrition, diminished absorption, and colitis. Dis Colon Rectum 1990; 33:858-62.

141. Vernia P, Gnaedinger A, Hauck W, Breuer RI. Organic anions and the diarrhea of inflammatory bowel disease. Dig Dis Sci 1988;3 3:1353-8. 
142. Cummings $\mathrm{JH}$. Short chain fatty acids in the treatment of distal colitis. Eur J Gastroenterol Hepatol 1997; 9:149-53.

143. Scheppach W, for the German-Austrian SCFA Study Group. Treatment of distal ulcerative colitis with short-chain fatty acids enemas: a placebo-controlled trial. Dig Dis Sci 1996; 41:2254-9.

144. Steinhart AH, Hiruki T, Brezinski A, Baker JP. Treatment of left-sided ulcerative colitis with butyrate enemas: a controlled trial. Aliment Pharmacol Ther 1996; 10:729-36.

145. Breuer Ri, Soergel KH, Lashner BA, Christ ML, Hanauer SB, Vanagunas V, et al. Short chain fatty acid rectal irrigation for left sided ulcerative colitis: a randomized, placebo controlled trial. Gut 1997; 40:485-91.

146. Roediger WEW. The colonic epithelium in ulcerative colitis: an energy-deficient disease? Lancet 1980; 2:712-5.

147. Scheppach W. Short-chain fatty acids improve epithelia in ulcerative colitis? Speculation on mechanisms. In: Binder HJ, Cummings J, Soergel KH. Short chain fatt acids. Dordrecht: Kluwer Academic Publishers, 1993:206-13.

148. Florin THJ, Gibson JR, Neale G, Cummings JH. A role for sulfate reducing bacteria in ulcerative colitis. Gastroenterology 1990; 98:A170.

149. LeLeko NS, Walsh MJ. The role of glutamine, short-chain fatty acids, and nucleotides in intestinal adaptiation to gastrointestinal disease. Ped Clin North Am. 1996; 43:451-69.

150. Hulst van der RRWJ, Kreel van BK, Meyenfeldt von MF, Brummer R-JM, Arends JW, Deutz NEP, Soeters PB. The role of parenteral glutamine administration in preserving gut integrity. Lancet 1993; 334:1363-5.

151. Wischmeyer P, Pemberton JH, Phillips SF. Chronic pouchitis after ileal pouch-anal anastomosis: responses to butyrat and glutamine suppositories in a pilot study. Mayo Clin Proc 1993; 68:978-81. 


\section{Diet as a risk factor for the development of ulcerative colitis}

Geerling BJ, Dagnelie PC, Badart-Smook A, Russel MGVM, Stockbrügger RW, Brummer R-JM 


\section{Abstract}

\section{Background}

Dietary factors have been considered as a possible risk factor for ulcerative colitis (UC), however, data are inconsistent. The aim of the present study was evaluate the etiological role of dietary factors in the development of UC.

\section{Patients and methods}

Recently diagnosed ( $<6$ months) UC patients $(n=43)$ and age- and sex-matched population controls $(n=43)$ were studied in a case-control study. The cross-check dietary history method was used to assess dietary intake of 5 years prior to the study. Adipose tissue fatty acid composition was used as a biomarker of long-term fat intake. Conditional logistic regression-derived odds ratios (OR), and $95 \%$ confidence intervals (CI) were calculated. Dietary intake ORs were adjusted for energy intake.

\section{Results}

High intakes of monounsaturated fatty acids (OR: 33.9 (95\% Cl 2.6-443.1)), polyunsaturated fatty acids (OR: $5.1(95 \% \mathrm{Cl}$ 1.0-26.7)), and vitamin B6 (OR: 6.9 (95\% Cl 1.6-30.7)) were associated with an increased risk to develop UC. No other significant associations were found with UC risk.

\section{Conclusion}

High intakes of mono- and polyunsaturated fatty acids and vitamin B6 may enhance the risk of developing UC. Whether this observation is a true risk factor in the development of UC or rather a reflection of a certain dietary life style needs to be investigated. 


\section{Introduction}

The etiology of ulcerative colitis (UC) is poorly understood. Possible determinants include genetic factors ${ }^{1-4}$, as well as environmental factors like thrombogenic factors $\mathrm{s}^{5 \cdot 7}$ and bacterial and viral agents ${ }^{8.9}$. In addition, for many years, dietary factors have been considered as a possible risk factor for UC.

In patients with Inflammatory Bowel Disease (IBD), many studies on sucrose consumption have been conducted since Martini and Brandes reported in 1976 that patients with Crohn's disease (CD) would consume an excess amount of sugar and sugar-containing products ${ }^{10}$. However, the role of sucrose in the etiology of UC is inconsistent ${ }^{11-20}$, which may be due to the methodological limitations of many studies ${ }^{21}$. In addition, also for other food items i.e. vegetables or fiber consumption, no clear association between intakes and the risk of UC was observed ${ }^{14,16-20}$.

Recently, Reif et al $^{18}$ reported that the composition of pre-illness diet was related with subsequent development of UC. Sucrose and fat consumption were associated with an increased risk for UC, whereas intakes of fructose, fluids, magnesium, vitamin $\mathrm{C}$ and fruit were associated with reduced UC risk.

The aim of the present study was to evaluate the etiologic role of dietary factors in the development of UC with special reference to nutrients. Since fatty acid composition of adipose tissue has been used as a potential biomarker of long-term dietary intake of some fatty acids, especially polyunsaturated fatty acids $^{22-27}$, adipose tissue biopsies were included in this study as a biomarker of long-term fat intake.

\section{Subjects and methods}

\section{Subjects}

Patients were recruited from the out-patient population of the Department of Gastroenterology of the University Hospital Maastricht, the Atrium Medical Center Brunssum and the Maasland Hospital Sittard, all located in the south of the province of Limburg in the Netherlands. The diagnosis of UC was based on the criteria of Truelove and Witts ${ }^{28}$. All patients who had been diagnosed with UC during the period June 1995-December $1997(n=49)$ were asked to participate in the study. Forty-six patients $(94 \%)$ agreed to participate. All patients had been diagnosed within 6 months prior to entering the study. Assessable data were available in 43 patients. Characteristics of these patients are shown in Table 3.1. Disease activity was assessed according to the Truelove-Witts criteria and graded numerically as 6-19 corresponding to "no disease activity", 20-32 as having "moderate disease activity" and 33-45 corresponding to "severe disease" ${ }^{29}$. In addition, the concentration of C-reactive 
protein (CRP) at the time of the investigation was assessed. Patients were included in the present study 1 to 5 months after diagnosis (median duration: 4 months). Median duration of complaints at time of diagnosis, as reported by patients, was 2 months with a range from 1-27 months.

Table 3.1 Characteristics of subjects

\begin{tabular}{|c|c|c|}
\hline & UC patients $(n=43$ ) & Controls $(n=43$ ) \\
\hline Age (years)' & $37.8 \pm 14.7$ & $37.7 \pm 14.6$ \\
\hline Gender (F/M) & $20 / 23$ & $20 / 23$ \\
\hline Weight $(\mathrm{kg})^{\prime}$ & $68.5 \pm 10.4$ & $71.5 \pm 11.1$ \\
\hline Smoking (\%) & 15.2 & 23.3 \\
\hline C-reactive protein (mg/L)' & $6.1 \pm 6.4$ & $4.9 \pm 3.7$ \\
\hline Truelove \& Witts index ${ }^{1,2}$ & $9.6 \pm 5.8$ & - \\
\hline Present use of - mesalazine & 93.4 & - \\
\hline - azathioprine use & 6.5 & - \\
\hline - prednisone $(\mathrm{mg} / \mathrm{day} \pm \mathrm{SD})$ & $19.5(11.3 \pm 7.0)$ & - \\
\hline
\end{tabular}

'Data are expressed as mean \pm SD. ${ }^{2}$ according to reference 29.

\section{Controls}

Control subjects were selected from the patient population of one large general practice (three general practitioners) in the same study area (Table 3.1). Controls were selected randomly from the database, corresponding to the ageand gender-distribution of UC patients. Controls were matched for age and sex (within 3 years) with UC patients. Subjects with a history of IBD were excluded; no other selections regarding health care problems were performed.

\section{Methods}

\section{Dietary intake}

The onset of disease symptoms was $<5$ years before the study in all patients. In all subjects (patients and controls) the usual dietary intake at 5 years prior to the interview was assessed using the cross-check dietary history method ${ }^{30}$. Patients and controls were interviewed about their dietary intake in an identical fashion during a home visit by an experienced dietician. Food quantities were specified in household measures and usual portion sizes were estimated with the aid of portion size models or pictures of foods. A self-administered semiquantitative validated food-frequency questionnaire (FFQ) ${ }^{31}$ was used as a cross check of the dietary history. All types of food and drink were converted into energy and nutrients using the extended computerized version of the Netherlands Food Table (NEVO) ${ }^{32}$. The following consumption of macronutrients subdivided into nutrient groups were noted: carbohydrates (total, mono- and 
disaccharides, and polysaccharides), protein (total, and amounts of animal and vegetable origin), fat (total, saturated, mono- and polyunsaturated fat). The following consumption of nutrients (linoleic acid and cholesterol) and micronutrients are reported: total iron, potassium, sodium, calcium, retinol, vitamin $\mathrm{B} 1$, vitamin $\mathrm{B} 2$, vitamin $\mathrm{B} 6$, vitamin $\mathrm{C}$, nicotinic acid.

\section{Adipose tissue fatty acid analysis}

Adipose tissue biopsies were taken from the outer quadrant of the right buttock with a 19-gauge needle attached to a syringe in 41 UC patients and 41 controls. The syringe was rinsed with methanol to dissolve the fat and the samples were stored at $-80^{\circ} \mathrm{C}$ until analysis ( $<3$ months). Total lipid extracts from the adipose tissue biopsy were prepared according to the method of Bligh and Dyer $^{33}$ by adding methanol and chloroform (1:1, vol: vol). The total lipid extract was saponified and the fatty acid converted to the corresponding methyl esters by reaction with $14 \%$ boron trifluoride in methanol at $100^{\circ} \mathrm{C}$ for 30 $\mathrm{min}^{34}$. To all organic solvents, butylated hydroxytoluene $(50 \mathrm{mg} / \mathrm{L})$ was added as an antioxidant. The fatty acid composition of adipose tissue was analyzed as described by Foreman et $\mathrm{al}^{35}$. The following fatty acid combinations were

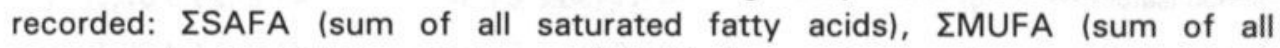
monounsaturated fatty acids), and EPUFA (sum of all polyunsaturated fatty acids). The amounts of the various fatty acids were expressed as percentages of total fatty acids on a wt/wt basis.

\section{Statistical analysis}

Results were expressed as median with 25 th and 75 th percentiles or as stated. Differences in absolute dietary intake between UC patients and controls were analyzed using the Wilcoxon matched-pairs signed -rank test. Spearman correlation coefficients were calculated. These statistical analyses were performed with the SPSS 7.0 for Windows package (SPSS Inc, Chicago).

Conditional logistic regression analysis adjusting for energy intake was performed using Stata, Version 5.0 (Stata Corporation, College Station, Texas, USA) ${ }^{36}$. Three tertiles of dietary intake (low, median, and high) were derived based on the distribution of dietary intakes of the control population. Subsequently, patients were classified according to these calculated tertiles of dietary intake. Odds ratios for the dietary intake levels were calculated, corresponding $95 \%$ confidence intervals were derived, and significance for linear trend was estimated. P-values $<0.05$ were considered statistically significant. 


\section{Results}

\section{Dietary intake}

Median daily dietary intake at 5 years prior to the study for patients and controls is shown in Table 3.2. Vitamin B6 intake was significantly higher $(P<0.01)$ in UC patients than in controls. No other significant differences in intake of energy or nutrients were observed between patients and controls.

Table 3.2 Daily dietary intake at 5 year prior to diagnosis'

\begin{tabular}{lcc}
\hline & Patients $(\mathbf{n = 4 3})$ & Controls $(\mathbf{n = 4 3})$ \\
\hline Energy intake (MJ/day) & $12.0(9.3-14.6)$ & $10.9(8.8-15.7)$ \\
Total protein (g) & $89.6(69.7-102.7)$ & $86.9(71.8-114.9)$ \\
Animal protein (g) & $51.7(42.8-64.9)$ & $57.6(45.5-72.0)$ \\
Total fat (g) & $122.2(96.5-157.5)$ & $108.7(80.9-170.2)$ \\
Saturated fat (g) & $46.7(38.5-63.2)$ & $47.4(34.9-67.8)$ \\
Monounsaturated fat (g) & $47.1(36.6-61.3)$ & $41.8(29.9-57.1)$ \\
Polyunsaturated fat (g) & $23.6(16.9-30.9)$ & $21.0(14.3-30.1)$ \\
Linoleic acid (g) & $19.2(14.3-27.3)$ & $18.6(11.5-26.5)$ \\
Cholesterol (mg) & $268.0(220.0-342.0)$ & $242.0(189.0-394.0)$ \\
Total carbohydrates (g) & $313.2(246.8-396.4)$ & $307.1(243.6-392.2)$ \\
Mono + disaccharides (g) & $156.4(117.2-219.6)$ & $143.1(107.1-188.9)$ \\
Fiber (g) & $30.4(24.6-37.7)$ & $29.8(23.0-39.2)$ \\
Alcohol (g) & $2.1(0.1-12.4)$ & $3.3(0.1-8.6)$ \\
Calcium (g) & $1.09(0.76-1.42)$ & $1.15(0.92-1.61)$ \\
Total iron (mg) & $11.7(9.2-14.3)$ & $12.5(9.1-16.8)$ \\
Vitamin A (mg RE) & $0.86(0.68-1.00)$ & $0.90(0.67-1.20)$ \\
Vitamin B1 (mg) & $1.20(0.99-1.51)$ & $1.29(0.99-1.72)$ \\
Vitamin B2 (mg) & $1.70(1.24-2.25)$ & $1.63(1.31-2.03)$ \\
Nicotinic acid (mg) & $13.5(10.4-18.0)$ & $13.0(9.1-18.4)$ \\
Vitamin B6 (mg) & $5.06(3.56-6.59)^{2}$ & $3.57(2.54-5.06)$ \\
Vitamin C (mg) & $81.8(52.9-115.7)$ & $84.8(62.4-123.8)$ \\
Sodium (g) & $3.84(3.30-5.06)$ & $3.79(2.72-5.35)$ \\
Total fluid (L) & $2.37(2.04-3.11)$ \\
\hline & $2.37(2.00-2.85)$ & \\
\hline & & \\
\hline
\end{tabular}

'Data are expressed as median; 25th and 75th percentile in parentheses.

${ }^{2}$ Significantly different from controls (Wilcoxon matched-pairs signed-ranks test): $P<0.01$. 
Table 3.3 shows odds ratios and $95 \%$ confidence intervals for UC patients at the intake levels of macronutrients. In addition, P-values for linear trend of OR are reported. Carbohydrate intake (total, mono- and disaccharides, polysaccharides, or fiber) did not show any significant association with UC risk. High intakes of mono- and polyunsaturated fat were associated with a significantly increased UC risk. Although the odds ratio for total fat was also increased, this was not statistically significant $(P=0.10)$.

Table 3.3 Odds ratios (OR) and confidence intervals (CI) for patients with ulcerative colitis at different levels of carbohydrates, protein, and fat intakes'

\section{OR (CI) at intake levels}

\begin{tabular}{lccc} 
Nutrients & Medium & High $^{2}$ & P-value $^{3}$ \\
\hline Carbohydrates total & $1.3(0.4-4.4)$ & $2.2(0.4-11.8)$ & 0.36 \\
Mono + disaccharides & $1.4(0.4-4.8)$ & $3.0(0.7-13.4)$ & 0.15 \\
Poly saccharides & $1.7(0.5-5.8)$ & $0.9(0.1-6.4)$ & 0.90 \\
Fiber & $1.0(0.4-2.6)$ & $0.7(0.2-3.4)$ & 0.79 \\
Protein total & $0.9(0.3-3.4)$ & $0.2(0.02-1.5)$ & 0.20 \\
Protein vegetable & $1.4(0.5-4.2)$ & $2.4(0.6-10.4)$ & 0.25 \\
Protein animal & $0.5(0.2-1.5)$ & $0.2(0.04-1.1)$ & 0.07 \\
Fat total & $3.4(1.0-12.2)$ & $4.1(0.6-28.4)$ & 0.10 \\
Saturated fat & $4.4(1.1-17.5)$ & $3.7(0.4-30.9)$ & 0.13 \\
Monounsaturated fat & $11.4(1.4-95.7)$ & $33.9(2.6-443.1)$ & 0.005 \\
Polyunsaturated fat & $2.9(0.7-11.3)$ & $5.1(1.0-26.7)$ & 0.05 \\
Linoleic acid & $2.1(0.6-7.4)$ & $1.9(0.4-8.6)$ & 0.52 \\
Cholesterol & $2.1(0.7-6.0)$ & $1.3(0.4-4.8)$ & 0.67 \\
\hline
\end{tabular}

1 Adjusted for energy intake.

${ }^{2}$ Versus the low intake category; dietary intake categories are derived from pair-matched population controls.

${ }^{3}$ P-value for linear trend.

Odds ratios and $95 \%$ confidence intervals for micronutrients are shown in Table 3.4. Of all micronutrients, only vitamin B6 was significantly associated with an increased risk of UC. 
Table 3.4 Odds ratios (OR) and confidence intervals $(\mathrm{CI})$ for patients with ulcerative colitis at different levels of micronutrients intakes.

OR (CI) at intake levels

\begin{tabular}{lccc} 
Nutrients & Medium & High' & P-value \\
\hline Iron total & $0.8(0.3-2.5)$ & $0.3(0.08-1.5)$ & 0.16 \\
Potassium & $1.1(0.4-3.5)$ & $1.9(0.4-9.8)$ & 0.48 \\
Sodium & $6.6(1.3-32.0)$ & $5.0(0.5-51.1)$ & 0.08 \\
Calcium & $0.9(0.3-2.8)$ & $0.8(0.2-2.8)$ & 0.69 \\
Retinol & $1.7(0.5-5.7)$ & $0.7(0.2-3.2)$ & 0.65 \\
Vitamin B1 & $1.3(0.4-3.8)$ & $0.4(0.07-2.2)$ & 0.49 \\
vitamin B2 & $0.7(0.3-2.0)$ & $0.9(0.3-3.3)$ & 0.82 \\
Vitamin B6 & $1.5(0.4-5.6)$ & $6.9(1.6-30.7)$ & 0.009 \\
Vitamin C & $0.8(0.3-2.2)$ & $0.5(0.1-2.1)$ & 0.37 \\
Nicotinic acid & $1.8(0.5-6.2)$ & $4.0(0.9-18.7)$ & 0.08 \\
Total fluid & $1.0(0.3-3.3)$ & $0.4(0.06-2.1)$ & 0.28 \\
\hline
\end{tabular}

1 Versus the low intake category; dietary intake categories are derived from pair-matched population controls.

2 P-value for linear trend.

\section{Adipose tissue fatty acid composition}

The distribution of adipose tissue fatty acids are shown in Table 3.5. No significant differences between UC patients and controls with regard to the fatty acid composition of adipose tissue were observed. A significant correlation was found between the PUFA intake (expressed as \% of total fat intake) and the sum of PUFA of adipose tissue, and in addition, between linoleic acid intake and linoleic acid content of adipose tissue in patients $(r=0.66, P<0.001$; $r=0.62, P<0.001$, respectively), as well as in controls $(r=0.39, P<0.01$; $r=0.48, P<0.01$, respectively). No correlations were found between dietary intake and adipose tissue content for saturated or monounsaturated fatty acids in patients.

High adipose tissue proportions of PUFA (OR: 1.4 (95\% Cl $0.4-4.8)$ ) or linoleic acid (OR: $1.3(95 \% \mathrm{Cl} 0.5-3.8))$ were not significantly associated with UC risk. 
Table 3.5 Fatty acid composition of adipose tissue (\% of total fatty acids) in patients with ulcerative colitis (UC) and controls'

\begin{tabular}{lcc}
\hline & UC patients $(n=41)$ & Controls $(n=41)$ \\
\hline SAFA & $25.6(23.1-28.9)$ & $27.2(24.0-28.8)$ \\
MUFA & $51.4(48.9-54.0)$ & $51.3(48.5-54.5)$ \\
PUFA & $19.0(17.4-21.5)$ & $19.1(16.8-21.1)$ \\
Linoleic acid & $16.5(14.3-18.7)$ & $16.0(14.5-17.8)$ \\
\hline
\end{tabular}

' Data are expressed as median; 25 th and 75 th percentile in parentheses.

SAFA: saturated fatty acids; MUFA: monounsaturated fatty acids; PUFA: polyunsaturated fatty acids.

\section{Discussion}

The major finding in the present study was the increased risk of UC in subjects with a high consumption of mono- and polyunsaturated fatty acids and vitamin B6. Other nutrients were not significantly associated with UC risk.

As the incidence of UC is too low to perform an acceptable prospective cohort study, a case-control study is the most appropriate design to study the etiological role of dietary factors in the development of UC. However, problems of selection and information bias in a case-control study have to be taken into account. In this respect, it is important to note that many studies have been subject to methodological flaws. They may have used hospital controls who suffer from other diseases which may influence dietary intake. Randomly chosen population controls are therefore preferable ${ }^{17.18}$. In several studies, postillness diet was investigated, even though it is quite clear that dietary habits may well have changed since onset of the illness and its symptoms.

Another limitation is that many reports only provide information on mean consumption of different food items or nutrients of patients and controls. This does not give an indication of the magnitude of the increased disease risk associated with different consumption levels, such as is provided by odds ratios or relative risk ratios. Where odds ratios are presented, intake categories llow, medium and high) have usually been based on the distribution of the combined population of patients and controls instead of on the distribution of a reference population, i.e. the control group ${ }^{16-18}$.

The present study was designed in an attempt to avoid these methodological problems. The controls in our study were selected from a database of one general practice in the same region. In the Netherlands, almost every resident is registered by a general practitioner and the population database used in the present study is therefore a sample frame of the population within the study region. We studied recently diagnosed UC patients (within 6 months of diagnosis) and used a dietary interview which covered the total pre-illness diet. 
A positive association between fat intake and UC risk was observed in a recent study conducted in $\mid$ Israel $^{18}$. These authors reported an increased risk for UC in patients consuming a high fat (animal fat, vegetable fat, unsaturated fat, and cholesterol) diet prior to the onset of disease. A Japanese study also showed that margarine use was related to an increased risk of $\mathrm{UC}^{19}$. Guthy suggested that chemically processed hydrogenated fats, such as margarine, might play a role in the development of $C^{37}$. He hypothesized that during the production of chemically processed fats or during their use for frying and cooking, toxic byproducts may occur which may contribute to the pathogenesis of CD. However, it is unclear whether this mechanism is also involved in the pathogenesis of UC. Fatty acids are involved in the immune response and inflammatory process of UC as they are precursors of the eicosanoids. Polyunsaturated fatty acids (fish oil) may have anti-inflammatory activity because they compete with $n-6$ fatty acids in the substrate pool of the lipoxygenase pathway, thus reducing the production of leukotrienes with high inflammatory activity. Several placebocontrolled crossover studies have demonstrated the efficacy of fish oil in treating active $U C^{38.40}$. Interestingly, the present study showed that polyunsaturated fat intake ( $n-6$ and $n-3$ fatty acids) was a risk factor for the development of UC. However, it should be noted that fish consumption of more than once per week was reported by only a few subjects in the present study. Hence, fish consumption has a negligible contribution to total polyunsaturated fatty acid intake of both patients and controls in the present study. Fish consumption, which may be useful in the treatment of inflammation, can not be considered as a risk factor for the development of UC on the basis of the present study.

No studies on vitamin B6 intake and UC risk have been reported. Vitamin B6 is mainly absorbed in the jejunum and serves as a cofactor for more than one hundred enzymes. Hence it can influence several processes in the human body, including amino acid metabolism, nicotinic acid formation, nervous system function, nucleic acid metabolism, hormone modulation and lipid metabolism ${ }^{41}$. Furthermore, vitamin B6 dependent enzymes are involved in essential fatty acid metabolism. This latter observation may be important as fatty acid metabolism is involved in the immune response and inflammation processes of IBD patients ${ }^{42}$. However, the mechanisms responsible for the increased UC risk with high intakes of vitamin B6 needs to elucidated.

To our knowledge, this is the first study which has used adipose tissue fatty acid composition as a biomarker for long-term fat intake in relation with the risk of developing UC. Results showed that in both patients and controls, the polyunsaturated fatty acids content in adipose tissue reflects the polyunsaturated fatty acids in the diet of 5 years prior to the study. As expected - given the endogenous synthesis of saturated and monounsaturated fatty acids ${ }^{43}$ - we observed no correlations between adipose tissue content and dietary intake of these two classes of fatty acids.

The increased UC risk with high consumption of polyunsaturated fatty acids 
as assessed by the dietary history method was not reflected by the adipose tissue results in the present study: polyunsaturated fatty acids in adipose tissue were not associated with an increased UC risk. The value of adipose tissue biopsies as a biomarker for long-term polyunsaturated fat intake is thus limited in the present study. The half-life time of adipose tissue in humans in energy balance is approximately 600 days ${ }^{26}$. The fatty acid composition of adipose tissue therefore reflects the dietary fat intake during the previous two or three years ${ }^{22}$. Subjects in the present study were interviewed about their usual dietary intake at 5 years before the study. Consequently, the retrospective time periods of the two methods are not completely congruent. Furthermore, although the median duration of complaints, as reported by the UC patients, was two months, nine patients reported duration of complaints to be $>6$ months. Complaints may influence dietary intake and subsequently fatty acid composition of adipose tissue. Also, adipose tissue biopsies were not taken on the day of diagnosis for practical reasons but were obtained within 6 months of diagnosis. It is therefore possible that adipose tissue composition has been influenced by a recent alteration of dietary intake after diagnosis in some patients. It cannot be ruled out that the medication administrated after diagnosis to achieve remission (especially corticosteroids) have influenced the fatty acid pattern in adipose tissue. Adipose tissue biopsies as an objective biomarker of the long-term polyunsaturated fatty acid intake may be of limited use in establishing dietary risk factors in UC.

The macro- and micronutrients reported with high odds ratios in the present study may reflect a certain dietary pattern which could have increased the risk of developing UC. In this respect it is interesting that some studies reported certain nutritional features of modern life styles (western food, fast food) to be risk factors in the development of UC $\mathrm{C}^{17,19,44}$. Future studies should address the role of food items, additionally to specific nutrients, in the etiology of UC and furthermore, to the disease course and prognosis of UC.

In conclusion, our data suggest that high intake of mono- and polyunsaturated fatty acids and vitamin B6 may enhance the risk of developing UC. Whether the reported findings are true risk factors in the development of UC or rather a reflection of a certain dietary life-style needs to be elucidated. 


\section{References}

1. Roth MP, Petersen GM, McElree C, Feldman E, Rotter JI. Geographic origins of Jewish patients with inflammatory bowel disease. Gastroenterology 1989; 97:900-4.

2. Oudkerk Pool M, Roca M, Reumaux D, Bouma G, Pena AS, Colombel JF, et al. The value of $\mathrm{P}$-anca as a serological marker for ulcerative colitis in different European regions. Eur J Gastroenterol Hepatol 1994; 6:399-403.

3. Shanahan F, Duerr RH, Rotter JI, Yang HY, Sutherland LR, McElree C, et al. Neutrophil autoantibodies in ulcerative colitis: familial aggregation and genetic heterogeneity. Gastroenterology 1992; 103:456-61.

4. Russel MGVM, Pastoor CJ, Janssen KMW, van Deursen CT, Muris JWM, van Wijlick EHJ, Stockbrügger RW and the South Limburg IBD Study Group: Familial aggregation of Inflammatory bowel disease: a population-based study in South Limburg, The Netherlands. Scand J Gastroenterol 1997; 32 Suppl 223:88-91.

5. Jick H, Walker AM. Cigarette smoking and ulcerative colitis. N Eng J Med 1983; 308:261-3.

6. Persson PG, Ahlbom A, Hellers G. Inflammatory bowel disease and tobacco smoke-a case control study. Gut 1990; 31:1377-81.

7. Russel MGVM, Volovics A, Schoon EJ, van Wijlick EHJ, Logan RF, Shivananda S, et al. Inflammatory bowel disease: is there any relationship between smoking status and disease presentation? Results of the European collaborative study on inflammatory bowel disease. Inflammatory Bowel Dis 1998; 4:182-6.

8. Burnham WR, Lennard-Jones JE. Mycobacterial disease as a possible cause of IBD. Lancet 1978; 2693-6.

9. Thompson NP, Montgomery SM, Pounder RE, Wakefield AJ. Is measles vaccination a risk factor for inflammatory bowel disease? Lancet 1995; 345:1071-4.

10. Martini GA, Brandes JW. Increased consumption of refined carbohydrates in patients with Crohn's disease. Klinische Wochenschrift 1976; 54:367-77.

11. Mayberry JF, Rhodes J, Newcombe RG: Increased sugar consumption in Crohn's disease. Digestion 1980; 20:323-6.

12. Penny WJ, Mayberry JF, Aggett PJ, Gilbert JO, Newcombe RG, Rhodes J. Relationship between trace elements, sugar consumption, and taste in Crohn's disease. Gut 1983; 24:288-92.

13. Jarnerot G, Jarnmark I, Nilsson K: Consumption of refined sugar by patients with Crohn's disease, ulcerative colitis or irritable bowel syndrome. Scand J Gastroenterol 1983; 18:999-1002.

14. Thornton JR, Emmet PM, Heaton KW. Diet and ulcerative colitis. Br Med J 1980; 2:293-4.

15. Thornton JR, Emmet PM, Heaton KW. Smoking, sugar and inflammatory bowel disease. Br Med J 1985; 290:1786-7.

16. Panza E, Franceschi S, La Vecchia C, Prazzini F, Petrillo M, Decarli A, Porro GB. Dietary factors in the etiology of inflammatory bowel disease. Ital J Gastroenterol 1987; 19:205-9.

17. Persson PG, Ahlbom A, Hellers G. Diet and inflammatory bowel disease: a case control study. Epidemiology 1992; 3:47-52.

18. Reif S, Klein I, Lubin F, Farbstein M, Hallak A, Gilat T. Pre-illness dietary factors in inflammatory bowel disease. Gut 1997; 40:754-60.

19. Epidemiology group of the research committee of inflammatory bowel disease in Japan. Dietary and other risk factors of ulcerative colitis: a case control study in Japan. J Clin Gastroenterol 1994; 19:166-71. 
20. Tragnone A, Valpiani D, Miglio F, Elmi G, Bazzocchi G, Pipitone E, Lanfranchi GA. Dietary habits as risk factors for inflammatory bowel disease. Eur J Gastroenterol \& Hepatol 1995; 7:47-51.

21. Riordan AM, Ruxton CHS, Hunter JO: A review of associations between Crohn's disease and consumption of sugars. Eur J Clin Nutr 1998; 52:229-38.

22. van Staveren WA, Deurenberg P, Katan MB, Burema J, de Groot LCPGM, Hoffmans MDAF. Validity of the fatty acid composition of subcutaneous fat tissue microbiopsies as an estimate of the long-term average fatty acid composition of the diet of separate individuals. Am J Epidemiol 1986; 123:455-63.

23. Field CJ, Angel A, Clandinin MT. Relationship of diet to the fatty acid composition of human adipose tissue structural and stored lipids. Am J Clin Nutr 1985; 42:1206-20.

24. Tjonneland A, Overvad K, Thorling E, Ewertz M. Adipose tissue fatty acids as biomarkers of dietary exposure in Danish men and women. Am J Clin Nutr 1993; 57:629-33.

25. London SJ, Sacks FM, Caesar J, Stampfer MJ, Siguel E, Willet WC. Fatty acid composition of subcutaneous adipose tissue and diet in postmenopausal US women. Am J Clin Nutr 1991; 54:340-5.

26. Dayton S, Hashimoto S, Dixon W. Composition of lipids in human serum and adipose tissue during prolonged feeding of a diet high in unsaturated fat. $\mathrm{J}$ Lipid Res 1966; 7:103-11.

27. Willet W. Nutritional epidemiology. Monographs in epidemiology and biostatistics. Vol 15. Oxford, England: Oxford University Press, 1990.

28. Lennard-Jones JE. Classification of inflammatory bowel disease. Scand J Gastroenterol 1989; 24:2S-6S.

29. Truelove SC, Witts LJ. Cortisone in ulcerative colitis. Br Med J 1955; 29:1047-8.

30. Beal VA. The nutritional history in longitudinal research. J Am Diet Assoc 1967; 51:426-32.

31. Al MDM, Badart-Smook A, v Houwelingen AC, Hasaart THM, Hornstra G. Fat intake of women during normal pregnancy: relationship with maternal and neonatal essential fatty acid status. J Am Coll Nutr 1996; 15:49-55.

32. NEVO Foundation. Dutch food composition table 1989-1990. Voorlichtingsbureau voor de Voeding. The Hague, The Netherlands (in Dutch).

33. Bligh EG, Dyer WJ: A rapid method for total lipid extraction and purification. Can J Biochem Physiol 1959; 37:911-7.

34. Morrison WR, Smith LM. Preparation of fatty acid methyl esters and dimethylacetals from lipids with boron fluoride methanol. J Lipid Res 1964; 5:600-8.

35. Foreman- $v$ Drongelen MMHP, Houwelingen AC v, Kester ADM, de Jong AEP, Blanco CE, Hasaart THM, Hornstra G. Long-chain polyene status of preterm infants with regard to the fatty acid composition of their diet: comparison between absolute and relative fatty acid levels in plasma and erythrocyte phospholipids. Br J Nutr 1995; 73:405-22.

36. Breslow NE, Day NE. Statistical methods in cancer research. In: The analysis of case control studies. Lyon: IARC, 1980; 32:327-31.

37. Guthy E. Morbus Crohn und nahrungsfette. Hypothese zur aetiologie der enteritis regionalis. Dtsch Med Wschr 1982; 107:71-3.

38. Stenson WF, Cort D, Rodgers J, Burakoff R, Deschyrverkecskemeti K, Gramlicch TL, Becker W: Dietary supplementation with fish oil in ulcerative colitis. Ann Intern Med 1992; 116:609-14. 
39. Aslan A, Triadafilipoulos F. Fish oil fatty acid supplementation in active ulcerativ colitis: a double-blind, placebo-controlled, crossover study. Am J Gastroentera $1992 ; 87: 432-7$.

40. Hawthorne AB, Daneshmend TK, Hawkey CJ. Treatment of ulcerative colitis witk fish oil supplementation: a prospective 12 month randomized controlled trial. Gu: 1992; 33:922-8.

41. Leklem JE. Vitamin B6. In Machlin LJ, ed.. Handbook of vitamins, 2nd edition. Dekker, New York, 341-92.

42. Rask-Madsen J. Eicosanoids in inflammatory bowel disease: advances, pitfalls anc therapeutic consequences. Eur J Gastroenterol Hepatol 1989; 1:133-65.

43. Lands WEM. Long-term fat intake and biomarkers. Am J Clin Nutr 1995; 61:721S-5S.

44. Russel MG, Engels LG, Muris JW, Limonard CB, Volovics A, Brummer R-JM, et al. 'Modern life' in the epidemiology of inflammatory bowel disease: a case-control study with special emphasis on nutritional factors. Eur J Gastroenterol 1998; 10:243-9. 


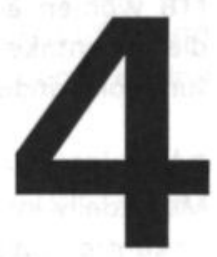

\section{Comprehensive nutritional status in patients with long- standing Crohn's disease currently in remission}

Geerling BJ, Badart-Smook A, Stockbrügger RW, Brummer R-JM 


\section{Abstract}

\section{Background}

Malnutrition is observed frequently and is an important complication in patients with Crohn's disease (CD). The pathophysiology of malnutrition in this disorder is complex.

\section{Methods}

To obtain a comprehensive picture of nutritional status in long-standing CD that was clinically in remission, we assessed four measures of nutritional status in 32 patients (18 women and 14 men) and 32 matched healthy controls: 1) body composition, 2) dietary intake, 3) biochemical parameters of nutrition, and 4) muscle strength (as a functional index).

\section{Results}

Mean daily intakes of fiber and phosphorus were significantly lower in CD patients than in control subjects. Serum concentrations of several nutrients (ß-carotene, vitamin C, vitamin $E$, selenium, and zinc) and the activity of the enzyme glutathione peroxidase were also significantly lower in $C D$ patients, as were antioxidant status and serum concentrations of magnesium and vitamin D. Percentage body fat and hamstring muscle strength were significantly lower in male CD patients than in controls, whereas muscle strength of the quadriceps was preserved.

\section{Conclusions}

In conclusion, this study showed a variety of nutritional and functional deficiencies in patients with long-standing $C D$ in remission, especially in male patients with a long history of $C D$ and a high lifetime prednisone dose. A comprehensive nutritional assessment seems superior to the assessment of one single dimension of the nutritional status. 


\section{Introduction}

Malnutrition is frequently observed in patients with Crohn's disease (CD) and is a result of reduced dietary intake, maldigestion, malabsorption, elimination of nutrients as a result of oxidative stress, and enteric loss of nutrients'. Previously published studies focused on hospitalized $C D$ patients or patients with active disease $^{2-10}$. In these patients, the metabolic disturbances associated with malnutrition may be caused by the malnutrition itself or by the inflammation: it is known that the prevalence and degree of malnutrition are markedly influenced by the activity and the extent of the disease ${ }^{11}$. The association between $C D$ and malnutrition per se should therefore preferably be investigated in patients during remission of the disease.

Jeejeebhoy ${ }^{12}$ described nutritional status as 'an equilibrium of the intake of a diet sufficient to meet or exceed the needs of the individual which will keep the composition and function of the otherwise healthy individuals within the normal range'. This equilibrium can be disturbed by decreased intake, increased requirements and altered metabolism. Obviously, nutritional status is influenced by several factors. The pathophysiology of malnutrition is complex and it seems inappropriate to assess nutritional status on the basis of a single set of assessments, e.g., laboratory indicators or body composition. Nutritional status should preferably be assessed by body composition, dietary intake, biochemical indexes of nutrition, and functional indexes such as muscle strength.

The aim of our study was to assess the comprehensive nutritional status of patients with long-standing $C D$ during remission of the disease and compare this with the status of healthy controls.

\section{Subjects and methods}

\section{Subjects}

The study protocol was approved by the Ethics Committee of the University Hospital Maastricht and all subjects gave their informed consent before the start of the study.

\section{Patients}

Patients characteristics are shown in Table 4.1. Out-patients coming to the Department of Gastroenterology for a routine visit during the period from November 1995 to May 1996 and who fulfilled the inclusion criteria were asked consecutively to participate in the study. Thirty-two patients (18 women, 14 men) who had $C D>10$ years and small bowel involvement participated in the study. The diagnosis of CD was based on the criteria of Lennard-Jones ${ }^{13}$. Disease activity was assessed according to the Crohn's disease activity index $(\mathrm{CDAl})^{14}$ and the van Hees index ${ }^{15}$ at the time of the investigation. The median 
CDAl was 139 for all patients, 127 for women and 173 for men (Table 4.1). Fifteen patients ( 7 women, 8 men) had a CDAI>150, which implies elevated disease activity. The high liquid stool frequency of many of the patients, all of whom suffered from ileal dysfunction, may explain the relatively high CDAI scores. Men complained more about stomach pain and an impaired well-being than did women. In addition, the CDAI was high because of reported underweight compared with the reference value ${ }^{14}$. However, the acute phase protein response (C-reactive protein) did not differ significantly between patients (median C-reactive protein: $6 \mathrm{mg} / \mathrm{L}$; women: $4.5 \mathrm{mg} / \mathrm{L} ;$ men: $6 \mathrm{mg} / \mathrm{L}$ ) and control subjects (median C-reactive protein: $2 \mathrm{mg} / \mathrm{L}$; women: $3.5 \mathrm{mg} / \mathrm{L}$; men:2 $\mathrm{mg} / \mathrm{L})$.

All patients had stable body weights during the 3 months preceding the study. The absence of a significant acute phase response indicated that the patients included in the study were clinically in remission. All patients received medical treatment during the study, including mesalazine $(n=26)$, azathioprine $(n=11)$ and low doses (median dose: $5 \mathrm{mg}$ ) of corticosteroids $(n=13)$. Two patients took vitamin $A$ and $D$ supplements daily, 10 patients used a supplement of $2.5 \mathrm{mg}$ folic acid daily, 22 patients were supplemented with intramuscular vitamin B-12 and two patients used cholestyramine. Two patients had an ileostomy. Twenty-two patients were current smokers, significantly more than in the control group $(13 / 32, P<0.05)$.

Table 4.1 Characteristics of patients with Crohn's disease'

\begin{tabular}{lccc}
\hline & $\begin{array}{c}\text { All } \\
(\mathbf{n}=32)\end{array}$ & $\begin{array}{c}\text { Women } \\
(\mathbf{n = 1 8})\end{array}$ & $\begin{array}{c}\text { Men } \\
(\mathbf{n}=14)\end{array}$ \\
\hline Age (years) & $40.0(34.3-54.0)$ & $39.0(32.0-48.0)$ & $49.5(36.5-56.8)$ \\
Number with colonic involvement & $n=18$ & $n=9$ & $n=9$ \\
Number with small bowel resection & $n=27$ & $n=13$ & $n=14$ \\
Disease duration (years) & $16.0(11.0-19.0)$ & $13.0(10.0-16.3)$ & $18.0(14.0-24.5)^{2}$ \\
Total extent of small bowel resection $(\mathrm{cm})$ & $75.0(40.0-110.0)$ & $45.0(32.5-100.0)$ & $80.0(60.0-135.0)$ \\
Lifetime prednisone dose $(\mathrm{g})$ & $10.3(4.6-24.6)$ & $6.1(4.1-15.5)$ & $26.6(7.8-30.0)^{2}$ \\
CDA ${ }^{3}$ & $139(86-193)$ & $127(41-200)$ & $173(118-205)$ \\
van Hees index & $146(127-159)$ & $136(127-150)$ & $156(138-169)$ \\
\hline
\end{tabular}

'Data are expressed as median; 25 th and 75 th percentile in parentheses.

${ }^{2}$ Significantly different from women, $\mathrm{P}<0.05$ (one-way ANOVA).

${ }^{3}$ Crohn's disease activity index ${ }^{14}$.

\section{Controls}

Thirty- two healthy volunteers (mean age: $43.8 \pm 13.5$ years) participated in this study as controls. They were selected randomly from the patient population database of a general practitioner in the same study region, which is a reliable 
dynamic sample frame of the Dutch general population. The controls were selected according to the following criteria: age- and sex-matched with CD patients (within 5 years of age) and no history of Crohn's disease.

\section{Nutritional status}

All measurements, except the assessment of the dietary intake, were performed on the day after an overnight fast.

\section{Body composition}

Body composition was assessed using anthropometry, the deuterium dilution technique and dual-energy $\mathrm{X}$-ray absorptiometry (DXA). Anthropometric measures included body height measured to the nearest millimeter using a wallmounted stadiometer and body weight measured with an electronic scale with a digital readout to an accuracy of 0.01 kilogram. Body mass index (BMI) was calculated from weight and height $\left(\mathrm{kg} / \mathrm{m}^{2}\right)$. Skinfold thickness measurements were taken in duplicate from the non-dominant side of the body at four different sites (biceps, triceps, sub-scapula, supra-iliac) using a Harpender skinfold caliper. Percentage body fat was calculated from the sum of the four skinfold thickness values according to Durnin and Wormersley ${ }^{16}$. Circumference measurements (of the upper arm, waist, hip and upper leg) were obtained from the non-dominant side ${ }^{17}$. Mid-arm muscle circumference (MAMC) was calculated $^{18}$.

Total body water (TBW) was assessed by deuterium $\left(D_{2} O\right)$ dilution. $A$ background urine sample was taken after an overnight fast. Subsequently, subjects consumed a quantity of $\mathrm{D}_{2} \mathrm{O}$ (99.8 atom percent excess, Akademie der Wissenschaften, Leipzig, Germany) corresponding to $0.1 \mathrm{~g} / \mathrm{L}$ estimated TBW mixed into $\approx 70 \mathrm{ml}$ water ${ }^{19}$. Urine samples were collected after 4 hours equilibration. Isotopic abundances in urine were determined in duplicate using an isotope-ratio mass spectrometer (Aqua Sira; VG Isogas, Cheshire, UK). The deuterium dilution space was calculated from the quantity of $\mathrm{D}_{2} \mathrm{O}$ administered and the $\mathrm{D}_{2} \mathrm{O}$ concentrations in urine after equilibration. TBW was assessed according to the equation proposed by Deurenberg et $\mathrm{al}^{19}$ and was calculated as the $\mathrm{D}_{2} \mathrm{O}$-dilution space divided by 1.04 , correcting for the exchange of the deuterium label with non-aqueous hydrogen of body solids ${ }^{20}$.

Body fat, fat-free mass (FFM), percentage body fat, total-body bone mineral content and T-score (total bone fracture risk) were determined by using a dualenergy X-ray absorptiometer (DPX-L, Lunar Corp., Madison, WI; using DPX-L 1.3 software $)^{21}$. The T-score was calculated according to the following formula: bone mineral density (subject) - mean peak bone mass (reference population)/ SD mean peak bone mass (reference population). Research on the reference population was conducted in the US, United Kingdom and Northern Europe. There was a $1.3 \%$ SD among geographical areas in the average density values. A scan over the entire length of each subject's body was performed. Any material that could attenuate the X-ray beam, eg. jewelry, watches or clothing 
with zippers, was removed before the examination.

\section{Dietary intake}

Dietary intake was assessed using the cross-check dietary history ${ }^{22}$. The subjects were visited at home by an experienced dietitian and the usual food consumption of the previous month was assessed. During this interview, food quantities were specified in household measures. Usual portion sizes were estimated with the aid of portion size models or pictures of foods; frequently consumed portions of food and common household measures were weighed on a balance with a precision of $0.5 \mathrm{~g}$. In addition, the subjects had previously completed a self-administered, validated, semiquantitative food-frequency questionnaire that was used as a crosscheck of the dietary history ${ }^{23}$. The foodfrequency questionnaire dealt specifically with the dietary intake of fat and antioxidants over the previous month.

All types of food and drink were coded according to the system used by the Netherlands Nutrient Databank (NEVO) and subsequently converted into energy and nutrients by using the extended computerized version of the Netherlands food table ${ }^{24}$. Intake of macronutrients and alcohol was expressed as $\%$ of energy. Cholesterol and fiber intakes were expressed as $\mathrm{mg} / \mathrm{MJ}$ and as $\mathrm{g} / \mathrm{MJ}$, respectively. Each subject's nutrient intake was compared with the Dutch recommended dietary allowances (RDAs) ${ }^{25}$.

Total energy expenditure was estimated as basal metabolic rate (BMR) $x$ activity level. BMR was calculated according to the equation developed by Westerterp et $\mathrm{al}^{26}$ :

$\mathrm{BMR}(\mathrm{MJ} /$ day $)=0.102 \mathrm{FFM}(\mathrm{kg})+0.024 \mathrm{BF}(\mathrm{kg})+0.85$

where $\mathrm{BF}=$ body fat. Activity levels of 1.78 for men and 1.62 for women were applied on the basis of calculations for free-living subjects ${ }^{27}$.

\section{Biochemical analyses}

After subjects had fasted overnight, a venous blood sample $(90 \mathrm{ml})$ was obtained and plasma and serum were stored at $-80^{\circ} \mathrm{C}$ until analyzed. Serum albumin, cholesterol, total protein, C-reactive protein, magnesium and wholeblood thiamin were measured by routine methods in use at the hospital, on a Beckman Synchron $\mathrm{CX}^{*}$ system (Brea, CA, USA). Serum prealbumin was measured using a radioimmunodiffusion technique (Beckman Immunochemistry systems).

Vitamin B-12 and folic acid concentrations were assessed with a commercial kit (Quantaphase B-12/folate Radioassay; Bio-RAD Laboratories B.V., Veenendaal, The Netherlands). 25-Hydroxy vitamin D3 was determined using a radioimmuno assay (INCSTAR, Stillwater, MN). Copper, zinc and selenium were measured by Zeeman-corrected electrothermal atomic-absorption spectrometry. The assessment of whole blood activity of glutathione peroxidase was based on the method developed by Paglia and Valentine ${ }^{28}$. Vitamins A and E (a-tocopherol) 
where measured with HPLC and $\beta$-carotene by spectrophotometric assessment at $450 \mathrm{Nm}$.

Total lipids were extracted as described by Bligh and Dyer ${ }^{29}$. Total lipid concentrations were assessed in plasma phospholipids, and the phospholipid fraction was separated by thin layer chromatography according to van der Vusse et $\mathrm{al}^{30}$. Vitamin $\mathrm{E}$ concentrations have been found to be closely related to serum lipids ${ }^{31}$, and the ratio of vitamin $E$ to serum lipids was calculated to accurately assess the vitamin E status in $C D$ patients. Patients were considered at risk of developing a nutritional deficiency of a trace element or vitamin if the serum concentrations of the nutrient was less than the $15^{\text {th }}$ percentile of the controls ${ }^{3}$.

\section{Muscle strength}

Strength of muscular quadriceps (extension) and the hamstrings (flexion) was measured with an isokinetic dynamometer (Cybex II, Eagle Performance Systems, Owatonna, MN) with angular velocities of $60^{\circ}$ and $180^{\circ} / \mathrm{s}^{32}$. Peak torque and work capacity were calculated from a five fold measurement at each angular velocity.

\section{Statistical analysis}

Results are expressed as means $\pm \mathrm{SD}$ or as stated. Differences in nutritional status between $C D$ patients and controls were analyzed by using a paired Student's t-test. Correlation coefficients and partial correlations were calculated by regression analysis. All statistical analyses were performed with the SPSS 6.0 for Windows package (SPSS Inc, Chicago).

\section{Results}

\section{Body composition}

Total-body bone mineral content and mean T-score were significantly lower in $C D$ patients than in controls $(P<0.025)$. There were no other significant differences in body composition between patients and controls (Table 4.2). However, in a sex-specific analysis, the percentage of body fat measured by DXA or anthropometry was significantly lower in male CD patients than in male controls. In females no significant differences were found. 
Table 4.2 Body composition in Crohn's disease (CD) patients and controls'

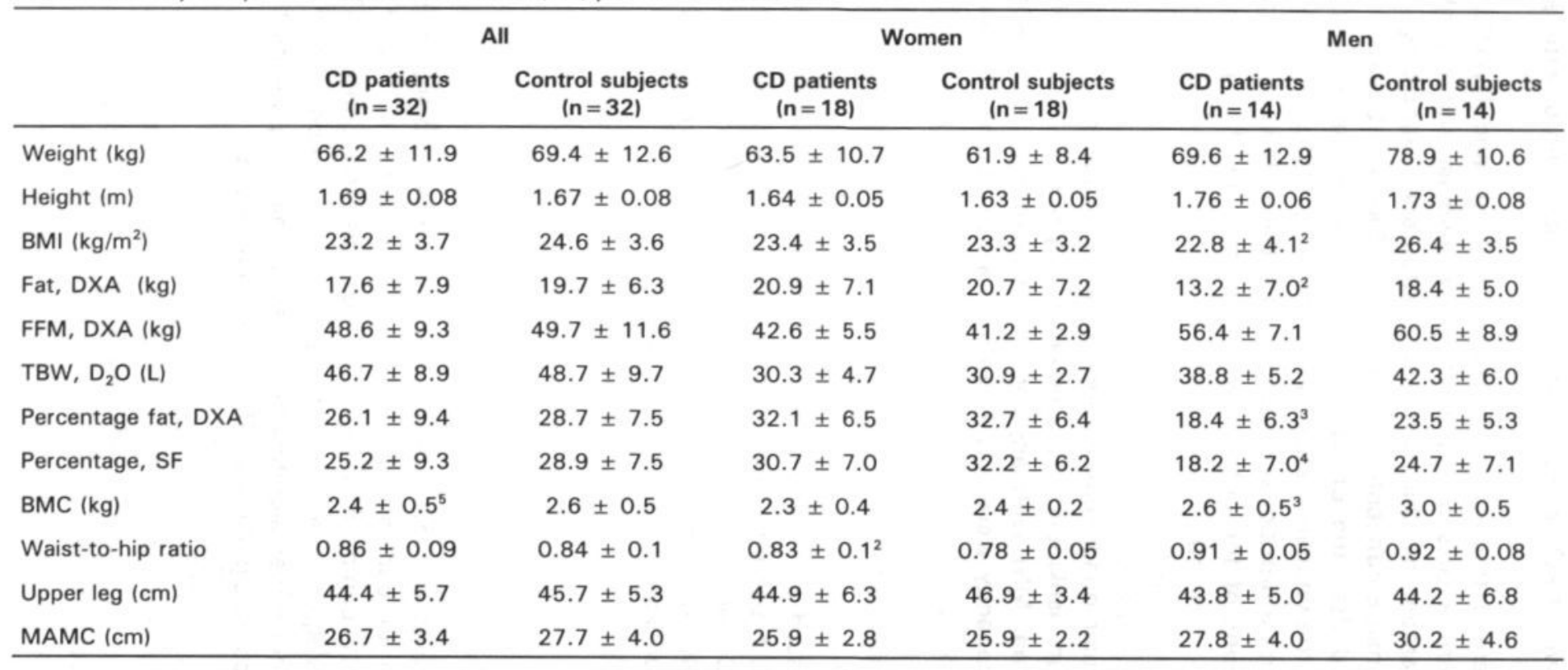

1 Data are expressed as mean \pm SD. DXA: dual-energy X-ray absorptiometry; FFM: fat-free mass; TBW: total body water; $\mathrm{D}_{2} \mathrm{O}$ : deuterium dilution; SF: skinfold thickness measurement; $\mathrm{BMC}$ : total body bone mineral content; MAMC: mid-arm muscle circumference.

$2 \mathrm{P}=0.06$ for difference between $C D$ patients and controls.

${ }^{3.5}$ Significantly different from controls (paired Student's t tests): ${ }^{3} P<0.05,{ }^{4} P<0.01,{ }^{5} P<0.025$. 


\section{Dietary intake}

The difference between mean energy intake and mean estimated total energy expenditure was $0.62 \mathrm{MJ} / \mathrm{d} \pm 3.11$ in $C D$ patients and $-0.60 \mathrm{MJ} / \mathrm{d} \pm 3.11$ in controls (NS). The subjects' mean daily nutrient intakes are shown in Table 4.3. Compared with controls, $C D$ patients had significantly lower mean daily intakes of fiber and phosphorus $(P<0.05)$. The mean daily intake of other nutrients did not differ significantly between patients and controls. The percentage of subjects who reported nutrient intakes below the RDA is shown in Table 4.4. Vitamin A intake was below the RDA in $69 \%$ of $C D$ patients and in $91 \%$ of controls $(P=0.01)$.

Table 4.3: Mean daily intake of nutrients'

\begin{tabular}{|c|c|c|}
\hline & $\begin{array}{l}\text { Crohn's disease patients } \\
\qquad(n=32)\end{array}$ & $\begin{array}{c}\begin{array}{c}\text { Control subjects } \\
(n=32)\end{array} \\
\end{array}$ \\
\hline Energy intake (MJ/day) & $11.2 \pm 3.5$ & $10.3 \pm 3.7$ \\
\hline Total protein ( $\%$ of energy) & $14.4 \pm 3.0^{2}$ & $15.9 \pm 3.3$ \\
\hline Total fat ( $\%$ of energy) & $35.1 \pm 5.9$ & $33.6 \pm 7.7$ \\
\hline SAFA ( $\%$ of energy) & $13.8 \pm 3.3$ & $12.6 \pm 3.0$ \\
\hline MUFA ( $\%$ of energy) & $13.0 \pm 2.5$ & $12.1 \pm 3.4$ \\
\hline PUFA ( $\%$ of energy) & $5.9 \pm 2.5$ & $6.6 \pm 2.6$ \\
\hline Linoleic acid ( $\%$ of energy) & $4.5 \pm 2.4$ & $5.3 \pm 2.7$ \\
\hline Cholesterol (mg/MJ) & $23.5 \pm 5.4$ & $23.2 \pm 5.1$ \\
\hline Total carbohydrates ( $\%$ of energy) & $47.8 \pm 6.2$ & $47.0 \pm 8.3$ \\
\hline Mono + disaccharides (\% of energy) & $24.7 \pm 8.0$ & $24.2 \pm 8.4$ \\
\hline Fiber $(g / \mathrm{MJ})$ & $1.5 \pm 0.6^{3}$ & $1.9 \pm 0.5$ \\
\hline Alcohol ( $\%$ of energy) & $3.0 \pm 4.1$ & $3.7 \pm 5.1$ \\
\hline Phosphorus (g) & $1.4 \pm 0.3^{4}$ & $1.7 \pm 0.6$ \\
\hline Calcium (g) & $1.0 \pm 0.3$ & $1.2 \pm 0.6$ \\
\hline Total iron (mg) & $13.3 \pm 3.4$ & $13.5 \pm 4.8$ \\
\hline Vitamin A (mg RE) & $0.9 \pm 0.7$ & $0.7 \pm 0.3$ \\
\hline$\beta$-Carotene $(\mathrm{mg})$ & $0.9 \pm 0.4$ & $1.0 \pm 0.5$ \\
\hline Thiamin $(\mathrm{mg})$ & $1.1 \pm 0.3$ & $1.2 \pm 0.5$ \\
\hline Riboflavin (mg) & $1.5 \pm 0.5$ & $1.8 \pm 1.5$ \\
\hline Pyridoxine (mg) & $1.8 \pm 0.5$ & $1.9 \pm 0.7$ \\
\hline Vitamin C (mg) & $77.5 \pm 43.1$ & $101.5 \pm 56.7$ \\
\hline
\end{tabular}

1 Data are expressed as mean \pm SD. SAFA: saturated fatty acids; MUFA: monounsaturated fatty acids; PUFA: polyunsaturated fatty acids; RE: retinol equivalent.

$2 \mathrm{P}=0.06$ for difference between Crohn's disease patients and controls.

${ }^{3,4}$ Significantly different from controls (paired Student's t-tests): ${ }^{3} \mathrm{P}<0.01,{ }^{4} \mathrm{P}<0.05$. 


\begin{tabular}{lcc}
\hline & $\begin{array}{c}\text { Crohn's disease } \\
\text { patients }(\mathbf{n = 3 2})\end{array}$ & $\begin{array}{c}\text { Control subjects } \\
\text { (n=32) }\end{array}$ \\
\hline $\begin{array}{l}\text { Percentage of subjects } \\
\text { above the RDA }\end{array}$ & & \\
Total fat (\% of energy) & 50 & 40 \\
Mono + disaccharides (\% of energy) & & 41 \\
& & \\
Percentage of subjects below the RDA & 19 & 22 \\
Total protein (g) & $69^{2}$ & 91 \\
Vitamin A (mg RE) & 34 & 41 \\
Thiamin (mg) & 38 & 38 \\
Riboflavin (mg) & 53 & 34 \\
Vitamin C (mg) & 38 & 47 \\
Total iron (mg) & 19 & 13 \\
Calcium (g) & 3 & 3 \\
Phosphorus (mg) & 100 & 97 \\
Fiber (g/MJ) & &
\end{tabular}

Recommended dietary allowances according to reference 25.

2 Significantly different from controls, $\mathrm{P}=0.01$ (Chi-square).

\section{Biochemical analysis}

The serum indexes of the subjects are shown in Table 4.5. Serum vitamin A concentrations did not differ significantly between patients and controls, but serum $\beta$-carotene concentrations were significantly lower in $C D$ patients $(P<0.001)$. Serum cholesterol concentrations and plasma total lipids were also significantly lower in $C D$ patients $(P<0.001)$. Serum albumin was significantly lower in $C D$ patients $(P<0.001)$, but serum total protein or serum prealbumin concentrations did not differ significantly between patients and controls.

The ratio of $\beta$-carotene to plasma total lipids was significantly lower in $C D$ patients $(0.84 \pm 0.69 \mu \mathrm{mol} / \mathrm{g})$ than in controls $(1.74 \pm 0.56 \mu \mathrm{mol} / \mathrm{g})(\mathrm{P}<0.001)$. Concentrations of vitamin $\mathrm{C}$, vitamin $\mathrm{E}$, selenium, magnesium and zinc and gluthatione peroxidase activity were also significantly lower in $C D$ patients than in controls $(P<0.05)$. We found a significant correlation between concentrations of zinc and albumin in $C D$ patients $(r=0.37, P<0.05)$, but not in controls. Significant correlations were also found between serum vitamin $E$ concentrations and cholesterol in both $C D$ patients and controls $(r=0.53$, $P<0.01)$ and between vitamin $E$ concentration and plasma total lipids in $C D$ 
patients and in controls $(r=0.64, P<0.01$, and $r=0.58 ; P<0.01$, respectively). The ratio of serum vitamin $\mathrm{E}$ to cholesterol or to plasma total lipids was not significantly different between the two groups. We found a significantly higher prevalence $(P<0.01)$ of vitamin $D$ deficiency (vitamin $D<70 \mathrm{nmol} / \mathrm{L}$ during summer and autumn and $<25 \mathrm{nmol} / \mathrm{L}$ during winter) in CD patients $(56 \%)$ than in controls $(28 \%)$.

In summary, a large proportion of CD patients were found to be at risk of developing nutritional deficiencies. The proportion of patients below the $15^{\text {th }}$ percentile of controls for several serum nutrient concentrations ${ }^{3}$ is shown in Figure 4.1.

Table 4.5 Serum concentrations of nutritional biochemical indexes'

\begin{tabular}{|c|c|c|c|}
\hline & $\begin{array}{l}\text { Reference } \\
\text { value }^{2}\end{array}$ & $\begin{array}{l}\text { Crohn's disease } \\
\text { patients }(n=32)\end{array}$ & $\begin{array}{c}\text { Control subjects } \\
(n=32)\end{array}$ \\
\hline Total protein $(\mathrm{g} / \mathrm{L})$ & $60.0-74.0$ & $69.2 \pm 5.7$ & $69.9 \pm 4.2$ \\
\hline Albumin (g/L) & $34.0-45.0$ & $37.7 \pm 3.3^{3}$ & $42.5 \pm 3.3$ \\
\hline Prealbumin $(\mathrm{g} / \mathrm{L})$ & $0.15-0.40$ & $0.29 \pm 0.07$ & $0.27 \pm 0.04$ \\
\hline Vitamin A $(\mu \mathrm{mol} / \mathrm{L})$ & $0.9-2.5$ & $2.6 \pm 1.3$ & $2.5 \pm 0.6$ \\
\hline$\beta$-Carotene $(\mu \mathrm{mol} / \mathrm{L})$ & $0.40-3.20$ & $0.98 \pm 0.91^{3}$ & $2.33 \pm 0.70$ \\
\hline Thiamin (nmol/L) & $85-155$ & $119 \pm 27.5$ & $114 \pm 26.4$ \\
\hline Vitamin B-12 (pmol/L) & $150-630$ & $403 \pm 282$ & $263 \pm 91.5$ \\
\hline Vitamin C $(\mu \mathrm{mol} / \mathrm{L})$ & $11-110$ & $35.3 \pm 25.8^{3}$ & $57.8 \pm 22.3$ \\
\hline Vitamin $\mathrm{E}(\mu \mathrm{mol} / \mathrm{L})$ & $14-40$ & $29.2 \pm 10.7^{4}$ & $34.8 \pm 8.6$ \\
\hline Folic acid (nmol/L) & $>4.5$ & $14.4 \pm 13.4$ & $13.4 \pm 5.88$ \\
\hline Magnesium (mmol/L) & $0.75-1.00$ & $0.79 \pm 0.07^{5}$ & $0.85 \pm 0.07$ \\
\hline Selenium $(\mu \mathrm{mol} / \mathrm{L})$ & $0.91-1.52$ & $0.86 \pm 0.14^{3}$ & $1.03 \pm 0.15$ \\
\hline Zinc $(\mu \mathrm{mol} / \mathrm{L})$ & $10.0-19.0$ & $12.0 \pm 1.67^{5}$ & $13.4 \pm 2.22$ \\
\hline Copper $(\mu \mathrm{mol} / \mathrm{L})$ & $12.0-22.0$ & $19.1 \pm 4.61$ & $20.1 \pm 6.90$ \\
\hline Glutathione peroxidase $(\mathrm{U} / \mathrm{mmolHb})$ & $780-1350$ & $768 \pm 232^{4}$ & $967 \pm 296$ \\
\hline Cholesterol (mmol/L) & $4.1-6.4$ & $4.3 \pm 0.9^{3}$ & $5.7 \pm 1.2$ \\
\hline Total lipid $(g / L)$ & $1.00-1.75$ & $1.16 \pm 0.2^{3}$ & $1.37 \pm 0.2$ \\
\hline
\end{tabular}

Data are expressed as mean \pm SD.

2 Based on normal values at our laboratory.

${ }^{3-5}$ Significantly different from controls (paired Student's t-tests): ${ }^{3} \mathrm{P}<0.001,{ }^{4} \mathrm{P}<0.05$, ${ }^{5} \mathrm{P}<0.01$. 


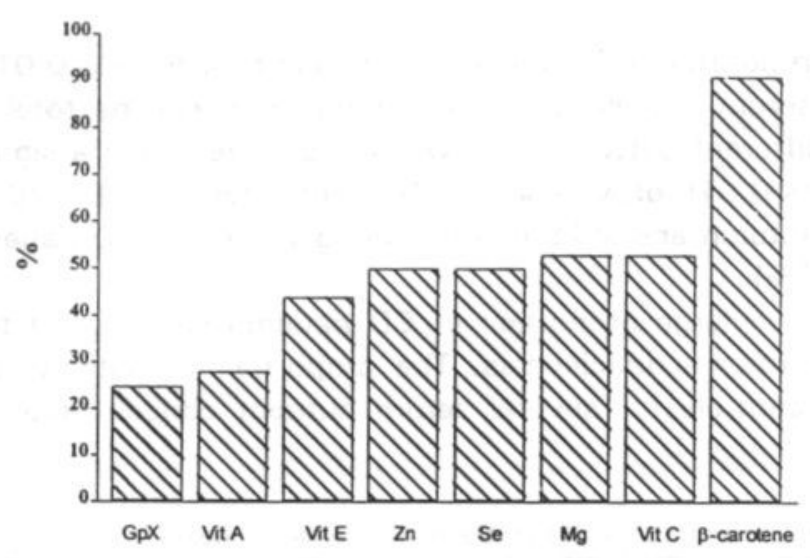

Figure 4.1 Proportion of patients with biochemical indexes below the $15^{\text {th }}$ percentile of controls. GpX: gluthatione peroxidase activity; vit, vitamin. Activity of $\mathrm{GpX}$ was determined in whole blood: other indexes were measured in serum.

\section{Muscle strength}

The results of the differential muscle strength measured with an isokinetic dynamometer are shown in Table 4.6. Hamstring peak torques at both velocities $\left(60^{\circ}\right.$ and $\left.180^{\circ} / \mathrm{s}\right)$ and hamstring work capacity measured at $180^{\circ} / \mathrm{s}$ were significantly lower in $C D$ patients than in controls $(P<0.05)$. However, the peak torque and work capacity of the quadriceps muscles were preserved in $C D$ patients. Sex-specific analysis showed that the differences in hamstring muscle strength could be explained by the differences in muscle function between the male patients and controls.

FFM estimated by DXA correlated significantly with peak torque and work capacity of the quadriceps muscles measured at both velocities in both patients and controls $(\mathrm{P}<0.001)$. Only controls, however, showed a significant correlation between FFM measured by DXA and peak torque and work capacity of the hamstring muscles $(\mathrm{P}<0.001)$.

\section{Association between malnutrition and medical indexes in $C D$ patients}

We did not observe a significant correlation between nutritional status and extent of small bowel resection or duration of disease. A significant correlation between disease activity assessed by the van Hees index and percentage body fat (by DXA) was found $(r=-0.55, P<0.01)$. We also observed a significant correlation between percentage body fat measured by DXA and serum selenium concentrations $(r=0.57, P<0.01)$. A significant correlation between serum vitamin $\mathrm{D}$ concentration and T-score (by DXA) was observed in $\mathrm{CD}$ patients $(r=0.42, \quad P<0.02)$ but not in controls. Lifetime prednisone dose was significantly higher in males than in females $(P<0.01$; Table 4.1). However, we did not observe any significant correlations between lifetime prednisone dose 
and muscle strength of the hamstring in either male or female patients.

Table 4.6 Muscle strength as measured with an isokinetic dynamometer'

\begin{tabular}{lcc}
\hline & $\begin{array}{c}\text { Crohn's disease patients } \\
(\mathbf{n}=32)\end{array}$ & $\begin{array}{c}\text { Controls } \\
(\mathbf{n}=32)\end{array}$ \\
\hline Peak torque extension, $180 \% / \mathrm{s}(\mathrm{Nm})$ & $81.5 \pm 18.5$ & $88.7 \pm 39.7$ \\
Peak torque flexion, $180 \% / \mathrm{s}(\mathrm{Nm})$ & $45.6 \pm 15.2^{2}$ & $59.3 \pm 31.9$ \\
Peak torque extension, $60 \% / \mathrm{s}(\mathrm{Nm})$ & $123.1 \pm 27.4$ & $136.5 \pm 53.8$ \\
Peak torque flexion, $60 \% / \mathrm{s}(\mathrm{Nm})$ & $71.6 \pm 22.2^{3}$ & $87.6 \pm 33.4$ \\
Work capacity extension, $180 \% / \mathrm{s}(\mathrm{J})$ & $367.4 \pm 110.7$ & $397.4 \pm 220.5$ \\
Work capacity flexion, $180 \% / \mathrm{s}(\mathrm{J})$ & $210.0 \pm 119.1^{2}$ & $298.4 \pm 212.4$ \\
Work capacity extension, $60 \% / \mathrm{s}(\mathrm{J})$ & $513.5 \pm 144.2$ & $571.2 \pm 272.7$ \\
Work capacity flexion, $60 \% / \mathrm{s}(\mathrm{J})$ & $382.3 \pm 164.0$ & $440.5 \pm 205.5$ \\
\hline
\end{tabular}

1 Data are expressed as mean \pm SD. Quadriceps muscle strength is measured by peak torque or work capacity extension, and hamstring muscle strength by peak torque or work capacity flexion.

${ }^{2,3}$ Significantly different from controls (paired Student's t-tests): ${ }^{2} \mathrm{P}<0.05,{ }^{3} \mathrm{P}<0.02$.

\section{Discussion}

It is generally accepted that malnutrition is a serious problem in patients with active $C D$ and that is has a negative effect on the morbidity and mortality of hospitalized patients ${ }^{1,33}$. Malnutrition also has a negative effect on the general health and well-being of many $C D$ outpatients ${ }^{34}$. In the present study, nutritional status was assessed by four different measurements (body composition, dietary intake, biochemical indexes, and muscle strength), all reflect the outcome of nutrition in a special way. Except for a significant correlation between serum selenium and percentage body fat, we found no significant associations between the various dimensions determining nutritional status. This implies that assessing just one dimension of the nutritional status is a poor predictor of other indexes of nutritional status.

Decreased dietary intake, resulting from a combination of postprandial abdominal pain and dietary restrictions, is an important cause of malnutrition in $C D$. Decreased intake is frequently observed in $C D$ patients with high disease activity ${ }^{35,36}$. In our patient population we found that energy intake was not decreased, but actually tended to be higher, which agrees with a study by Lanfranchi et $\mathrm{al}^{11}$. In patients, the difference between mean energy intake and estimated total energy expenditure was $0.62 \mathrm{MJ} / \mathrm{d}$. This suggests that $C D$ patients in remission increase their energy intake to compensate for possible maldigestion or malabsorption. It has been assumed that weight loss in $C D$ patients could be caused by increased resting metabolic expenditure ${ }^{9}$. However, 
Stokes and $\mathrm{Hill}^{37}$ showed that total energy expenditure was not raised in $\mathrm{CD}$ patients.

The present study showed that the nutrient intakes were below the RDA in a high percentage of both patients and controls, with no significant differences between the groups except for vitamin A. Intake of vitamin $E$ were in fact more inadequate in control subjects than in patients. This result stresses the importance of including a control group in a nutritional survey. Compared with controls, CD patients had significantly lower intakes of fiber and phosphorus.

Although daily nutrient intakes of $C D$ patients were not significantly different from those of control subjects, patients had low serum concentrations of nutrients of a variety of nutrients. Besides impaired absorption of nutrients in $C D$ (small bowel resection or mucosal damage) ${ }^{38}$, intraluminal factors may play a role in the decreased absorption of nutrients. Formation of soap complexes due to steatorrhoea may be important ${ }^{39}$ and divalent cations such as magnesium, selenium or zinc may form unabsorbable subcomplexes with malabsorbed fats; also, decreased concentrations of fat-soluble vitamins may occur in patients with steatorrhoea.

Reactive oxygen and nitrogen species seem to be involved in the tissue damage occurring in $C D^{40-42}$. Abundant production of these reactive species (ie, oxidative stress) has been observed in the bowels of $C D$ patients with active disease. Under normal physiological conditions, antioxidant defenses protect tissues against the damaging effects of these reactive species, but chronic gut inflammation promotes an imbalance between prooxidant and antioxidant mechanisms ${ }^{42}$. In patients, we found low serum concentrations of nutritional antioxidants ( $\beta$-carotene, vitamin $C$, vitamin $E$, selenium, zinc) and low activity of the enzyme glutathione peroxidase. The patient population had no signs of active disease; therefore, these deficiencies cannot be completely explained by elimination of nutrients as a result of oxidative stress. However, the fact that significantly more patients than controls were current smokers may have contributed to the patients' reduced antioxidant status.

In the present study the ratio of serum vitamin $E$ to serum cholesterol and to total lipids did not differ significantly between patients and controls, suggesting that the decreased vitamin $E$ levels in $C D$ patients could be explained by the decreased serum concentrations of cholesterol and plasma total lipids ${ }^{31,43}$. However, the ratio of $\beta$-carotene to total lipids was significantly decreased in $\mathrm{CD}$ patients compared with controls. $\beta$-Carotene depletion is thus not explained by hypolipidemia.

Several studies found decreased selenium concentrations in CD patients with moderate or high disease activity ${ }^{44-47}$. Our study, comprising $C D$ patients in remission, also found decreased selenium concentrations as well as reduced gluthatione peroxidase activity, which is thought to be a sensitive indicator of selenium deficiency ${ }^{47}$. Whereas Rannem et al $^{46}$ found a significant reduction of selenium concentrations and gluthatione peroxidase activity in CD patients with a small bowel resection $>200 \mathrm{~cm}$, such a correlation was not found in the 
present study.

The zinc status of patients is difficult to assess, especially in the presence of inflammation, and no single measurement of zinc status is entirely satisfactory ${ }^{48}$. Acute inflammation and hypoalbuminemia may decrease serum zinc concentrations, despite normal total-body zinc content ${ }^{49}$. However, serum zinc concentrations may provide enough information about the zinc status in our patient population with quiescent disease, because circulating zinc reflects the metabolizable or exchangeable zinc that is delivered to metabolically active tissues ${ }^{4}$. The decreased albumin concentrations in CD patients may, however, be a confounding factor in this respect.

Osteopenia is a common problem in $C D$, as was recently reported in a population-based study ${ }^{50}$. We observed a significant correlation between serum vitamin $D$ concentrations and total-body bone fracture risk in this patient population. Our data suggest that the significantly decreased dietary intake of phosphorus and the significantly decreased serum concentrations of magnesium and vitamin $D$ could be risk factors for the development of osteopenia in patients with long-standing CD.

Underweight has been reported in $65-75 \%$ of $C D$ patients ${ }^{1,5,9,51}$. However, only a few studies have described the body composition of CD patients and these studies were predominantly performed in patients with high disease activity $^{5,9}$. Patients in the present study had stable body weights and were not catabolic. Except for the decreased total bone mineral content no other differences in body composition were observed. However, sex-specific analysis showed that male $C D$ patients had a significantly reduced percentage of body fat, measured by both DXA and anthropometry, compared with controls. Life time prednisone dose was significantly higher in males than in females $(P<0.05)$, but this cannot explain the decreased percentage of body fat found in male patients, because prednisone use tends to increase body fat. Disease history was significantly longer in males than in females, however, and hence may have been a contributing factor to the observed difference in body composition. More research is required to provide a full explanation of this apparent sex difference of body composition in CD patients.

We observed reduced strength of the hamstring muscles in $C D$ patients whereas the strength of the quadriceps muscles was preserved. The hamstring muscle has a higher percentage of type Ilb muscle fibers than does the quadriceps muscle ${ }^{52}$, and it is known from in vivo and in vitro studies that corticosteroid therapy induces selective type $\mathrm{llb}$ fiber atrophy ${ }^{53}$. Eighty-four percent of our patients had been treated with corticosteroids and the lifetime prednisone dose was significantly higher in males than in females. The use of corticosteroids could therefore be involved in the etiology of the reduced hamstring muscle strength. Although, we did not find any significant correlations between life-time prednisone dose and hamstrings muscle strength in either males or females, this may be explained by the fact that corticosteroidinduced muscle atrophy is a partially reversible process ${ }^{53,54}$. Other factors may 
be involved in the pathophysiology of the observed muscle dysfunction. Malnutrition is known to be associated with muscle fatigue ${ }^{55,56}$. The lower percentage body fat in male patients compared with controls may be an important explanation for the decreased hamstring muscle strength observed. It is unknown, however, whether malnutrition selectively affects certain muscle fiber types. Further research will therefore be required to elucidate the etiology of the reduced hamstring muscle strength in CD.

This study revealed the importance of using comprehensive measures of nutritional status in patients with long-standing $C D$ that is clinically in remission. Many patients in the present study were at risk of developing nutritional deficiencies, especially of antioxidants. This may imply a deteriorated antioxidant status in patients with long-standing $C D$ and hence an increased susceptibility to oxidative tissue damage. Antioxidant supplementation may thus be justified and may be of therapeutic value. The observed nutritional deficiencies are important because malnutrition is associated with immune dysfunction ${ }^{57}$, decreased quality of life $^{34}$, and increased susceptibility to oxidative tissue damage ${ }^{58}$. We found that male patients, who had suffered significantly longer from $C D$ and had a significantly higher mean lifetime prednisone dose than females, were particularly at risk for nutritional deficiencies. More research is needed to elucidate the effect of malnutrition and of nutritional supplementation on the course of $C D$ in this group of patients. 


\section{References}

1. Zurita VF, Rawls DE, Dyck WP. Nutritional support in inflammatory bowel disease. Dig Dis 1995; 503;92-107.

2. Harries AD, Heatley RV. Nutritional disturbances in Crohn's disease. Postgraduate Med J 1983; 59:690-7.

3. Fernández-Bañares F, Abad-Lacruz A, Xiol X, Gine JJ, Dolz C, Cabré E, et al. Vitamin status in patients with inflammatory bowel disease. Am J Gastroenterol $1989 ; 84: 744-8$.

4. Fernández-Bañares $F$, Mingorance $M D$, Esteve $M$, Cabré $E$, Lachica $M$, AbadLacruz A, et al. Serum zinc, copper, and selenium levels in inflammatory bowel disease: effect of total enteral nutrition on trace element status. Am J Gastroenterol 1990; 85:1584-9.

5. Cristie PM, Hill GL. Effect of intravenous nutrition on nutrition and function in acute attacks of inflammatory bowel disease. Gastroenterology 1990; 99:730-6.

6. Janczewska I, Bartnik W, Butruk E, Tomecki R, Kazik E, Ostrowski J. Metabolism of vitamin $A$ in inflammatory bowel disease. Hepatogastroenterol 1991; 38:391-5.

7. Stokes MA. Crohn's disease and nutrition. Br J Surg 1992; 79:391-4.

8. Kuroki F, lida M, Tominaga M, Matsumoto T, Hirakawa K, Sugiyama S, Fujishima M. Multiple vitamin status in Crohn's disease. Correlation with disease activity. Dig Dis Sci 1993; 38:1614-8.

9. Royall D, Greenberg GR, Allard JP, Baker JP, Jeejeebhoy KN. Total enteral nutrition support improves body composition of patients with active Crohn's disease. J Parenter Enteral Nutr 1995; 19:95-9.

10. Teahon K, Pearson M, Smith T, Bjarnason I. Alternations in nutritional status and disease activity during treatment of Crohn's disease with elemental diet. Scand J Gastroenterol 1995; 30:54-60.

11. Lanfranchi GA, Brignola C, Campieri M. Assessment of nutritional status in Crohn's disease in remission or low activity. Hepatogastroenterol 1984; 31:129-32.

12. Jeejeebhoy, KN, Detsky AS, Baker JP. Assessment of nutritional status. J Parenter Enteral Nutr 1990; 14:193S-196S.

13. Lennard-Jones JE. Classification of inflammatory bowel disease. Scand J Gastroenterol 1989; 24:2S-6S.

14. Best WR, Becktel JM, Singleton W. Rederived values of the eight coefficients of the Crohn's disease activity index (CDAl). Gastroenterology 1979; 77:843-6.

15. van Hees PA, van Elteren $\mathrm{PH}$, van Lier $\mathrm{HJ}$, van Tongeren $\mathrm{JH}$. An index of inflammatory activity in patients with Crohn's disease. Gut 1980; 21:279-86.

16. Durnin JVGA, Womersley J. Body fat assessed from total body density and its estimation from skinfold thickness measurements on 461 men and women aged 16-72 years. Br J Nutr 1974; 32:77-97.

17. Lohman TG, Roche AF, Martorell R. Anthropometric standardization reference manual. Champaign, IL: Human Kinetics Books, 1988.

18. Frisancho AR. Triceps skin fold and upper arm muscle size norms for assessment of nutritional status. Am J Clin Nutr 1974; 27:1052-8.

19. Deurenberg $P$, Weststrate JA, Seidell JC. Body mass index as a measure of body fatness: age- and sex-specific prediction formulas. Br J Nutr 1991; 65:105-14.

20. Schoeller DA. Isotope dilution methods. In: Bjöntröp P, Brodoff BN, eds. Obesity. Philadelphia: JB Lippincott Company, 1992:80-8. 
21. Mazess RB, Barden HS, Bisek JP, Hanson J. Dual-energy X-ray absorptiometry for total-body and regional bone-mineral and soft-tissue composition. Am J Clin Nutr 1990; 51:1106-12.

22. Beal VA. The nutritional history in longitudinal research. J Am Diet Assoc 1967; 51:426-32.

23. Al MDM, Badart-Smook A, v Houwelingen AC, Hasaart THM, Hornstra G. Fat intake of women during normal pregnancy: relationship with maternal and neonatal essential fatty acid status. J Am Coll Nutr 1996; 15:49-55.

24. NEVO Foundation. Dutch food composition table 1989-1990. The Hague: Voorlichtingsbureau voor de Voeding, 1989 (in Dutch).

25. Netherlands Nutrition Council. Guidelines for a healthy diet. The Hague: Voedingsraad, 1989 (in Dutch).

26. Westerterp KR, Donkers JHHLM, Frederix EWHM, Boekhoudt P. Energy intake, physical activity and body weight: a simulation model. $\mathrm{Br} J$ Nutr 1995; 73:337-47.

27. Goldberg, GR, Black AE, Cole TJ, Murgatroyd PR, Coward WA, Prentice AM. Critical evaluation of energy intake data using fundamental principles of energy physiology: 1 . derivation of cut-off limits to identify under recording. Eur $\mathrm{J}$ Clin Nutr $1991 ; 45: 569-81$.

28. Paglia DE, Valentine WN. Studies on the quantitative and qualitative characterization of erythrocyte gluthatione peroxidase. J Lab Clin Med 1967; 70:158.

29. Bligh EG, Dyer WJ. A rapid method for total lipid extraction and purification. Can J Biochem Physiol 1959; 37:911-17.

30. Vusse van der GJ, Roemen ThHM, Prinzen FW, Coumans WA, Reneman RS. Uptake and tissue content of fatty acids in dog myocardium under normoxic and ischemic conditions. Circ Res 1982; 50:538-46.

31. Horwitt MK, Harvey CC, Dahm CH, Searcy MT. Relationship between tocopherol and serum lipid levels for determination of nutritional adequacy. Ann NY Acad Sci 1972; 203:223-36.

32. Gleeson NP, Mercer TH. The utility of isokinetic dynamometry in the assessment of human muscle function. Sports Med 1996; 21:18-34.

33. Charney P. Nutrition assessment in the 1990s: Where are we now? Nutr Clin Prac 1995; 10:131-9.

34. Binder V. Quality of life. In: Järnerot G, ed. Inflammatory bowel disease. Arlöv: Berlings, 1992: 583-93.

35. Gee MI, Grace MG, Wensel RH, Sherbaniuk RW, Thomson AB. Nutritional status of gastroenterology outpatients: comparison of inflammatory bowel disease with functional disorders. J Am Diet Assoc 1985; 85:1591-9.

36. Rigaud D, Angel LA, Cerf M, Carduner MJ, Melchior JC, Sautier C, et al. Mechanisms of decreased food intake during weight loss in adult Crohn's disease patients without obvious malabsorption. Am J Clin Nutr 1994; 60:775-81.

37. Stokes MA, Hill GL. Total energy expenditure in patients with Crohn's disease: measurement by the combined body scan technique. J Parenter Enteral Nutr $1993 ; 17 ; 3-7$.

38. Sandström B, Davidsson L, Bosaeus I, Eriksson R, Alpsten M. Selenium status and absorption of zinc $\left({ }^{65} \mathrm{Zn}\right)$, selenium $\left({ }^{75} \mathrm{Se}\right)$ and manganese $\left({ }^{54} \mathrm{Mn}\right)$ in patients with short bowel syndrome. Eur J Clin Nutr 1990; 44: 697-703.

39. Andersson H, Bosaeus I, Brummer R-J, Fasth S, Hultén L, Mangusson O, Strauss B I. Nutritional and metabolic consequences of extensive bowel resection. Dig Dis $1986 ; 4: 193-202$. 
40. Simmonds NJ, Rampton DS. Inflammatory bowel disease-a radical view. Gut 1993; 34:865-8.

41. Gross V, Arndt H, Andus T, Palitzsch KD, Scholmerich J. Free radicals in inflammatory bowel diseases pathophysiology and therapeutic implications. Hepatogastroenterol 1994; 41:320-7.

42. Grisham MB. Oxidants and free radicals in inflammatory bowel disease. Lancet $1994 ; 344: 859-61$.

43. Kuroki F, lida M, Tominaga M, Matsumoto T, Kanamoto K, Fujishima M. Is vitamin $E$ depleted in Crohn's disease at initial diagnosis? Dig Dis 1994; 12:248-54.

44. Hinks LJ, Inwards KD, Lloyd B, Clayton B. Reduced concentrations of selenium in mild Crohn's disease. J Clin Pathol 1988; 41:198-201.

45. Ringstad J, Kildebo S, Thomassen Y. Serum selenium, copper, and zinc concentrations in Crohn's disease and ulcerative colitis. Scand J Gastroenterol 1993; 28:605-8.

46. Rannem T, Ladefoged K, Hylander E, Hegnhøj, Jarnym S. Selenium status in patients with Crohn's disease. Am J Clin Nutr 1992; 56:933-7.

47. Thomas AG, Muller V, Shenkin A, Fell GS, Taylor F. Selenium and gluthatione peroxidase status in pediatric health and gastrointestinal disease. J Ped Gastroenterol Nutr 1994; 19:213-9.

48. Fleming CR, Huizenga KA, Mc Call JT, Gildea J, Dennis R. Zinc nutrition in Crohn's disease. Dig Dis Sci 1981; 26:865-70.

49. Hendricks KM, Walker WA. Zinc deficiency in inflammatory bowel disease. Nutr Rev $1988 ; 46: 401-8$.

50. Schoon EJ, van Nunen AB, Heidendal G, Geerling BJ, Stockbrügger RW, Russel MGVM. Low body fat and risk for osteoporosis in Crohn's disease. Gut 1996;39S:A958.

51. Fleming CR. Nutrition considerations in patients with Crohn's disease. Sem Colon Rec Surg 1994; 51:167-73.

52. Garret $W E$, Mummen $M$, Lucareche $C$. Ultrastructural differences in human skeletal muscle fiber types. Orthop Clin North Am 1983; 14:413-25.

53. van Balkom RHH, van der Heijden HFM, van Herwaarden CLA, Dekhuijzen PNR. Corticosteroid-induced myopathy of the respiratory muscles. Neth J Med 1994; 45:114-22.

54. Ruff RL. Endocrine myopathies. In: Engel AG, Banke BQ, eds, Myology. New York: McGraw-Hill Book Company, 1986: 1871-906.

55. Lopes J, Russell DMcR, Whitwell J, Jeejeebhoy KN. Skeletal muscle function in malnutrition. Am J Clin Nutr 1982; 36:602-10.

56. Berkelhammer CH, Leiter LA, Jeejeebhoy KN, Detsky AS, Oreopoulos DG, Udall PR, Baker JP. Skeletal muscle function in chronic renal failure: an index of nutritional status. Am J Clin Nutr 1985; 42:845-54.

57. Gallagher HJ, Daly JM. Malnutrition, injury, and the host immune response: nutrient substitution. Curr Op Gen Surg 1993; 10:92-104.

58. Halliwell B. Free radicals, antioxidants, and human disease: curiosity, cause, or consequence? (see comments). Lancet 1994; 344:721-4. 



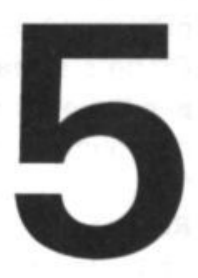

\section{Comprehensive nutritional} status in recently diagnosed patients with Inflammatory Bowel Disease compared with
population controls

Geerling BJ, Badart-Smook A, Stockbrügger RW, Brummer R-JM 


\section{Abstract}

\section{Introduction}

Malnutrition is observed frequently in patients with Inflammatory Bowel Disease (IBD). Knowledge about the nutritional status in patients with recently diagnosed IBD is limited.

\section{Methods}

To obtain a comprehensive picture of the nutritional status in recently diagnosed IBD patients, we assessed four measures of nutritional status in 69 IBD patients (23 Crohn's disease (CD) and 46 with ulcerative colitis (UC)) and 69 age- and sex-matched population controls: 1) body composition, 2) dietary intake, 3) biochemical indexes of nutrition, 4) and muscle strength.

\section{Results}

Body weight and body mass index were significantly lower in UC patients compared with controls. The mean daily intake of carbohydrates was significantly higher in CD patients and the intakes of protein, calcium, phosphorus, and riboflavin significantly lower in UC patients compared with controls, respectively. Serum concentrations of several nutrients ( $\beta$-carotene, magnesium, selenium and zinc) were significantly lower in UC patients compared with controls. Serum vitamin B12 concentration was significantly lower in $C D$ patients. Muscle strength did not significantly differ between IBD patients and controls.

\section{Conclusions}

In conclusion, this study showed that the nutritional status of IBD patients was already affected negatively at time of diagnosis. It needs to be elucidated whether nutritional supplementation in recently diagnosed IBD patients may improve the clinical course of the disease. 


\section{Introduction}

Inflammatory Bowel Disease (IBD) is a chronic inflammatory disorder that involves the colon in ulcerative colitis (UC) and may involve any part of the entire gastrointestinal tract in Crohn's disease (CD). In these patients malnutrition is often reported, especially in $C D$ patients with active disease $e^{1-11}$. In a recent study, we found several nutritional and functional deficiencies in patients with long-standing $C D$, currently in remission ${ }^{12}$. It is known that malnutrition is associated with immune dysfunction ${ }^{13-15}$ and increased susceptibility to oxidative tissue damage ${ }^{16}$. Adequate nutritional support may be an important therapeutic tool in improving the nutritional status and attenuating the inflammatory process in these patients.

In chronic disease, the nutritional status is the result of various physiological and pathophysiological processes ${ }^{17}$. It is therefore important to assess a comprehensive nutritional status, measuring body composition, dietary intake, biochemical indexes of nutrition, and functional indexes such as muscle strength $^{12}$.

There is only one study, to our knowledge, regarding nutritional status in $C D$ patients at initial diagnosis ${ }^{18}$. This study, however, was restricted to the assessment of vitamin $E$ status. Hence, the knowledge about the comprehensive nutritional status of newly diagnosed IBD patients is very limited. This knowledge could be important as achieving an optimal nutritional status may be beneficial for the clinical course of the disease in recently diagnosed IBD patients. The aim of the present study was to assess the comprehensive nutritional status of recently diagnosed IBD patients and to compare this with the status of controls.

\section{Subjects and methods}

The study protocol was approved by the Ethics Committee of the University Hospital Maastricht and all subjects gave their informed consent before the start of the study.

\section{Patients}

Patients were recruited from the out-patient population of the Department of Gastroenterology of the University Hospital Maastricht, Atrium Medical Center Brunssum and the Maasland Hospital Sittard, all located in the south of the province Limburg in the Netherlands. The diagnosis of IBD was based on the criteria proposed by Lennard-Jones ${ }^{19}$. All patients who had been diagnosed with IBD $(n=76)$ during the period June 1995-December 1997 were asked to participate in the study. Sixty nine patients ( $23 \mathrm{CD}, 46 \mathrm{UC}$ ) agreed to participate $(91 \%)$. All patients (mean age 35.4 years \pm 13.6 ) had been 
diagnosed within 6 months prior to entering the study. Patient characteristics are shown in Table 5.1. Disease activity for $C D$ patients was assessed according to the Crohn's disease activity index $(\mathrm{CDAl})^{20}$ as well as by the concentration of C-reactive protein (CRP) at the time of the investigation. For UC patients, disease activity was assessed according to the Truelove and Witts criteria and was graded numerically as 6-19 corresponding to "no disease activity", 20-32 as having "moderate disease activity" and 32-45 corresponding to "severe disease" 21 . In addition, the concentration of CRP at the time of the investigation was assessed.

Table 5.1 Characteristics of patients with Crohn's disease (CD) and ulcerative colitis (UC) ${ }^{1}$

\begin{tabular}{lcc}
\hline & $\begin{array}{c}\text { CD patients } \\
(\mathbf{n = 2 3 )}\end{array}$ & $\begin{array}{c}\text { UC patients } \\
(\mathbf{n = 4 6 )}\end{array}$ \\
\hline Age (years) & $30.4 \pm 10.2^{4}$ & $37.8 \pm 14.7$ \\
Gender (F/M) & $15 / 8$ & $21 / 25$ \\
Small bowel involvement (\%) & 87.0 & 0 \\
Small bowel resection (\% (mean \pm SD)) & $17.3(21.3 \mathrm{~cm} \pm 8.1)$ & 0 \\
Mesalazine use (\%) & 100 & 93.4 \\
Azathioprine use (\%) & 4.0 & 6.5 \\
Prednisone use (\% (mean \pm SD)) & $26.0(9.5 \mathrm{mg} \pm 5.6)$ & $19.5(11.3 \pm 7.0)$ \\
CDAl & $96.9 \pm 66.5$ & - \\
Truelove \& Witts index ${ }^{3}$ & - & $9.6 \pm 5.8$ \\
C-reactive protein (mg/L) & $17.1 \pm 19.9^{4}$ & $6.4 \pm 6.1$ \\
Smoking (\%) & 34.7 & 15.2 \\
\hline
\end{tabular}

1 Data are expressed as mean \pm SD or as stated

${ }^{2}$ Crohn's disease activity index ${ }^{20}$

3 According to reference 21

${ }^{4}$ Significantly different from UC patients (one-way ANOVA): ${ }^{4} \mathrm{P}<0.05$

\section{Controls}

Sixty-nine volunteers (mean age 35.4 years \pm 13.7 ) participated in this study as controls. They were randomly selected from the patient population database of a general health care center ( 3 general practitioners) located in the same study area. The controls were age- and sex-matched with IBD patients (within 3 years of age). Subjects with a history of IBD were excluded.

\section{Nutritional status}

All measurements, except the assessment of dietary intake, were performed during one day after an overnight fast at the University Hospital Maastricht. 


\section{Body composition}

Body composition was assessed using anthropometry and dual-energy X-ray absorptiometry (DXA). Body height was measured to the nearest millimeter with a wall-mounted stadiometer and while body weight measured with an electronic scale with a digital readout to an accuracy of 0.01 kilogram. Body mass index (BMI) was calculated from weight and height $\left(\mathrm{kg} / \mathrm{m}^{2}\right)$. Mid-arm muscle circumference (MAMC) was assessed ${ }^{22}$.

Body fat, fat-free mass (FFM), percentage body fat and total body bone mineral content (BMC) were determined using a dual-energy X-ray absorptiometer (DPX-L, Lunar Corp., Madison, WI; using DPX-L 1.3 software) ${ }^{23}$. Research on the reference population was conducted in the US, United Kingdom and Northern Europe. There was a $1.3 \%$ SD among geographical areas in the average density values. A total body scan over the entire length of a subject's body was performed. Any material that could attenuate the X-ray beam, e.g. jewelry, watches or clothing with zippers, were removed before the examination.

\section{Dietary intake}

Dietary intake was assessed using the cross-check dietary history ${ }^{24}$. The subjects were visited at home by an experienced dietitian and the usual food consumption of the previous month was assessed. During this interview, food quantities were specified in household measures. Usual portion sizes were estimated with the aid of portion size models or pictures of foods; frequently consumed portions of food and common household measures were weighed on a balance with a precision of $0.5 \mathrm{gram}$. In addition, the subjects had previously completed a self-administered semi-quantitative validated food-frequency questionnaire (FFQ), which was used as a cross check of the dietary history ${ }^{25}$. The FFQ dealt specifically with the dietary intake of fat and antioxidants over the previous month. All types of food and drink were coded according to the system used by the Netherlands Nutrient Databank (NEVO), and subsequently converted into energy and nutrients by using the extended computerized version of the Netherlands Food Table ${ }^{26}$. Intake of macronutrients and alcohol was expressed as \% of energy intake. Cholesterol and fiber intakes were expressed as $\mathrm{mg} / \mathrm{MJ}$ and as $\mathrm{g} / \mathrm{MJ}$, respectively.

\section{Biochemical analyses}

After subjects had fasted overnight, a venous blood sample $(90 \mathrm{ml})$ was obtained and plasma and serum were stored at $-80^{\circ} \mathrm{C}$ until analyzed. Serum albumin, cholesterol, total protein, C-reactive protein (CRP), magnesium and whole blood thiamin were determined by routine methods in use at the hospital, on a Beckman Synchron $\mathrm{CX}^{*}$ system (Brea, CA, USA). Serum prealbumin was measured using a radioimmunodiffusion technique (Beckman Immunochemistry systems, (Brea, CA, USA). Serum vitamin B-12 and folic acid concentrations were assessed by means of a commercial kit (Quantaphase ${ }^{*}$ B-12/folate 
Radioassay; Bio-RAD Laboratories B.V., Veenendaal, The Netherlands). Serum copper, zinc and selenium were determined by Zeeman-corrected electrothermal atomic absorption spectrometry. The assessment of whole blood activity of glutathione peroxidase was based on the method developed by Paglia and Valentine ${ }^{27}$.Serum vitamins $\mathrm{A}$ and $\mathrm{E}$ ( $a$-tocopherol) were determined with High Pressure Liquid Chromatography (HPLC) and serum $\beta$-carotene by spectrophotometric assessment at $450 \mathrm{Nm}$.

The concentration of vitamin $\mathrm{E}$ has been found to be closely related to serum lipids ${ }^{28}$, and the ratio of serum vitamin $E$ to serum cholesterol was applied to accurately assess the vitamin E status in IBD patients.

\section{Muscle strength}

Prior to testing each subject underwent a 5-min warm-up period of aerobic ergometer cycling. The subjects were then fixed to the testing apparatus, an isokinetic dynamometer (Cybex II, Eagle Performance Systems, Owatonna, $M N)^{29}$. The strength of m.quadriceps (extension) and of the hamstrings (flexion) were measured. They completed a few sub-maximal warm-up muscle actions at each angular velocity, and then 5 maximal muscle actions. Peak torque was determined from a five fold measurement at velocities of 60 and $180 \%$ s. In addition, the flexor/extensor ratio at each velocity was calculated.

\section{Statistical analysis}

Results were expressed as mean \pm SD or as stated. Differences in nutritional status between IBD patients and controls were analyzed using a paired Student's t-test. Correlation coefficients and partial correlations were calculated by regression analysis. All statistical analyses were performed with the SPSS 7.0 for Windows package (SPSS Inc, Chicago).

\section{Results}

\section{Body composition}

The body composition results of the subjects are shown in Table 5.2.

\section{$C D$ patients}

Patients were significantly $(P<0.05)$ longer than controls and FFM was significantly higher in $C D$ patients compared with controls. Furthermore, BMC was significantly $(P<0.05)$ lower in $C D$ patients. We did not find other significant differences between patients and controls. 
Body composition of patients with Crohn's disease (CD) and ulcerative colitis $(\mathrm{UC})^{1}$

\begin{tabular}{lcccc}
\hline & \multicolumn{2}{c}{ CD patients } & \multicolumn{2}{c}{ UC patients } \\
& $\begin{array}{c}\text { Patients } \\
(\mathbf{n = 2 3 )}\end{array}$ & $\begin{array}{c}\text { Controls } \\
(\mathbf{n = 2 3 )}\end{array}$ & $\begin{array}{c}\text { Patients } \\
(\mathbf{n = 4 6 )}\end{array}$ & $\begin{array}{c}\text { Controls } \\
(\mathbf{n = 4 6})\end{array}$ \\
\hline Weight $(\mathrm{kg})$ & $67.4 \pm 10.3$ & $65.9 \pm 10.4$ & $68.6 \pm 10.2^{4}$ & $72.3 \pm 12.0$ \\
Height $(\mathrm{m})$ & $1.74 \pm 0.09^{4}$ & $1.70 \pm 0.11$ & $1.72 \pm 0.09$ & $1.71 \pm 0.08$ \\
BMI $\left(\mathrm{kg} / \mathrm{m}^{2}\right)$ & $22.2 \pm 2.7$ & $22.7 \pm 2.7$ & $23.1 \pm 3.0^{3}$ & $24.7 \pm 3.5$ \\
Fat, DXA (kg) & $18.5 \pm 6.5$ & $19.0 \pm 6.8$ & $17.5 \pm 7.2$ & $19.3 \pm 6.7$ \\
FFM, DXA (kg) & $48.9 \pm 9.8^{4}$ & $46.9 \pm 8.9$ & $51.1 \pm 10.5^{2}$ & $53.0 \pm 11.1$ \\
Percentage fat, DXA (\%) & $27.5 \pm 8.4$ & $28.7 \pm 8.7$ & $25.5 \pm 9.6$ & $26.9 \pm 8.0$ \\
BMC $(\mathrm{kg})$ & $2.6 \pm 0.6^{4}$ & $2.8 \pm 0.5$ & $2.8 \pm 0.5$ & $2.8 \pm 0.6$ \\
MAMC $(\mathrm{cm})$ & $26.4 \pm 2.5$ & $26.5 \pm 2.5$ & $26.8 \pm 2.8$ & $27.9 \pm 3.9$ \\
\hline
\end{tabular}

1 Data are expressed as mean \pm SD. DXA: dual-energy X-ray absorptiometry; FFM: fat-free mass; TBW: total body water; BMC: total body bone mineral content; MAMC: mid-arm muscle circumference;

$2 \quad \mathrm{P}=0.06$ for difference between patients and controls.

${ }^{3,4}$ Significantly different from controls (paired Student's t-tests): ${ }^{3} \mathrm{P}<0.01,{ }^{4} \mathrm{P}<0.05$.

\section{UC patients}

Body weight and BMI were significantly $(P<0.05)$ lower in the total group of patients than in controls. Sex-specific analysis showed that alterations in body composition were predominantly observed in male UC patients. BMI was significantly $(P<0.01)$ lower in male patients $\left(23.3 \mathrm{~kg} / \mathrm{m}^{2} \pm 2.9\right)$ than in controls $\left(25.7 \mathrm{~kg} / \mathrm{m}^{2} \pm 3.2\right)$; body weight and fat mass were significantly $(P<0.05)$ lower in male patients $(73.4 \mathrm{~kg} \pm 8.7$ and $13.7 \mathrm{~kg} \pm 4.8)$ than in controls (78.5 kg \pm 9.7 and $17.2 \mathrm{~kg} \pm 5.4)$. Body height was significantly $(P<0.05)$ higher in male patients $(1.78 \mathrm{~m} \pm 0.08)$ than in controls $(1.75 \mathrm{~m} \pm 0.08)$. We observed no significant differences in body composition between female UC patients and controls. 


\section{Dietary intake}

The subjects' mean daily nutrient intakes are shown in Table 5.3.

Table 5.3 Mean daily intake of nutrients'

\begin{tabular}{|c|c|c|c|c|}
\hline & \multicolumn{2}{|c|}{ Crohn's disease } & \multicolumn{2}{|c|}{ Ulcerative colitis } \\
\hline & $\begin{array}{l}\text { Patients } \\
(n=23)\end{array}$ & $\begin{array}{l}\text { Controls } \\
(n=23)\end{array}$ & $\begin{array}{l}\text { Patients } \\
(n=46)\end{array}$ & $\begin{array}{l}\text { Controls } \\
(n=46)\end{array}$ \\
\hline Energy intake (MJ/day) & $11.0 \pm 3.4$ & $10.8 \pm 3.5$ & $10.3 \pm 2.6$ & $10.3 \pm 3.5$ \\
\hline Total protein ${ }^{2}(\%)$ & $14.7 \pm 2.2$ & $14.7 \pm 2.8$ & $14.8 \pm 2.5^{5}$ & $16.1 \pm 2.8$ \\
\hline Total fat ${ }^{2}(\%)$ & $34.0 \pm 7.6$ & $36.4 \pm 6.8$ & $35.2 \pm 6.3$ & $33.7 \pm 7.6$ \\
\hline $\operatorname{SAFA}^{2}(\%)$ & $12.6 \pm 2.8$ & $12.9 \pm 2.4$ & $12.8 \pm 2.7$ & $12.3 \pm 3.0$ \\
\hline $\operatorname{MUFA}^{2}(\%)$ & $12.8 \pm 3.5$ & $13.8 \pm 3.2$ & $12.9 \pm 2.7$ & $12.4 \pm 3.4$ \\
\hline PUFA $^{2}(\%)$ & $6.1 \pm 2.3^{5}$ & $7.4 \pm 2.8$ & $7.0 \pm 2.4$ & $6.6 \pm 2.4$ \\
\hline Linoleic acid $^{2}(\%)$ & $4.5 \pm 2.2$ & $5.9 \pm 2.6$ & $5.3 \pm 2.5$ & $5.5 \pm 2.2$ \\
\hline Cholesterol (mg/MJ) & $22.1 \pm 5.9$ & $22.2 \pm 4.9$ & $21.7 \pm 4.8$ & $22.1 \pm 6.5$ \\
\hline Total carbohydrates $^{2}(\%)$ & $51.0 \pm 7.4^{5}$ & $46.0 \pm 7.2$ & $49.3 \pm 7.7$ & $47.9 \pm 7.3$ \\
\hline Mono + disaccharides ${ }^{2}(\%)$ & $26.7 \pm 6.6^{3}$ & $22.9 \pm 8.6$ & $23.6 \pm 8.0$ & $23.9 \pm 7.7$ \\
\hline Fiber $(g / \mathrm{MJ})$ & $1.6 \pm 0.5$ & $1.8 \pm 0.5$ & $1.9 \pm 0.5$ & $2.0 \pm 0.6$ \\
\hline Alcohol $^{2}(\%)$ & $0.9 \pm 1.3^{4}$ & $4.0 \pm 4.7$ & $1.8 \pm 3.0^{3}$ & $3.4 \pm 4.3$ \\
\hline Phosphorus (g) & $1.6 \pm 0.7$ & $1.6 \pm 0.5$ & $1.5 \pm 0.4^{5}$ & $1.7 \pm 0.6$ \\
\hline Calcium (g) & $1.3 \pm 0.8$ & $1.1 \pm 0.4$ & $0.9 \pm 0.3^{5}$ & $1.3 \pm 0.5$ \\
\hline Total iron (mg) & $13.0 \pm 4.9$ & $13.7 \pm 4.0$ & $13.7 \pm 0.4$ & $14.0 \pm 4.7$ \\
\hline Vitamin A (mg RE) & $0.8 \pm 0.5$ & $0.7 \pm 0.2$ & $0.7 \pm 0.3$ & $0.7 \pm 0.3$ \\
\hline$\beta$-Carotene $(\mathrm{mg})$ & $1.0 \pm 0.9$ & $0.9 \pm 0.5$ & $1.0 \pm 0.7$ & $1.1 \pm 0.7$ \\
\hline Thiamin (mg) & $1.2 \pm 0.5$ & $1.3 \pm 0.5$ & $1.2 \pm 0.4$ & $1.4 \pm 0.8$ \\
\hline Riboflavin (mg) & $1.7 \pm 1.2$ & $1.6 \pm 0.7$ & $1.4 \pm 0.5^{5}$ & $1.8 \pm 1.3$ \\
\hline Pyridoxine (mg) & $1.9 \pm 0.6$ & $1.9 \pm 0.6$ & $1.8 \pm 0.6$ & $2.0 \pm 0.7$ \\
\hline Vitamin C (mg) & $103.0 \pm 84.2$ & $91.5 \pm 39.6$ & $88.9 \pm 47.1^{5}$ & $113.7 \pm 58.8$ \\
\hline
\end{tabular}

1. Data are expressed as mean \pm SD. SAFA: saturated fatty acids; MUFA: monounsaturated fatty acids; PUFA: polyunsaturated fatty acids; RE: retinol equivalent.

$2 \%$ of energy

$3=0.06$ for difference between patients and controls.

${ }^{4.5}$ Significantly different from controls (paired Student's t-tests): ${ }^{4} \mathrm{P}<0.01,{ }^{5} \mathrm{P}<0.05$.

\section{$C D$ patients}

The mean daily total carbohydrate intake was significantly $(P<0.05)$ higher in CD patients at time of diagnosis than in controls (Table 5.3). This might be explained by a tendency of higher mono- and disaccharides intake in CD patients compared with controls $(P=0.06)$. $C D$ patients with high disease activity $(C D A I>150)$ showed a significantly $(P<0.025)$ higher total carbohydrate intake $(56.4 \% \pm 5.4)$ than $C D$ patients in remission $148.7 \% \pm$ 5.8). The difference in mono- and disaccharides intake between patients with 
active $C D(31.1 \% \pm 5.5)$ and patients with no disease activity $(24.9 \% \pm 6.1)$ did not reach significance $(P=0.08)$.

PUFA and alcohol intakes were significantly $(P<0.05)$ lower in $C D$ patients than in controls.

\section{UC patients}

The mean daily intake of total protein, phosphorus, calcium, riboflavin, and vitamin $C$ were significantly $(P<0.05)$ lower in UC patients than in controls.

\section{Biochemical analysis}

The serum indexes of the subjects are shown in Table 5.4.

\section{$C D$ patients}

Serum albumin and vitamin B-12 concentrations were significantly $(P<0.05)$ lower in $C D$ patients than in controls. The activity of the enzyme glutathione peroxidase was lower in $C D$ patients compared with controls, however, this did not reach significance $(P=0.06)$. We found significant correlations between cholesterol and $\beta$-carotene concentration $(r=0.38, P<0.05)$ and vitamin $E$ concentration $(r=0.52, P<0.01)$, respectively.

\section{UC patients}

Serum albumin, $\beta$-carotene, magnesium, zinc and selenium concentrations were significantly $(P<0.05)$ lower in UC patients than in controls. The ratio of $\beta$ carotene to serum cholesterol concentration was significantly $(P<0.05)$ lower in UC patients $(0.39 \mu \mathrm{mol} / \mathrm{g} \pm 0.14)$ than in controls $(0.47 \mu \mathrm{mol} / \mathrm{g} \pm 0.17)$. The ratio of serum vitamin $E$ concentration to cholesterol concentration did not significantly differ between patients and controls. Significant correlations were found between cholesterol and $\beta$-carotene concentration $(r=0.58, P<0.001)$ and vitamin $E(r=0.77, P<0.001)$, respectively. A significant correlation between concentration of zinc and albumin was observed in patients as well as in controls $(r=0.41, P<0.01 ; r=0.33, P<0.01$, respectively). We found a significant correlation between the activity of glutathione peroxidase and selenium concentration in UC patients $(r=0.39, P<0.01)$ but not in controls $(r=0.10, P=0.53$; Figure 5.1). 
Table 5.4 Serum concentrations of nutritional biochemical indexes'

\begin{tabular}{|c|c|c|c|c|}
\hline & \multicolumn{2}{|c|}{ Crohn's disease } & \multicolumn{2}{|c|}{ Ulcerative colitis } \\
\hline & $\begin{array}{l}\text { Patients } \\
(n=23)\end{array}$ & $\begin{array}{l}\text { Controls } \\
(n=23)\end{array}$ & $\begin{array}{l}\text { Patients } \\
(n=46)\end{array}$ & $\begin{array}{l}\text { Controls } \\
(n=46)\end{array}$ \\
\hline Total protein (g/L) & $71.6 \pm 5.0$ & $71.2 \pm 3.0$ & $71.4 \pm 4.3$ & $70.5 \pm 4.0$ \\
\hline Albumin (g/L) & $38.2 \pm 4.4^{3}$ & $42.7 \pm 3.8$ & $40.5 \pm 3.5^{3}$ & $42.5 \pm 3.1$ \\
\hline Prealbumin $(g / L)$ & $0.24 \pm 0.06$ & $0.27 \pm 0.03$ & $0.26 \pm 0.04$ & $0.28 \pm 0.04$ \\
\hline Vitamin A $(\mu \mathrm{mol} / \mathrm{L})$ & $2.2 \pm 0.8$ & $2.4 \pm 0.6$ & $2.3 \pm 0.6$ & $2.6 \pm 0.6$ \\
\hline$\beta$-Carotene $(\mu \mathrm{mol} / \mathrm{L})$ & $1.8 \pm 0.7$ & $2.2 \pm 1.3$ & $2.0 \pm 0.9^{4}$ & $2.4 \pm 0.7$ \\
\hline Thiamin (nmol/L) & $109 \pm 277$ & $115 \pm 15.2$ & $109 \pm 22.1$ & $117 \pm 24.5$ \\
\hline Vitamin B-12 (pmol/L) & $225 \pm 60.7^{4}$ & $270 \pm 88.2$ & $269 \pm 87.9$ & $264 \pm 89.7$ \\
\hline Vitamin C $(\mu \mathrm{mol} / \mathrm{L})$ & $47.6 \pm 17.7$ & $54.5 \pm 22.9$ & $51.9 \pm 21.4$ & $57.9 \pm 20.6$ \\
\hline Vitamin $E(\mu \mathrm{mol} / \mathrm{L})$ & $28.8 \pm 5.8$ & $30.4 \pm 8.7$ & $29.6 \pm 7.7$ & $32.5 \pm 9.1$ \\
\hline Folic acid (nmol/L) & $10.7 \pm 9.1$ & $12.4 \pm 5.6$ & $11.4 \pm 8.6$ & $13.1 \pm 6.7$ \\
\hline Magnesium (mmol/L) & $0.79 \pm 0.09$ & $0.82 \pm 0.06$ & $0.79 \pm 0.07^{4}$ & $0.83 \pm 0.07$ \\
\hline Selenium ( $\mu \mathrm{mol} / \mathrm{L})$ & $0.92 \pm 0.16$ & $0.99 \pm 0.16$ & $0.91 \pm 0.18^{4}$ & $1.00 \pm 0.17$ \\
\hline Zinc $(\mu \mathrm{mol} / \mathrm{L})$ & $12.3 \pm 3.0$ & $12.9 \pm 1.3$ & $12.6 \pm 1.7^{4}$ & $13.3 \pm 2.1$ \\
\hline Copper $(\mu \mathrm{mol} / \mathrm{L})$ & $23.6 \pm 8.9$ & $22.2 \pm 7.4$ & $21.2 \pm 7.1$ & $20.1 \pm 6.4$ \\
\hline $\begin{array}{l}\text { Glutathione peroxidase } \\
\text { (U/mmolHb) }\end{array}$ & $786 \pm 276^{2}$ & $949 \pm 218$ & $878 \pm 272$ & $946 \pm 314$ \\
\hline Cholesterol (mmol/L) & $4.6 \pm 0.8$ & $5.1 \pm 1.2$ & $5.1 \pm 1.1$ & $5.4 \pm 1.3$ \\
\hline
\end{tabular}

Data are expressed as mean \pm SD.

$\mathrm{P}=0.06$ for difference between patients and controls.

${ }^{3,4}$ Significantly different from controls (paired Student's t-tests): ${ }^{3} \mathrm{P}<0.01,{ }^{4} \mathrm{P}<0.05$.

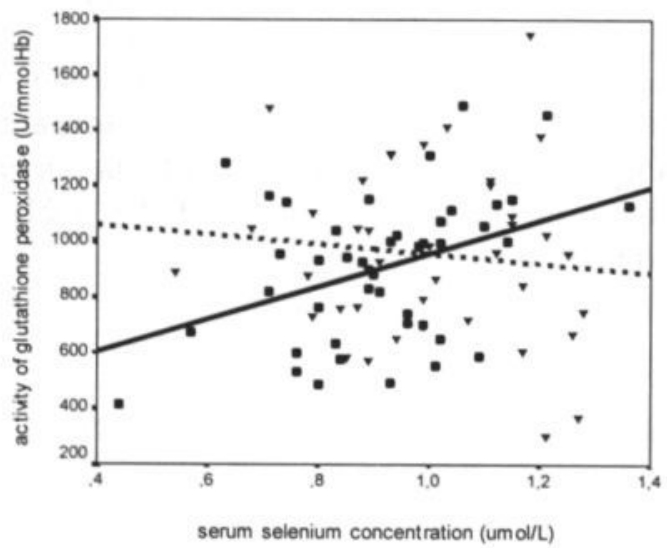

Figure 5.1 Correlation between serum selenium and activity of glutathione peroxidase in UC patients (closed circles and straight line: $r=0.39, P<0.01$ ) and controls (closed triangles and dotted line: $r=0.10, P=0.53$ ) 


\section{Muscle strength}

The results of differential muscle strength measured with an isokinetic dynamometer are shown in Table 5.5. We did not found any significant differences in peak torques of hamstrings or quadriceps muscles between patients and controls. The flexor/extensor ratio at both velocities did not significantly differ between patients and controls. Peak torque of the flexor and extensor muscles correlated significantly $(P<0.01)$ with FFM estimated by DXA in both patient groups and controls (Figure 5.2).

Table 5.5 Muscle strength as measured with an isokinetic dynamometer'

\begin{tabular}{lcccc}
\hline & \multicolumn{2}{c}{ Crohn's disease } & \multicolumn{2}{c}{ Ulcerative colitis } \\
& $\begin{array}{l}\text { Patients } \\
(\mathbf{n = 1 3 )}\end{array}$ & $\begin{array}{c}\text { Controls } \\
(\mathbf{n = 1 3 )}\end{array}$ & $\begin{array}{c}\text { Patients } \\
(\mathbf{n}=30)\end{array}$ & $\begin{array}{c}\text { Controls } \\
(\mathbf{n}=30)\end{array}$ \\
\hline Peak torque extension $180 \% / \mathrm{s}(\mathrm{Nm})$ & $81.5 \pm 25.7$ & $93.2 \pm 37.2$ & $96.1 \pm 30.7$ & $100.5 \pm 38.4$ \\
Peak torque flexion $180 \% / \mathrm{s}(\mathrm{Nm})$ & $46.8 \pm 25.3$ & $57.8 \pm 22.0$ & $58.6 \pm 21.3$ & $64.8 \pm 30.4$ \\
Peak torque extension $60 \% / \mathrm{s}(\mathrm{Nm})$ & $127.5 \pm 33.4$ & $142.4 \pm 33.2$ & $148.8 \pm 44.6$ & $155.7 \pm 50.0$ \\
Peak torque flexion $60 \% / \mathrm{s}(\mathrm{Nm})$ & $74.9 \pm 23.5$ & $86.8 \pm 19.8$ & $89.7 \pm 31.9$ & $98.5 \pm 37.3$ \\
Flexor/extensor ratio $180 \% / \mathrm{s}$ & $0.56 \pm 0.18$ & $0.64 \pm 0.20$ & $0.61 \pm 0.12$ & $0.64 \pm 0.14$ \\
Flexor/extensor ratio $60 \% / \mathrm{s}$ & $0.62 \pm 0.11$ & $0.59 \pm 0.11$ & $0.60 \pm 0.09$ & $0.63 \pm 0.11$ \\
\hline
\end{tabular}

'Data are expressed as mean \pm SD. Quadriceps muscle strength is measured by peak torque extension, and hamstrings muscle strength by peak torque flexion.
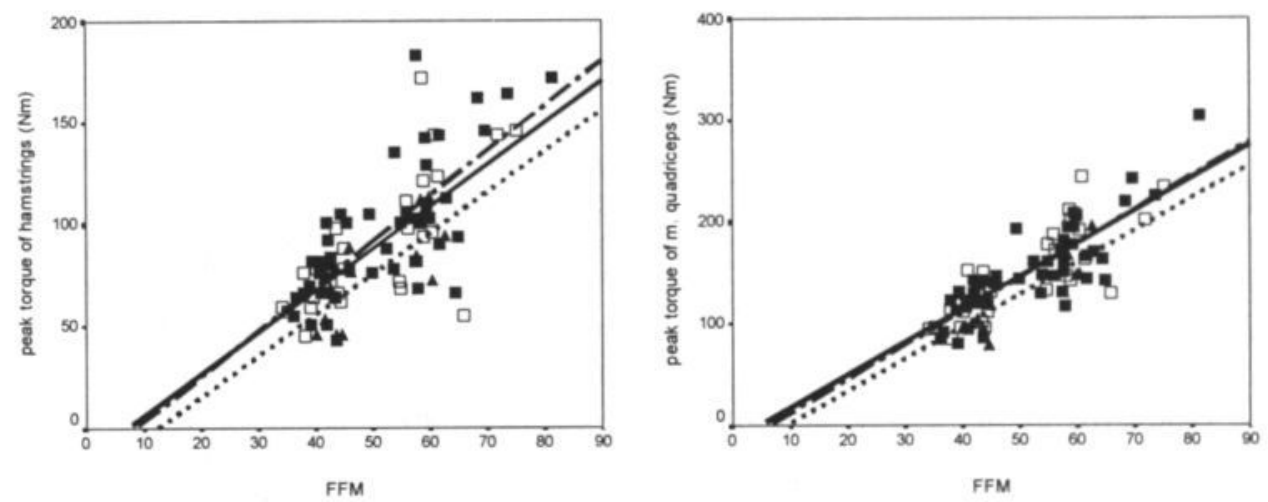

Figure 5.2 Correlation between peak torque of hamstring (flexor) muscles measured at $60 \%$ sec and fat-free mass (FFM) estimated by dual-energy $X$-ray absorptiometry (DXA) for controls (closed squares, semi dotted line; $r=0.73, P<0.001$ ), UC patients (open squares, straight line; $r=0.72, P<0.001$ ) and $C D$ patients (closed triangles, dotted line; $r=0.72, P<0.01$ ), and correlation between peak torque of $\mathrm{m}$. quadriceps (extensor) measured at $60 \% \mathrm{sec}$ and FFM estimated by DXA for controls $(r=0.83, P<0.001)$, UC patients $(r=0.81, P<0.001)$ and $C D$ patients $(r=0.80, P<0.01)$. 


\section{Disease activity}

$83 \%$ of CD patients and $92 \%$ of UC patients were clinically in remission according to the CDAI criteria $(C D A I<150)$ and Truelove and Witts criteria (Truelove and Witts <19), respectively. One patient with active CD $(C D A I \geq 150)$ and one patient with active UC (Truelove and Witts $\geq 19$ ) were treated with steroids.

\section{Discussion}

The present study showed that the nutritional status of IBD patients is already affected at time of diagnosis. Nutritional status was assessed by four different measurements (body composition, dietary intake, biochemical indexes, and muscle strength), all of which reflect the outcome of nutrition in a special way. IBD patients in the present study differ from controls concerning the four different measurements of the nutritional status, resulting in a deteriorated nutritional status. To our knowledge, the present study is the first to report a comprehensive nutritional status in recently diagnosed IBD patients.

Weight loss is often reported in IBD patients, especially in patients with active $C D^{8,10,30,31}$. The significantly higher body length of $C D$ patients in the present study could explain the significantly higher amount of FFM in these patients compared with controls. Hence, relative measurements of body composition, e.g. percentage body fat, are appropriate indicators of possible differences between $C D$ patients and controls. However, no such differences were observed between CD patients and controls. This could also be due to the small number of patients studied, which may have induced a type II error ( $\beta$ error).

There is only one study, to our knowledge, which evaluated a comprehensive body composition in UC patients ${ }^{32}$. These authors did not show any significant differences regarding body composition parameters between patients with inactive UC and controls, in contrast with results of our study. It should be noted, however, that the study population and the used methods differed from ours. We studied recently diagnosed UC patients, whereas the disease duration is unknown in the study of Capristo et al. Secondly, we used age- and sexmatched population controls and performed gender specific analyses of body composition changes which may have increased the power of our study. Thirdly, in the study of Capristo et al body composition was measured by bioelectric impedance with the assumption of a constant TBW/FFM ratio of 0.732. We showed in a previous study that body hydration of female IBD patients differs from that of controls ${ }^{33}$. In the present study, the height of UC patients was comparable with controls and in this group we found a reduced body weight and body mass index compared with controls. Sex- specific analysis showed that the differences in body composition between male UC patients and controls contributed to the differences in body composition. These 
data are in line with our previous observation in which we showed that body composition differences were predominantly found between male patients with long-standing $C D$, clinically in remission and controls ${ }^{12}$. Some studies suggested that gender differences may play a role in the efficiency of energy metabolism under metabolic stress ${ }^{34}$. Furthermore, gender-specific hormonal responses after metabolic stress may be a possible mechanism for the observed sex differences in body composition ${ }^{35}$. However, more studies in humans are necessary to elucidate the observed gender-specific differences concerning disease- induced alterations of body composition.

The dietary energy intake of IBD patients in the present study did not differ from controls. The majority of the patients did not have a strongly elevated disease activity which may explain their normal energy intake ${ }^{12}$. An interesting finding however, was the significantly higher intake of total carbohydrates in CD patients compared to controls. Many studies postulated that sugar intake may be a risk factor in the development of $C^{36-39}$. It is suggested however, that the greater consumption of sugars in $C D$ patients may be a result rather than a cause of the disease. Furthermore, it was recently suggested by Riordon et al, that the reported increased current sugar intake of $C D$ patients may be a consequence of active disease ${ }^{40}$. In the present study, 4 CD patients scored a CDAl above 150, indicating active disease. The total carbohydrate intake expressed as percentage of energy was significantly higher in the patients with high disease activity than in patients with a CDAl below 150. Furthermore, if the $C D$ patients with high disease activity were excluded from the analyses, we did not find significant differences between the total carbohydrate or mono- plus disaccharides intakes between $C D$ patients and controls. This is in line with studies which reported similar intakes of energy and sugars in CD patients in remission compared with randomly selected controls ${ }^{12,41}$. It is known that sugarcontaining foods are found to be more palatable which may explain the high carbohydrate intake during active disease. It was suggested that zinc deficiency may depress taste acuity, which may cause an increased sugar intake. However, studies were unable to show impaired taste acuity in CD patients ${ }^{42}$.

Total energy intake was not found to be different between CD patients and controls. A dietary advice for $C D$ patients is often to reduce their fat intake. In the present study we showed that the fat intake of $C D$ was lower compared with controls, however not significantly.

In UC patients, we found significantly lower intakes of phosphorus, calcium, riboflavin, and protein than in controls. This may be a contributing factor to the development of osteoporosis in UC patients ${ }^{43}$.

In a recent study, we reported that patients with long-standing $C D$, currently in remission, were at risk of developing nutritional deficiencies, especially of antioxidants $^{12}$. In the present study, we also found significant reductions of several serum antioxidants ( $\beta$-carotene, selenium and zinc), especially in UC patients. Serum selenium concentrations were significantly correlated with the activity of glutathione peroxidase in UC patients, but not in controls. This 
suggests that the selenium requirement for enzyme activity was met in the majority of the controls and not in the UC patients ${ }^{44,45}$. The decrease in serum antioxidants of UC patients may be explained by increased consumption of antioxidants by the recently inflamed tissue rather than by impaired digestion and absorption of nutrients which is unlikely in UC patients. Studies showed that the antioxidant defense may be depleted by increased reactive oxidative species found in inflamed mucosa of IBD patients ${ }^{46-48}$. It is therefore possible that the antioxidant status in UC patients of the present study was not completely restored after the recent inflammation period. In CD patients, the reductions in serum antioxidants did not reach significance which could have been caused by a type II error.

The majority of the patients in the present study showed no strongly elevated disease activity; we found that $83 \%$ of CD patients and $92 \%$ of UC patients were clinically in remission during the study. Furthermore, the reported deteriorated antioxidant status in these patients, especially UC patients, could not be explained by a reduced dietary intake or smoking $(15.2 \%$ of UC patients were current smokers vs $23.3 \%$ of matched controls).

The present data support the hypothesis that in IBD patients an imbalance exist between increased reactive oxidative species production and reduced antioxidant defenses with regard to the pathogenesis of tissue injury in $\mathrm{IBD}^{14,49,50}$. In a recent study, we were able to improve the antioxidant status of patients with long-standing CD, clinically in remission, by three months' supplementation with antioxidants and/or n-3 fatty acids in addition to their regular diet ${ }^{51}$. However, it needs to be elucidated, whether improvement of antioxidant status by supplementation, is beneficial for the clinical course of IBD.

Vitamin B-12 deficiency is frequently observed in CD patients, however rarely in UC patients ${ }^{10,30}$. In the present study, we also found that vitamin B-12 concentrations were significantly lower in CD patients compared with controls, however, no differences were found between UC patients and controls. Vitamin B-12 is absorbed in the distal ileum, and it is generally thought that malabsorption of this vitamin occurs due to ileal resection or after prolonged small bowel inflammation'. The present study showed that each CD patient, even at time of diagnosis deserves serious attention concerning the vitamin B12 status.

It has been shown that skeletal muscle function seems to be sensitive indicator of nutritional status in patients ${ }^{52}$, as functional changes occurred before abnormalities in conventional indices of malnutrition were observed ${ }^{4,53}$. In patients with long-standing $C D$, currently in remission, we observed a significantly reduced strength of the hamstrings muscles (with a high percentage of type Ilb fibers), whereas the strength of the quadriceps muscles was preserved $^{12}$. It is known that corticosteroids therapy and also malnutrition may induce selective type $\mathrm{Ilb}$ fiber atrophy ${ }^{53,54}$. Furthermore, malnutrition is associated with altered energy generation in the mitochondria (i.e., impaired 
rephosphorylation of ADP in the muscle $)^{55}$ and with relative loss of muscle creatine and phosphorus in relation to ATP ${ }^{56}$. Jeejeebhoy suggested that ATP generation in muscle may be abnormal despite normal body composition in these patients ${ }^{57}$. In the present study, muscle strength was not significantly different between IBD patients and controls. This suggests that in the patients at time of diagnosis, muscle strength is not already affected. Malnutrition and steroid use may affect muscle strength as the disease is progressing. Physical fitness may also alter muscle strength. Physical activity of patients and controls was not taken into account in our study, however, none of the patients was hospitalized during the study and both patients and controls were sedentary, with a few of them performing regular physical activity. Further studies are required to elucidate the effect of malnutrition, corticosteroid therapy and physical activity on the selective reduction in muscle function of IBD patients. This study revealed that IBD patients already at time of diagnosis were at risk of developing several nutritional deficiencies, especially that of antioxidants. Nutritional status was comprehensively assessed in four different dimensions. More research is needed to elucidate the effect of nutritional supplementation on the clinical course of patients with recently diagnosed IBD. 


\section{References}

1. Harries AD, Heatley RV. Nutritional disturbances in Crohn's disease. Postgraduate Med J 1983; 59:690-7.

2. Fernández-Bañares $F$, Abad-Lacruz A, Xiol X, Gine JJ, Dolz C, Cabré E, et al. Vitamin status in patients with inflammatory bowel disease. Am J Gastroenterol $1989 ; 84: 744-8$.

3. Fernández-Bañares $F$, Mingorance MD, Esteve M, Cabré E, Lachica M, AbadLacruz A, et al. Serum zinc, copper, and selenium levels in inflammatory bowel disease: effect of total enteral nutrition on trace element status. Am J Gastroenterol 1990; 85:1584-9.

4. Cristie PM, Hill GL. Effect of intravenous nutrition on nutrition and function in acute attacks of inflammatory bowel disease. Gastroenterol 1990; 99:730-6.

5. Janczewska I, Bartnik W, Butruk E, Tomecki R, Kazik E, Ostrowski J. Metabolism of vitamin A in inflammatory bowel disease. Hepatogastroenterol 1991; 38:391-5.

6. Stokes MA. Crohn's disease and nutrition. Br J Surg 1992; 79:391-4.

7. Kuroki F, lida M, Tominaga M, Matsumoto T, Hirakawa K, Sugiyama S, Fujishima M. Multiple vitamin status in Crohn's disease. Correlation with disease activity. Dig Dis Sci 1993; 38:1614-8.

8. Royall D, Greenberg GR, Allard JP, Baker JP, Jeejeebhoy KN. Total enteral nutrition support improves body composition of patients with active Crohn's disease. J Parenter Enteral Nutr 1995; 19:95-9.

9. Teahon K, Pearson M, Smith T, Bjarnason I. Alternations in nutritional status and disease activity during treatment of Crohn's disease with elemental diet. Scand J Gastroenterol 1995; 30:54-60.

10. Zurita VF, Rawls DE, Dyck WP. Nutritional support in inflammatory bowel disease. Dig Dis 1995; 503;92-107.

11. Ascue M, Rashid M, Griffiths A, Pencharz PB. Energy expenditure and body composition in children with Crohn's disease: effect of enteral nutrition and treatment with prednisolone. Gut 1997; 41:203-8.

12. Geerling BJ, Badart-Smook A, Stockbrügger RW, Brummer R-JM. Comprehensive nutritional status in patients with long-standing Crohn's disease in remission. Am $\mathrm{J}$ Clin Nutr 1998; 67:919-26.

13. Gallagher HJ, Daly JM. Malnutrition, injury, and the host immune response: nutrient substitution. Curr Op Gen Surg 1993; 10:92-104.

14. Grimble RF Nutritional antioxidants and the modulation of inflammation: Theory and practice. New Horizons 1994; 32:175-85.

15. Wan JMF, Haw MP, Blackburn GL. Nutrition, immune function, and inflammation: an overview. Proc Nutr Soc 1989; 48:315-35.

16. Halliwell B. Free radicals, antioxidants, and human disease: curiosity, cause, or consequence? (see comments). Lancet 1994; 344:721-4.

17. Jeejeebhoy, KN, Detsky AS, Baker JP. Assessment of nutritional status. J Parenter Enteral Nutr 1990; 14:193S-196S.

18. Kuroki $F$, lida M, Tominaga M, Matsumoto $T$, Kanamoto K, Fujishima M. Is vitamin $\mathrm{E}$ depleted in Crohn's disease at initial diagnosis? Dig Dis 1994; 12:248-54.

19. Lennard-Jones JE. Classification of inflammatory bowel disease. Scand J Gastroenterol 1989; 24:2S-6S.

20. Best WR, Becktel JM, Singleton W. Rederived values of the eight coefficients of the Crohn's disease activity index (CDAI). Gastroenterol 1979; 77:843-6. 
21. Truelove SC, Witts LJ. Cortisone in ulcerative colitis. Br Med J 1955; 29: 1047-8.

22. Frisancho AR. Triceps skin fold and upper arm muscle size norms for assessment of nutritional status. Am J Clin Nutr 1974; 27:1052-8.

23. Mazess RB, Barden HS, Bisek JP, Hanson J. Dual-energy x-ray absorptiometry for total-body and regional bone-mineral and soft-tissue composition. Am J Clin Nutr 1990; 51:1106-12.

24. Beal VA. The nutritional history in longitudinal research. J Am Diet Assoc 1967; 51:426-32.

25. Al MDM, Badart-Smook A, v Houwelingen AC, Hasaart THM, Hornstra G. Fat intake of women during normal pregnancy: relationship with maternal and neonatal essential fatty acid status. J Am Coll Nutr 1996; 15:49-55.

26. NEVO Foundation. Dutch food composition table 1989-1990. Voorlichtingsbureau voor de Voeding. The Hague, The Netherlands (in Dutch).

27. Paglia DE, Valentine WN. Studies on the quantitative and qualitative characterization of erythrocyte glutathione peroxidase. J Lab Clin Med 1967; 70:158.

28. Horwitt MK, Harvey CC, Dahm CH, Searcy MT. Relationship between tocopherol and serum lipid levels for determination of nutritional adequacy. Ann NY Acad Sci 1972; 203:223-36.

29. Gleeson NP, Mercer TH. The utility of isokinetic dynamometry in the assessment of human muscle function. Sports Med 1996; 21:18-34.

30. Kelly DG, Fleming CR. Nutritional considerations in inflammatory bowel diseases. Gastroenterol Clin North Am 1995; 24:597-611.

31. Tjellesen L, Nielsen PK, Staun M. Body composition by dual-energy X-ray absorptiometry in patients with Crohn's disease. Scand J Gastroenterol 1998; 33:956-60.

32. Capristo E, Mingrone G, Addolorato G, Greco AV, Gasbarrini G. Metabolic features in inflammatory bowel disease in a remission phase of the disease activity. J Int Med 1998; 243:339-47.

33. Geerling BJ, van Marken Lichtenbelt WD, Stockbrügger RW, Brummer R-JM. Body water compartments of patients with inflammatory bowel disease compared to controls. Clinical Nutrition; 1996: 15;A70:19.

34. Bjorntorp PA. Sex differences in the regulation of energy balance. Am J Clin Nutr 1989; 49:958-61.

35. Cortright RN, Chandler MP, Lemon PWR, Dicarlo SE. Daily exercise reduces fat, protein and body mass in male but not in female rats. Physiol Behav 1997; 62:105-11.

36. Persson PG, Ahlbom A, Hellers G. Diet and inflammatory bowel disease: a case control study. Epidemiology 1992; 3:47-52.

37. Tragnone A, Valpiani D, Miglio F, Elmi G, Bazzocchi G, Pipitone E, et al. Dietary habits as risk factors for inflammatory bowel disease. Eur J Gastroenterol \& Hepatol 1995; 7:47-51.

38. Thornton JR, Emmet PM, Heaton KW. Diet and Crohn's disease: characteristics of the pre-illness diet. Br Med J 1979; 2:762-4.

39. Reif S, Klein I, Lubin F, Farbstein M, Hallak A, Gilat T. Pre-illness dietary factors in inflammatory bowel disease. Gut 1997; 40:754-60.

40. Riordan AM, Ruxton CHS, Hunter JO. A review of associations between Crohn's disease and consumption of sugars. Eur J Clin Nutr 1998; 52:229-38.

41. Brauer PM, Gee MI, Grace M Thomson ABR, Diet of women with Crohn's and other gastrointestinal diseases. Am Diet Ass 1983; 82:659-64. 
42. Penny WJ, Mayberry JF, Aggett PJ, Gilbert JO, Newcombe RG, Rhodes J. Relationship between trace elements, sugar consumption, and taste in Crohn's disease. Gut 1983; 24:288-92.

43. Schoon EJ, Blok BM, Geerling BJ, Russel MG, Stockbrügger RW, Brummer R-JM. Is bone mineral density in patients with inflammatory bowel disease low at diagnosis? Bone 1998; 23:T364.

44. Rannem T, Ladefoged K, Hylander E, Hegnhøj, Jarnym S. Selenium status in patients with Crohn's disease. Am J Clin Nutr 1992; 56:933-7.

45. Thomas AG, Muller V, Shenkin A, Fell GS, Taylor F. Selenium and gluthatione peroxidase status in pediatric health and gastrointestinal disease. J Ped Gastroenterol Nutr 1994; 19:213-9.

46. Simmonds NJ, Rampton DS. Inflammatory bowel disease-a radical view. Gut 1993; 34:865-8.

47. Gross V, Arndt $H$, Andus T, Palitzsch KD, Scholmerich J. Free radicals in inflammatory bowel diseases pathophysiology and therapeutic implications. Hepatogastroenterol 1994; 41:320-7.

48. Ramakrishna BS, Varghese R, Jayakumar S, Mathan M, Balasubramanian KA. Circulating antioxidants in ulcerative colitis and their relationship to disease severity and activity. J Gastroenterol Hepatol 1997; 12:490-4.

49. Verspaget HW, Mulder TPJ, van der Sluys Veer A, Peña AS, Lamers CBHW. Reactive oxygen metabolites and colitis; a disturbed balance between damage and protection. Scan J Gastroenterol 1991; 26:44S-51S.

50. Conner EM, Grisham MB. Inflammation, Free radicals, and antioxidants. Nutrition $1996 ; 12: 274-7$.

51. Geerling BJ, Van Deursen C, Stockbrügger RW, Brummer R-JM. Improved antioxidant status after supplementation with n-3 fatty acids and/or antioxidants in addition to a regular diet in patients with Crohn's disease in a double blind placebo controlled study. Proceedings of the Spring meeting of the Dutch Society of Gastroenterology, page 100; 19-20 March 1998 in Veldhoven, The Netherlands.

52. Lopes J, Russell DMCR, Whitwell J, Jeejeebhoy KN. Skeletal muscle function in malnutrition. Am J Clin Nutr 1982; 36:602-10.

53. Russell DMCR, Leiter LA, Whitwell J, Marliss EB, Jeejeebhoy KN. Skeletal muscle function during hypocaloric diets and fasting: a comparison with standard nutritional assessment parameters. Am J Clin Nutr 1983; 37:133-8.

54. van Balkom RHH, van der Heijden HFM, van Herwaarden CLA, Dekhuijzen PNR. Corticosteroid-induced myopathy of the respiratory muscles. Neth J Med 1994; 45:114-22.

55. Mijan de la Torre A, Madapallimattam A, Cross A, Armstrong RL, Jeejeebhoy KN. Effect of fasting, hypocaloric feeding, and refeeding on the energetics of stimulated rat muscle as assessed by nuclear magnetic resonance spectroscopy. $J$ Clin Invest 1993; 92:114-21.

56. Thompson A, Damyanovich A, Madapallimattam A, Mikalus D, Allard J, Jeejeebhoy KN. ${ }^{31} \mathrm{P}$-nuclear magnetic resonance studies of bioenergetic changes in skeletal muscle in malnourished human adults. Am J Clin Nutr 1998; 67:39-43.

57. Jeejeebhoy KN. The many faces of malnutrition in Crohn disease. Am J Clin Nutr 1998; 67:819-20. 


\section{Gender specific alterations of body composition in patients with Inflammatory Bowel Disease compared with controls}

Geerling BJ, van Marken Lichtenbelt WD, Stockbrügger RW, Brummer R-JM 


\section{Abstract}

\section{Background}

Body hydration and the distribution of the body water compartments were assessed in defined populations of patients with Inflammatory Bowel Disease (IBD) compared with those of matched healthy controls.

\section{Patients and methods}

52 Patients with IBD at time of diagnosis (20 patients with Crohn's disease (CD-new) and 32 patients with ulcerative colitis (UC-new)), 40 patients with long-standing CD (CD-long) and 2 matched healthy control groups $(n=52$ and $n=40$ ) were recruited for the study. Total body water (TBW) and extracellular water (ECW) were measured by deuterium oxide and bromide dilution, respectively. Intracellular water (ICW) was calculated as TBW-ECW. In addition, hydration of fat-free mass (FFM) and the ECW:ICW ratio were calculated. FFM, body fat and percentage body fat were assessed by dual-energy $\mathrm{X}$-ray absorptiometry.

\section{Results}

In female IBD patients, the ECW:ICW ratio was significantly $(P<0.05)$ higher than in controls (CD-new: $0.89 \pm 0.11$ vs $0.79 \pm 0.08, P<0.01$; UC-new: $0.85 \pm 0.15$ vs $0.77 \pm 0.10, P<0.05$; CD-long: $0.86 \pm 0.14$ vs $0.80 \pm 0.10, P<0.05)$. In these female patients, the ICW:FFM ratio was significantly $(P<0.05)$ lower than in controls. Fluid shifts were especially pronounced in female patients with recently diagnosed CD. In male patients with recently diagnosed UC and in those with long-standing CD, body weight, body mass index, body fat and percentage body fat were significantly $(\mathrm{P}<0.05)$ lower than in controls. No differences in body hydration or body water distribution were observed between male patients and controls.

\section{Conclusions}

An altered body water distribution and body hydration were observed in female IBD patients, especially in female patients with recently diagnosed $C D$. 


\section{Introduction}

Inflammatory Bowel Disease (IBD) is a chronic inflammatory disorder that involves the colon in ulcerative colitis (UC) and may involve any part of the entire gastrointestinal tract in Crohn's disease (CD). Malnutrition has often been reported in these patients, especially in $C D$ patients ${ }^{1-11}$. Assessment of the degree of malnutrition in IBD requires accurate measurements of body composition.

Body composition can be assessed by a simple model in which the body is divided in two main compartments: body fat (BF) and fat-free mass (FFM). FFM can be assessed by deuterium dilution assuming a constant hydration ratio of $73 \%{ }^{12}$. Studies have shown however, that malnutrition influenced body hydration ${ }^{13}$. Furthermore, malnutrition may result in a reduced body cell mass $(B C M)$, accompanied by an increase in extracellular water $(E C W)^{14}$. There is both clinical and experimental evidence that chronic inflammation may lead to an expansion of $\mathrm{ECW}^{15}$ and a decrease in intracellular water (ICW) compartments ${ }^{16}$. This phenomenon can be elucidated by measuring ECW and ICW compartments. ICW is the greatest part of $\mathrm{BCM}$, which is the metabolically active part of the human body, and can be calculated by subtracting ECW from total body water (TBW). Changes in the ECW:ICW ratio may give important information about body water distribution and fluid shifts.

Measurement of body water compartments is an essential part of nutritional assessment and it may be helpful in understanding the metabolic alterations (that is, changes in energy metabolism, substrate oxidation and nutritional status) in IBD.

The aim of this present study was to assess the body hydration and the distribution of the body water compartments in defined populations of IBD patients compared with those of matched healthy controls.

\section{Subjects and methods}

The study protocol was approved by the Ethics Committee of the University Hospital Maastricht, and all subjects gave their informed consent before the start of the study.

\section{Subjects}

Characteristics of the patients are shown in Table 6.1. They were recruited from the out-patient population of the Department of Gastroenterology. The diagnosis of IBD was based on the criteria proposed by Lennard-Jones ${ }^{17}$. Disease activity for $C D$ patients was assessed according to the Crohn's disease activity index $(\mathrm{CDAI})^{18}$ as well as by the concentration of $\mathrm{C}$-reactive protein (CRP) at the time of the investigation. For UC patients, disease activity was assessed according 
to the Truelove and Witts index ${ }^{19}$ and graded numerically as 6-19 corresponding to "no disease activity", 20-32 as having "moderate disease activity" and 32-45 corresponding to "severe disease". In addition, CRP concentrations were measured at the time of investigation.

Table 6.1 Characteristics of patients with Inflammatory Bowel Disease (IBD)'

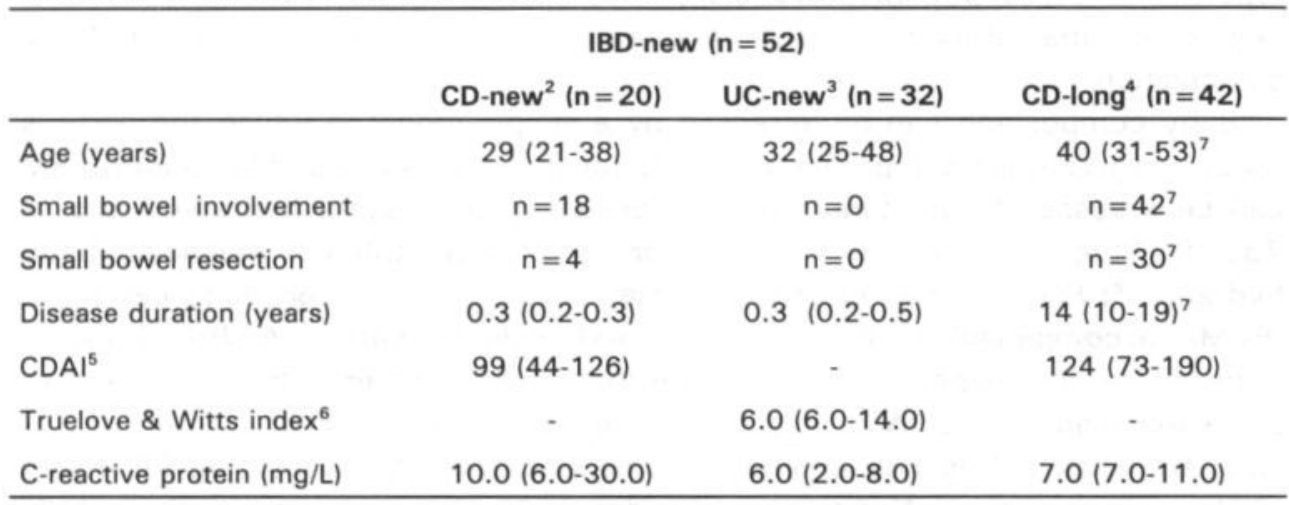

1 Data are expressed as median; 25th and 75th percentile in parentheses

2 Patients with recently diagnosed Crohn's disease (within 6 months of diagnosis)

${ }^{3}$ Patients with recently diagnosed ulcerative colitis (within 6 months of diagnosis)

4 Patients with long-standing ( $>10$ years) Crohn's disease

5 CDAl, Crohn's disease activity index ${ }^{18}$

${ }^{6}$ According to reference 19.

7 Significantly different from other patient groups (Chi-square and one-way ANOVA): $\mathrm{P}<0.001$.

\section{Patients with recently diagnosed IBD (IBD-new)}

All patients who had been diagnosed with IBD during the period June 1995December 1997 were asked to participate in the study. Ninety-one percent agreed to participate. All patients had been diagnosed within 6 months before the study. Fifty-two patients $(20 \mathrm{CD}, 32 \mathrm{UC})$ were included. Three CD-new patients scored a $C D A I>150$, which is regarded as active disease ${ }^{18}$. Acute phase protein response did differ significantly $(P<0.05)$ between $C D-n e w$ patients (median C-reactive protein: $10 \mathrm{mg} / \mathrm{L}$; females $10 \mathrm{mg} / \mathrm{L}$; males $8 \mathrm{mg} / \mathrm{L}$ ) and controls (median C-reactive protein: $3.5 \mathrm{mg} / \mathrm{L}$; females $7 \mathrm{mg} / \mathrm{L}$; males 2 $\mathrm{mg} / \mathrm{L})$. Two UC-new patients scored a Truelove \& Witts index $>20$, which is regarded as active disease ${ }^{19}$. However, acute phase protein response did not differ significantly between UC-new patients (median C-reactive protein: 6 $\mathrm{mg} / \mathrm{L}$; females $7 \mathrm{mg} / \mathrm{L}$; males $2 \mathrm{mg} / \mathrm{L}$ ) and controls (median C-reactive protein: 2 $\mathrm{mg} / \mathrm{L}$; females $5 \mathrm{mg} / \mathrm{L}$ : males $2 \mathrm{mg} / \mathrm{L}$ ). All patients used medication during the study, including mesalazine $(n=52)$ and azathioprine $(n=3)$. Thirteen patients $(25 \%)$ used corticosteroids (median dose $10 \mathrm{mg}$ ). A dose of $\geq 10 \mathrm{mg} /$ day was prescribed to 7 IBD-new patients ( 4 females, 3 males). 


\section{Patients with long-standing $C D$ (CD-long)}

Patients who had been suffering from $C D$ with small bowel involvement for more than 5 years and who were clinically in remission, were consecutively asked to participate in the study during a visit to the outpatient clinic of the Department of Gastroenterology in the periods November 1995-May 1996 and April 1997-July 1997. Forty patients ( 23 females, 17 males) participated in the study. Median CDAl was 124 for all patients, 110 for females and 135 for males, respectively. Fourteen patients $(7$ females, 7 males $)$ scored a CDAI $>150$, which is regarded as active disease ${ }^{18}$. The high liquid stool frequency of many of these patients, all of whom suffered from ileal dysfunction, may explain the relatively high scores on the CDAI. However, acute phase protein response did not differ significantly between patients (median C-reactive protein: $7 \mathrm{mg} / \mathrm{L}$; females $7 \mathrm{mg} / \mathrm{L}$; males $9 \mathrm{mg} / \mathrm{L}$ ) and controls (median C-reactive protein: $4 \mathrm{mg} / \mathrm{L}$; females $6 \mathrm{mg} / \mathrm{L}$; males $2 \mathrm{mg} / \mathrm{L}$ ). All patients had stable body weights during the 3 months preceding the study. The absence of a significant acute phase response indicated that these patients were clinically in remission. Most patients $(92 \%)$ used medication during the study, including mesalazine $(n=35)$, azathioprine $(n=12)$, cholestyramine $(n=7)$ and low doses (median dose $5 \mathrm{mg}$ ) of corticosteroids $(n=13)$. Two patients had an ileostomy.

\section{Controls}

The controls were randomly selected from the patient population database of a general practitioner in the same study region, which is a reliable dynamic sampling frame of the Dutch general population. They were selected according to the following criteria: age- and sex-matched with IBD patients (within 3 years of age) and no history of IBD. Two healthy control groups, one group ( $n=52$ ) matched with IBD-new (median age 32 years) and another control group $(n=40)$ matched with CD-long (median age 38 years), participated in the study.

\section{Methods}

Body composition was assessed using anthropometry, deuterium and bromide dilution techniques and dual-energy $\mathrm{X}$-ray absorptiometry (DXA).

\section{Anthropometry}

Body height $(\mathrm{BH})$ was measured to the nearest millimetre using a wall-mounted stadiometer, while body weight (BW) was measured using an electronic scale with a digital readout to an accuracy of 0.01 kilogram. Body mass index (BMI) was calculated from weight and height $\left(\mathrm{kg} / \mathrm{m}^{2}\right)$.

\section{Dilution techniques}

Subjects consumed a cocktail containing a quantity of deuterium (99.8 atom percent excess, Akademie der Wissenschaften, Leipzig, Germany) corresponding to $0.1 \mathrm{~g} / \mathrm{L}$ estimated TBW, and $60 \mathrm{mg}$ sodium bromide/L predicted TBW mixed 
into $\approx 70 \mathrm{ml}$ water ${ }^{20}$.

\section{Assessment of TBW}

TBW was assessed using deuterium oxide. A background urine sample was taken after an overnight fast. After consumption of the deuterium/bromide cocktail, urine was collected after 4 hours of equilibration. Isotopic abundances in urine were determined in duplicate using an isotope-ratio mass spectrometer (Aqua Sira; VG Isogas, Cheshire, UK). Deuterium dilution space was calculated from the quantity of deuterium administered and the urine deuterium concentrations after equilibration. TBW was assessed according to the equation proposed by Deurenberg et $\mathrm{al}^{20}$ and was calculated as the deuterium-dilution space divided by 1.04 , correcting for the exchange of the deuterium label with non-aqueous hydrogen in body solids ${ }^{21}$.

\section{Assessment of ECW}

ECW was assessed using bromide dilution. A background serum sample was taken after an overnight fast. After consumption of the deuterium/bromide cocktail, serum samples were collected after 4 hours of equilibration. Bromide concentration in serum ultrafiltrate was determined by HPLC using the anionexchange chromatographic method ${ }^{22}$. ECW was estimated from the corrected bromide space $^{22,23}$.

\section{Assessment of ICW}

ICW was calculated according to the equation: ICW $=$ TBW-ECW.

\section{Dual-energy $X$-ray absorptiometry}

Fat-free mass (FFM), body fat and percentage body fat were determined using a dual-energy X-ray absorptiometer (DPX-L, Lunar Corp., Madison, WI; using DPX$L 1.3$ software $)^{24}$. A total body scan over the entire length of a subject's body was performed. Any materials that could attenuate the X-ray beam, for example jewelry, watches or clothing with zippers, were removed before the examination.

\section{Statistical analysis}

Results are expressed as mean \pm SD or as stated. Differences in body composition between IBD patients and matched controls were analyzed using a paired Student's t-test, and ANOVA was used to analyze differences in body composition parameters between different IBD groups. Correlation coefficients were calculated by regression analysis. All statistical analyses were performed with the SPSS 7.0 for Windows package (SPSS Inc, Chicago). 


\section{Results}

\section{CD-new patients}

Table 6.2 shows body composition results for CD-new patients compared with controls. No significant differences in body weight, BMI, body fat or percentage body fat were observed between patients and controls. However, CD-new patients were significantly $(P<0.05)$ taller and $F F M$ was significantly $(P<0.02)$ higher than in controls. The ECW:ICW ratio was significantly $(P<0.02)$ higher in CD-new patients, while the ICW:FFM ratio was significantly $(P<0.02)$ lower than in controls. Gender-specific analysis showed that these differences in body water distribution could be explained by differences between female CD- new patients and controls. In males, we did not observe any significant differences in body composition parameters between the CD-new patients and the controls.

\section{UC-new patients}

Body composition results of UC-new patients are shown in Table 6.3. Body weight, BMI, and body fat were significantly lower in UC-new patients than in controls. The ECW:ICW ratio was significantly $(P<0.05)$ higher in female UCnew patients.

In male patients, body weight, BMI, body fat and percentage body fat were significantly $(P<0.05)$ lower than in controls. No differences in FFM hydration or body water distribution were found between male patients and controls.

\section{CD-long patients}

Results for patients with long-standing $C D$ are shown in Table 6.4. FFM and the ICW:FFM ratio were significantly ( $P<0.05)$ lower in $C D$-long patients than in controls. The ECW:ICW ratio was significantly $(P<0.05)$ higher in patients. This difference in ECW:ICW ratio was only observed in female CD-long patients compared with controls.

In male patients, body weight, BMI, FFM, body fat, percentage body fat were all significantly $(P<0.05)$ lower than in controls. However, the male $C D$-long patients did not differ significantly from the controls as regards body hydration and body water distribution.

Disease activity indices showed no significant correlation with body composition parameters in any patient group.

\section{Body composition differences between UC and CD}

We did not find any significant differences in body composition parameters between CD-new, UC-new or CD-long patients (Table 6.2-6.4). 
Table 6.2 Body composition of patients with recently diagnosed (within 6 months of diagnosis) Crohn's disease (CD-new) compared with age- and sex- matched controls'

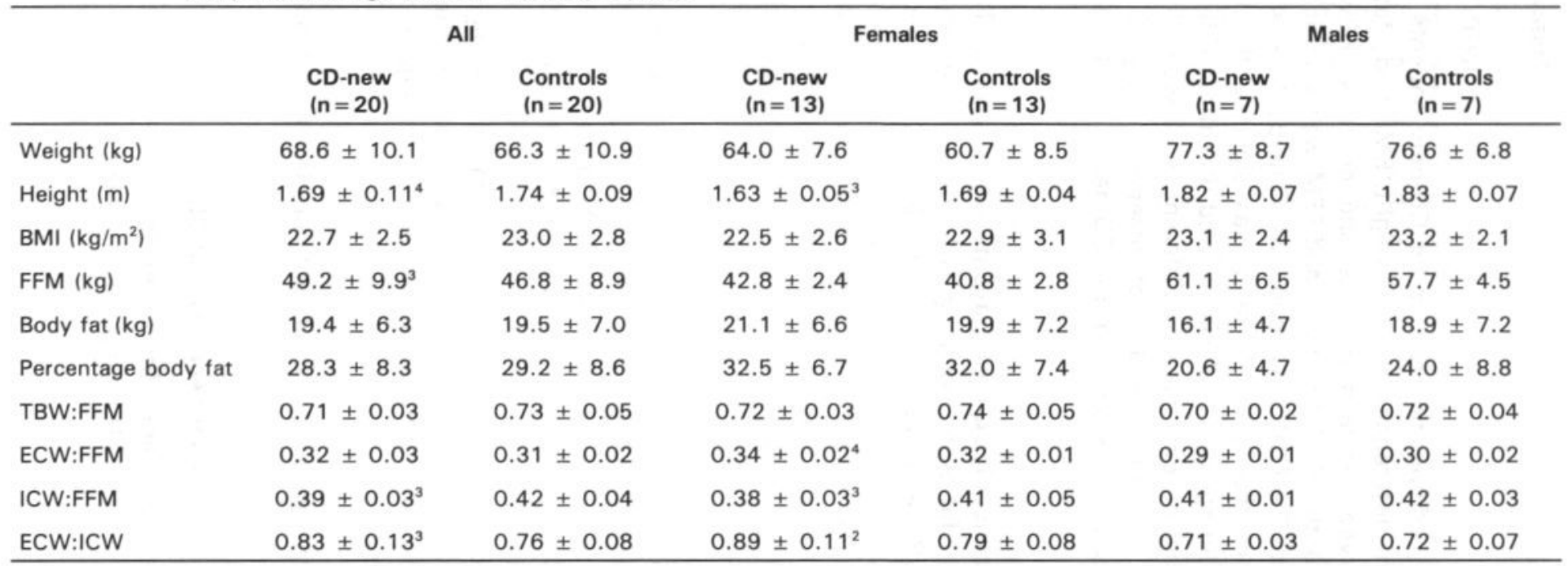

1 Data are expressed as mean \pm SD. BMI: body mass index; FFM: fat-free mass assessed by dual-energy X-ray absorptiometry; Body fat: assessed by dual-energy X-ray absorptiometry; TBW: total body water; ECW: extracellular water; ICW: intracellular water.

TBW:FFM, ratio of TBW and FFM; ECW:FFM, ratio of ECW and FFM; ICW:FFM, ratio of ICW and FFM; ECW:ICW, ratio of ECW and ICW.

2.3.4 Significantly different from controls (paired Student's t-tests): ${ }^{2} \mathrm{P}<0.01,{ }^{3} \mathrm{P}<0.02,{ }^{4} \mathrm{P}<0.05$. 

age- and sex-matched controls ${ }^{1}$

\begin{tabular}{|c|c|c|c|c|c|c|}
\hline & \multicolumn{2}{|c|}{ All } & \multicolumn{2}{|c|}{ Females } & \multicolumn{2}{|c|}{ Males } \\
\hline & $\begin{array}{l}\text { UC-new } \\
(n=32)\end{array}$ & $\begin{array}{l}\text { Controls } \\
(n=32)\end{array}$ & $\begin{array}{l}\text { UC-new } \\
(n=18)\end{array}$ & $\begin{array}{l}\text { Controls } \\
(n=18)\end{array}$ & $\begin{array}{l}\text { UC-new } \\
(n=14)\end{array}$ & $\begin{array}{l}\text { Controls } \\
(n=14)\end{array}$ \\
\hline Weight (kg) & $66.4 \pm 9.6^{4}$ & $71.1 \pm 12.4$ & $61.2 \pm 7.3$ & $64.2 \pm 9.0$ & $73.2 \pm 8.0^{4}$ & $80.1 \pm 10.4$ \\
\hline Height $(\mathrm{m})$ & $1.71 \pm 0.09$ & $1.69 \pm 0.07$ & $1.66 \pm 0.05$ & $1.66 \pm 0.08$ & $1.73 \pm 0.05^{4}$ & $1.77 \pm 0.08$ \\
\hline BMI $\left(\mathrm{kg} / \mathrm{m}^{2}\right)$ & $22.7 \pm 2.4^{2}$ & $24.7 \pm 3.4$ & $22.3 \pm 2.6$ & $23.2 \pm 2.4$ & $23.2 \pm 2.2^{2}$ & $26.7 \pm 3.6$ \\
\hline $\mathrm{FFM}(\mathrm{kg})$ & $49.6 \pm 10.8$ & $51.7 \pm 11.6$ & $41.3 \pm 3.5$ & $43.2 \pm 4.9$ & $60.3 \pm 6.8$ & $62.5 \pm 8.2$ \\
\hline Body fat $(\mathrm{kg})$ & $16.8 \pm 6.2^{4}$ & $19.5 \pm 5.4$ & $19.8 \pm 5.8$ & $20.9 \pm 5.1$ & $12.9 \pm 4.6^{3}$ & $17.7 \pm 5.3$ \\
\hline Percentage body fat & $25.7 \pm 9.4$ & $27.8 \pm 7.0$ & $32.2 \pm 5.8$ & $32.3 \pm 4.2$ & $17.4 \pm 5.9^{4}$ & $22.0 \pm 5.4$ \\
\hline TBW:FFM & $0.71 \pm 0.03$ & $0.71 \pm 0.03$ & $0.72 \pm 0.03$ & $0.72 \pm 0.03$ & $0.70 \pm 0.04$ & $0.70 \pm 0.03$ \\
\hline ECW:FFM & $0.31 \pm 0.04$ & $0.30 \pm 0.03$ & $0.33 \pm 0.03$ & $0.31 \pm 0.03$ & $0.29 \pm 0.03$ & $0.29 \pm 0.03$ \\
\hline ICW:FFM & $0.40 \pm 0.03$ & $0.41 \pm 0.03$ & $0.39 \pm 0.03^{4}$ & $0.41 \pm 0.03$ & $0.41 \pm 0.02$ & $0.41 \pm 0.04$ \\
\hline ECW:ICW & $0.78 \pm 0.14$ & $0.74 \pm 0.11$ & $0.85 \pm 0.15^{4}$ & $0.77 \pm 0.10$ & $0.70 \pm 0.08$ & $0.72 \pm 0.12$ \\
\hline
\end{tabular}

1 Data are expressed as mean \pm SD. BMI: body mass index; FFM: fat-free mass assessed by dual-energy X-ray absorptiometry; Body fat: assessed by dual-energy X-ray absorptiometry; TBW: total body water; ECW: extracellular water; ICW: intracellular water. TBW:FFM, ratio of TBW and FFM; ECW:FFM, ratio of ECW and FFM; ICW:FFM, ratio of ICW and FFM; ECW:ICW, ratio of ECW and ICW.

2.3.4 Significantly different from controls (paired Student's t-tests): ${ }^{2} P<0.01,{ }^{3} P<0.02,{ }^{4} P<0.05$. 
Table 6.4 Body composition of patients with long-standing ( $>10$ years) Crohn's disease (CD-long) compared with age- and sexmatched controls'

\begin{tabular}{|c|c|c|c|c|c|c|}
\hline & \multicolumn{2}{|c|}{ All } & \multicolumn{2}{|c|}{ Females } & \multicolumn{2}{|c|}{ Males } \\
\hline & $\begin{array}{l}\text { CD-long } \\
(n=40)\end{array}$ & $\begin{array}{l}\text { Controls } \\
(n=40)\end{array}$ & $\begin{array}{l}\text { CD-long } \\
(n=23)\end{array}$ & $\begin{array}{l}\text { Controls } \\
(n=23)\end{array}$ & $\begin{array}{l}\text { CD-long } \\
(n=17)\end{array}$ & $\begin{array}{l}\text { Controls } \\
(n=17)\end{array}$ \\
\hline Weight (kg) & $64.8 \pm 12.0$ & $68.9 \pm 12.4$ & $63.3 \pm 11.0$ & $61.2 \pm 7.3$ & $67.0 \pm 13.2^{4}$ & $79.2 \pm 10.2$ \\
\hline Height (m) & $1.69 \pm 0.07$ & $1.69 \pm 0.08$ & $1.65 \pm 0.04$ & $1.65 \pm 0.06$ & $1.75 \pm 0.06$ & $1.74 \pm 0.06$ \\
\hline BMI $\left(\mathrm{kg} / \mathrm{m}^{2}\right)$ & $22.8 \pm 4.0$ & $24.0 \pm 3.3$ & $23.2 \pm 3.8$ & $22.4 \pm 2.2$ & $22.1 \pm 4.1^{3}$ & $26.2 \pm 3.3$ \\
\hline FFM (kg) & $47.1 \pm 8.7^{5}$ & $49.9 \pm 11.0$ & $41.6 \pm 4.5$ & $42.2 \pm 4.3$ & $54.6 \pm 7.4^{5}$ & $60.3 \pm 8.6$ \\
\hline Body fat (kg) & $17.7 \pm 8.7$ & $18.9 \pm 4.9$ & $21.7 \pm 7.4$ & $19.0 \pm 4.5$ & $12.4 \pm 7.0^{3}$ & $18.9 \pm 5.4$ \\
\hline Percentage body fat & $26.7 \pm 10.6$ & $27.7 \pm 6.3$ & $33.4 \pm 7.2$ & $30.7 \pm 4.8$ & $17.5 \pm 6.7^{3}$ & $23.7 \pm 5.8$ \\
\hline TBW:FFM & $0.71 \pm 0.04$ & $0.71 \pm 0.04$ & $0.72 \pm 0.03$ & $0.71 \pm 0.04$ & $0.69 \pm 0.04$ & $0.71 \pm 0.03$ \\
\hline ECW:FFM & $0.31 \pm 0.03$ & $0.31 \pm 0.02$ & $0.33 \pm 0.03^{2}$ & $0.31 \pm 0.02$ & $0.30 \pm 0.03$ & $0.30 \pm 0.03$ \\
\hline ICW:FFM & $0.39 \pm 0.04^{5}$ & $0.41 \pm 0.04$ & $0.39 \pm 0.04$ & $0.40 \pm 0.04$ & $0.40 \pm 0.04$ & $0.41 \pm 0.04$ \\
\hline ECW:ICW & $0.81 \pm 0.14^{5}$ & $0.77 \pm 0.12$ & $0.86 \pm 0.14^{5}$ & $0.80 \pm 0.10$ & $0.75 \pm 0.13$ & $0.72 \pm 0.12$ \\
\hline
\end{tabular}

1 Data are expressed as mean \pm SD. BMI: body mass index; FFM: fat-free mass assessed by dual-energy X-ray absorptiometry; Body fat: assessed by dual-energy X-ray absorptiometry; TBW: total body water; ECW: extracellular water; ICW: intracellular water; TBW:FFM, ratio of TBW and FFM; ECW:FFM, ratio of ECW and FFM; ICW:FFM, ratio of ICW and FFM; ECW:ICW, ratio of ECW and ICW.

$2 \mathrm{P}=0.06$ for difference between $\mathrm{CD}$-long patients and controls.

${ }^{3.5}$ Significantly different from controls (paired Student's t-tests: ${ }^{3} \mathrm{P}<0.01,{ }^{4} \mathrm{P}<0.02,{ }^{5} \mathrm{P}<0.05$. 


\section{Steroid use versus non-steroid use}

Steroid therapy did not significantly influence differences in body hydration or ECW:ICW ratios between patients and controls. Figure 6.1 shows genderspecific values of percentage body fat between patients with steroid or without steroid therapy, respectively, and controls. Females with steroids tended to have a higher percentage body fat compared with controls. In males an opposite trend was observed.
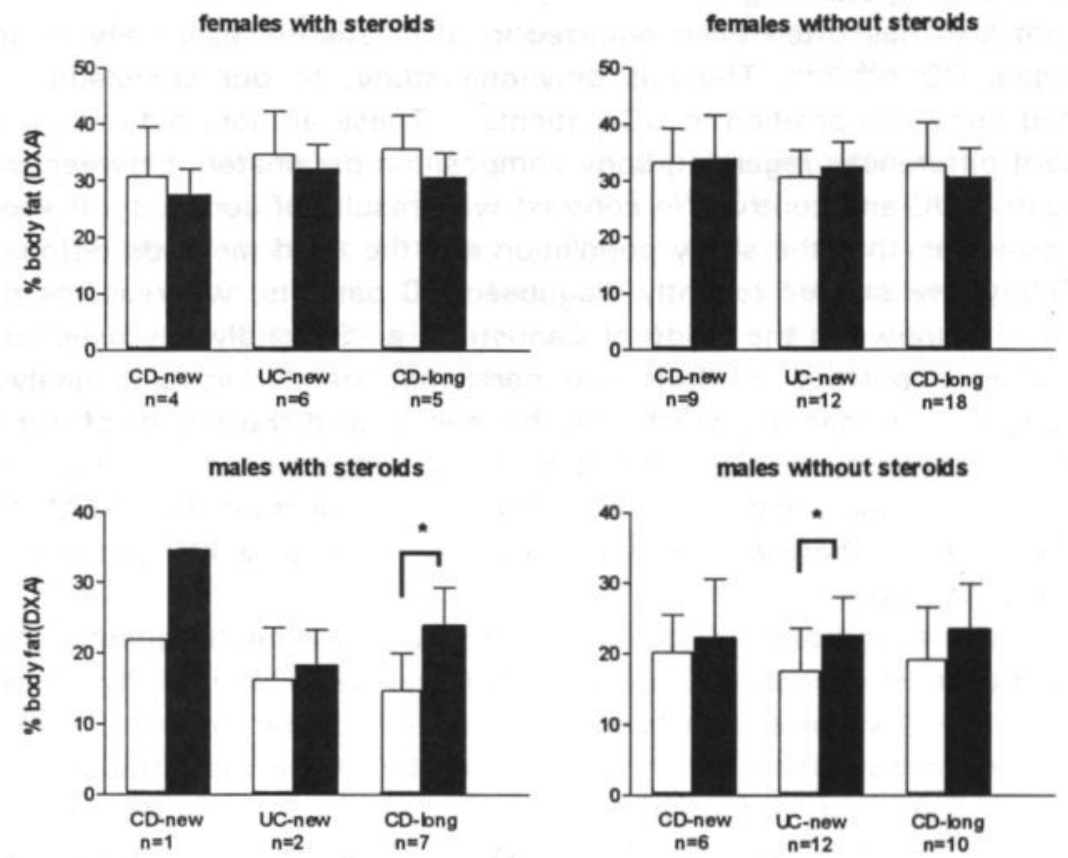

Figure 6.1 Percentage body fat measured by dual-energy $X$-ray absorptiometry (DXA) in patients (open bars) with recently diagnosed Crohn's disease (CD-new), ulcerative colitis (UC-new) and in patients with long-standing $C D$, clinically in remission (CD-long), respectively, compared with controls (solid bars). The total number $(n)$ of patients is shown for each analysis and patients were ageand-sex matched with controls ( $n)$. Data are shown as mean \pm SD, separately for females and males, with and without corticosteroid therapy, respectively. Significance level for differences in \% body fat between patients and controls (paired student t-tests): * $\mathrm{P}<0.05$. 


\section{Discussion}

This study revealed an altered distribution of body water compartments in female IBD patients compared with controls. Fluid shifts were observed in female patients with recently diagnosed $C D$ and $U C$, but also in female patients with long-standing $C D$ compared with controls. In male IBD patients, however, a different alteration in body composition was seen, comprising decreased body fat, BMI and percentage body fat, which was especially pronounced in male patients with long-standing $C D$.

Weight loss has often been reported in IBD patients, especially in patients with active $C D^{7 \cdot 9 \cdot 10,25.26}$. There is only one study, to our knowledge, which evaluated body composition in UC patients ${ }^{10}$. These authors did not show any significant differences regarding body composition parameters between patients with inactive UC and controls, in contrast with results of our study. It should be noted, however, that the study population and the used methods differed from ours. Firstly, we studied recently diagnosed UC patients, whereas the disease duration is unknown in the study of Capristo et al. Secondly, we used age- and sex-matched population controls and performed gender specific analyses of body composition changes which may have increased the power of our study. Thirdly, in the study of Capristo et al body composition was measured by bioelectric impedance with the assumption of a constant TBW/FFM ratio of 0.732 . Our study showed that body hydration of female IBD patients differs from that of controls.

It has been suggested that the decreased body weight, frequently observed in IBD patients, represents a proportionally larger decrease in body fat, sparing $\mathrm{FFM}^{7}$. However, available data about body water compartments of FFM in IBD patients are limited. Measurement of extracellular water and intracellular water may give important information about metabolic changes in chronic inflammatory disorders as chronic inflammation may lead to an expansion of $\mathrm{ECW}^{15}$ and cell shrinkage ${ }^{16}$.

In the present study, all patients were matched with controls according to age and sex, though not to body mass index. If controls would have been matched according to body mass index, this would probably have resulted in over-matching and consequently to a loss of power in our study, as we tried to reveal differences in body composition between patients and controls. Hence, in the present study it is not useful to compare absolute sizes of body compartments between patients and controls. Hence, this may explain the significantly higher absolute size of FFM in CD patients at time of diagnosis, because these patients were significantly taller than controls.

An increased ECW:FFM ratio and ECW:ICW ratio and a decreased ICW:FFM ratio were observed in female IBD patients compared with controls. The fluid shifts were especially pronounced in female patients with recently diagnosed $C D$. The recent acute inflammatory process in these patients could be a determinant of the disturbed body water distribution observed in these patients. 
The absence of an acute phase response in patients with long-standing CD indicated that these patients were clinically in remission. The body composition alterations observed in the latter patients are more likely to be associated with malnutrition per se. It is known that ECW may increase as a consequence of malnutrition ${ }^{27}$. Several nutritional and functional deficiencies have been reported in patients with long-standing $C D$ in remission, although these patients were weight stable and not catabolic ${ }^{11}$. Consequently, the increased ECW:ICW ratio in female patients with long-standing $C D$ in remission may be caused by malnutrition. Dietary intake did not significantly differ between patients and controls $^{11}$. Hence, the body composition alterations of the patients in the present study are probably disease-induced rather than caused by limited food intake $^{28}$.

A few studies have reported fluid shifts in patients with chronic inflammatory disorders. In children with active CD, the ECW:ICW ratio was found to be significantly higher than in controls ${ }^{29}$. The ECW:ICW ratio was significantly decreased to normal values after treatment with either enteral nutrition or prednisone. It should be noted however, that the gender distribution in this study was not equal between patients and controls, which may have influenced the outcome. Baarends et al found a significantly increased ECW:ICW ratio in depleted patients (FFM/height ${ }^{2}<15 \mathrm{~kg} / \mathrm{m}^{2}$ ) with chronic obstructive pulmonary disease (COPD) compared with non-depleted COPD patients ${ }^{30}$. In patients with juvenile rheumatoid arthritis, a significantly higher ECW:ICW ratio was found compared with controls ${ }^{31}$. In this study too, however, gender was not equally distributed between patients and controls. The increased presence of certain cytokines (interleukine-1ß and tumour necrosis factor- $a$ ) was found to be inversely correlated with the amount of FFM in patients with rheumatoid arthritis $^{32}$ and the authors suggested that rheumatoid cachexia is at least partly driven by inflammation.

Flear and Singh suggested that cell membrane function may be changed by disease, which may cause fluid shifts ${ }^{33}$. The pathogenesis of tissue injury in IBD involves an imbalance between increased reactive oxidative compounds production and reduced antioxidant defenses, resulting in oxidative stress ${ }^{34,35}$. Evidence has been presented that inhibition of $\mathrm{Na}^{+}-\mathrm{K}^{+-}-2 \mathrm{Cl}^{-}$cotransport occurs in response to oxidative stress in vascular endothelial cells, which tend to shrink under these circumstances ${ }^{36}$. This cell shrinkage may result in a decreased intracellular hydration of FFM, as we observed in the present study. The results of our study suggests that the increased ECW:ICW ratio found in female IBD patients may predominantly be the result of a decreased intracellular hydration of FFM. It is assumed that the ICW compartment is a constant fraction of $\mathrm{BCM}^{37}$. We did not directly measure $\mathrm{BCM}$, but our data suggests that $\mathrm{BCM}$ - the metabolically active part of the human body-, may be decreased in female IBD patients.

In male patients, we did not observe any significant differences in body water distribution compared with controls. However, body weight, and 
consequently body fat and FFM were significantly lower, except for patients with recently diagnosed $C D$. This latter observation could be due to a $B$-error in the small group studied. The body water distribution of FFM in male patients was not disturbed, as was shown by their normal hydration ratios. The proportionally decreased ECW and ICW compartments may have resulted in a normal ECW:ICW ratio.

Corticosteroids may influence body composition by stimulating food intake ${ }^{26}$, promoting fat deposition ${ }^{38}$, or by reducing energy expenditure ${ }^{26}$. In the present study population, corticosteroid therapy did not significantly influence dietary intake ${ }^{11}$ or body hydration. However, percentage body fat tended to by higher in those females with steroid therapy compared with controls. In males, an opposite trend was observed.

Although small but homogenous patients groups were studied, the observed differences between males and females in the present study are interesting and have not often been described. Medical treatment and disease activity did not differ between males and females. To our knowledge, only one previous study reported gender differences in the change of body water compartments due to inflammation or malnutrition-associated disease ${ }^{30}$. An elevated ECW:ICW ratio was shown in depleted females with COPD compared with non-depleted females, while no such difference was found in males with COPD. Data suggests that there may be gender differences in the efficiency of energy metabolism under metabolic stress. This hypothesis was tested in rats in a study by Cortright et $\mathrm{al}^{9}$ and it was found that daily exercise reduced fat, protein and body mass in male but not in female rats despite a more negative estimated energy balance in female rats. The authors mentioned gender-specific hormonal responses as a possible mechanism for their findings. However, the cause of the altered body water distribution in female patients compared with controls observed in the present study is not yet clear. It should be noted however, that we did not standardise for menstrual cycle. This may have caused an increase in variation (standard deviation) in the results of the females.

In summary, female patients with IBD showed a significantly increased ECW:ICW ratio, and a decreased intracellular hydration of FFM was observed. Fluid shifts were most pronounced in female patients with recently diagnosed $C D$, which suggests that an recent acute inflammatory process, besides malnutrition, could be a major contributing factor to the altered body composition. In male IBD patients, no significant changes in body water distribution were observed. Our findings stress the importance of a comprehensive measurement of body composition in IBD patients, and further studies are warranted to elucidate the observed disease-induced differences in body composition between female and male IBD patients. 


\section{References}

1. Harries AD, Heatley RV. Nutritional disturbances in Crohn's disease. Postgraduate Med J 1983; 59:690-7.

2. Fernández-Bañares F, Abad-Lacruz A, Xiol X, Gine JJ, Dolz C, Cabre E, Esteve M, Gonzalez-Huix F, Gassull MA. Vitamin status in patients with inflammatory bowel disease. Am J Gastroenterol 1989; 84:744-8.

3. Fernández-Bañares $F$, Mingorance $M D$, Esteve $M$, Cabre $E$, Lachica $M$, Abad Lacruz A, Gil A, Boix J, Gassull MA. Serum zinc, copper, and selenium levels in inflammatory bowel disease: effect of total enteral nutrition on trace element status. Am J Gastroenterol 1990; 85:1584-9.

4. Cristie PM, Hill GL. Effect of intravenous nutrition on nutrition and function in acute attacks of inflammatory bowel disease. Gastroenterol 1990; 99:730-6.

5. Stokes MA. Crohn's disease and nutrition. Br J Surg 1992; 79:391-4.

6. Kuroki F, lida M, Tominaga M, Matsumoto T, Hirakawa K, Sugiyama S, Fujishima M. Multiple vitamin status in Crohn's disease. Correlation with disease activity. Dig Dis Sci 1993; 38:1614-8.

7. Royall D, Greenberg GR, Allard JP, Baker JP, Jeejeebhoy KN. Total enteral nutrition support improves body composition of patients with active Crohn's disease. J Parent Enter Nutr 1995; 19:95-9.

8. Teahan K, Pearson M, Smith T, Bjarnason I. Alterations in nutritional status and disease activity during treatment of Crohn's disease with elemental diet. Scand J Gastroenterol 1995; 30:54-60.

9. Zurita VF, Rawls DE, Dyck WP. Nutritional support in inflammatory bowel disease. Dig Dis 1995; 503:92-107.

10. Capristo E, Mingrone G, Addolorato G, Greco AV, Gasbarrini G. Metabolic features in inflammatory bowel disease in a remission phase of the disease activity. J Int Med 1998; 243:339-47.

11. Geerling BJ, Badart-Smook A, Stockbrügger RW, Brummer R-JM. Comprehensive nutritional status in patients with long-standing Crohn's disease in remission. Am J Clin Nutr 1998; 67:919-26.

12. Pace N, Rathbun FN. Studies on body composition III. The body water and chemically combined nitrogen content in relation to fat content. J Biol Chem 1945; 158:685-91.

13. Streat SJ, Beddoe AH, Hill GL. Measurement of body fat and hydration of the fatfree body in health and disease. Metabolism 1985; 34:509-18.

14. Shetty PS. Body composition in malnutrition. In Body composition techniques in health and disease. Davies PSW and Cole TJ, eds. 1995; 71-84. Cambridge, UK: Cambridge University Press.

15. Chrousos GP. The hypothalamic-pituitary-adrenal axis and immune-mediated inflammation. New Eng J Med 1995; 332:1351-62.

16. Haüssinger $D$, Roth $E$, Lang $F$, Gerok W. Cellular hydration state: an important determinant of protein catabolism in health and disease. Lancet 1993; 341:1330-2.

17. Lennard-Jones JE. Classification of inflammatory bowel disease. Scand J Gastroenterol 1989; 24:2S-6S.

18. Best WR, Becktel JM, Singleton W. Rederived values of the eight coefficients of the Crohn's disease activity index (CDAI). Gastroenterol 1979; 77:843-6.

19. Truelove SC, Witts LJ. Cortisone in ulcerative colitis. Br Med J 1955; 29:1047-8.

20. Deurenberg P, Weststrate JA, Seidell JC. Body mass index as a measure of body fatness: age- and sex-specific prediction formulas. Br J Nutr 1991; 65:105-14. 
21. Schoeller DA. Isotope dilution methods. In Obesity. Bjöntröp P, Brodoff BN, eds. 1992; 80-88. Philadelphia: JB Lippincott Company.

22. Miller ME, Cosgriff JM, Forbes GB. Bromide space determination using anionexchange chromatography for measurement of bromide. Am J Clin Nutr 1989; 33:2686-93.

23. Bell EF, Ziegler EE, Forbes GB. Letter to the editor. Pediatr Res 1984; 18:392-3.

24. Mazess RB, Barden HS, Bisek JP, Hanson J. Dual-energy X-ray absorptiometry for total-body and regional bone-mineral and soft-tissue composition. Am J Clin Nutr 1990; 51:1106-12.

25. Kelly DG, Fleming CR. Nutritional considerations in inflammatory bowel diseases. Gastroenterol Clin North Am 1995; 24:597-611.

26. Mingrone G, Benedetti G, Capristo E, De Gaetano A, Virgillo Greco A, Tataranni PA, Gasbarrini G. Twenty-four-hour energy balance in Crohn disease patients: metabolic implications of steroid treatment. Am J Clin Nutr 1998; 67:118-23.

27. Shetty PS. Chronic undernutrition and metabolic adaptation. Proc Nutr Soc 1993; 52:267-84.

28. Kinney JM, Weissman C. Forms of malnutrition in stressed and unstressed patients. Clin Chest Med 1986; 7:19-28.

29. Ascue M, Rashid M, Griffiths A, Pencharz PB. Energy expenditure and body composition in children with Crohn's disease: effect of enteral nutrition and treatment with prednisolone. Gut 1997; 41:203-8.

30. Baarends EM, Schols AMWJ, Marken Lichtenbelt van WD, Wouters EFM. Analysis of body water compartments in relation to tissue depletion in clinically stable patients with chronic obstructive pulmonary disease. Am J Clin Nutr 1997; 65:88-94.

31. Bedogni C, Polito C, Severi S, Manzieri AM, Alessio M, lovene A, Battistini N. Altered body water distribution in subjects with juvenile rheumatoid arthritis and its effects on the measurement of water compartments from bioelectric impedance. Eur J Clin Nutr 1996; 50:335-9.

32. Roubenoff R, Rall LC. Humoral mediation of changing body composition during aging and chronic inflammation. Nutr Rev 1993; 51:1-11.

33. Flear CTG, Singh CM. Hyponatraemia and sick cells. Br J Anaesth 1973; 45:976-94.

34. Grisham MB. Oxidants and free radicals in inflammatory bowel disease. Lancet 1994; 344:859-61.

35. Lih-Brody L, Powell SR, Collier KP, Reddy GM, Cerchia R, Kahn E, Weissman GS, Katz S, Floyd RA, Kinley MJ, Fisher SE, Mullin GE. Increased oxidative stress and decreased antioxidant defences in mucosa of inflammatory bowel disease. Dig Dis Sci 1996; 41:2078-86.

36. Haüssinger D, Lang F, Gerok W. Regulation of cell function by cellular hydration state. Am J Physiol 267 Endocrinol Metab 1994; 30:E343-55.

37. Moore FD, Olesen KH, Mc Murrey JD, Parker HV, Ball MR, Boyden CM. The body cell mass and its supporting environment. Philadelphia USA: WB Saunders, 1963.

38. Chalaw S, Nagel H, Shore S. The hypothalamic-pituitary-adrenal axis in obesity. Obes Res 1995; 4:371-82.

39. Cortright RN, Chandler MP, Lemon PWR, Dicarlo SE. Daily exercise reduces fat, protein and body mass in male but not in female rats. Physiol Behav 1997; 62:105-11. 


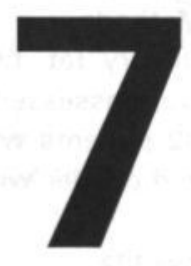

\section{Fat intake and fatty acid} profile in plasma phospholipids and adipose tissue in patients with Crohn's disease compared with controls

Geerling BJ, van Houwelingen AC, Badart-Smook A, Stockbrügger RW, Brummer R-JM 


\section{Abstract}

\section{Background}

Fatty acid metabolism is involved in the immune response and inflammation processes in patients with Crohn's disease (CD). Fatty acid changes may be relevant to the clinical course of the disease. The aim of this study was to compare the qualitative and quantitative fat intake and the fatty acid composition of plasma phospholipids and adipose tissue in a defined population of $C D$ patients with those in matched controls.

\section{Methods}

Dietary fat intake and fatty acid profile of plasma phospholipids and adipose tissue were assessed in two patient populations: 20 patients with recently diagnosed $C D$ and 32 patients with longstanding ( $>10$ years) CD clinically in remission, matched for age and gender with healthy controls.

\section{Results}

We observed no significant differences in quantitative or qualitative fat intake between CD patients and controls. Percentages of linoleic acid and $a$-linolenic acid in plasma phospholipids or adipose tissue were not significantly different between patients and controls. However, we observed a significantly $(P<0.05)$ lower percentage of the sum of the $\mathrm{n}-3$ fatty acids, with significantly $(\mathrm{P}<0.01)$ higher levels of clupanodonic acid $(22: 5 n-3)$ and significantly $(P<0.05)$ lower levels of docosahexaenoic $(22: 6 n-3)$ and arachidonic acid $(20: 4 n-6)$. The aberrant fatty acid profile was more evident in patients with longstanding $C D$ than in patients with recently diagnosed $C D$.

\section{Conclusions}

The aberrant fatty acid profile found in these CD patients is a result of altered metabolism rather than of essential fatty acid malabsorption. The reported findings may be important in the pathophysiology of $C D$ and hence in the choice of fatty acids to be used when therapeutic supplementation is considered in $C D$ patients. 


\section{Introduction}

The fatty acid patterns in plasma and tissue in patients with Crohn's disease (CD) have become the focus of increasing interest, because the long chain polyunsaturated fatty acids (PUFA) are the precursors of eicosanoids, which participate in the regulation of immunological and inflammatory responses ${ }^{1,2}$. Supplementation with n-3 PUFAs, as in fish oil, leads to the production of leukotrienes and prostaglandins with attenuated inflammatory effects ${ }^{3.4}$ in comparison to the leukotrienes and prostaglandins produced from n-6 PUFA. Recently, studies have been conducted on fish oil supplementation in $C D$ patients, but the results are controversial ${ }^{5 \cdot 7}$.

It is known that acute inflammation alters fatty acid metabolism due to increased demands for essential fatty acids (EFA) necessary for tissue repair and membrane formation ${ }^{8}$, which may lead to EFA deficiency. In addition, fat malabsorption in CD could also cause EFA deficiency ${ }^{9}$. Furthermore, studies indicate that malnutrition, which is a common feature in $C D^{10-15}$, and especially zinc deficiency, influence PUFA metabolism ${ }^{8,16,17}$.

Knowledge of fatty acid metabolism in $C D$ patients is limited. There have been a few studies that showed changes in fatty acid profile ${ }^{8,18-24}$. However, results have been equivocal, which may be explained from the use of different methods to analyze fatty acid (FA) composition and assessment in different body compartments. In addition, different CD populations were studied. Most studies did not measure dietary fat intake, although this significantly affects serum FA profile ${ }^{25}$.

More knowledge of tissue FA composition in CD patients may have both pathophysiological and therapeutic implications.

The aim of the present study was to assess the qualitative and quantitative fat intake, as well as the fatty acid composition of plasma phospholipids and adipose tissue, in a defined population of $C D$ patients, compared with those of matched healthy controls. In addition, the relation between changes in fatty acid composition and disease duration was studied by comparing the fatty acid composition of plasma phospholipids and adipose tissue in patients who were recently diagnosed with $C D(<6$ months) and in patients with longstanding $C D$ (>10 years).

\section{Subjects and methods}

The study protocol had been approved by the Ethics Committee of the University Hospital Maastricht and all subjects gave their informed consent before the start of the study. 


\section{Patients}

Characteristics of the patients are shown in Table 7.1. They were recruited from the outpatient population of the Department of Gastroenterology. The diagnosis of $C D$ was based on the criteria of Lennard-Jones ${ }^{26}$. Disease activity was assessed by C-reactive protein (CRP) and according to the Crohn's disease activity index $(\mathrm{CDAl})^{27}$ and the index of van $\mathrm{Hees}^{28}$ at the time of the investigation.

Table 7.1 Characteristics of two Crohn's disease (CD) patient populations'

\begin{tabular}{lcc}
\hline & $\begin{array}{c}\text { CD-new } \\
(\mathbf{n}=20)\end{array}$ & $\begin{array}{c}\text { CD-long } \\
(\mathbf{n}=32)\end{array}$ \\
\hline Gender (F/M) & $13 / 7$ & $18 / 14$ \\
Age (years) & $29.5(23.0-37.5)$ & $40.0(34.3-54.0)$ \\
Colonic involvement & $n=9$ & $n=18$ \\
Small bowel resection & $n=4$ & $n=27$ \\
Disease duration (months) ${ }^{2}$ & $3.0(2.0-3.0)$ & $192(132-228)^{5}$ \\
Total extent of small bowel resection $(\mathrm{cm})^{2}$ & $20.0(14.0-30.0)$ & $75.0(40.0-110.0)$ \\
Lifetime prednisone dose $(\mathrm{g})^{2}$ & $1.5(0.5-1.6)$ & $10.3(4.6-24.6)^{5}$ \\
C-reactive protein (mg/L) ${ }^{2}$ & $9.0(6.0-19.3)$ & $6.0(2.0-9.0)$ \\
CDAl $^{2.3}$ & $99(47-142)$ & $139(86-193)$ \\
van Hees index 2.4 & $145(127-177)$ & $146(127-159)$ \\
Smoking & $n=6$ & $n=22^{5}$ \\
\hline
\end{tabular}

1 CD-new: $C D$ patients diagnosed within 6 months before the study; $C D$-long: patients with longstanding $C D$ ( $>10$ years).

2 Data are expressed as median; 25 th and 75 th percentile in parentheses.

${ }^{3}$ Crohn's disease activity index ${ }^{27}$

${ }^{4}$ According to reference 28

${ }^{5}$ Significantly different from CD-new (Mann-Whitney $U$ test and Chi-square): ${ }^{5} \mathrm{P}<0.01$.

\section{Patients with recently diagnosed $C D$ (CD-new)}

All patients, who were diagnosed with $C D$ with small bowel involvement during the period June 1995-September 1997, were asked to participate in the study. Ninety-one percent agreed to participate. All patients had been diagnosed within 6 months before the study. Twenty patients ( 13 women, 7 men) were included. All patients used medication during the study, including mesalazine $(n=17)$ and low doses (median dose, $2.5 \mathrm{mg}$ ) of corticosteroids $(n=3)$. One patient used a supplement of $2.5 \mathrm{mg}$ folic acid every day and four patients were supplemented with intramuscular vitamin B-12. 


\section{Patients with longstanding $C D$ (CD-long)}

Patients suffering from $C D$ with small bowel involvement for $>10$ years and who were clinically in remission, were consecutively asked to participate in the study during a visit to the outpatient clinic of the Department of Gastroenterology during the period November 1995-May 1996. Thirty-two patients (18 women, 14 men) participated in the study. Median CDAI was 139 for all patients, 127 for females and 173 for males. Fifteen patients $(7$ women, 8 men) scored a CDAl>150, which is regarded as active disease. The high liquid stool frequency of many of the patients, all of whom suffered from ileal dysfunction, may explain the relatively high scores on the CDAI. However, acute-phase protein response did not differ significantly between patients (median CRP, $6 \mathrm{mg} / \mathrm{L}$ ) and controls (median CRP, $2 \mathrm{mg} / \mathrm{L}$ ). All patients had stable body weights during the 3 months before the study. The absence of a significant acute-phase response indicated that these patients were clinically in remission. All patients used medication during the study, including mesalazine $(n=26)$, azathioprine $(n=11)$ and low doses (median dose, $5 \mathrm{mg}$ ) of corticosteroids $(n=13)$. Ten patients used a supplement of $2.5 \mathrm{mg}$ folic acid every day, 22 patients were supplemented with intramuscular vitamin B-12 and two patients used cholestyramine. Two patients had an ileostomy.

\section{Controls}

The controls were randomly selected from a patient population database of general practitioners in the same study region, which is a reliable dynamic sample frame of the Dutch general population. They were selected on the following criteria: age- and sex-matched with $C D$ patients (within 3 years of age) and no history of Crohn's disease. Two healthy control groups, one $(n=20)$ matched with $C D-n e w$ (median age, 29 years; range, 19-53 years) and the other $(n=32)$ matched with CD-long (median age, 39.5 years; range 24-69 years), participated in this study.

\section{Dietary intake}

Dietary intake was assessed using the cross-check dietary history method which is a validated method to assess dietary intake ${ }^{29.30}$. The subjects were visited at home by an experienced dietician and the usual food consumption of the previous month was assessed. During this interview, food quantities were specified in household measures. Usual portion sizes were estimated with the aid of portion size models or pictures of foods; frequently consumed portions of food and common household measures were weighed on a balance with a precision of $0.5 \mathrm{~g}$. In addition, the subjects had previously completed a validated self-administered semiquantitative Food-Frequency Questionnaire (FFQ), which was used as a cross-check of the dietary history ${ }^{31}$. The FFO dealt specifically with the dietary intake of fat and antioxidants over the previous month. All types of food and drink were coded according to the system used by 
the Netherlands Nutrient Databank (NEVO), and subsequently converted into energy and nutrients using the extended computerized version of the Netherlands Food Table ${ }^{32}$.

\section{Plasma phospholipids fatty acid analysis}

After an overnight fast, a venous blood sample $(2 \mathrm{ml})$ was obtained and plasma was stored at $-80^{\circ} \mathrm{C}$ until analysis. A total lipid extract from $100 \mu \mathrm{l}$ plasma was prepared according to the method of Bligh and Dyer, by adding $2 \mathrm{ml}$ methanol and $2 \mathrm{ml}$ chloroform (1:1, vol:vol $)^{33}$. L- $\alpha$-dinonadecanoyl was used as an internal standard. Plasma phospholipid fractions were isolated by solid phase extraction on an aminopropyl-silica column ${ }^{33}$. The plasma phospholipids were saponified and the fatty acids were converted to the corresponding methyl esters by reaction with $14 \%$ boron trifluoride (BF3) in methanol at $100^{\circ} \mathrm{C}$ for one hour ${ }^{35}$, with butylated hydroxytoluene $(50 \mathrm{mg} / \mathrm{L})$ was added as an antioxidant. Temperature-programmed GC-FID (Gas Chromatograph-Flame lonization Detector) on a $50 \mathrm{~m} \times 0.25 \mathrm{~mm}$ CP-Sil $5 \mathrm{CB}, \mathrm{df}=0.12 \mu \mathrm{m}$ column (Chrompack ${ }^{\odot}$, Middelburg, The Netherlands), with $\mathrm{N}_{2}$ as the carrier gas, was used for the analysis of fatty acid methyl esters.

In total, 27 fatty acids were identified, but fatty acids percentages $<0.1 \%$ were not recorded; therefore 20 fatty acids were reported. The following fatty acid combinations were recorded: $\Sigma$ SAFA (sum of all saturated fatty acids),

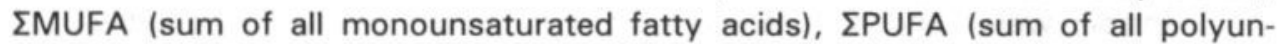
saturated fatty acids), $\Sigma n-6$ (sum of all n- 6 fatty acids), $\Sigma n-6$ LCP (sum of the long chain polyunsaturated fatty acids (LCPs) formed from the parent linoleic acid (18:2n-6) by alternate desaturation and elongation), $\Sigma n-3$ (sum of all n-3 fatty acids), and $\Sigma \mathrm{n}-3$ LCP (sum of the LCPs formed from the parent $a$-linolenic acid (18:3n-6) by alternate desaturation and elongation). In addition, the following indices were calculated: the unsaturation index (UI) which is defined as the sum of the number of double bounds multiplied by the percentage of fatty acids; the saturation index (SI), which is the sum of all saturated fatty acids divided by the unsaturation index; EFA status $\left(\sum n-6+n-3 / \Sigma n-7+n-9\right)^{36}$; EFA deficiency index (EFADI), which is defined as $(20: 3 n-9 / 20: 4 n-6)^{37}$. The amounts of the various fatty acids were expressed as percentages (wt/wt).

\section{Adipose tissue fatty acid analysis}

Adipose tissue biopsies were taken by needle biopsy from the outer quadrant of the buttock and samples were stored at $-80^{\circ} \mathrm{C}$ until analysis ( $<3$ months). Total lipid extracts from the adipose tissue biopsy were prepared according to the method of Bligh and Dyer ${ }^{33}$ by adding methanol and chloroform $11: 1$, vol: vol). The total lipid extract was saponified and the fatty acid were converted to the corresponding methyl esters by reaction with $14 \% \mathrm{BF} 3$ in methanol +0.2 $\mathrm{ml}$ toluene and $0.55 \mathrm{ml}$ methanol at $100^{\circ} \mathrm{C}$ for $30 \mathrm{~min}^{35}$. The fatty acid composition of adipose tissue was analyzed as described earlier for the plasma 
phospholipids. In total, 23 fatty acids were identified, but fatty acids percentages $<0.1 \%$ were not recorded; thus 12 fatty acids were reported. The

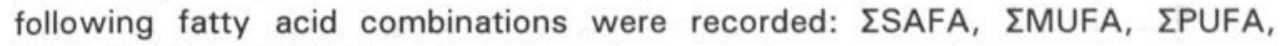
$\Sigma \mathrm{n}-6, \Sigma \mathrm{n}-3$, and EFA status.

\section{Serum zinc}

Zinc was determined by Zeeman-corrected electrothermal atomic absorption spectroscopy.

\section{Statistical analysis}

Results are expressed as median with 25 th and 75 th percentile in parentheses or as stated. Differences between CD patients and matched controls in the fatty acid patterns of plasma phospholipids and adipose tissue or in fat intake were analyzed using a Wilcoxon matched-pairs signed-rank test because variables were not normally distributed. The Mann-Whitney $U$ test was used to test differences in variables between CD-new and CD-long patients. Spearman's correlation coefficients were calculated by linear regression analysis. All statistical analyses were performed with the SPSS 7.0 for Windows package (SPSS Inc, Chicago).

\section{Results}

\section{Fatty acid profile of plasma phospholipids}

Percentages of the various fatty acids in plasma phospholipids in CD patients (CD-new and CD-long) and matched controls are shown in Table 7.2. The saturated fatty acids $22: 0,23: 0$ en $24: 0$ were significantly lower $(P<0.05)$ in CD-long patients than in controls. Of the $n-9$ series, oleic acid $(18: 1 n-9)$ was significantly higher $(P<0.01)$ and arachidonic acid $(20: 4 n-6)$, one of the $n-6$ series, was significantly $(P<0.05)$ lower in $C D$-long patients, compared with controls. Interestingly, CD-long patients showed a higher percentage of clupanodonic (22:5n-3) and a lower percentage of docosahexaenoic acid $(22: 6 n-3)$ in the $n-3$ series compared with controls. $\Sigma$ MUFA and SI were significantly higher, while $\Sigma P U F A, \Sigma n-3, \Sigma n-3 L C P$, UI and EFA status were significantly $(P<0.05)$ lower in $C D$-long patients than in controls. CD-new patients showed a similar trend in fatty acid composition as CD-long patients, though these differences did not reach significance except for the significantly higher SI and significantly lower UI compared with controls ( $\mathrm{P}<0.05)$.

The saturated fatty acids 22:0, 23:0 and 24:0 were significantly lower in CD-long patients compared with $C D$-new $(P<0.05)$. Oleic acid $(18: 1 n-9)$ and mead acid $(20: 3 n-9)$ of the $n-9$ series, and $22: 5 n-3$ of the $n-3$ series showed significantly higher percentages in CD-long patients compared with CD-new $(P<0.05)$. 
Table 7.2 Fatty acid composition of plasma phospholipids (\% of total fatty acids) in two different patient populations with CD (patients with recently diagnosed $C D$ (within 6 months prior to the study), indicated as CD-new, and patients with longstanding (>10 years), indicated as CD-long), compared with matched healthy controls'.

\begin{tabular}{|c|c|c|c|c|}
\hline & CD-new $(n=20)$ & Controls $(\mathbf{n}=20)^{2}$ & CD-long $(n=32)$ & Controls $(n=32)^{3}$ \\
\hline Total $(\mathrm{mg} / \mathrm{L})$ & $1200(997-1300)^{4}$ & $1370(1038-1561)$ & $1150(998-1292)^{5}$ & $1372(1257-1530)$ \\
\hline $16: 0$ & $28.2(26.9-29.1)$ & $28.3(26.6-29.7)$ & $28.4(27.1-29.3)$ & $27.3(26.4-29.3)$ \\
\hline $18: 0$ & $12.2(10.8-13.0)$ & $12.1(11.0-13.4)$ & $12.3(11.8-13.0)$ & $13.0(11.6-13.5)$ \\
\hline 22:0 & $1.67(1.48-1.83)^{6}$ & $1.52(1.40-1.94)$ & $1.47(1.30-1.67)^{4}$ & $1.73(1.45-1.95)$ \\
\hline 23:0 & $0.60(0.52-0.67)^{6}$ & $0.55(0.48-0.63)$ & $0.49(0.40-0.61)^{5}$ & $0.67(0.58-0.74)$ \\
\hline $24: 0$ & $1.29(1.24-1.44)^{6}$ & $1.36(1.15-1.67)$ & $1.19(1.01-1.32)^{5}$ & $1.42(1.29-1.63)$ \\
\hline $16: 1 n-7$ & $0.32(0.27-0.45)$ & $0.43(0.30-0.62)$ & $0.35(0.22-0.51)$ & $0.37(0.25-0.56)$ \\
\hline $18: 1 n-7$ & $1.18(0.99-1.28)$ & $1.19(1.05-1.31)$ & $1.10(1.02-1.33)$ & $1.17(1.06-1.27)$ \\
\hline $18: 1 n-9$ & $7.93(7.25-8.54)^{6}$ & $7.85(6.63-8.55)$ & $8.52(7.89-9.30)^{5}$ & $7.65(6.42-8.57)$ \\
\hline $20: 3 n-9$ & $0.12(0.09-0.16)^{6}$ & $0.16(0.12-0.20)$ & $0.15(0.14-0.18)$ & $0.15(0.13-0.19)$ \\
\hline $18: 2 n-6$ & $21.9(19.9-22.7)$ & $21.7(20.0-24.0)$ & $21.6(19.5-23.7)$ & $21.8(20.3-23.6)$ \\
\hline $20: 2 n-6$ & $0.36(0.31-0.39)$ & $0.38(0.31-0.41)$ & $0.31(0.27-0.37)$ & $0.34(0.32-0.41)$ \\
\hline $20: 3 n-6$ & $3.06(2.64-3.43)$ & $3.10(2.48-3.47)$ & $2.94(2.44-3.62)$ & $2.86(2.50-3.48)$ \\
\hline $20: 4 n-6$ & $9.05(7.16-9.71)$ & $9.49(8.19-10.03)$ & $8.49(7.06-9.91)^{4}$ & $9.13(8.13-10.4)$ \\
\hline $22: 4 n-6$ & $0.33(0.27-0.41)$ & $0.34(0.27-0.39)$ & $0.33(0.25-0.42)$ & $0.31(0.28-0.35)$ \\
\hline $22: 5 n-6$ & $0.26(0.20-0.38)$ & $0.29(0.22-0.34)$ & $0.24(0.19-0.28)$ & $0.26(0.21-0.31)$ \\
\hline $18: 3 n-3$ & $0.23(0.11-0.32)$ & $0.15(0.11-0.23)$ & $0.20(0.11-0.30)$ & $0.18(0.12-0.23)$ \\
\hline $20: 4 n-3$ & $0.14(0.09-0.16)$ & $0.15(0.11-0.19)$ & $0.13(0.11-0.18)$ & $0.14(0.11-0.16)$ \\
\hline $20: 5 n-3$ & $0.60(0.38-0.91)$ & $0.65(0.40-0.74)$ & $0.74(0.58-0.88)$ & $0.65(0.44-0.88)$ \\
\hline $22: 5 n-3$ & $0.80(0.57-0.98)^{7}$ & $0.69(0.57-0.92)$ & $0.95(0.76-1.11)^{5}$ & $0.86(0.69-0.94)$ \\
\hline $22: 6 n-3$ & $2.91(2.29-3.88)$ & $3.09(2.44-3.52)$ & $2.71(2.11-3.06)^{4}$ & $3.00(2.42-3.82)$ \\
\hline
\end{tabular}




\begin{tabular}{|c|c|c|c|c|}
\hline & CD-new $(n=20)$ & Controls $(n=20)^{2}$ & CD-long $(n=32)$ & Controls $(n=32)^{3}$ \\
\hline ESAFA & $46.3(45.2-46.9)$ & $46.3(45.7-46.6)$ & $46.4(45.6-47.1)$ & $46.6(45.7-47.3)$ \\
\hline ¿MUFA & $12.3(11.3-13.1)$ & $12.2(10.3-12.8)$ & $12.3(11.3-13.2)^{5}$ & $11.5(10.3-12.6)$ \\
\hline ¿PUFA & $39.8(38.4-41.1)$ & $40.3(39.3-42.0)$ & $39.9(38.9-40.8)^{5}$ & $40.9(39.7-41.7)$ \\
\hline$\sum n-6$ & $34.9(32.8-36.1)$ & $35.0(34.3-35.8)$ & $34.9(33.1-36.4)$ & $35.1(33.1-36.8)$ \\
\hline$\Sigma n-6 L C P$ & $12.7(10.4-13.9)$ & $12.5(11.8-14.0)$ & $11.8(10.2-13.7)$ & $12.3(10.4-13.7)$ \\
\hline$\sum n-3$ & $4.75(3.97-5.89)$ & $4.80(4.20-6.38)$ & $4.62(4.15-5.36)^{4}$ & $5.15(4.41-7.04)$ \\
\hline En-3LCP & $4.46(3.79-5.79)$ & $4.68(4.01-6.12)$ & $4.43(3.94-5.13)^{4}$ & $4.93(4.13-6.86)$ \\
\hline SI & $0.35(0.33-0.38)^{4}$ & $0.35(0.33-0.36)$ & $0.36(0.34-0.37)^{4}$ & $0.35(0.33-0.36)$ \\
\hline UI & $130(124-136)^{4}$ & $133(130-139)$ & $128(126-135)^{5}$ & $133(131-139)$ \\
\hline EFA index & $3.20(2.94-3.52)$ & $3.29(3.04-3.98)$ & $3.16\left(2.95-3.45^{5}\right.$ & $3.51(3.08-3.98)$ \\
\hline EFADI & $0.01(0.01-0.02)$ & $0.02(0.01-0.02)$ & $0.02(0.02-0.03)$ & $0.02(0.01-0.02)$ \\
\hline
\end{tabular}

1 Data are expressed as median; 25 th and 75 th percentile in parentheses.

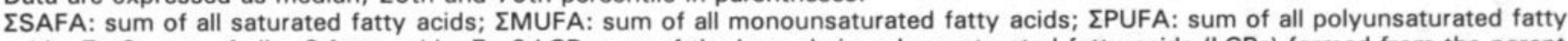
acids; $\Sigma$ n-6: sum of all n-6 fatty acids; $\Sigma$ n-6 LCP: sum of the long chain polyunsaturated fatty acids (LCPs) formed from the parent linoleic acid $(18: 2 n-6)$ through alternate desaturation and elongation; $\Sigma n-3$ : sum of all $n-3$ fatty acids; $\Sigma n-3$ LCP: sum of the LCPs formed from the parent $a$-linolenic acid $(18: 3 n-6)$ through alternate desaturation and elongation; UI: sum of (number of double bounds $X$ percentage of fatty acid)); SI: sum of all saturated fatty acids/ unsaturation index; EFA index (essential fatty acid status): $\Sigma n-6+n-3 / \Sigma n-7+n-9$; EFADI (EFA deficiency index): 20:3n-9/20:4n-6.

2 matched with CD-new.

3 matched with CD-long.

${ }^{4,5}$ Significantly different from controls (Wilcoxon matched-pairs signed-ranktest: ${ }^{4} P<0.05,{ }^{5} \mathrm{P} \leq 0.01$

6.7 Significantly different from CD-long (Mann-Whitney $U$ test): ${ }^{6} P<0.05 ;{ }^{7} P \leq 0.01$. 
Fatty acid profile of adipose tissue

Percentages of the different fatty acids in adipose tissue in CD patients (CDnew and CD-long) and matched controls are shown in Table 7.3. The saturated fatty acid 16:0 was significantly $(P<0.05)$ higher in $C D$-long, whereas dihomo$y$-linolenic $(20: 3 n-6)$ and docosahexaenoic acid $(22: 6 n-3)$ were significantly $(P \leq$ 0.01 ) lower in CD-long patients than in controls.

\section{Fat intake}

Table 7.4 shows the daily qualitative and quantitative fat intake in $C D$ patients (CD-new and CD-long) and matched controls. There were no significant differences in energy intake or fat intake (total fat, saturated fatty acids, monounsaturated fatty acids, polyunsaturated fatty acids or linoleic acid) between $C D$ patients and controls.

\section{Correlations with clinical parameters}

We observed no significant correlation between length of resected small bowel, lifetime prednisone dose, CDAl, van Hees index, or elevated acute-phase response $(C R P \geq 9)$ and fatty acid profile in $C D$ patients (CD-new and $C D$-long).

\section{Zinc and fatty acid profile}

Serum zinc concentration was significantly $(P<0.05)$ lower in $C D$-long patients $(12.0 \mu \mathrm{mol} / \mathrm{L}$ (10.8-13.2)) than in controls $(13.1 \mu \mathrm{mol} / \mathrm{L}$ (12.0-14.2)). We observed no significant differences in serum zinc concentrations between CDnew $(12.4 \mu \mathrm{mol} / \mathrm{L}(11.0-13.2))$ and controls $(13.0 \mu \mathrm{mol} / \mathrm{L}(12.1-14.8))$ $(P=0.08)$. We found no significant correlation between serum zinc and fatty acid profile in $C D$ patients. In addition, $C D$ patients who were considered zinc deficient (serum zinc concentration < reference value of $10 \mu \mathrm{mol} / \mathrm{L}$ ) showed no significantly different fatty acid profile compared with $C D$ patients without zinc deficiency. 
Table 7.3 Fatty acid composition of adipose tissue (\% of total fatty acids) in two different patient populations with $C D$ (patients with recently diagnosed $C D$ (within 6 months prior to the study), indicated as CD-new, and patients with longstanding $(>10$ years) $C D$, indicated as $C D$-long), compared with matched healthy controls'.

\begin{tabular}{|c|c|c|c|c|}
\hline & CD-new $(n=15)$ & Controls $^{2}(n=15)$ & CD-long $(n=28$ ) & Controls $^{3}(n=28)$ \\
\hline $16: 0$ & $19.6(17.3-20.5)$ & $19.1(17.6-20.8)$ & $19.7(18.4-21.7)^{4}$ & $19.1(17.3-19.8)$ \\
\hline $18: 0$ & $3.95(3.46-4.56)$ & $3.27(2.67-4.04)$ & $3.68(3.02-4.49)$ & $3.93(3.30-4.66)$ \\
\hline $16: 1 n-7$ & $4.88(3.77-5.82)^{6}$ & $5.61(4.49-6.84)$ & $5.85(4.85-7.36)$ & $5.49(4.83-6.49)$ \\
\hline $18: 1 n-7$ & $1.91(1.75-2.21)$ & $2.19(1.93-2.32)$ & $2.01(1.70-2.45)$ & $1.93(1.77-2.27)$ \\
\hline $18: 1 n-9$ & $43.5(41.6-45.2)$ & $42.5(41.4-44.0)$ & $43.0(41.9-45.8)$ & $41.9(40.9-44.4)$ \\
\hline $18: 2 n-6$ & $16.1(14.8-16.5)$ & $15.6(13.4-17.6)$ & $15.0(13.1-17.5)$ & $15.7(13.2-18.8)$ \\
\hline $20: 2 n-6$ & $0.20(0.15-0.22)$ & $0.22(0.19-0.24)$ & $0.15(0.13-0.22)$ & $0.21(0.17-0.24)$ \\
\hline $20: 3 n-6$ & $0.16(0.12-0.21)$ & $0.18(0.17-0.22)$ & $0.12(0.10-0.17)^{5}$ & $0.21(0.16-0.26)$ \\
\hline $20: 4 n-6$ & $0.31(0.26-0.39)$ & $0.38(0.31-0.47)$ & $0.33(0.23-0.41)$ & $0.41(0.30-0.47)$ \\
\hline $18: 3 n-3$ & $0.78(0.67-1.06)$ & $0.93(0.74-1.10)$ & $0.68(0.55-0.99)$ & $0.77(0.69-0.97)$ \\
\hline $22: 5 n-3$ & $0.14(0.09-0.18)$ & $0.15(0.12-0.19)$ & $0.19(0.08-0.24)$ & $0.19(0.13-0.23)$ \\
\hline $22: 6 n-3$ & $0.11(0.07-0.19)$ & $0.15(0.10-0.20)$ & $0.11(0.07-0.16)^{5}$ & $0.15(0.12-0.22)$ \\
\hline ¿SAFA & $25.4(22.3-27.7)$ & $24.3(22.6-26.2)$ & $25.9(23.9-29.0)$ & $24.7(22.0-27.3)$ \\
\hline$\Sigma M U F A$ & $53.0(51.5-54.5)$ & $53.5(51.2-55.6)$ & $52.4(49.7-54.4)$ & $52.4(50.4-55.4)$ \\
\hline EPUFA & $18.7(17.6-19.1)$ & $18.5(16.4-21.1)$ & $17.5(15.7-19.8)$ & $18.9(16.1-21.6)$ \\
\hline$\sum n-6$ & $17.1(16.2-17.8)$ & $16.6(14.8-19.1)$ & $15.6(14.0-18.2)$ & $17.1(14.4-20.0)$ \\
\hline$\sum n-3$ & $1.24(0.91-1.32)$ & $1.29(1.16-1.54)$ & $1.16(0.90-1.42)$ & $1.36(1.11-1.48)$ \\
\hline EFA index & $0.34(0.32-0.37)$ & $0.34(0.27-0.39)$ & $0.33(0.27-0.36)$ & $0.35(0.30-0.41)$ \\
\hline
\end{tabular}

Data are expressed as median; 25 th and 75 th percentile in parentheses.

2 Matched with CD-new;

3 Matched with CD-long;

Abbreviations and ${ }^{4-6}$ as in Table 7.2.

\section{Discussion}

In patients with longstanding $C D$, clinically in remission, the sum of the $n-3$ fatty acids was significantly lower than in controls, leading to a lower EFA status. In these patients, however, the percentage of clupanodonic acid $(22: 5 n-3)$, an elongation product of eicosapentaenoic acid, was significantly higher, and the percentage docosahexaenoic acid (22:6n-3) was significantly lower, than in controls. Furthermore, we found a significantly higher percentage of MUFA in patients with longstanding CD, compared with controls. 
Table 7.4 Daily nutrient intake in two different patient populations with CD (patients with recently diagnosed CD (within 6 months prior to the study), indicated as CD-new, and patients with longstanding (>10 years) CD, indicated as CD-long), compared with matched healthy controls ${ }^{1}$

\begin{tabular}{|c|c|c|c|c|}
\hline & $\begin{array}{l}\text { CD-new } \\
(n=20)\end{array}$ & $\begin{array}{l}\text { Controls } \\
(n=20)\end{array}$ & $\begin{array}{l}\text { CD-long } \\
(n=32)\end{array}$ & $\begin{array}{l}\text { Controls } \\
(n=32)\end{array}$ \\
\hline Energy intake (MJ/day) & $11.2(8.5-13.4)$ & $9.9(8.6-13.1)$ & $10.7(8.9-13.2)$ & $9.3(8.4-12.6)$ \\
\hline Total fat $(\%)$ & $34.7(31.6-43.2)$ & $34.8(28.4-40.3)$ & $34.2(30.5-38.7)$ & $34.5(31.8-39.1)$ \\
\hline SAFA $(\%)$ & $12.9(10.4-14.1)$ & $12.4(11.6-14.2)$ & $12.8(11.4-15.7)$ & $13.2(10.8-14.3)$ \\
\hline MUFA $(\%)$ & $13.0(11.1-14.8)$ & $13.0(12.0-15.5)$ & $13.0(10.9-14.9)$ & $12.1(10.5-14.2)$ \\
\hline PUFA $(\%)$ & $5.8(5.0-7.2)$ & $7.1(5.7-8.4)$ & $5.5(4.1-7.4)$ & $6.3(4.2-7.8)$ \\
\hline Linoleic acid $(\%)$ & $4.2(3.7-5.6)$ & $5.3(4.2-6.8)$ & $4.0(2.8-5.7)$ & $4.7(3.1-6.5)$ \\
\hline Protein (\%) & $14.2(12.7-16.3)$ & $14.6(12.6-15.8)$ & $14.1(12.0-16.3)$ & $15.2(13.9-18.3)$ \\
\hline Total carbohydrates $(\%)$ & $51.3(45.6-52.8)^{2}$ & $44.3(38.5-51.7)$ & $48.0(43.4-52.5)$ & $47.4(39.8-52.1)$ \\
\hline Mono and disaccharides ( $\%)$ & $26.1(22.0-29.4)^{2}$ & $19.1(16.4-26.4)$ & $26.1(19.2-29.4)$ & $21.6(18.0-29.2)$ \\
\hline
\end{tabular}

1 Data are expressed as median; 25th and 75th percentile in parentheses.

SAFA: saturated fatty acids; MUFA: monounsaturated fatty acids; PUFA: polyunsaturated fatty acids; $\%$ : $\%$ of total energy intake.

2 Significantly different from controls (Wilcoxon matched-pairs signed-rank test): $P<0.05$. 
A few studies have assessed fatty acids patterns ${ }^{8,18-24,38,39}$ in CD patients. To our knowledge, however, ours is the first matched-control study in CD patients to analyze fatty acid patterns in both plasma phospholipids and in adipose tissue and to include a comprehensive quantitative and qualitative fat intake analysis. Assessment of fat intake is important, as dietary fats are known modulators of fatty acid distribution ${ }^{25}$. We did not observe any significant differences in the quantitative or qualitative daily fat intake between patients with recently diagnosed or longstanding $C D$ and their respective controls. Furthermore, in plasma phospholipids and adipose tissue, the percentages of linoleic acid and $a$ linolenic acid, the precursors of the $n-6$ and $n-3$ fatty acid series, were not significantly different between patients and controls, which suggests that preferential EFA malabsorption did not occur in these patients. Consequently, the aberrant fatty acid profile found in these CD patients must be a result of altered metabolism (i.e., altered hepatic plasma phospholipid metabolism) rather than malabsorption of EFA. It should be noted, however, that quantitative fat malabsorption can not be excluded, because the total fatty acids concentration in plasma phospholipids of CD patients was significantly lower than in controls. In addition, in patients with gross malabsorption of EFA (e.g., in patients with extensive small bowel resection or with active disease), a different fatty acid profile may be found.

The EFA index was found to be significantly lower in patients with longstanding $C D$ than in controls. However, the classic EFA deficiency index (triene/tetraene ratio) was not significantly different between patients and controls. We used the EFA index because the classic EFA deficiency index does not account for changes in $\Delta-5$ desaturase ${ }^{36}$.

We found a significantly lower percentage of docosahexaenoic acid $(22: 6 n-3)$ in patients with longstanding $C D$ in remission. However, Esteve-Comas et al ${ }^{18,19}$ found increased plasma concentrations of $a$-linolenic acid and docosahexaenoic acid in patients with active and nonactive CD. There are several reasons that may explain the observed discrepancy between the studies of Esteve-Comas et al and our study. In the studies of Esteve-Comas et al, the proportions of total (both free and bound) fatty acids in plasma were determined. However, although triacylglycerols, cholesterol esters and free fatty acids all contribute to the plasma total fatty acid profile, the most important quantitative sources of both circulating and membrane PUFA are the phospholipids ${ }^{24}$. We therefore assessed the fatty acid profile in plasma phospholipids. Secondly, the method used by Esteve-Comas et al is less accurate than the method in our study. They used a 30-m column and a fast (short) method for peak separation which probably could not prevent superimposement of fatty acids peaks. Thirdly, dietary fats are known modulators of fatty acid distribution. Esteve-Comas et al did not assess dietary fat intake and could not excluded that the dietary intake of $C D$ patients differed from that of controls (i.e. with respect to fish intake).

A disturbed fatty acid profile was not as evident in the patients with recently diagnosed $C D$ as in the patients with longstanding $C D$. The results indicate that 
disease duration may be an important factor regarding the disturbed fatty acid profile, but steroids use or malnutrition may also affect the fatty acid pattern (as discussed later). It is possible, however, that the results are obscured by the small number of patients with recently diagnosed $C D$, suggesting the possibility of a $\beta$-error.

The aberrant fatty acid profile found in CD patients may be explained by changes in the activities of desaturases or elongation enzymes (Figure 7.1). It is shown that steroid therapy depresses protein synthesis ${ }^{40}$. The significantly higher percentage of clupanodonic acid (22:5n-3) and the lower percentage of docosahexaenoic acid in patients with longstanding CD, compared with controls might be explained by the depression of $\Delta-6$ desaturase due to steroid therapy. The other substrates of $\Delta-6$ desaturase were not significantly different from controls. However, all patients used low doses of steroids in the present study. More research is required to elucidate the effect of steroids on the fatty acid synthesis in CD patients. Another explanation for the observed aberrant fatty acid profile could be that $C D$ patients have a deficiency in one or more peroxisomal enzymes. A decreased peroxisomal $\beta$-oxidation may result in low levels of docosahexaenoic acid, and hence provoke an accumulation of clupanodonic acid ${ }^{41}$.

Nutritional factors may also modify the activity of desaturases. A proteindeficient diet or a carbohydrate-rich diet might cause EFA deficiency as a consequence of decreased desaturases activities ${ }^{42-44}$. However, dietary intake of protein and carbohydrate (except in patients with recently diagnosed CD) did not significantly differ between patients and controls. Zinc plays a role in lipid metabolism, modulating long-chain fatty acid desaturation and elongation ${ }^{45}$. Belluzi et al $^{16}$ showed that zinc supplementation normalized the fatty acid profiles in CD patients. We found significantly lower serum zinc concentrations in patients with longstanding $C D$, but did not find any significant differences in fatty acid patterns between patients with or without zinc deficiency.

Supplementation with n-3 fatty acids has been regarded as beneficial in CD patients, but the results are controversial. Experiments by Dias and Parsons ${ }^{46}$ showed that supplementation with eicosapentaenoic acid in the human intestinal $\mathrm{CaCo}-2$ cell line inhibited both $\Delta-6$ and $\Delta-5$ desaturase activity, resulting in a decrease in arachidonic acid levels. The patients in the present study received no eicosapentaenoic acid supplementation, but the eicosapentaenoic acid content was higher than that in controls, with significantly lower levels of arachidonic acid (20:4n-6). One may hypothesize that these patients develop a mechanism to regulate eicosanoid synthesis in order to remain in remission. It is therefore important to note that any supplementation with fatty acids in CD patients requires a careful choice of $n-3$ fatty acids ${ }^{3}$. In addition, the quantitative balance between the availability of $n-6$ and n-3 fatty acids for metabolism may be of importance.

To summarize, we found no significant differences in quantitative or qualitative fat intake between $C D$ patients and controls. In plasma phospholipids 
and adipose tissue, the proportions of linoleic acid and $\boldsymbol{a}$-linolenic acid were not significantly different between patients and controls. However, we observed a significantly lower percentage of the sum of the $n-3$ fatty acids, with significantly higher levels of $22: 5 n-3$ and significantly lower levels of docosahexaenoic acid, in patients with longstanding $C D$ compared with controls. Consequently, the aberrant EFA profile found in these CD patients is a result of altered metabolism rather than of EFA malabsorption. The reported findings may be important with regard to immune response and inflammation in $C D$ patients. These results could influence the choice of fatty acids when therapeutic supplementation is considered. More research is necessary to improve the understanding of the control of long-chain fatty acid biosynthesis and especially the role of desaturases and elongation enzymes activities in CD.

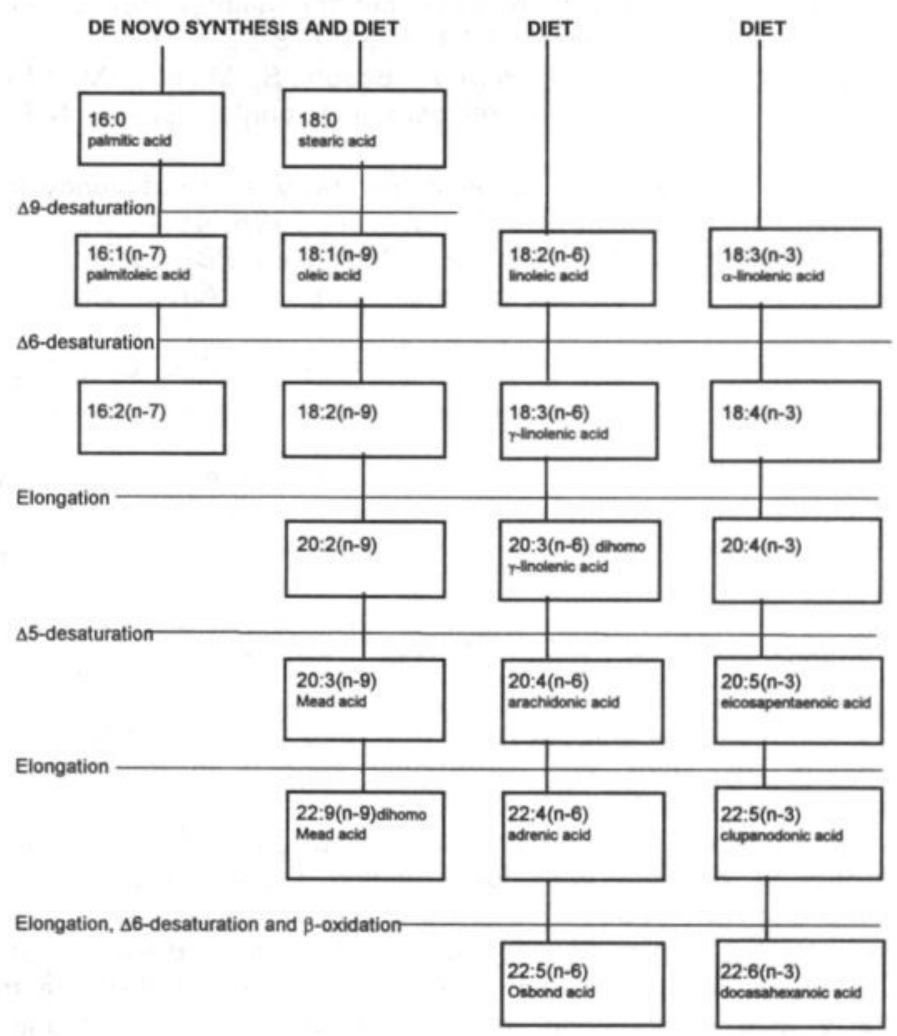

Figure 7.1 The main pathways of fatty acid synthesis and conversion. 


\section{References}

1. Rask-Madsen J. Eicosanoids in inflammatory bowel disease: advances, pitfalls and therapeutic consequences. Eur J Gastroenterol Hepatol 1989; 1:133-65.

2. Lands WEM. Biosynthesis of prostaglandins. Annu Rev Nutr 1991; 11:41-60.

3. Shoda R, Matsueda K, Yamato S, Umeda N. Therapeutic efficiency of n-3 polyunsaturated fatty acid in experimental Crohn's disease. J Gastroenterol 1995; 30:98-101.

4. Campbell JM, Fahey GC, Lichtensteiger CA, Dernichele SJ, Garleb KA. An enteral formula containing fish oil, indigestible oligosaccharides, gum arabic and antioxidants affects plasma and colonic phosholipid fatty acid and prostaglandin profiles in pigs. J Nutr 1997; 127:137-45.

5. Matè J, Castanos J, Garcia-Samaniego S. Does dietary fish oil maintain the remission of Crohn's disease: a study case control. Gastroenterol 1993; 100:A228.

6. Lorenz-Meyer H, Nicolay C, Schulz B, Purrmann J, Fleig WE, Scheurlen C, et al. Omega-3 fatty acids and low carbohydrate diet for maintenance of remission in Crohn's disease. Scand J Gastroenterol 1996; 31:778-85.

7. Belluzi A, Brignola C, Campieri M, Pera A, Boschi S, Migliolo M. Effect of an enteric-coated fish-oil preparation on relapses in Crohn's disease. N Eng J Med 1996; 334:1557-60.

8. Siguel EN, Lerman RH. Prevalence of essential fatty acid deficiency in patients with chronic gastrointestinal disorders. Metabolism 1996; 45:12-23.

9. Jeppesen PB, Christensen MS, Høy CE, Mortensen PB. Essential fatty acid deficiency in patients with severe fat malabsorption. Am J Clin Nutr 1997; 65:837-43.

10. Fernández-Bañares F, Abad-Lacruz A, Xiol X, Gine JJ, Dolz C, Cabré E, et al. Vitamin status in patients with inflammatory bowel disease. Am J Gastroenterol $1989 ; 84: 744-8$.

11. Fernández-Bañares $F$, Mingorance $M D$, Esteve $M$, Cabré $E$, Lachica $M$, AbadLacruz A, et al. Serum zinc, copper, and selenium levels in inflammatory bowel disease: effect of total enteral nutrition on trace element status. Am J Gastroenterol 1990; 85:1584-9.

12. Kuroki F, lida M, Tominaga M, Matsumoto T, Hirakawa K, Sugiyama S, Fujishima M. Multiple vitamin status in Crohn's disease. Correlation with disease activity. Dig Dis Sci 1993; 38:1614-8.

13. Stokes MA. Crohn's disease and nutrition. Br J Surg 1992; 79:391-4.

14. Zurita VF, Rawls DE, Dyck WP. Nutritional support in inflammatory bowel disease. Dig Dis 1995; 503:92-107.

15. Geerling BJ, Badart-Smook A, Stockbrügger RW, Brummer R-JM. Comprehensive nutritional status in patients with longstanding Crohn's disease currently in remission. Am J Clin Nutr 1998; 67:919-26.

16. Belluzi A, Brignola C, Campieri M, Gionchetti P, Rizzello F, Boschi S, et al. Short report: zinc sulphate supplementation corrects abnormal erythrocyte membrane long-chain fatty acid composition in patients with Crohn's disease. Aliment Pharmacol Ther 1994; 8:127-30.

17. Cabré E, Periago JL, Mingorance MD, Fernández-Bañares F, Abad A, Esteve E, et al. Factors related to the plasma fatty acid profile in healthy subjects, with special reference to antioxidant micronutrient status: a multivariate analysis. Am J Clin Nutr $1992 ; 55: 831-7$. 
18. Esteve-Comas M, Ramírez M, Fernández-Bañares F, Abad-Lacruz A, Gil A, Cabré $E$, et al. Plasma polyunsaturated fatty acid pattern in active inflammatory bowel disease. Gut 1992; 33:1365-9.

19. Esteve-Comas M, Nuñez MC, Fernández-Bañares F, Abad-Lacruz A, Gil A, Cabré $E$, et al. Abnormal plasma polyunsaturated fatty acid pattern in non-active inflammatory bowel disease. Gut 1993; 34:1370-3.

20. Johansson C, Walldius G, Rössner S. Fatty acid composition in serum lipids and adipose tissue in patients with morbus Crohn after ileal resection. Digestion 1987: 37:171-7.

21. Färkkilä MA, Tilvis RS, Miettinen TA. Plasma fatty acid composition in patients with ileal dysfunction. Scand J Gastroenterol 1987; 22:411-9.

22. Tribl B, Frotz S, Widhalm F. Serum fatty acid pattern in patients with Crohn's disease. Clin Nutr 1988; 7:80S.

23. Kuroki F, Lida M, Matsumoto T, Aoyadi K, Kanamoto K, Fujishima M. Serum n3 polyunsaturated fatty acid are depleted in Crohn's disease. Dig Dis Sci 1997; 42:1137-41.

24. Pereira, SP, Cassell TB, Engelman JL, Sladen GE, Murphy GM, Dowling H. Plasma arachidonic acid-rich phospholipids in Crohn's disease: response to treatment. Clin Sci 1996; 91:509-12.

25. Bjerve KS, Brubakk AM, Fougner KJ, Johnsen $H$, Midthjell K, Vik T. Omega-3 fatty acids: essential fatty acids with important biological effects, and serum phospholipid fatty acid as markers of dietary w3- fatty acid intake. Am J Clin Nutr 1993; 57:801S-6S.

26. Lennard-Jones JE. Classification of inflammatory bowel disease. Scand J Gastroenterol 1989; 24:2S-6S.

27. Best WR, Becktel JM, Singleton W. Rederived values of the eight coefficients of the Crohn's disease activity index (CDAl). Gastroenterol 1979; 77:843-6.

28. van Hees PA, van Elteren $\mathrm{PH}$, van Lier $\mathrm{HJ}$, van Tongeren $\mathrm{JH}$. An index of inflammatory activity in patients with Crohn's disease. Gut 1980; 21:279-86.

29. Beal VA. The nutritional history in longitudinal reseach. J Am Diet Assoc 1967; 51:426-32.

30. Cameron ME, Staveren van WA. Manual on methodology for food consumption studies. Oxford: Oxford Medical Publications, 1988.

31. Al MDM, Badart-Smook A, v Houwelingen AC, Hasaart THM, Hornstra G. Fat intake of women during normal pregnancy: relationship with maternal and neonatal essential fatty acid status. J Am Coll Nutr 1996; 15:49-55.

32. NEVO Foundation. Dutch food composition table 1989-1990. Voorlichtingsbureau voor de Voeding. The Hague, The Netherlands (in Dutch).

33. Bligh EG, Dyer WJ. A rapid method for total lipid extraction and purification. Can J Biochem Physiol 1959; 37:911-17.

34. Kaluzny MA, Duncan LA, Meritt MV, Epps DE. Rapid separation of lipid classes in high yield and purity using bonded phase columns. J Lipid Res 1985; 26:135-40.

35. Morrison WR, Smith LM. Preparation of fatty acid methyl esters and dimethylacetals from lipids with boron fluoride methanol. J Lipid Res 1964; 5:600-8.

36. Hornstra G. Essential fatty acids, pregnancy and pregnancy complications: a round table discussion. In: Sinclair A, Gibson R, eds. Essential fatty acids and eicosanoids. Invited papers from the third international congress. Champaign (IL): Am Oil Chem Soc 1992; 177-82.

37. Holman RT. The ratio of trienoic:tetraenoic acids in tissue lipids as a measure of essential fatty acid requirement. J Nutr 1960; 70:405-10. 
38. Bühner S, Nagel E, Körber J, Vogelsang H, Linn T, Pichlmayr. Ileal and colonic fatty acid profiles in patients with active Crohn's disease. Gut 1994; 35:1424-28.

39. Esteve-Comas M, Navarro E, Fernandez-Bañares F, Abad-Lacruz A, Gil A, Cabré E, et al. Mucosal fatty acid pattern in inflammatory bowel disease patients. Clin Nutr 1997; 16S:A45.

40. Brenner, RR. Nutritional and hormonal factors influencing desaturation of essential fatty acids. Prog Lipid Res 1981; 20:41-7.

41. De Craemer D, Pauwels M, van den Branden C. Dietary docosahexaenoic acid has little effect on peroxisomes in healthy mice. Lipids 1996; 31:1157-61.

42. Hill EG, Holman RT. Effect of dietary protein level upon essential fatty acid deficiency. J Nutr 1980; 110:1057-60.

43. Tomas ME, Mercuri O, Rodrigo A. Effects of dietary protein and EFA deficiency on liver $\Delta 5, \Delta 6$ and $\Delta 9$ desaturase activities in the early developing rat. J Nutr $1980 ; 110: 595-9$.

44. Wolff JA, Margolis S, Bujdoso-Wolff K, Matusick E, MacLean WC. Plasma and red blood cell fatty acid composition in children with protein-calorie malnutrition. Pediatr Res $1984 ; 18: 162-6$.

45. Clejan S, Castro-Magna M, Collip PJ. Effects of zinc deficiency and castration on fatty acid composition and desaturation in rats. Lipids $1982 ; 17: 129$.

46. Dias VC, Parsons HG. Modulation in $\Delta 9, \Delta 6$, and $\Delta 5$ fatty acid desaturase activity in the human intestinal CaCo-2 cell line. J Lipid Res 1995; 36:552-63. 


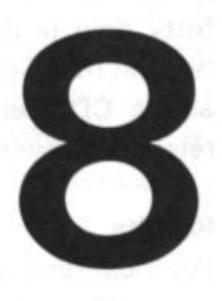

\section{The relation between antioxidant status and alterations in fatty acid profile in patients with Crohn's disease and controls}

Geerling BJ, van Houwelingen AC, Badart-Smook, A, Stockbrügger RW, Brummer R-JM 


\section{Alastases:}

\section{Slatektherand:}

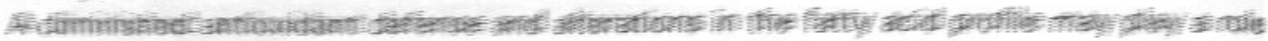

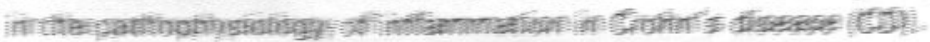

\section{Feteinteand intetilised:}

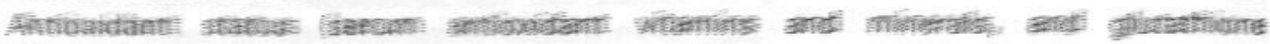

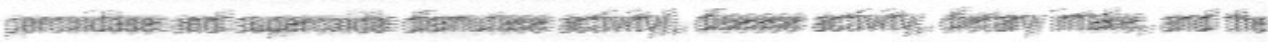

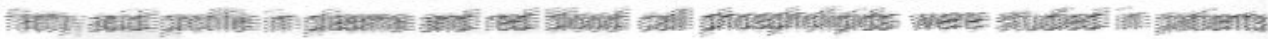

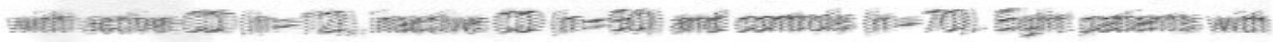

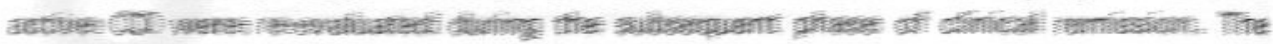

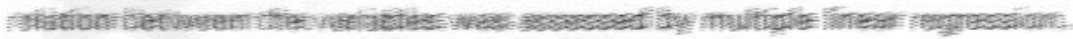

\section{Hesale:}

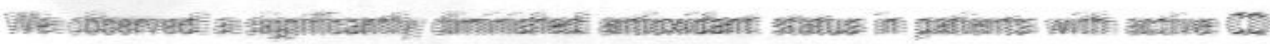

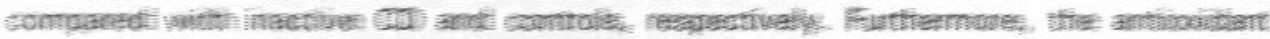

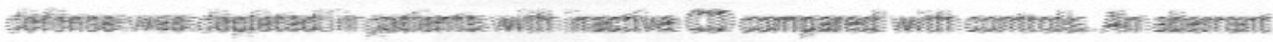

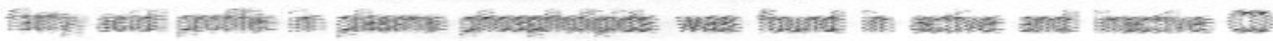

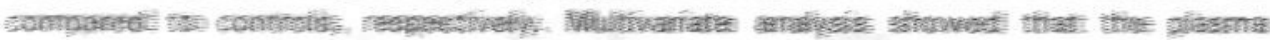

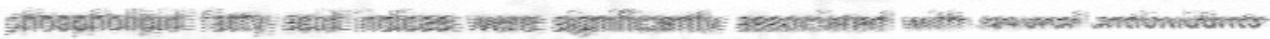
( $\beta$-carotene, vitamin $E$ and glutathione peroxidase) in $C D$ patients, however not in controls.

\section{Conclusion}

The fatty acid profile in $C D$ patients is significantly associated with disease activity and serum antioxidant concentrations. This observation, along with the diminished antioxidant defense in patients with active and inactive $C D$, indicates that antioxidants should be considered in the therapy of inflammation in CD. 


\section{Introduction}

Crohn's disease $(C D)$ is a chronic inflammatory process, which may affect any part of the gastrointestinal tract. The etiology of $C D$ is still unknown, but studies indicate that oxidative stress may be important in its pathogenesis'. Reactive oxygen species (ROS) such as superoxide $\left(\mathrm{O}_{2}{ }^{\circ}\right)$, the hydroxyl radical $\left(\mathrm{OH}^{*}\right)$, hydrogen peroxide $\left(\mathrm{H}_{2} \mathrm{O}_{2}\right)$ and hypocholorous acid $(\mathrm{HOCL})$ are produced in excess by activated neutrophils and monocytes in the circulation and in the inflamed mucosa of patients with Inflammatory Bowel Disease (IBD) ${ }^{1-3}$. Oxidative stress in IBD may result from either excessive activation of radical producing systems (e.g. mucosal phagocytic leukocytes), or from a pro-oxidant effect of tumour necrosis factor- $a$ produced by activated macrophages ${ }^{4,5}$. In these cases, oxidative stress is the consequence of disease activity. However, depletion of endogenous antioxidant defenses may also cause oxidative stress. Several studies have reported reduced antioxidant concentrations in patient groups with active $e^{6-8}$ or inactive $C D^{9-11}$ compared with controls. It is unclear, however, if the antioxidant defense in patients with active $C D$ is significantly different from that in $C D$ patients who are clinically in remission.

Endogenous antioxidant systems and adequate nutritional intake of antioxidants, especially vitamin $E$, vitamin $C$ and selenium, are essential in the control of membrane damage initiated by ROS ${ }^{12}$. Polyunsaturated fatty acids (PUFAs) are the main target of ROS. The fatty acid profile might be influenced by antioxidants because they prevent lipid peroxidation in cell membranes. Consequently, excessive ROS production or a depleted antioxidant defense system leads to lipid peroxidation. PUFAs are also the precursors of eicosanoids, which play an important role in the inflammatory process in $C D$, and may be mediators in its pathophysiology ${ }^{13}$. Several studies have reported an altered fatty acid profile in CD patients ${ }^{14 \cdot 17}$.

Although dietary intake can significantly affect fatty acid profile and serum antioxidant concentrations ${ }^{18}$, most studies on fatty acid profile or antioxidant status in IBD patients did not report dietary intake data.

In healthy subjects, a significant relation between the fatty acid profile and serum antioxidants has been found ${ }^{19}$, but knowledge about the fatty acid profile in relation to antioxidant status and disease activity in $C D$ patients is lacking. The aim of the present study was therefore to assess dietary intake, antioxidant status and the fatty acid profile in plasma, and red blood cell phospholipids in patients with active $C D$ and to compare them with those of $C D$ patients clinically in remission and with population controls. In addition, associations between these variables were determined for both $C D$ patients and controls. 


\section{Subjects and methods}

The study protocol had been approved by the Ethics Committee of the University Hospital Maastricht and all subjects gave their informed consent before the start of the study.

\section{Patients}

The study included $12 \mathrm{CD}$ patients with small bowel involvement who were admitted to the University Hospital of Maastricht, the Netherlands due to an exacerbation of $C D$. Of these, 8 patients were re-evaluated during the subsequent phase of clinical remission. Patients were included in the study before they received high doses of corticosteroids or other medication to suppress the inflammatory process. Characteristics of these 8 patients are shown in Table 8.1. In addition, 50 consecutive patients suffering from CD with small bowel involvement but who were clinically in remission were asked to participate in the study as they visited the outpatient clinic of the Department of Gastroenterology. Characteristics of these patients are shown in Table 8.2. The diagnosis of $C D$ was based on the criteria of Lennard-Jones ${ }^{20}$. Disease activity was assessed using the Van Hees index ${ }^{21}$. In addition, C-reactive protein levels and erythrocyte sedimentation rates (ESR) were determined in all patients.

Table 8.1 Characteristics of patients with Crohn's disease (CD) during an episode of exacerbation and subsequent remission

\begin{tabular}{|c|c|c|c|c|c|c|c|c|c|}
\hline & \multirow[b]{2}{*}{ age } & \multicolumn{4}{|c|}{ Exacerbation } & \multicolumn{4}{|c|}{ Remission } \\
\hline & & $\begin{array}{c}\text { CRP } \\
\text { (mg/L) }\end{array}$ & $\begin{array}{c}\text { ESR } \\
(\mathrm{mm} / \mathrm{h})\end{array}$ & $\begin{array}{c}\text { Van Hees } \\
\text { index }{ }^{1}\end{array}$ & $\begin{array}{c}\text { weight } \\
\text { (kg) }\end{array}$ & $\begin{array}{c}\text { CRP } \\
\text { (mg/L) }\end{array}$ & $\begin{array}{c}\text { ESR } \\
(\mathrm{mm} / \mathrm{h})\end{array}$ & $\begin{array}{c}\text { van Hees } \\
\text { index }\end{array}$ & $\begin{array}{c}\text { weight } \\
\text { (kg) }\end{array}$ \\
\hline pat $1(F)$ & 32 & 25 & 10 & 154 & 72 & 8 & 4 & 126 & 72 \\
\hline pat 2 (F) & 18 & 11 & 15 & 152 & 75 & 7 & 13 & 115 & 84 \\
\hline pat $3(\mathrm{M})$ & 33 & 119 & 32 & 258 & 73 & 8 & 2 & 132 & 85 \\
\hline pat $4(F)$ & 53 & 98 & 47 & 215 & 58 & 6 & 19 & 123 & 60 \\
\hline pat $5(\mathrm{~F})$ & 50 & 218 & 49 & 289 & 62 & 9 & 6 & 130 & 67 \\
\hline pat $6(\mathrm{M})$ & 59 & 33 & 66 & 187 & 66 & 9 & 9 & 140 & 68 \\
\hline pat $7(\mathrm{~F})$ & 33 & 34 & 40 & 160 & 92 & 17 & 11 & 124 & 92 \\
\hline pat $8(F)$ & 40 & 110 & 34 & 169 & 57 & 28 & 11 & 142 & 62 \\
\hline
\end{tabular}

'van Hees index ${ }^{21}$. ESR: erythrocyte sedimentation rate; CRP: C-reactive protein; pat: patient number;

F: female; M: male. Median time between exacerbation and remission was 4.5 months.

\section{Controls}

Seventy volunteers (Table 8.2) were randomly selected from a population database of one general practice ( 3 general practitioners) in the same study region, which is a reliable dynamic sample frame of the Dutch general population. Subjects with a history of CD were excluded. 
Table 8.2 Characteristics of patients with Crohn's disease (CD) and controls

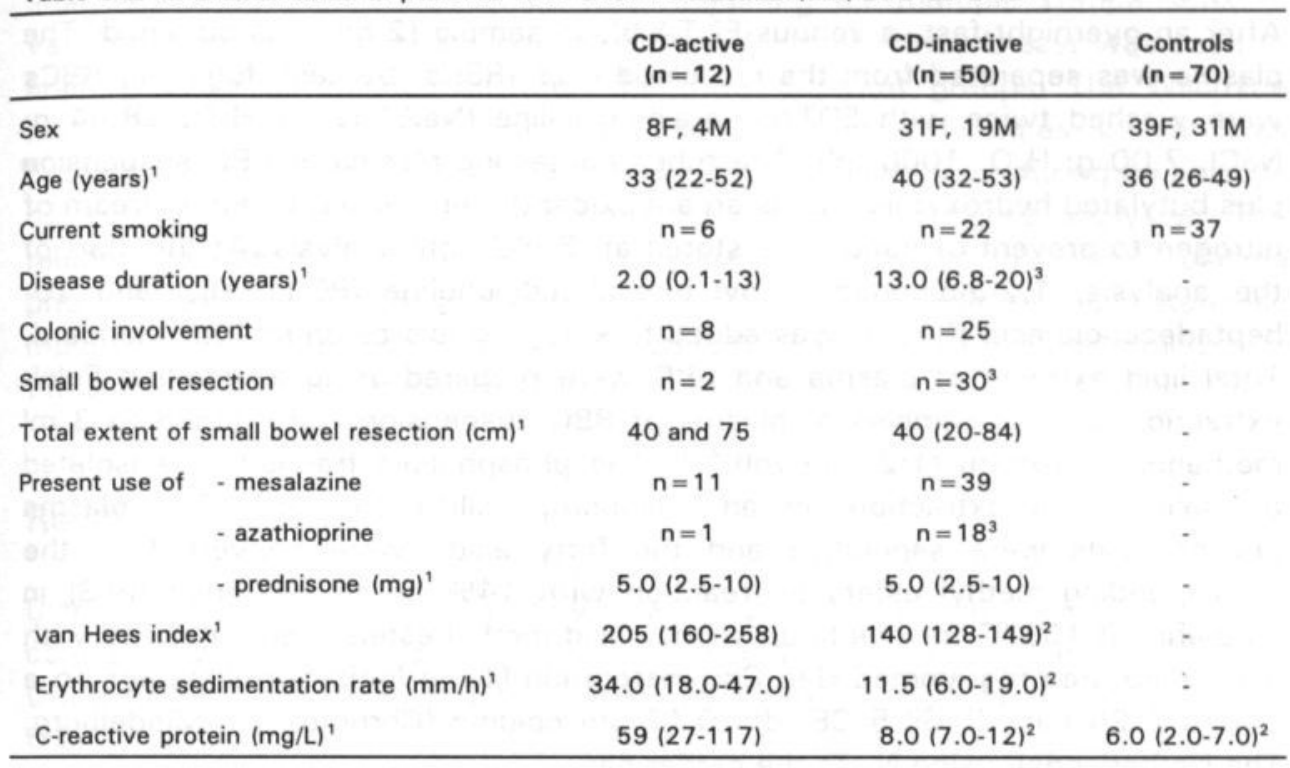

'Data are expressed as median; 25 th and 75 th percentile in parentheses.

${ }^{2,3}$ Significantly different from active $C D$ (Mann-Whitney $U$ test, Chi-square): ${ }^{2} P<0.001,{ }^{3} P<0.05$

\section{Methods}

\section{Antioxidant status}

After an overnight fast, a venous blood sample $(90 \mathrm{ml})$ was obtained and plasma and serum were stored at $-80^{\circ} \mathrm{C}$ until analysis. Antioxidant status was assessed by serum concentrations of B-carotene, copper, vitamin A, vitamin C, vitamin $E$, selenium, zinc, and by enzyme activities in whole blood of glutathione peroxidase $(\mathrm{GpX})$ and superoxide dismutase (SOD). Serum Creactive protein, copper, zinc and selenium were determined by Zeemancorrected electrothermal atomic absorption spectrometry. The assessment of whole blood activity of $\mathrm{GpX}$ was based on the method developed by Paglia and Valentine ${ }^{22}$, while SOD (copper/zinc) activity was assessed using a RANSOD kit (RANDOX Laboratories Ltd., Antrium, United Kingdom). Vitamins A and E ( $a$ tocopherol) were determined with High Pressure Liquid Chromatography (HPLC) and $\beta$-carotene by spectrophotometric assessment at $450 \mathrm{Nm}$. In addition, Total Antioxidant Status (TAS) was measured using the Randox Total Antioxidant Status Kit (RANDOX Laboratories Ltd., Antrium, United Kingdom) in CD patients who were evaluated twice $(n=8)$, during an episode of exacerbation and during subsequent remission. As vitamin $\mathrm{E}$ concentrations have been found to be closely related to fatty acids ${ }^{23}$, the ratio of vitamin $E$ to serum cholesterol concentration was calculated to accurately assess vitamin $E$ status. 


\section{Fatty acid analysis of plasma and red blood cell phospholipids}

After an overnight fast, a venous EDTA blood sample $(2 \mathrm{ml})$ was obtained. The plasma was separated from the red blood cells (RBCs) by centrifugation. RBCs were washed twice with EDTA-containing saline $\left(\mathrm{Na}_{2}\right.$ EDTA. $2 \mathrm{H}_{2} \mathrm{O}, 28.64 \mathrm{~g}$; $\mathrm{NaCl}, 7.00 \mathrm{~g} ; \mathrm{H}_{2} \mathrm{O}, 1000 \mathrm{ml}$ ). The tubes containing plasma or RBC suspension plus butylated hydroxytoluene (as an antioxidant) were closed under a stream of nitrogen to prevent oxidation and stored at $-80^{\circ} \mathrm{C}$ until analysis. At the start of the analysis, 1,2-a-dinonadecanoyl phosphatidylcholine (PC- $\left.(19: 0)_{2}\right)$ and 10heptadecenoic acid (C17:1) was added to every sample as an internal standard. Total lipid extracts of plasma and RBC were prepared using a modified Folch extraction; $200 \mu \mathrm{l}$ samples of plasma or RBC suspension were added to $3 \mathrm{ml}$ methanol-chloroform $(1: 2, \mathrm{vol}: \mathrm{vol})^{24.25}$. The phospholipid fraction was isolated by solid phase extraction on an aminopropyl-silica column ${ }^{26}$. The plasma phospholipids were saponified and the fatty acids were converted to the corresponding methyl esters by reaction with $14 \%$ boron trifluoride (BF3) in methanol at $100^{\circ} \mathrm{C}$ for one hour ${ }^{27}$. Fatty acid methyl esters were analyzed with a temperature-programmed Gas Chromatograph-Flame lonization Detector on a $50 \mathrm{~m} \times 0.25 \mathrm{~mm}$ CP-Sil $5 \mathrm{CB}, \mathrm{df}=0.12 \mu \mathrm{m}$ column $\left(\right.$ Chrompack $^{\oplus}$, Middelburg, The Netherlands), using $\mathrm{N}_{2}$ as the carrier gas.

In total, 27 fatty acids were identified. The following fatty acid combinations were recorded: $\Sigma$ SAFA (sum of all saturated fatty acids), IMUFA (sum of all monounsaturated fatty acids), and EPUFA (sum of all polyunsaturated fatty acids). In addition, the following indices were calculated: the unsaturation index (UI), which is defined as the sum of the number of double bounds multiplied by the percentage of fatty acids; the saturation index (SI), which is the sum of all saturated fatty acids divided by the unsaturation index; EFA status $(\Sigma n-6+n$ $3 / \Sigma n-7+n-9)^{28,29}$. Fatty acids percentages $<0.1 \%$ were not recorded. The amounts of the various fatty acids were expressed as percentages (wt/wt). In controls, fatty acid pattern was assessed only in plasma phospholipids.

\section{Dietary intake}

Dietary intake was assessed using a food-frequency questionnaire (FFQ) ${ }^{30}$. The FFO was specifically developed to assess the dietary intake of fat (total fat, saturated fatty acids (SAFA), mono-unsaturated fatty acids (MUFA), polyunsaturated fatty acids (PUFA), linoleic acid (LA) and antioxidants ( $\beta$ carotene, vitamin $\mathrm{C}$ and zinc) over the previous month. All types of food and drink were coded by an experienced dietician according to the system used by the Netherlands Nutrient Databank (NEVO), and subsequently converted into nutrients by using the extended computerised version of the Netherlands Food $\mathrm{Table}^{31}$. Dietary intake data were not available from control subjects.

\section{Statistical analysis}

Data are expressed as median (25th and 75th percentile) or as indicated. Differences in antioxidant status and fatty acid profile between groups were 
analyzed using the Krusal Wallis test, adjusting for multiple comparisons. If variables showed statistical significance, the Mann-Whitney $U$ test was used to analyze these differences between the three different groups. The Wilcoxon matched-pairs signed-rank test was used to test differences in variables between those $C D$ patients who were investigated twice, i.e., during an episode of exacerbation and after they went into remission (paired analysis). The relations between antioxidant parameters, disease activity and plasma phospholipid fatty acid pattern were multivariately assessed by stepwise multiple linear regression analyses. All statistical analyses were performed with the SPSS 7.0 for Windows package (SPSS Inc, Chicago).

\section{Results}

Disease activity was significantly lower in patients with inactive disease compared with active disease, as was indicated by significantly lower levels of $C$-reactive protein, ESR and the van Hees index $(P<0.001)$ (Tables 8.1 and 8.2).

\section{Antioxidant status}

Serum $\beta$-carotene concentration was significantly $(P<0.02)$ lower, while copper concentration and SOD activity were significantly $(P<0.05)$ higher in patients with active $C D$ compared with patients with inactive $C D$ (Table 8.3). Vitamin A, $\beta$-carotene, vitamin $C$, selenium concentrations and $\mathrm{GpX}$ activity were significantly lower in patients with active disease compared with controls.

In patients with inactive $C D, \beta$-carotene, vitamin $E$, vitamin $C$, zinc, selenium concentrations and the activity of $\mathrm{GpX}$ were significantly $(\mathrm{P}<0.05)$ lower than in controls (Table 8.3).

The paired analysis of $C D$ patients who went into remission after an episode of exacerbation $(n=8)$ is shown in Figure 8.1: copper concentration decreased significantly $(28.5 \mu \mathrm{mol} / \mathrm{L}(22.4-38.8)$ to $21.2 \mu \mathrm{mol} / \mathrm{L}$ (19.6-27.0)), while concentrations of $\beta$-carotene and vitamin $A$ increased significantly after patients went into remission.

We found cholesterol concentrations of $5.0 \mu \mathrm{mol} / \mathrm{L}$ (3.1-5.7), $4.4 \mu \mathrm{mol} / \mathrm{L}$ (3.7$5.1)$, and $5.3 \mu \mathrm{mol} / \mathrm{L}(4.5-6.3)$ in patients with active $C D$, inactive $C D$ and controls, respectively. The ratio of vitamin $E$ to cholesterol was significantly $(P<0.01)$ lower in patients with inactive $C D(6.5 \mu \mathrm{mol} / \mathrm{g}(5.7-7.8))$ compared with controls $(6.0 \mu \mathrm{mol} / \mathrm{g}(5.1-6.8))$, but did not significantly differ between active $C D(6.4 \mu \mathrm{mol} / \mathrm{g}(5.0-9.0))$ and inactive $C D$ or controls, respectively. 


\begin{tabular}{|c|c|c|c|c|c|c|}
\hline & $\begin{array}{c}\text { active CD } \\
(n=12)\end{array}$ & P-value* & $\begin{array}{c}\text { inactive CD } \\
(n=50)\end{array}$ & P-value** & $\begin{array}{l}\text { controls } \\
(n=70)\end{array}$ & P-value*** \\
\hline Vitamin A $(\mu \mathrm{mol} / \mathrm{L})$ & $1.80(1.33-2.48)$ & 0.23 & $2.25(1.80-2.83)$ & 0.11 & $2.40(2.00-3.00)$ & 0.03 \\
\hline$\beta$-Carotene $(\mu \mathrm{mol} / \mathrm{L})$ & $1.04(0.71-1.54)$ & 0.017 & $1.74(1.28-2.45)$ & 0.003 & $2.24(1.80-2.86)$ & 0.000 \\
\hline Vitamin E $(\mu \mathrm{mol} / \mathrm{L})$ & $30.0(25.3-33.5)$ & 0.98 & $29.0(23.8-34.0)$ & 0.05 & $31.0(27.0-38.3)$ & 0.20 \\
\hline Vitamin C $(\mu \mathrm{mol} / \mathrm{L})$ & $23.0(16.0-50.0)$ & 0.07 & $38.0(26.8-57.0)$ & 0.002 & $54.0(40.8-70.0)$ & 0.001 \\
\hline Copper $(\mu \mathrm{mol} / \mathrm{L})$ & $26.2(21.3-38.8)$ & 0.009 & $19.9(17.1-23.7)$ & 0.14 & $18.0(15.1-25.2)$ & 0.007 \\
\hline Zinc $(\mu \mathrm{mol} / \mathrm{L})$ & $10.9(10.3-14.4)$ & 0.57 & $12.4(10.8-13.5)$ & 0.007 & $13.1(12.2-13.9)$ & 0.06 \\
\hline Selenium ( $\mu \mathrm{mol} / \mathrm{L})$ & $0.80(0.69-0.92)$ & 0.20 & $0.87(0.76-1.02)$ & 0.000 & $1.00(0.89-1.12)$ & 0.000 \\
\hline $\mathrm{SOD}(\mathrm{U} / \mathrm{mmol} \mathrm{Hb})$ & $16.9(15.0-20.2)$ & 0.035 & $15.5(13.8-17.3)$ & - & NR & - \\
\hline $\mathrm{GpX}(\mathrm{U} / \mathrm{mmol} \mathrm{Hb})$ & $746(658-1012)$ & 0.45 & 815 (707-945) & 0.002 & 972 (784-1163) & 0.02 \\
\hline
\end{tabular}

1 Data are expressed as median; 25 th-75th percentiles in parentheses.

SOD: superoxide dismutase; GpX: glutathione peroxidase; Hb: hemoglobin; NR: not assessed.

P-value*: significance levels for difference in antioxidant parameters between CD patients with active disease and those

with inactive disease (Mann-Whitney $U$ test); $P$-value ${ }^{* *}$ : inactive $C D$ patients compared with controls; $P$-value ${ }^{* * *}$ : active CD patients compared with controls. 

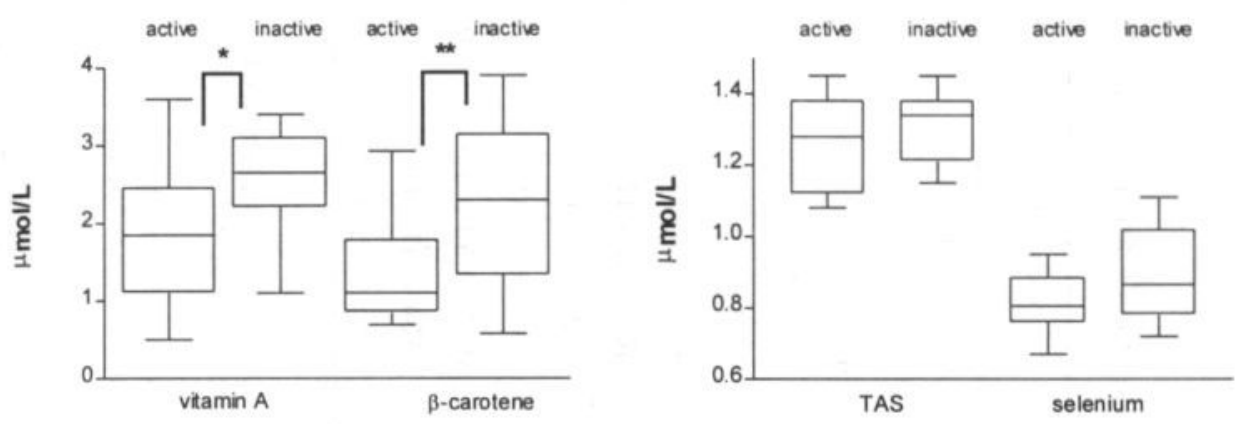

Figure 8.1 Serum antioxidant parameters in $C D$ patients $(n=8)$ during an episode of exacerbation (active) and during subsequent remission (inactive); TAS (total antioxidant status) was assessed using the Randox Total Antioxidant Status Kit (RANDOX Laboratories Ltd., Antrium, United Kingdom).

Fatty acid profile of plasma phospholipids

Plasma phospholipid fatty acid profile in patients with active CD significantly differed from that of patients with inactive CD and controls (Table 8.4). ¿SAFA and the $\mathrm{SI}$ were significantly $(P<0.01)$ higher in patients with active $C D$ compared with inactive disease and controls. Linoleic acid (18:2n-6), ¿PUFA, $\mathrm{UI}$, and EFA index were significantly $(P<0.05)$ lower in patients with active $C D$ compared to inactive $C D$ and controls.

In patients with inactive $C D$, SSAFA and SI were significantly higher, while arachidonic acid $(20: 4 n-6), a$-linolenic acid $(18: 3 n-3), U I$ and EFA index were significantly lower than in controls.

The paired analysis in CD patients who went into remission after an episode of exacerbation $(n=8)$ showed a trend similar (Table 8.5) to the results of the comparison between active and inactive $C D$ patients.

The multiple linear regression equations obtained to predict the values of different fatty acids indices of plasma phospholipids in CD patients are shown in Table 8.6. After adjusting for the linear effects of all the serum antioxidants, serum $\beta$-carotene and vitamin $E$ concentrations and $\mathrm{GpX}$ activity were significantly correlated with EPUFA and EFA status, respectively. However, serum $\beta$-carotene and vitamin $E$ concentrations were inversely related to IMUFA. Furthermore, disease activity measured by CRP levels, and age were inversely related to $\Sigma$ PUFA and $\Sigma$ SAFA, respectively. 
Table 8.4 Fatty acid profile of plasma phospholipids (\% of total fatty acidis) of patients with active Erehn's disease (CP). inactive $C D$ and controls

\begin{tabular}{|c|c|c|c|c|c|c|}
\hline & $\begin{array}{c}\text { active } C D \\
(n=10)\end{array}$ & P-value* & $\begin{array}{c}\text { inactive } C D \\
\quad(n=49)\end{array}$ & P-valuen: : & $\begin{array}{c}\text { eqatrols } \\
n=70\end{array}$ & P.yalue " " * \\
\hline Total lipid (mg/L) & $1377(1106-1614)$ & 0.27 & $1255(1064-1396)$ & 0.06 & $1336(1160-1477)$ & 0.89 \\
\hline $18: 2 n-6$ & $20.4(18.0-22.3)$ & 0.007 & $23.2(20.8-25.4)$ & 0.19 & $21.8(20.5-23.6)$ & 0.02 \\
\hline $20: 4 n-6$ & $8.79(8.07-9.06)$ & 0.36 & $8.17(7.11-9.28)$ & 0.001 & $9.17(9.05-19.95)$ & 9.2. 24 \\
\hline $18: 3 n-3$ & $0.16(0.14-0.27)$ & 0.60 & $0.19(0.14-0.26)$ & 9.04 & $0.1610 .12-0.231$ & 9.59 \\
\hline $20: 5 n-3$ & $0.46(0.34-0.62)$ & 0.06 & $0.62(0.45-0.92)$ & 0.34 & $0.5610 .43-0.781$ & Q. 11 \\
\hline $22: 6 n-3$ & $2.70(1.70-3.22)$ & 0.82 & $2.56(2.16-3.25)$ & 0.006 & $3.11(2.48-3.86)$ & 0.13 \\
\hline ¿SAFA & $49.0(47.7-50.2)$ & 0.003 & $47.2(46.4-47,6)$ & 0,007 & $46.5,(45.8-47.2)$ & Q.000 \\
\hline ¿MUFA & $11.6(11.1-13.1)$ & 0.09 & $11.2(10.4 \times 12.1)$ & 0.50 & $11.5(10.5-12.5)$ & 0.26 \\
\hline EPUFA & $37.6(36.6-39.1)$ & 0.001 & $40.3(39.2 .41 .5)$ & 0.17 & $40.8(39.9-41,7)$ & 0.000 \\
\hline SI & $0.40(0.38-0.43)$ & 0.003 & $0.37(0.35-0.38)$ & 0.000 & $0.3510 .33 \cdot 0.361$ & 0,000 \\
\hline UI & $121(117-125)$ & 0.02 & $129(123-133)$ & 0,000 & $134(131=149)$ & 0.000 \\
\hline EFA index & $3.17(2.74-3.42)$ & 0.02 & $3.52(3.22 \times 3.93)$ & 0.90 & $3.49(3,13-9,94)$ & 0.02 \\
\hline
\end{tabular}

1 Data are expressed as median; 25 th-75th percentiles in parentheses.

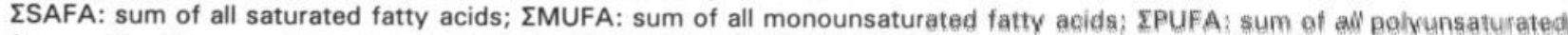
fatty acids; UI: sum of (number of double bounds $X$ percentage of fatty acid)); Si: sum of all saturated fatty acids.

unsaturation index; EFA index (essential fatty acid status): $\Sigma n-6+n-3 / \Sigma n-7+n=9$.

P-value*: significance levels for difference in antioxidant parameters between CD patients with active disease and thase

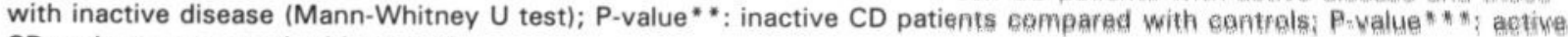
CD patients compared with controls. 
Table 8.5 Fatty acid profile of plasma phospholipids (\% of total fatty acids) of patients during an episode of exacerbation of Crohn's disease (CD) and subsequent remission'

\begin{tabular}{lcc}
\hline & Exacerbation $(\mathbf{n}=8)$ & Remission $(\mathbf{n}=8)$ \\
\hline Total lipid $(\mathrm{mg} / \mathrm{L})$ & $1343(1146-1499)$ & $1202(1170-1453)$ \\
$18: 2 \mathrm{n}-6$ & $20.7(18.8-22.7)$ & $23.1(22.5-25.6)$ \\
$20: 4 n-6$ & $8.41(7.61-8.99)$ & $7.57(6.98-9.80)$ \\
$18: 3 n-3$ & $0.16(0.15-0.50)$ & $0.22(0.16-0.32)$ \\
$20: 5 n-3$ & $0.37(0.33-0.50)$ & $0.65(0.40-0.81)$ \\
$22: 6 n-3$ & $2.96(2.38-3.21)$ & $2.87(2.56-3.08)$ \\
$\Sigma S A F A$ & $49.2(48.1-50.5)^{2}$ & $46.5(45.7-48.6)$ \\
$\Sigma M U F A$ & $11.6(11.2-13.0)^{2}$ & $11.2(10.5-11.8)$ \\
SPUFA & $37.7(35.7-39.1)$ & $39.8(38.2-41.8)$ \\
SI & $0.40(0.39-0.44)^{2}$ & $0.37(0.35-0.40)$ \\
UI & $120(114-123)$ & $129(118-132)$ \\
EFA index & $3.23(2.76-3.38)$ & $3.53(3.22-3.93)$ \\
\hline
\end{tabular}

' Data are expressed as median; 25th-75th percentiles in parentheses.

Abbreviarions as in Table 8.4.

${ }^{2} \mathrm{P}=0.07$ for difference between exacerbation and remission (Wilcoxon matched-pairs signedrank test).

Table 8.6 Summary of multiple regression equations assessed in patients with Crohn's disease

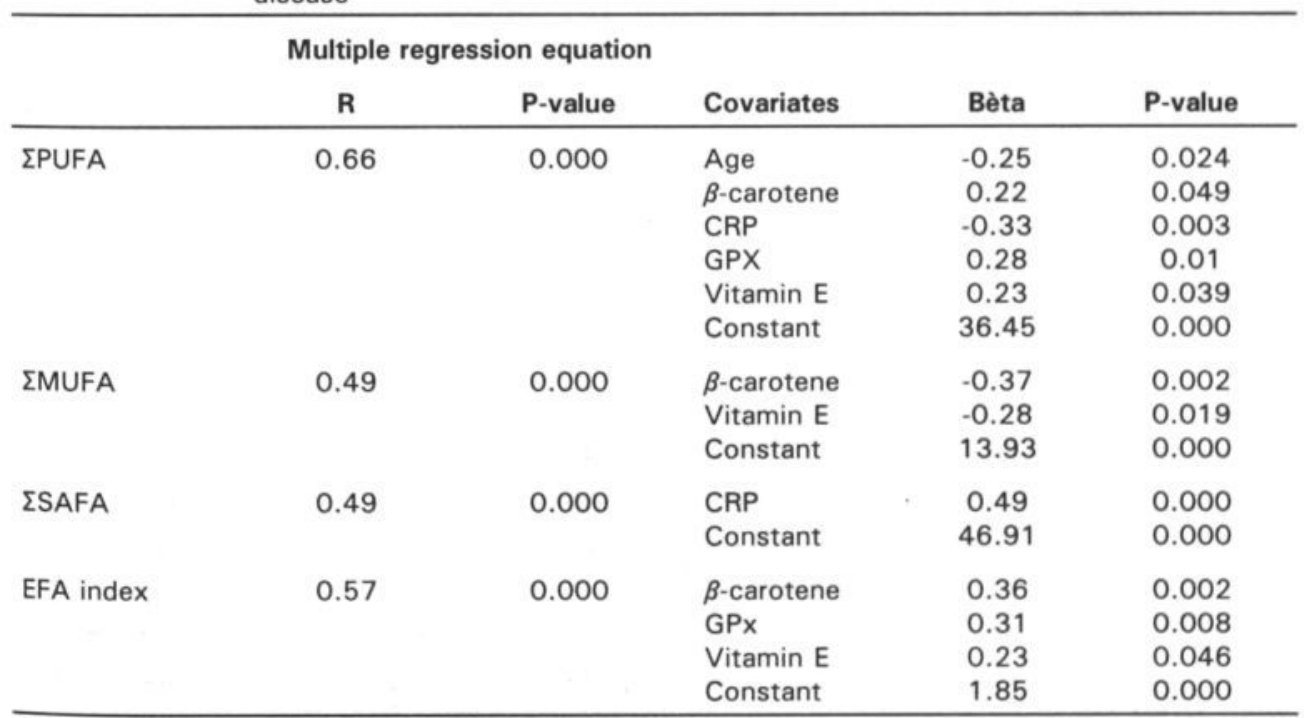

ISAFA: sum of all saturated fatty acids; IMUFA: sum of all monounsaturated fatty acids; IPUFA: sum of all polyunsaturated fatty acids; EFA index (essential fatty acid status): $\Sigma n-6+n$ $3 / \Sigma n-7+n-9$; CRP: C-reactive protein; GpX: glutathione peroxidase. 
In controls, the multiple linear regression analysis did not show any significant correlations between antioxidant concentrations and fatty acid pattern.

\section{Fatty acid profile of red blood cell phospholipids}

We did not observe any significant differences in the fatty acid profile in red blood cell phospholipids. However, a trend similar to that for plasma phospholipids was found between patients with active and inactive $C D$. In particular, linoleic acid and the EFA index were lower $(P=0.08)$ in active $C D$ (11.3 (10.5-11.8); 1.60 (1.50-1.67), respectively) compared with inactive CD (12.9 (11.9-13.4); $1.82(1.50-1.91)$, respectively) and the sum of MUFA was higher $(P=0.08)$ in active $C D(20.1(19.2-21.1)$ than in inactive $C D(19.0$ (18.4-20.5)).

\section{Dietary intake}

We did not observe any significant differences in dietary intake between patients with active and inactive CD (Table 8.7).

In 6 CD patients, dietary intake data were available during an exacerbation of $C D$ and subsequent remission. The absolute intake of total fat, SAFA, MUFA, and PUFA did not significantly differ between patients with an exacerbation and subsequent remission; total fat intake $69.8 \mathrm{~g}$ (59.4-101) during exacerbation and $100 \mathrm{~g}(67.6-142)$ during remission; SAFA intake $25.7 \mathrm{~g}(19.9-43.6)$ and $35.8 \mathrm{~g}$ (20.9-48.6); MUFA intake $26.0 \mathrm{~g}$ (21.1-33.9) and $39.5 \mathrm{~g}$ (26.4-63.6); PUFA intake $14.6 \mathrm{~g}(11.4-17.6)$ and $18.7 \mathrm{~g}(11.4-28.8)$, respectively.

Table 8.7 Dietary intake of patients with Crohn's disease (CD) ${ }^{1}$

\begin{tabular}{lcc}
\hline & $\begin{array}{c}\text { patients with active CD } \\
(\mathbf{n}=10)\end{array}$ & $\begin{array}{c}\text { patients with inactive CD } \\
(\mathbf{n}=45)\end{array}$ \\
\hline Total fat (g) & $79.7(60.1-96.8)$ & $97(74.8-124)$ \\
SAFA (g) & $30.5(20.2-39.8)$ & $35.9(27.8-47.4)$ \\
MUFA (g) & $30.0(21.5-35.4)$ & $35.1(28.2-48.1)$ \\
PUFA (g) & $12.8(11.7-18.2)$ & $17.5(12.2-22.4)$ \\
Linoleic acid (g) & $9.8(8.7-14.8)$ & $13.3(9.0-19.4)$ \\
$\beta$-Carotene (mg) & $0.52(0.32-0.86)$ & $0.50(0.34-0.75)$ \\
Vitamin C (mg) & $58.1(22.3-89.9)$ & $59.1(35.2-104)$ \\
Zinc (mg) & $8.5(7.3-9.6)$ & $8.8(7.2-10.9)$ \\
\hline
\end{tabular}

' Data are expressed as median; 25 th-75th percentiles in parentheses. SAFA: saturated fatty acids; MUFA: monounsaturated fatty acids; PUFA: polyunsaturated fatty acids. 


\section{Discussion}

The present study revealed a diminished antioxidant defense in patients with active $C D$ compared with $C D$ patients who were clinically in remission. The plasma phospholipid fatty acid profile differed significantly between patients with active compared with inactive disease, as was illustrated by the increased sum of the saturated fatty acids, the decreased sum of the unsaturated fatty acids and the decreased EFA status in the former group. A similar trend of changes in antioxidant defense and fatty acid profile was observed for $C D$ patients during exacerbation and subsequent remission. Furthermore, serum concentrations of several antioxidant parameters as well as disease activity were significantly correlated to the plasma phospholipid fatty acid profile in $C D$ patients.

The observed lower concentrations of antioxidants in patients with active $C D$ could be explained by a reduced dietary intake, resulting from postprandial abdominal pain ${ }^{32,33}$. In the present study, however, the dietary intake of antioxidants did not differ significantly between active and inactive CD patients, which may be due to the small group studied ( $\beta$-error). In addition, in these patients, the dietary intake of the previous month was assessed by a food frequency questionnaire. Patients were studied in an early phase of the exacerbation and hence the 48-hr recall method would be more appropriate to assess the dietary intake in these patients ${ }^{34}$. In a previous study we showed that the intake of antioxidants did not significantly differ between $C D$ patients clinically in remission and controls ${ }^{11}$. Besides impaired absorption of nutrients in $C D$ (small bowel resection and/or mucosal damage) ${ }^{35}$, intraluminal factors may also play a role in the decreased absorption of antioxidants. Divalent cations such as magnesium, selenium, or zinc may form unabsorbable subcomplexes with malabsorbed fats ${ }^{36}$.

An important factor in the diminished antioxidant defense in active $C D$ patients compared with $C D$ patients with inactive disease may be the increased utilisation of antioxidants because of increased oxidative stress. The present study confirmed that the antioxidant status is significantly lower in patients with active $C D$ and even in $C D$ patients who were clinically in remission compared with controls ${ }^{6-11}$. It could be argued that low levels of endogenous antioxidants which are found in patients with inactive $C D$, may increase oxidative damage and possibly promote inflammation. Under normal circumstances, the production of reactive oxidative species (ROS) and the antioxidant defense are in balance. Excess ROS production may overwhelm the endogenous antioxidant defense system, particularly in the presence of an antioxidant deficiency.

Maintaining an adequate antioxidant status has been suggested as a useful approach to attenuate the cellular injury and dysfunction observed in CD. Antioxidant administration has been successful in experimental models of intestinal inflammation ${ }^{37,38}$. In a recent study, it was shown that antioxidants 
inhibit in vitro production of inflammatory cytokines in IBD patients ${ }^{39}$. We recently showed that antioxidant status was significantly improved in patients receiving antioxidant supplementation for three months in addition to their regular $\operatorname{diet}^{40}$. It remains to be determined whether antioxidant supplementation will have any effect on the course of the disease in CD patients.

In the present study, SOD activity in whole blood was significantly increased in patients with active CD compared with inactive disease. One other study also found increased activity of SOD in patients receiving lipid-based home parenteral nutrition ${ }^{41}$. SOD can be induced rapidly after exposure to oxidative stress, such as lipid peroxidation. Other studies have found reduced levels of SOD and copper in inflamed intestinal tissue from IBD patients ${ }^{42,43}$. Copper and zinc are co-factors for the intracellular cytosolic copper-zinc SOD enzyme. It has been shown that copper deficiency reduces the activity of SOD in the liver and the lung $^{44}$. The increased serum copper concentration observed in CD patients with active disease in our study may be explained by the increased production of the acute-phase protein ceruloplasmin ${ }^{45}$. However, this could not explain the higher SOD activity, as ceruloplasmin is found in blood plasma and extracellular fluids and is not part of the exchangeable copper plasma pool. The increased SOD activity in these patients, in the presence of sufficient copper, may be caused by increased requirements due to oxidative stress related to inflammation.

In a previous study we reported an aberrant fatty acid profile in CD patients who were clinically in remission, and showed that the disturbed fatty acid pattern was a result of altered metabolism rather than of essential fatty acid malabsorption ${ }^{46}$. The results of the present study confirmed these findings and showed that the fatty acid pattern was even more disturbed in patients with active $C D$ than in inactive $C D$ patients compared to controls.

Conditions of oxidative stress may accelerate the consumption of PUFAs, which are the main target of lipid peroxidation ${ }^{47}$. It has been suggested that the presence of antioxidants might influence fatty acid composition because they prevent lipid peroxidation in cell membranes ${ }^{19}$. In the multivariate analysis, we did indeed find significant correlations between fatty acid indices in plasma phospholipids and several antioxidants in CD patients, however, not in controls. In the patients, the sum of PUFA was significantly related to the concentrations of $\beta$-carotene, vitamin $E$ and the activity of the enzyme glutathione peroxidase, which are all essential in the control of membrane damage initiated by free radicals $^{12}$.

Vitamin $E$ and $\beta$-carotene concentrations were inversely related to the sum of MUFA in plasma phospholipids. It has been hypothesized that patients with essential fatty acid deficiency compensate by producing more MUFAs ${ }^{17}$, which means that essential fatty acids are substituted by MUFAs in an attempt to maintain membrane fluidity. In the present study, patients with active CD showed a significantly lower essential fatty acid status compared with inactive disease and controls. This observation along with the above hypothesis may explain the inverse relation between antioxidants and MUFA. 
Selenium was not found to be associated with the fatty acid pattern in $C D$ patients. In a study of healthy subjects, however, selenium was significantly related to the percentages of EFA and $n-6 P U F A^{19}$. The significant number of subjects with marginal selenium status may explain the discriminant role of selenium in that study. Serum selenium concentrations of CD patients in the present study, including patients with active $C D$, as well as the selenium concentrations reported in another Dutch study on antioxidants and cardiovascular mortality ${ }^{48}$, were higher than those in the healthy subjects in the study by Cabré et al $^{19}$. It is also known, that antioxidant defenses are highly interactive; vitamin $\mathrm{E}$, vitamin $\mathrm{C}$ and glutathione are integral components of a regenerating redox cycle $^{49}$. Selenium is a co-factor for the enzyme glutathione peroxidase and is of major importance in the overall mechanism protecting against oxidative stress ${ }^{12}$. A change in any of these antioxidants may be counter-balanced by alterations in the others. The multivariate regression analysis used in the present study showed the individual antioxidants which may contribute to the aberrant fatty acid profile in $C D$ patients.

In a study by Esteve-Comas et $\mathrm{al}^{50}$, the most important factor influencing plasma fatty acid profile in IBD was the activity of the disease, but they did not assess antioxidant parameters in their group of patients. Our results also show that disease activity, as measured by $\mathrm{C}$-reactive protein level, was inversely correlated with the sum of PUFA, SAFA, n- 6 fatty acids and linoleic acid. The Van Hees index was not associated with the fatty acid profile in CD patients. We studied patients with active $C D$ in an early phase of the exacerbation. It is known that the synthesis of C-reactive protein is extremely rapid during the onset of an inflammatory response, while changes in ESR and albumin (important factors contributing to the Van Hees index) due to inflammation progress slower ${ }^{51}$. This may explain the significant correlation between Creactive protein levels and changes in fatty acid profile in CD patients in spite of the lack of correlation with the Van Hees index.

The fatty acid pattern in red blood cell phospholipids did not significantly differ between patients with active and inactive $C D$. Patients with active CD were studied in an early phase of the exacerbation episode. Hence, it is possible that changes in the fatty acid profile were not found because lipid turnover and fatty acid changes in this compartment are slower and are rather a marker of the long-term fatty acid pattern.

To summarize, this study showed that changes in plasma phospholipid fatty acid profile were significantly related to several serum antioxidants and disease activity in $C D$ patients. Furthermore, it was shown that the deteriorated antioxidant status may contribute to the imbalance of antioxidant defense and ROS production in CD patients. These results suggest that antioxidants may play an important role in the pathophysiology and potentially also in the treatment of CD inflammation. 


\section{References}

1. Grisham MB. Oxidants and free radicals in inflammatory bowel disease. Lancet $1994 ; 344: 859-61$.

2. Simmonds NJ, Rampton DS. Inflammatory bowel disease, a radical view. Gut 1993; 34:865-8.

3. Keshavarzian A, Sedghi S, Kanofsky J, List T, Robinson C, Ibrahim C, Winship D. Excessive production of reactive oxygen metabolites by inflamed colon: analysis by chemiluminescence probe. Gastroenterology 1992; 103:177-85.

4. Das UN, Podma M, Sogar PS, Ramesh G, Koratkar R. Stimulation of free radical generation in human leucocytes by various agents including tumor necrosis factor is a calmodulin-dependent proces. Biochem Biophys Res Commun 1990; 167:1030-6.

5. Halliwell B. Free radical and antioxidants: a personal view. Nutr Rev 1994; 52:253-65.

6. Fernández-Bañares $F$, Abad-Lacruz A, Xiol X, Gine JJ, Dolz C, Cabré E, et al. Vitamin status in patients with inflammatory bowel disease. Am J Gastroenterol $1989 ; 84: 744-8$.

7. Fernández-Bañares $F$, Mingorance $M D$, Esteve $M$, Cabré E, Lachica M, AbadLacruz A, et al. Serum zinc, copper, and selenium levels in inflammatory bowel disease: effect of total enteral nutrition on trace element status. Am J Gastroenterol 1990; 85:1584-9.

8. Kuroki F, lida M, Tominaga M, Matsumoto T, Hirakawa K, Sugiyama S, Fujishima M. Multiple vitamin status in Crohn's disease. Correlation with disease activity. Dig Dis Sci 1993; 38:1614-8.

9. Hinks LJ, Inwards KD, Lloyd B, Clayton B. Reduced concentrations of selenium in mild Crohn's disease. J Clin Path 1988; 41:198-201.

10. Hoffenberg EJ, Deutsch J, Smith S, Sokol RJ. Circulating antioxidant concentrations in children with inflammatory bowel disease. Am J Clin Nutr 1997; 65:1482-8.

11. Geerling BJ, Badart-Smook A, Stockbrügger RW, Brummer R-JM. Comprehensive nutritional status in patients with long-standing Crohn's disease in remission. Am J Clin Nutr 1998; 67:919-26.

12. Diplock AT. Antioxidant nutrients and disease prevention: an overview. Am J Clin Nutr 1991; 53:189S-93S.

13. Kinsella JR, Lokesh B, Broughton S, Whelan J. Dietary polyunsaturated fatty acids and eicosanoids: potential effects on the modulation of inflammatory and immune cells: an overview. Nutr 1990; 6:24-44.

14. Esteve-Comas M, Ramírez M, Fernández-Bañares F, Abad-Lacruz A, Gil A, Cabré $E$, et al. Plasma polyunsaturated fatty acid pattern in active inflammatory bowel disease. Gut 1992; 33:1365-9.

15. Esteve-Comas $M$, Nuñez MC, Fernández-Bañares F, Abad-Lacruz A, Gil A, Cabré $E$, et al. Abnormal plasma polyunsaturated fatty acid pattern in non-active inflammatory bowel disease. Gut 1993; 34:1370-3.

16. Kuroki F, lida M, Matsumoto T, Aoyagi K, Kanamoto K, Fujishima M. Serum n3 polyunsaturated fatty acid are depleted in Crohn's disease. Dig Dis Sci 1997; 42:1137-41.

17. Siguel EN, Lerman RH. Prevalence of essential fatty acid deficiency in patients with chronic gastrointestinal disorders. Metabolism 1996; 45:12-23. 
18. Bjerve KS, Brubakk AM, Fougner KJ, Johnsen $H$, Midthjell K, Vik T. Omega-3 fatty acids: essential fatty acids with important biological effects, and serum phospholipid fatty acid as markers of dietary w3- fatty acid intake. Am J Clin Nutr 1993; 57:801S-6S.

19. Cabré E, Periago JL, Mingorance MD, Fernández-Bañares F, Abad A, Esteve M, et al. Factors related to the plasma fatty acid profile in healthy subjects, with special reference to antioxidant micronutrient status: a multivariate analysis. Am J Clin Nutr $1992 ; 55: 831-7$.

20. Lennard-Jones JE. Classification of inflammatory bowel disease. Scand J Gastroenterol 1989; 24:2S-6S.

21. van Hees PA, van Elteren $\mathrm{PH}$, van Lier $\mathrm{HJ}$, van Tongeren. An index of inflammatory activity in patients with Crohn's disease. Gut 1980; 21:279-86.

22. Paglia DE, Valentine WN. Studies on the qantitative and qualitative characterization of erythrocyte gluthathione peroxydase. J Lab Clin Med 1967; 70:158.

23. Horwitt MK, Harvey CC, Dahm CH, Searcy MT. Relationship between tocopherol and serum lipid levels for determination of nutritional adequacy. Ann NY Acad Sci 1972; 203:223-36.

24. Folch J, Lees M, Sloane-Stanley GH. A simple method for the isolation and purification of total lipids from animal tissues. J Biol Chem 1957; 226:497-509.

25. Hoving EB, Jansen G, Volmar M, van Doormaal JJ, Muskiet FAJ. Profiling of plasma triglyceride fatty acids as their methyl esters by capillary gas chromatography, preceded by a rapid aminopropyl silica column chromatographic separtion of lipid classes. J Chromatography 1988; 434:395-409.

26. Kaluzny MA, Duncan LA, Meritt MV, et al. Rapid separation of lipid classes in high yield and purity using bonded phase columns. J Lipid Res 1985; 26:135-40.

27. Morrison WR, Smith LM. Preparation of fatty acid methyl esters and dimethylacetals from lipids with boron fluoride methanol. J Lipid Res 1964; 5:600-8.

28. Hornstra G. Essential fatty acids, pregnancy and pregnancy complications: a round table discussion. In: Sinclair A, Gibson R, eds. Essential fatty acids and eicosanoids. Invited papers from the third international congress. Champaign (IL): Am Oil Chem Soc 1992; 177-82.

29. Holman RT. The ratio of trienoic: tetraenoic acids in tissue lipids as a measure of essential fatty acid requirement. J Nutr 1960; 70:405-10.

30. Al MDM, Badart-Smook A, v Houwelingen AC, Hasaart THM, Hornstra G. Fat intake of women during normal pregnancy: relationship with maternal and neonatal essential fatty acid status. J Am Coll Nutr 1996; 15:49-55.

31. NEVO Foundation. Dutch food composition table 1989-1990. Voorlichtingsbureau voor de Voeding. The Hague, The Netherlands (in Dutch).

32. Gee MI, Grace MG, Wensel RH, Sherbaniuk RW, Thomson AB. Nutritional status of gastroenterology outpatients: comparison of inflammatory bowel disease with functional disorders. J Am Diet Ass 1985; 85:159-9.

33. Rigaud D, Angel LA, Cerf M, Carduner MJ, Melchior JC, Sautier C, et al. Mechanisms of decreased food intake during weight loss in adult Crohn's disease patients without obvious malabsorption. Am J Clin Nutr 1994; 60:775-81.

34. Cameron ME, Van Staveren WA. Manual on methodology for food consumption studies. Oxford: Oxford University Press, 1988.

35. Sandström B, Davidsson L, Bosaeus I, Eriksson R, Alpsten M. Selenium status and absorption of zinc $\left({ }^{65} \mathrm{Zn}\right)$, selenium $\left({ }^{75} \mathrm{Se}\right)$ and manganese $\left({ }^{54} \mathrm{Mn}\right)$ in patients with short bowel syndrome. Eur J Clin Nutr 1990; 44:697-703. 
36. Andersson H, Bosaeus I, Brummer R-J, Fasth S, Hultén L, Mangusson O, Strauss B. Nutritional and metabolic consequences of extensive bowel resection. Dig Dis $1986 ; 4: 193-202$.

37. Keshavarzian A, Haydek J, Zabihi R, Doria M, D'Astice M, Sorenson JRJ. Agents capable of eliminating reative oxygen species. Dig Dis Sci 1992; 37:1866-73.

38. Millar AD, Rampton DS, Chander CL, Claxson AWD, Blades S, Coumbe A, et al. Evaluating the antioxidant potential of new treatments for inflammatory bowel disease using a rat model of colitis. Gut 1996; 39:407-15.

39. Reimund JM, Allison AC, Muller CD, Dumont S, Kenney JS, Baumann R, et al. Antioxidants inhibit the in vitro production of inflammatory cytokines in Crohn's disease and ulcerative colitis. Eur J Clin Invest 1998; 28:145-50.

40. Geerling BJ, Van Deursen C, Stockbrügger RW, Brummer R-JM. Improved antioxidant status after supplementation with n-3 fatty acids and/or antioxidants in addition to a regular diet in patients with Crohn's disease in a double blind placebo controlled study. Proceedings of the Spring meeting of the Dutch Society of Gastroenterology, page 100; 19-20 March 1998 in Veldhoven, The Netherlands.

41. Pironi L, Ruggeri E, Zolezzi C, Savarino L, Incasa E, Belluzzi A, et al. Lipid peroxidation and antioxidant status in adults receiving lipid-based home parenteral nutrition. Am J Clin Nutr 1998; 68:888-93.

42. Mulder TP, Verspaget HW, Janssens AR, de Bruin PA, Pena AS, Lamers CV. Decrease in two intestinal copper-zinc containing proteins with antioxidant function in inflammatory bowel disease. Gut $1991 ; 32: 1146-50$.

43. Lih-Brody L, Powell SR, Collier KP, Reddy GM, Cerchia R, Kahn E, et al. Increased oxidative stress and decreased antioxidant defenses in mucosa of inflammatory bowel disease. Dig Dis Sci 1996; 41:2078-86.

44. Taylor CG, Bettger WJ, Bray TM. Effect of dietary zinc or copper deficiency on the primary free radical defense system in rats. J Nutr $1991 ; 118: 613-21$.

45. Thurnham DI. Impact of disease on markers of micronutrient status. Proc Nutr Soc 1997; 56:421-31.

46. Geerling BJ, van Houwelingen AC, Badart-Smook A, Stockbrügger RW, Brummer R-JM. Fat intake and fatty acid profile in plasma phospholipids and adipose tissue in patients with Crohn's disease compared with controls. Am J Gastroenterol 1999; 94:410-7.

47. Gross V, Arndt $H$, Andus T, Palitzsch KD, Scholmerich J. Free radicals in inflammatory bowel diseases pathophysiology and therapeutic implications. Hep Gastroenterol 1994; 41:320-7.

48. Kok FJ, de Bruijn AM, Vermeeren R, et al. Serum selenium, vitamin antioxidants, and cardiovascular mortality: a 9-year follow-up study in the Netherlands. Am J Clin Nutr 1987; 45:462-8.

49. Winckler BS, Orselli SM, Rex TS. The redox couple between glutathione and ascorbic acid: a chemical and physiological perspective. J Free Rad Biol Med 1994 ; 17:333-49.

50. Esteve-Comas M, Ramirez M, Fernández-Bañares F, Abad-Larcruz A, Gil A, Cabre E, González-Huix F, Bertrán X, Gassull MA. Determinants of plasma fatty acids abnormalities in patients with active inflammatory bowel disease: a multivariate analysis. Inflammatory Bowel Dis 1995; 1:95-100.

51. Mazlam MZ, Hodgson HJF. Why measure C-reactive protein? Gut 1994; 35:5-7. 


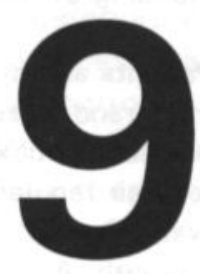

\section{Nutritional supplementation} with n-3 fatty acids and antioxidants in patients with Crohn's disease in remission: effects on nutritional status and fatty acid profile

Geerling BJ, Badart-Smook A, van Deursen C, van Houwelingen AC, Russel MGVM, Stockbrügger RW, Brummer R-JM 


\section{Abstract}

\section{Background}

In patients with Crohn's disease (CD), malnutrition is frequently observed and is generally accepted to be an important issue. The aim of this study was to investigate the effects of 3 months of supplementation with a liquid formula containing either antioxidants or n-3 fatty acids plus antioxidants on nutritional status and fatty acid profile of plasma phospholipids and adipose tissue, respectively in patients with longstanding CD currently in remission.

\section{Patients and methods}

In a randomized, double-blind placebo-controlled study, $C D$ patients received either placebo, antioxidants, or n-3 fatty acids plus antioxidants for three months in addition to their regular diet. In all, 25/37 CD patients completed the study. Nutritional status was assessed by body composition, dietary intake, biochemical parameters and muscle strength. A statistical per-protocol analysis was performed.

\section{Results}

Antioxidant status was significantly $(\mathrm{P}<0.05)$ improved and muscle strength was significantly $(\mathrm{P}<0.05)$ restored after supplementation with $n-3$ fatty acids and/or antioxidants. n-3 Fatty acids plus antioxidants supplementation significantly $(P<0.05)$ decreased the proportion of arachidonic acid, and increased the proportion of eicosapentaenoic acid and docosahexaenoic acid in both plasma phospholipids and adipose tissue.

\section{Conclusions}

Supplementation with n-3 fatty acids and/or antioxidants improved nutritional status and antioxidant status in patients with $C D$ in remission. In addition, supplementation with n-3 fatty acids plus antioxidants significantly changed the eicosanoid precursor profile, which may lead to the production of eicosanoids with attenuated proinflammatory activity. This study indicates that an immunomodulating formula containing n-3 fatty acids and/or antioxidants may have the potential to play a role in the treatment of $\mathrm{CD}$. 


\section{Introduction}

Crohn's disease $(C D)$ is a chronic inflammatory process of unknown etiology, which may affect any part of the gastrointestinal tract. Malnutrition and nutrient malassimilation have often been described as a consequence of substantial inflammation and of malabsorption, especially in patients with active $C D^{1.11}$.

In a recent study, we assessed a comprehensive nutritional status in patients with long-standing ( $>10$ years) $C D$, clinically in remission, and observed a variety of nutritional and functional deficiencies ${ }^{12}$. Moreover, a deteriorated antioxidant status, which may negatively affect the inflammatory process, was evident in this group of $C D$ patients compared with matched healthy controls.

It has been shown that nutritional deficiencies are associated with reduced immunological competence in $C D$ patients ${ }^{13,14}$. Nutritional support may therefore be an important therapeutic tool in regulating the inflammatory process. Studies reported beneficial effects of immunomodulating nutrients, e.g. fish oil, by modifying cell membrane structure and by altering eicosanoid metabolism in CD patients ${ }^{15,16}$ or by improving host immune response in intensive care unit patients with trauma, sepsis or cancer ${ }^{17-20}$.

Two studies have so far examined whether orally administered fish oil could prolong remission in $C D$ patients, but results have been contradictory ${ }^{15,21}$. A German study showed no significant effects of fish oil ${ }^{21}$, while an Italian study found that an increased percentage of fish oil treated $C D$ patients remained in remission compared to placebo ${ }^{15}$. However, the mechanism by which fish oil may exerts its effect is still unknown, and it remains to be established whether the possible beneficial effects of $n-3$ fatty acids supplementation in CD patients are caused by the change of fatty acid profile and the subsequent shift to the less inflammatory active 5-series leukotrienes at the expense of the 4-series leukotrienes.

Antioxidants have been used successfully in experimental models of intestinal inflammation ${ }^{22}$. Recently, it was shown that the antioxidants butylated hydroxyanisol, tetrahydropapaveroline and nordihydroguaiaretic acid inhibit in vitro production of inflammatory cytokines in $C D$ and ulcerative colitis patients ${ }^{23}$. It is unknown whether supplementation with dietary antioxidants may improve the deteriorated antioxidant status of $C D$ patients. Furthermore, it would be interesting to know whether immunomodulating supplements, e.g. fish oil or antioxidants, may improve the nutritional status of $C D$ patients.

As disease activity and nutritional status are highly correlated ${ }^{24}$, the above question should be studied in CD patients without disease activity. The aim of the present study was to investigate effects of a liquid supplement during 3 months containing either antioxidants or antioxidants plus n-3 fatty acids in addition to a regular diet in patients with long-standing $C D$, clinically in remission, with as primary endpoints effects on the nutritional status and the fatty acid profile. 


\section{Subjects and methods}

The study protocol had been approved by the Ethics Committee of the University Hospital Maastricht and all patients gave their informed consent before the start of the study.

\section{Study design}

A randomized double blind, placebo controlled study design was used. The nutritional supplements were orally administered for three months in addition to the patients' regular diet. The composition of the isocaloric nutritional supplements is shown in Table 9.1. The patients were instructed to take 2 sachets a day. Nutritional status, fatty acid composition of plasma phospholipids and adipose tissue, disease activity, lipid peroxidation, and quality of life were assessed before and after 3 months of supplementation. During the study, patients were monitored by routine visits to the Gastroenterology outpatient department and by telephone calls. In addition, compliance was assessed by checking a patient diary and by counting returned sachets of the nutritional supplement each month.

\section{Patients}

Outpatients of the department of Gastroenterology who met the inclusion criteria of having suffered from small bowel CD for more than 5 years, and who were clinically in remission were consecutively asked to participate in the study. The diagnosis of CD was based on the criteria developed by Lennard-Jones ${ }^{25}$. Thirty-seven patients were first stratified by sex and age and then randomly assigned to receive either placebo, the antioxidants formula, or the $n-3$ fatty acids plus antioxidants formula (IMPACT') (Table 9.1). During the study, 10 patients ( $3 / 14$ males and $7 / 23$ females) dropped out because of diarrhea $(n=2)$, dyspepsia $(n=4)$ or intolerance due to satiety induced by the supplement $(n=4)$. However, the drop-out rate was not specific for any of the nutritional supplements (4 patients who were assigned to the placebo treatment, 3 patients who received the antioxidant formula and 3 patients who were assigned to the n-3/antioxidant formula did not complete the study). Two other patients were excluded from the study due to an exacerbation of $C D(n=1)$ or intercurrent gastritis $(n=1)$. In all, 25 patients (15 females, 10 males) completed the study (median age 41 years (32-53)). Characteristics of the patients before supplementation are shown in Table 9.2. Treatment groups did significantly differ in disease duration, but were comparable for other variables. Medical treatment was not changed during the study period. 
Table 9.1 Composition of the supplements (1 sachet)

\begin{tabular}{|c|c|c|c|c|}
\hline & & Placebo & Antioxidants & n-3 FA/AO (IMPACT ${ }^{\circ}$ ) \\
\hline Content & $\mathbf{g}$ & 74 & 74 & 74 \\
\hline Energy & kcal & 306 & 307 & 324 \\
\hline - Protein/fat/carbohydrates & $\%$ & $18 / 24 / 57$ & $18 / 24 / 58$ & $21 / 24 / 55$ \\
\hline Protein & g & 13.6 & 13.7 & 17.4 \\
\hline whey-protein & g & 13.6 & 13.7 & 13.7 \\
\hline - L-arginine & g & - & - & 3.7 \\
\hline Fat & g & 8.5 & 8.5 & 8.5 \\
\hline$-n-6$ FS (LA) & g & 3.00 & 3.00 & 0.86 \\
\hline - SAFA & g & 3.9 & 3.9 & 4.6 \\
\hline - MUFA & $\mathbf{g}$ & 1.5 & 1.5 & 1.7 \\
\hline - PUFA & g & 3.0 & 3.0 & 1.9 \\
\hline$-n-3 F S(E P A+D H A+L N S)$ & g & 0.05 & 0.05 & 1.02 \\
\hline Carbohydrates & g & 43.8 & 44.0 & 44.5 \\
\hline Lactose & g & 0.68 & 0.68 & 0.68 \\
\hline Fiber & g & 2.7 & 2.7 & 2.9 \\
\hline Calcium & mg & 251 & 251 & 259 \\
\hline Magnesium & $\mathrm{mg}$ & 71 & 71 & 75 \\
\hline Copper & $\mathrm{mg}$ & 0.003 & 0.55 & 0.55 \\
\hline Zinc & mg & 0.005 & 4.6 & 4.6 \\
\hline Selenium & $\mu g$ & - & 12.4 & 12.4 \\
\hline Vitamin A & $\mathrm{mg}$ & 0.02 & 0.38 & 0.38 \\
\hline - from $\beta$-carotene & $\mathrm{mg}$ & - & 0.15 & 0.15 \\
\hline Vitamin D3 & $\mu \mathrm{g}$ & 0.02 & 1.3 & 1.4 \\
\hline Vitamin E & $\mathrm{mg}$ & - & 4.0 & 4.0 \\
\hline - as antioxidant & $\mathrm{mg}$ & 3.3 & 17.0 & 16.2 \\
\hline Vitamin $\mathrm{K}$ & $\mu \mathrm{g}$ & 3.1 & 21 & 19.4 \\
\hline Thiamin & $\mathrm{mg}$ & 0.20 & 0.61 & 0.62 \\
\hline Riboflavin & $\mathrm{mg}$ & 1.16 & 1.70 & 1.70 \\
\hline Pyridoxine & $\mathrm{mg}$ & 0.31 & 0.81 & 0.81 \\
\hline Vitamin C & mg & 4.5 & 20 & 20 \\
\hline - as antioxidant & $\mathrm{mg}$ & - & 86 & 88 \\
\hline Folic acid & $\mu \mathrm{g}$ & 60 & 124 & 124 \\
\hline
\end{tabular}

FA: fatty acids; AO: antioxidants; SAFA: saturated fatty acids; MUFA: monounsaturated fatty acids; PUFA: polyunsaturated fatty acids; LA: linoleic acid $(18: 2 n-6)$; LNS: $a$-linolenic acid $(18: 3 n-3) ;$ EPA: eicosapentaenoic acid; DHA: docosahexaenoic acid. 
Table 9.2 Characteristics of patients at the start of the study

\begin{tabular}{lccc}
\hline & $\begin{array}{c}\text { Placebo } \\
(\mathrm{n}=8)\end{array}$ & $\begin{array}{c}\text { Antioxidants } \\
(\mathrm{n}=8)\end{array}$ & $\begin{array}{c}\mathrm{n}-3 \mathrm{FA} / \mathrm{AO} \\
(\mathrm{n}=9)\end{array}$ \\
\hline Gender (F/M) & $6 / 2$ & $4 / 4$ & $5 / 4$ \\
Age' (years) & $38(30-61)$ & $43(33-52)$ & $41(31-56)$ \\
BMI (kg/m $\left.{ }^{2}\right)^{1}$ & $23.8(20.3-30.8)$ & $21.2(19.4-26.2)$ & $22.1(19.2-25.4)$ \\
Disease duration' (years) & $16.0(11.5-18.5)$ & $20.5(11.8-31.3)^{2}$ & $11.0(9.0-13.5)$ \\
CDAl' & $79(47-120)$ & $119(37-152)$ & $99(70-169)$ \\
C-reactive protein' (mg/L) & $7.0(2.0-15.0)$ & $8.5(7.0-13.0)$ & $10.0(4.0-11.5)$ \\
Medication - mesalazine & $n=5$ & $n=7$ & $n=9$ \\
& $n=1$ & $n=2$ & $n=3$ \\
Smoking - prednisone & $n=1$ & $n=2$ & $n=3$ \\
\hline
\end{tabular}

1 Data are expressed as medians; $25^{\text {th }}$ and $75^{\text {th }}$ percentile in parentheses.

BMI: body mass index; CDAl: Crohn's disease activity index; FA: fatty acids; AO: antioxidants.

${ }^{2}$ Significantly different from other treatment groups (Chi-square): $P<0.05$.

\section{Nutritional status}

The nutritional status assessment comprised assessment of body composition, dietary intake, biochemical parameters of nutrition and muscle strength as a functional parameter. All measurements were performed during one day, after an overnight fast.

\section{Body composition}

Body height $(\mathrm{BH})$ was measured to the nearest millimeter using a wall-mounted stadiometer, while body weight (BW) was measured using an electronic scale with a digital readout to an accuracy of 0.01 kilogram. Body mass index (BMI) was calculated from weight and height $\left(\mathrm{kg} / \mathrm{m}^{2}\right)$. Body fat, fat-free mass, and percentage body fat were determined using a dual-energy $\mathrm{X}$-ray absorptiometer (DPX-L, Lunar Corp., Madison, WI; using DPX-L 1.3 software) ${ }^{26}$. A total body scan over the entire length of a subject's body was performed. Any materials that could attenuate the X-ray beam, e.g. jewelry, watches or clothing with zippers, were removed before the examination.

\section{Dietary intake}

Regular dietary intake was assessed using a food-frequency questionnaire $(F F Q)^{27}$. The FFQ dealt specifically with the dietary intake of fat (total fat (TF), saturated fatty acids (SAFA), mono-unsaturated fatty acids (MUFA), polyunsaturated fatty acids (PUFA) and linoleic acid (LA)) and antioxidants ( $\beta$ carotene, vitamin $\mathrm{C}$ and zinc) over the previous month. All types of food and drink were coded by an experienced dietician according to the system used by the Netherlands Nutrient Databank (NEVO), and subsequently converted into 
energy and nutrients using the extended computerized version of the Netherlands Food Table ${ }^{28}$.

\section{Biochemical analyses}

After an overnight fast, a venous blood sample $(90 \mathrm{ml})$ was obtained and plasma and serum were stored at $-80^{\circ} \mathrm{C}$ until analysis. Serum cholesterol, total protein, magnesium and whole blood thiamin were determined by routine methods in use at the hospital, on a Beckman Synchron CX system (Brea, CA, USA). Serum pre-albumin was measured using a radioimmunodiffusion technique (Beckman immunochemistry systems (Brea, CA, USA). Antioxidant status was assessed by serum concentrations of copper, zinc, selenium, vitamin $A$ and $E, \beta$-carotene and by the activities of the enzymes glutathione peroxidase (GpX) and superoxide dismutase (SOD). In addition, total antioxidant status (TAS) was measured using the Randox Total Antioxidant Status Kit (RANDOX Laboratories Ltd., Antrium, United Kingdom). Serum copper, zinc and selenium were determined by Zeeman-corrected electrothermal atomic absorption spectrometry. The assessment of whole blood activity of $\mathrm{GpX}$ was based on the method developed by Paglia and Valentine ${ }^{29}$, and the activity of SOD was assessed using a RANSOD kit (RANDOX Laboratories Ltd., Antrium, United Kingdom). Vitamins $A$ and $E$ ( $a$-tocopherol) were determined with High Pressure Liquid Chromatography (HPLC) and $\beta$-carotene by spectrophotometric assessment at $450 \mathrm{Nm}$.

\section{Muscle strength}

Strength of extensor (quadriceps) muscles $(\mathrm{mm}$. vastus lateralis, vastus medialis, vastus intermedius and rectus femoris), and flexor (hamstrings) muscles ( $\mathrm{mm}$. biceps femoris, semi tendinosis and semi membranosis) were measured using an isokinetic dynamometer (Cybex II, Eagle Performance Systems, Owatonna, MN) with angular velocities of 60 and $180 \% / \mathrm{s}^{30}$. Peak torque (PT) was determined from a fivefold measurement at each angular velocity. In addition, the strength of m.quadriceps and hamstrings was assessed in 25 population controls ( 15 females and 10 males), matched for age and sex with the $C D$ patients (median age 40 years(33-53)). Controls were randomly selected from the population database of a general practitioner in the same study area.

\section{Fatty acids analysis}

Adipose tissue biopsies were taken by needle biopsy from the outer quadrant of the right buttock and samples were stored at $-80^{\circ} \mathrm{C}$ until analysis ( $<3$ months). Fatty acid composition of plasma phospholipids and adipose tissue was analyzed as described by $\mathrm{Al}$ et $\mathrm{al}^{31}$. The amounts of the various fatty acids are expressed as percentages (wt/wt). 


\section{Disease activity}

Disease activity was assessed according to the Crohn's disease activity index (CDAI) at the time of the nutritional assessment ${ }^{32}$. In addition, C-reactive protein (CRP) was determined by routine methods in use at the hospital, on a Beckman Synchron $\mathrm{CX}^{*}$ system (Brea, CA, USA).

\section{Lipid peroxidation}

Lipid peroxidation was determined by means of the thiobarbituric acid (TBA) reaction described by Naito et $\mathrm{al}^{33}$. The TBA reaction is a reaction between TBA and malondialdehyde, which is produced from lipoperoxides during heating. TBA reactive substances (TBARs) were measured at $535 \mathrm{Nm}$.

\section{Quality of life}

Quality of life was measured using the validated Dutch version of the Inflammatory Bowel Disease Questionnaire (IBDQ) ${ }^{34}$. It considers the patient's situation over the preceding two weeks and includes 32 questions, grouped into four dimensions: "bowel symptoms" (10 items), "systemic symptoms" (5 items), "emotional function" (12 items) and "social function" (5 items). Response options are consistently presented as seven-point Likert scales in which ' 7 ' represents best function and ' 1 ' represents worst function. Thus, the maximum (best) total IBDQ score is 224 .

\section{Statistical analysis}

Data are expressed as median (25th and 75 th percentile) or as indicated. The effects of nutritional supplementation on the various variables were analyzed using a Wilcoxon matched-pairs signed-rank test. Spearman's correlation coefficients were calculated by linear regression analysis. Data in figures are presented in Box \& Whiskers plots: median (line in box), 25th and 75th percentile (box) and range (minimum and maximum value). The results were analyzed by means of a 'per-protocol analysis', because the physiological effects of 3 months of nutritional supplementation were assessed. All statistical analyses were performed with the SPSS 7.0 for Windows package (SPPS Inc, Chicago).

\section{Results}

\section{Nutritional status}

Body composition

Table 9.3 shows the body composition results, before and after 3 months of supplementation, for the three different treatment groups. After 3 months of supplementation, body weight as well as body fat were significantly $(P<0.05)$ 
increased in patients receiving placebo and n-3 fatty acids plus antioxidants, whereas FFM and percentage body fat had not significantly changed after supplementation. No significant body composition changes were observed in patients supplemented with the antioxidants formula.

\section{Dietary intake}

Table 9.4 shows fat intake (regular fat intake of the diet assessed by FFO and the fat amount in the supplement). Regular fat intake significantly $(P<0.05)$ decreased in patients receiving placebo or antioxidants. In patients receiving placebo or n-3 fatty acids plus antioxidants, total fat intake (regular + supplement) had increased after 3 months of supplementation. After supplementation with antioxidants, total fat (regular + supplement) intake had decreased. Total SAF intake (regular + supplement) had significantly increased in patients receiving $n-3$ fatty acids plus antioxidants. However, between treatment groups, we observed no significant differences in the various (SAFA, MUFA, PUFA or LA) total fatty acid intakes (regular fat intakes + amounts in the supplements) after 3 months supplementation.

Regular antioxidant intake had not changed significantly in either group after 3 months supplementation. Hence, total antioxidant intake (regular intake + amounts in the supplement) increased significantly in patients receiving either antioxidants or $\mathrm{n}-3$ fatty acids plus antioxidants (Table 9.4).

\section{Biochemical parameters of nutrition}

Results regarding the biochemical parameters of nutrition are shown in Table 9.5. Serum vitamin $E$ and vitamin $C$ concentrations and whole blood $S O D$ activity increased significantly in the patients supplemented with either antioxidants or with $\mathrm{n}-3$ fatty acids plus antioxidants. Whole blood $\mathrm{GpX}$ activity decreased significantly $(P<0.05)$ in the $n-3$ fatty acids plus antioxidants group. TAS increased in the $\mathrm{n}-3$ fatty acids plus antioxidants supplementation group, but this increase did not reach significance $(P=0.07)$.

\section{Muscle strength}

Peak torques had not changed in CD patients after 3 months of supplementation in either treatment group. At baseline, however, hamstrings and quadriceps peak torques measured at 60 and $180 \%$ s were significantly $(P<0.01)$ lower in $C D$ patients $(n=25)$ than in the matched controls (Figure 9.1). After 3 months of supplementation with either antioxidants or $n-3$ fatty acids plus antioxidants, hamstrings and quadriceps PTs in CD patients did not differ significantly from controls. In contrast, after placebo supplementation, hamstrings and quadriceps PTs in $C D$ patients still were significantly $(P<0.05)$ lower than in controls (Table 9.6). 
Table 9.3 Body composition in Crohn's disease patients before and after 3 months of nutritional supplementation with placebo, antioxidants or $\mathrm{n}-3$ fatty acids plus antioxidants'.

\begin{tabular}{|c|c|c|c|c|c|c|}
\hline & \multicolumn{2}{|c|}{ Placebo $(n=8)$} & \multicolumn{2}{|c|}{ Antioxidants $(\mathrm{n}=8$ ) } & \multicolumn{2}{|c|}{$n-3$ fatty acids/antioxodants $(n=9)$} \\
\hline & before & after & before & after & before & after \\
\hline Weight $(\mathbf{k g})^{2}$ & $63.4(55.4-84.4)$ & $64.4(55.9-85.2)^{3}$ & $64.5(55.7-72.8)$ & $64.4(56.2-73.1)$ & $68.0(60.2-77.2)$ & $69.4(61.9-77.4)^{3}$ \\
\hline Body fat $(\mathrm{kg})$ & $22.7(11.9-30.6)$ & $23.8(12.2-31.5)^{3}$ & $17.2(9.2-27.9)$ & $17.3(10.6-25.4)$ & $18.2(11.9-28.2)$ & $18.5(11.6-29.4)^{3}$ \\
\hline Fat-free mass (kg) & $45.2(38.4-54.0)$ & $45.4(38.5-53.7)$ & $45.6(42.8-56.2)$ & $45.3(40.8-55.3)$ & $50.8(43.4-53.1)$ & $50.0(43.7-53.2)$ \\
\hline Percentage body fat & $34.9(22.2-37.2)$ & $35.0(22.5-37.8)$ & $24.7(15.5-38.2)$ & $24.7(15.6-37.9)$ & $24.2(20.8-37.9)$ & $24.2(20.8-37.5)$ \\
\hline
\end{tabular}

'Data are expressed as median; 25 th and 75 th percentile in parentheses.

${ }^{2}$ Body fat plus fat-free mass assessed by dual-energy $\mathrm{X}$-ray absorptiometry does not correspond with body weight because median values are given.

${ }^{3}$ Significantly different from before 3 months of supplementation (Wilcoxon matched-pairs signed-rank tests): $P<0.05$. 
Table 9.4 Dietary intake of fat and antioxidants in Crohn's disease patients before and after 3 months of nutritional supplementation with placebo, antioxidants or $\mathrm{n}-3$ fatty acids plus antioxidants ${ }^{1}$

\begin{tabular}{|c|c|c|c|c|c|c|c|c|c|}
\hline & \multicolumn{3}{|c|}{ Placebo $(n=8)$} & \multicolumn{3}{|c|}{ Antioxidants $(n=8)$} & \multicolumn{3}{|c|}{$n-3$ fatty acids/antioxidants $(n=9)$} \\
\hline & before & after & after + suppl & before & after & after + suppl & before & after & after + suppl \\
\hline Total fat $(g)$ & $\begin{array}{l}80.1 \\
(56.8-148)\end{array}$ & $\begin{array}{l}70.6^{2} \\
(45.8-105)\end{array}$ & $\begin{array}{l}83.4 \\
(56.4-122)\end{array}$ & $\begin{array}{l}113 \\
(82.6-138)\end{array}$ & $\begin{array}{l}83.4^{2} \\
(68.0-109)\end{array}$ & $\begin{array}{l}99.8 \\
(83.2-126)\end{array}$ & $\begin{array}{l}88.9 \\
(83.8-137)\end{array}$ & $\begin{array}{l}103 \\
(70.2-120)\end{array}$ & $\begin{array}{l}115 \\
(83.8-137)\end{array}$ \\
\hline SAFA (g) & $\begin{array}{l}28.1 \\
(22.9-55.3)\end{array}$ & $\begin{array}{l}27.3^{2} \\
(16.5-46.4)\end{array}$ & $\begin{array}{l}32.9 \\
(22.6-54.0)\end{array}$ & $\begin{array}{l}37.5 \\
(29.8-46.2)\end{array}$ & $\begin{array}{l}33.9 \\
(23.2-40.6)\end{array}$ & $\begin{array}{l}39.6 \\
(30.8-48.2)\end{array}$ & $\begin{array}{l}36.7 \\
(31.1-50.7)\end{array}$ & $\begin{array}{l}38.7 \\
(27.9-46.4)\end{array}$ & $\begin{array}{l}43.9^{2} \\
(34.9-55.6)\end{array}$ \\
\hline MUFA (g) & $\begin{array}{l}27.0 \\
(20.8-55.0)\end{array}$ & $\begin{array}{l}26.8 \\
(15.8-42.6)\end{array}$ & $\begin{array}{l}29.0 \\
(18.4-45.6)\end{array}$ & $\begin{array}{l}47.3 \\
(33.9-57.3)\end{array}$ & $\begin{array}{l}31.2^{2} \\
(25.9-45.9)\end{array}$ & $\begin{array}{l}34.2 \\
(28.6-48.9)\end{array}$ & $\begin{array}{l}34.8 \\
(28.9-46.1)\end{array}$ & $\begin{array}{l}31.9 \\
(26.2-44.2)\end{array}$ & $\begin{array}{l}35.3 \\
(28.8-46.7)\end{array}$ \\
\hline PUFA (g) & $\begin{array}{l}18.6 \\
(6.9-26.1)\end{array}$ & $\begin{array}{l}10.6^{2} \\
(5.8-16.7)\end{array}$ & $\begin{array}{l}15.1 \\
(11.1-22.7)\end{array}$ & $\begin{array}{l}19.9 \\
(11.4-27.1)\end{array}$ & $\begin{array}{l}15.2 \\
(10.5-19.5)\end{array}$ & $\begin{array}{l}21.2 \\
(14.5-24.5)\end{array}$ & $\begin{array}{l}16.0 \\
(12.5-19.7)\end{array}$ & $\begin{array}{l}13.4 \\
(11.1-18.6)\end{array}$ & $\begin{array}{l}16.4 \\
(14.5-21.6)\end{array}$ \\
\hline Linoleic acid (g) & $\begin{array}{l}14.0 \\
(3.9-19.2)\end{array}$ & $\begin{array}{l}7.1^{2} \\
(4.2-10.8)\end{array}$ & $\begin{array}{l}11.7 \\
(8.9-16.8)\end{array}$ & $\begin{array}{l}13.1 \\
(7.9-21.9)\end{array}$ & $\begin{array}{l}12.1 \\
(7.4-14.1)\end{array}$ & $\begin{array}{l}18.1 \\
(12.1-20.1)\end{array}$ & $\begin{array}{l}10.1 \\
(7.9-14.9)\end{array}$ & $\begin{array}{l}9.2 \\
(7.3-13.5)\end{array}$ & $\begin{array}{l}10.9 \\
(8.9-14.8)\end{array}$ \\
\hline$\beta$-Carotene (mg) & $\begin{array}{l}0.41 \\
(0.21-0.53)\end{array}$ & $\begin{array}{l}0.56 \\
(0.29-0.71)\end{array}$ & $\begin{array}{l}0.56 \\
(0.29-0.71)\end{array}$ & $\begin{array}{l}0.49 \\
(0.31-0.77)\end{array}$ & $\begin{array}{l}0.48 \\
(0.29-0.86)\end{array}$ & $\begin{array}{l}0.79^{2} \\
(0.60-1.16)\end{array}$ & $\begin{array}{l}0.39 \\
(0.23-0.68)\end{array}$ & $\begin{array}{l}0.73 \\
(0.39-0.91)\end{array}$ & $\begin{array}{l}1.03^{4} \\
(0.61-1.05)\end{array}$ \\
\hline Vitamin C (mg) & $\begin{array}{l}43.8 \\
(27.5-135)\end{array}$ & $\begin{array}{l}54.0 \\
(40.3-95.3)\end{array}$ & $\begin{array}{l}63.0 \\
(45.9-103)\end{array}$ & $\begin{array}{l}68.9 \\
(49.9-82.8)\end{array}$ & $\begin{array}{l}49.9 \\
(35.6-85.6)\end{array}$ & $\begin{array}{l}89.9^{4} \\
(75.7-121)\end{array}$ & $\begin{array}{l}84.2 \\
(42.6-125)\end{array}$ & $\begin{array}{l}91.9 \\
(25.7-118)\end{array}$ & $\begin{array}{l}126 \\
(65.1-158)\end{array}$ \\
\hline Zinc (mg) & $\begin{array}{l}8.4 \\
(7.4-13.2)\end{array}$ & $\begin{array}{l}8.6 \\
(5.7-9.5\end{array}$ & $\begin{array}{l}8.6 \\
(5.7-9.5\end{array}$ & $\begin{array}{l}9.2 \\
(7.7-10.8)\end{array}$ & $\begin{array}{l}9.0 \\
(8.1-9.6)\end{array}$ & $\begin{array}{l}17.7^{3} \\
(14.6-18.4)\end{array}$ & $\begin{array}{l}8.6 \\
(6.7-10.4) \\
\end{array}$ & $\begin{array}{l}7.6 \\
(5.8-12.2) \\
\end{array}$ & $\begin{array}{l}16.8^{4} \\
(14.0-21.4)\end{array}$ \\
\hline
\end{tabular}

1 Data are expressed as median; 25th and 75th percentile in parentheses. Before: regular dietary intake before supplementation; After:

regular dietary intake after supplementation. After + suppl: regular dietary intake after supplementation + dietary intake of supplement; SAFA:

saturated fatty acids; MUFA: monounsaturated fatty acids; PUFA: polyunsaturated fatty acids.

2,3.4 Significantly different from before nutritional supplementation (Wilcoxon matched-pairs signed-rank tests): ${ }^{2} \mathrm{P}<0.05,{ }^{3} \mathrm{P}<0.02,{ }^{4} \mathrm{P}<0.01$. 
Serum and whole blood concentrations of nutritional biochemical parameters in Crohn's disease patients before and after 3 months of nutritional supplementation with placebo, antioxidants or n-3 fatty acids plus antioxidants'.

\begin{tabular}{|c|c|c|c|c|c|c|}
\hline & \multirow{2}{*}{$\begin{array}{l}\text { Placebo }(n=8) \\
\text { before }\end{array}$} & \multirow[b]{2}{*}{ after } & \multicolumn{2}{|l|}{ antioxidants $(n=8)$} & \multicolumn{2}{|c|}{$n-3$ fatty acids/antioxidants $(n=9)$} \\
\hline & & & before & after & before & after \\
\hline Total protein $(\mathrm{g} / \mathrm{L})$ & $68.2(64.6-71.5)$ & $66.8(62.1-69.0)$ & $68.9(65.6-72.6)$ & $68.3(64.9-70.1)$ & $66.6(64.4-73.2)$ & $66.7(62.5-72.0)$ \\
\hline Pre-albumin (g/L) & $0.26(0.21-0.29)$ & $0.27(0.21-0.31)$ & $0.23(0.21-0.35)$ & $0.25(0.22-0.39)$ & $0.27(0.24-0.29)$ & $0.27(0.25-0.30)$ \\
\hline Vitamin A $(\mu \mathrm{mol} / \mathrm{L})$ & $2.30(1.35-2.58)$ & $2.50(1.50-3.10)$ & $2.00(1.53-3.20)$ & $2.10(1.67-2.98)$ & $1.90(1.45-2.50)$ & $2.25(2.03-2.85)$ \\
\hline$\beta$-Carotene $(\mu \mathrm{mol} / \mathrm{L})$ & $1.77(1.48-2.19)$ & $1.36(1.08-2.04)$ & $1.53(0.77-2.53)$ & $2.09(0.79-2.96)$ & $1.74(0.76-2.77)$ & $1.52(1.07-2.66)$ \\
\hline Thiamin (nmol/L) & $128(92.8-138)$ & $98(87.5-123)^{3}$ & $135(129-142)$ & $127(105-158)$ & $124(113-129)$ & $93.0(89.5-145.5)$ \\
\hline Vitamin C $(\mu \mathrm{mol} / \mathrm{L})$ & $31.5(15.2-55.8)$ & $37.0(26.0-47.3)$ & $30.5(23.8-47.0)$ & $55.5(15.5-48.3)^{3}$ & $40.0(23.5-56.5)$ & $68.0(50.0-73.5)^{3}$ \\
\hline Vitamin E $(\mu \mathrm{mol} / \mathrm{L})$ & $29.0(26.5-33.8)$ & $33.0(30.0-36.0)$ & $29.0(15.5-48.3)$ & $37.5(22.3-53.3)^{4}$ & $29.0(17.0-35.5)$ & $34.5(25.8-45.5)^{3}$ \\
\hline Magnesium (mmol/L) & $0.70(0.64-0.76)$ & $0.78(0.72-0.85)$ & $0.66(0.58-0.73)$ & $0.76(0.69-0.84)^{4}$ & $0.72(0.62-0.86)$ & $0.82(0.73-0.88)$ \\
\hline Selenium $(\mu \mathrm{mol} / \mathrm{L})$ & $0.99(0.87-1.11)$ & $0.90(0.77-1.08)$ & $0.92(0.72-0.95)$ & $0.96(0.75-1.16)$ & $0.80(0.68-1.01)$ & $1.00(0.82-1.14)$ \\
\hline Zinc $(\mu \mathrm{mol} / \mathrm{L})$ & $12.6(9.5-14.0)$ & $12.4(11.6-12.8)$ & $12.8(12.0-13.1)$ & $12.8(11.9-13.6)$ & $13.0(11.3-14.0)$ & $12.1(10.8-13.3)$ \\
\hline Copper ( $\mu \mathrm{mol} / \mathrm{L})$ & $21.8(20.7-25.3)$ & $18.6(17.4-22.7)$ & $19.6(17.1-23.1)$ & $18.4(15.4-22.8)$ & $17.1(16.3-21.9)$ & $17.6(15.3-20.8)$ \\
\hline $\mathrm{GpX}(\mathrm{U} / \mathrm{mmolHb})$ & $867(735-976)$ & $744(647-978)$ & $714(606-904)$ & $714(644-1079)$ & $876(724-1039)$ & $700(642-962)^{3}$ \\
\hline $\mathrm{SOD}(\mathrm{U} / \mathrm{mmolHb})$ & $15.6(13.6-16.1)$ & $17.7(17.0-18.7)$ & $14.4(12.6-15.8)$ & $16.7(14.8-18.7)^{4}$ & $14.2(13.4-16.3)$ & $17.7(15.6-20.7)^{3}$ \\
\hline TAS $(\mu \mathrm{mol} / \mathrm{L})$ & $1.21(1.11-1.28)$ & $1.21(1.02-1.27)$ & $1.19(1.14-1.26)$ & $1.22(1.20-1.37)$ & $1.20(1.12-1.24)$ & $1.27(1.20-1.38)^{2}$ \\
\hline
\end{tabular}

1 Data are expressed as median; 25 th and 75 th percentile in parentheses.

GpX: glutathione peroxidase; SOD: superoxide dismutase; TAS: total antioxidant status.

$2 \quad \mathrm{P}=0.07$ for difference between before and after nutritional supplementation.

3.4 Significantly different from before nutritional supplementation (Wilcoxon matched-pairs signed-rank tests): ${ }^{3} \mathrm{P}<0.05,{ }^{4} \mathrm{P}<0.02$. 
Isokinetic muscle strength measured by Cybex after 3 months of supplementation for different treatment groups compared with matched healthy controls'.

\begin{tabular}{|c|c|c|c|c|c|c|}
\hline & \multicolumn{2}{|c|}{ Placebo } & \multicolumn{2}{|c|}{ Antioxidants } & \multicolumn{2}{|c|}{$\mathrm{n}-3$ fatty acids/antioxidants } \\
\hline & CD patients $(n=8)$ & Controls $(n=8)$ & CD patients $(n=8)$ & Controls $(n=8)$ & CD patients $(n=9)$ & Controls $(n=9)$ \\
\hline $\begin{array}{l}\text { PT extension } \\
\left(60^{\circ} / \mathrm{sec}\right)(\mathrm{Nm})\end{array}$ & $98.5(73.0-124)^{3}$ & $116(82.5-142)$ & $112(98.7-141)$ & $136(123-149)$ & $119(88.0-147)$ & $123(95.0-154)$ \\
\hline $\begin{array}{l}\text { PT extension } \\
\left(180^{\circ} / \mathrm{sec}\right)(\mathrm{Nm})\end{array}$ & $64.5(41.0-79.0)^{2}$ & $76.0(50.8-95.8)$ & $66.0(56.8-93.3)^{2}$ & $87.0(77.0-101)$ & $74.0(42.0-105)$ & $80.0(58.5-108)$ \\
\hline $\begin{array}{l}\text { PT flexion } \\
\left(60^{\circ} / \mathrm{sec}\right)(\mathrm{Nm})\end{array}$ & $57.5(4.5-75.5)^{3}$ & $74.0(55.0-101)$ & $70.0(51.5-83.0)$ & $88.0(71.5-105)$ & $62.0(50.0-93.0)$ & $76.0(64.0-98.5)$ \\
\hline $\begin{array}{l}\text { PT flexion } \\
\left(180^{\circ} / \mathrm{sec}\right)(\mathrm{Nm})\end{array}$ & $29.0(13.3-52.0)^{3}$ & $51.0(33.0-67.3)$ & $36.0(23.0-59.3)$ & $53.0(45.0-84.5)$ & $29.0(18.0-65.0)^{2}$ & $53.0(41.0-72.0)$ \\
\hline
\end{tabular}

1 Data are expressed as median; 25 th and 75 th percentile in parenthese.

PT: peak torque; Nm: Newton meter. Quadriceps muscle strength was measured by peak torque extension, and hamstring muscle strength by peak torque flexion.

$2 \mathrm{P}=0.05$ for difference between Crohn's disease patients and controls.

${ }^{3}$ Significantly different from controls (Wilcoxon matched-pairs signed-rank tests): ${ }^{3} \mathrm{P}<0.05$. 

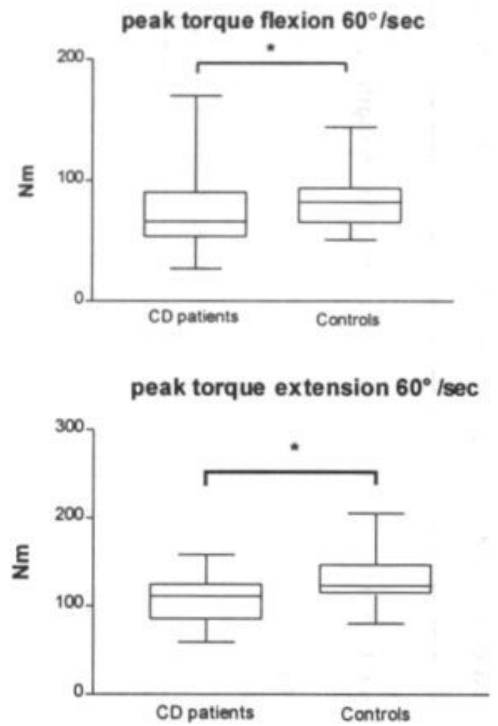
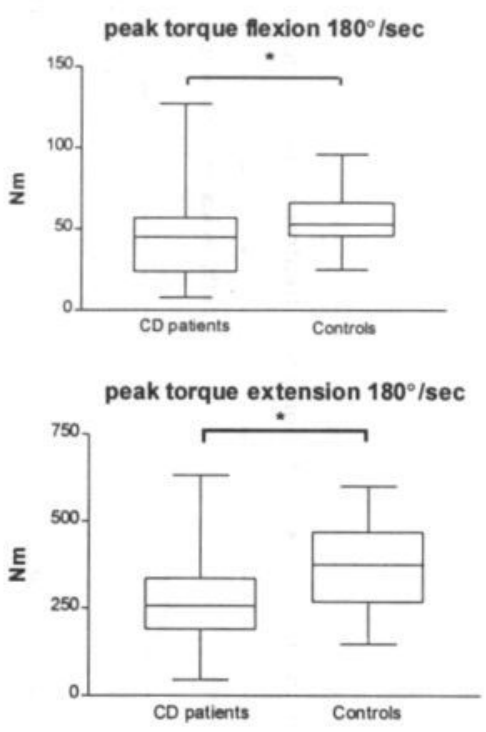

Figure 9.1 Box \& Whiskers plot of muscle function in $C D$ patients $(n=25)$ before nutritional supplementation compared with matched healthy controls $(n=25)$; peak torque flexion: peak torque of hamstring muscles, peak torque extension: peak torque of $\mathrm{m}$. quadriceps femoris. Significance level of difference in muscle strength between patients and controls (Wilcoxon matched-pairs signed-rank test): ${ }^{\circ} \mathrm{P}<0.05$.

\section{Fatty acid analysis}

\section{Plasma phospholipids}

After 3 months of supplementation with $n-3$ fatty acids plus antioxidants, a significant $(P<0.01)$ increase of $57.8 \%$ for the sum of the $n-3$ fatty acids was observed. Figure 9.2 shows the results for some individual fatty acids: arachidonic acid $(18: 4 n-6)$ significantly $(P<0.05)$ decreased $(6.6 \%)$ in the patients receiving $n-3$ fatty acids plus antioxidants, while eicosapentaenoic acid (EPA) and docosahexaenoic acid $(D H A)$ had significantly $(P<0.03)$ increased $(163 \%$ and $37.1 \%$, respectively) after 3 months of supplementation with $n-3$ fatty acids plus antioxidants. No changes in fatty acid profile of plasma phospholipids were observed in patients who had been supplemented with placebo or antioxidants.

\section{Adipose tissue}

In patients supplemented with n-3 fatty acids plus antioxidants, the sum of the $n-3$ fatty acids had significantly $(P<0.02)$ increased with $15.5 \%$ after 3 months 
of supplementation. EPA and DHA had significantly $(P<0.05)$ increased $125 \%$ and $80.0 \%$, respectively) after 3 months of supplementation with $n-3$ fatty acids plus antioxidants. DHA also increased significantly $(P<0.05)$ with $60 \%$ in patients receiving antioxidants.

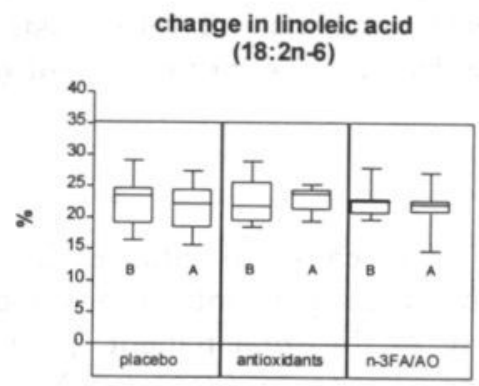

change in eicosapentaenoic acid $(20: 5 n-3)$

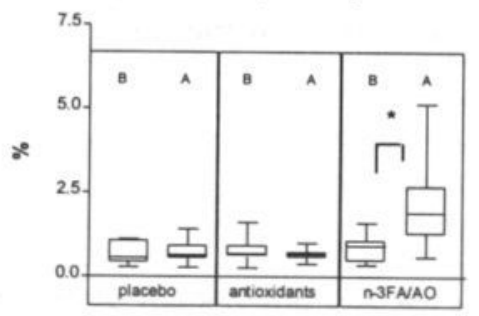

change in arachidonic acid (20:4n-6)

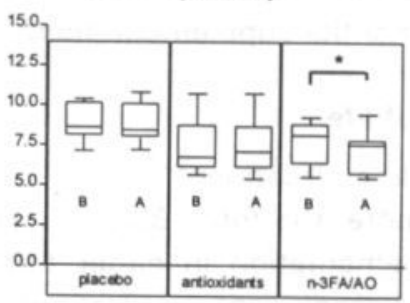

change in docosahexaenoic acid (22:6n-3)

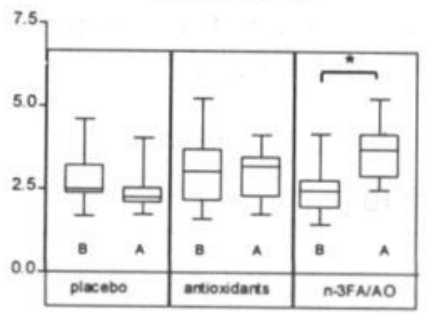

Figure 9.2 Box \& Whiskers plot of plasma phospholipids fatty acid profile ( $\%$ of total fatty acids) in $C D$ patients before $(=B)$ and after $(=A) 3$ months of supplementation with placebo $(n=8)$, antioxidants $(n=8)$ or $n-3$ fatty acids plus antioxidants $(n=9)$. EPA: eicosapentaenoic acid; DHA: docosahexaenoic acid; Significance level of change in plasma phospholipid fatty acid profile before and after 3 months of supplementation for the three treatment groups (Wilcoxon matched-pairs signed-rank test): ${ }^{*} \mathrm{P}<0.05$.

\section{Lipid peroxidation}

Lipid peroxidation did not change significantly after supplementation in either treatment group (placebo: $2.1 \mu \mathrm{mol} / \mathrm{L}(1.9-2.5)$ to $2.2 \mu \mathrm{mol} / \mathrm{L} \quad(2.0-2.4)$; antioxidant group: $2.6 \mu \mathrm{mol} / \mathrm{L}(2.3-2.7)$ to $2.7 \mu \mathrm{mol} / \mathrm{L}(2.3-3.2) ; \mathrm{n}-3$ fatty acids plus antioxidant group: $2.1 \mu \mathrm{mol} / \mathrm{L}(2.0-2.6)$ to $2.3 \mu \mathrm{mol} / \mathrm{L}(2.1-2.7))$. At baseline, levels of TBARs showed a significant negative correlation with serum selenium $(r=-0.59, P<0.01)$, and with serum $\beta$-carotene $(r=-0.49, P<0.02)$. We did not observe any significant correlations between levels of TBARs and antioxidants or fatty acids after 3 months of supplementation.

\section{Disease activity}

At baseline, patients did not differ significantly as regards disease activity measured by CDAI and CRP levels. CDAl significantly $(P<0.05)$ decreased from 
$99.6(69.5-169)$ to $78.1(45.9-154)$ in patients receiving n-3 fatty acids plus antioxidants, compared with no significant change in CDAl for those receiving antioxidants (119 (36.7-153) to $85.1(21.3-179) ; P=0.58)$ or placebo $(79.2$ $(47.1-120)$ to $56.3(34.4-111) ; P=0.20)$. Less abdominal pain, improved wellbeing and increased body weight, which are factors used in the calculation of CDAl, explained the reduced CDAl in patients receiving $n-3$ fatty acids plus antioxidants. CRP levels had not changed significantly in either treatment group after 3 months supplementation.

\section{Quality of life}

At baseline, treatment groups did not differ significantly in total IBDQ score. Furthermore, the total IBDQ scores had not changed significantly after 3 months of supplementation in either treatment group. In the total patient group, we observed significant correlations between the change in CDAI ICDAI before supplementation minus CDAI after supplementation) and the change in the "bowel symptoms" dimension of the IBDQ $(r=-0.54, P<0.01)$, and in addition, with the change of the "systemic symptoms" dimension of the IBDQ $(r=-0.51$, $P<0.01)$, respectively.

\section{Discussion}

This study showed an improved nutritional status and antioxidant status in CD patients, currently in remission, after 3 months of supplementation with a liquid formula containing either antioxidants or n-3 fatty acids plus antioxidants (IMPACTO) in addition to the regular diet. The latter formula contained a sufficient amount of $\mathrm{n}-3$ fatty acids to significantly decrease the eicosanoid precursor arachidonic acid and to increase eicosapentaenoic acid (EPA) and docosahexaenoic acid (DHA) in both plasma phospholipids and adipose tissue. This may eventually lead to the production of eicosanoids with attenuated proinflammatory activity ${ }^{16}$ and to a reduction of inflammatory cytokines ${ }^{35}$.

We performed a 'per-protocol' analysis because the primary aim of the present study was to investigate the physiological effects of 3 months of supplementation with either antioxidants or with antioxidants plus n-3 fatty acids, rather than to evaluate the efficacy of the supplementation on disease parameters. Patients who dropped out of the study were not investigated after 3 months. Absence of a significant difference after 3 months of supplementation with either formula may be caused by a $\beta$-error (type II error), because of the small number of patients studied.

Many studies have shown low compliance in dietary intervention studies, probably because of food intolerance, frequently reported in $C D$ patients ${ }^{36}$. There was a $30 \%$ patient drop out rate in the present study during intervention. However, this rate was not specifically related to one of the nutritional supplements. Most patients reported intolerance due to satiety induced by the 
supplement, indicating that it was difficult to consume calories in addition to the regular diet. It was shown that the fat intake of the regular diet had decreased after supplementation in patients receiving placebo and the antioxidant formula. Regular antioxidant intake had not significantly changed in either treatment group after 3 months supplementation. This shows that with nutritional supplementation, patients can positively adapt their regular food intake by reducing their fat intake, while preserving their regular antioxidant intake, resulting in significantly higher total intakes of antioxidants.

The metabolic events that occur during inflammation cause increased demands for certain nutrients which are involved in the elaboration and maintenance of antioxidant defenses ${ }^{37}$. Studies have indicated that an imbalance between increased reactive oxidative species production and reduced antioxidant defenses is involved in the pathogenesis of tissue injury in $C D^{38-42}$. Several studies have reported low concentrations of circulating antioxidant vitamins $^{2,7}$ and antioxidant minerals ${ }^{3,43}$ in $C D$ patients. In a recent study, we characterized the antioxidant status in patients with $C D$ in remission compared with controls and found deficiencies for vitamin $C$, vitamin $E, \beta$-carotene, selenium and zinc $^{12}$. Maintaining an adequate antioxidant status has been suggested as a useful approach to attenuate the cellular injury and dysfunction observed in $C D$. To our knowledge, the present study is the first intervention trial with dietary antioxidants in $C D$ patients. Antioxidant status was significantly improved in patients receiving antioxidant or antioxidant plus n-3 fatty acid supplementation for three months in addition to the regular diet. In the latter groups, the antioxidant status after supplementation was comparable with the antioxidant status of controls assessed in our previous study ${ }^{12}$.

A significantly decreased activity of the enzyme glutathione peroxidase was observed in patients receiving $n-3$ fatty acids plus antioxidants. Studies have shown that lipid peroxidation may increase after $n-3$ fatty acids supplementation because PUFAs are particularly vulnerable to free-radical attack caused by the process of hydrogen abstraction. ${ }^{44,45}$ Glutathione peroxidase is involved in detoxification of lipid hydroperoxides ${ }^{46.47}$, and it is therefore possible that the decreased activity of glutathione peroxidase in patients receiving $n-3$ fatty acids is explained by an increased use of glutathione peroxidase to prevent lipid peroxidation. Adequate nutritional selenium intake is also of major significance in patients supplemented with n-3 fatty acids, as the activity of glutathione peroxidase is dependent on selenium. Selenium concentrations had not increased significantly after 3 months of supplementation with n-3 fatty acids and/or antioxidants, which may indicate that more selenium is necessary for the overall protective mechanism of glutathione peroxidase. Fat malabsorption and steatorrhoea may also be involved ${ }^{48}$, as divalent cations such as selenium, magnesium or zinc may form unabsorbable subcomplexes (soaps) with malabsorbed fats.

The present study was not designed to examine the rate of relapse after $n-3$ supplementation in CD patients, but to estimate the absorption of $n-3$ fatty 
acids administered in a food supplement. EPA and DHA were incorporated into plasma phospholipids and adipose tissue at the expense of $n-6$ fatty acids, especially arachidonic acid. Pereira et al showed that circulating arachidonic acid levels in phospholipids fell significantly during successful treatment, induced by either elemental diet or steroids ${ }^{49}$. In a previous study we found that patients with long-standing $C D$, clinically in remission, who did not obtain fish oil supplementation, showed significantly lower concentrations of arachidonic acid $^{50}$. Results of a recent study suggested that fish oil is anti-inflammatory, principally through a reduction in the arachidonic acid content of phospholipids ${ }^{51}$. We hypothesize that these patients develop a mechanism to regulate eicosanoid synthesis in order to remain in remission. The results of the present study underline the possible beneficial effects of $n-3$ fatty acids in changing the precursors of the eicosanoids.

The formula with n-3 fatty acids and antioxidants also contained arginine. Dietary arginine has been shown to increase immune response (increased thymic weight, increased thymic lymphocyte content and increased lymphocyte interleukin 2 production and receptor activity ${ }^{45}$. In addition, arginine is the precursor for nitric oxide which is now recognized to be a cellular messenger with important immunological functions. Hence, arginine could theoretically influence disease activity and its effect in active $C D$ needs further investigation.

A variety of nutritional and functional deficiencies have been observed in patients with long-standing CD in remission ${ }^{12}$. Nutritional status is influenced by several factors such as decreased dietary intake, increased energy requirements or altered metabolism ${ }^{24}$. The pathophysiology of malnutrition is complex and it seems inappropriate to assess nutritional status on the basis of one set of parameters, e.g., laboratory parameters or body composition. The present study therefore assessed a comprehensive nutritional status by measuring body composition, dietary intake, biochemical parameters of nutrition and muscle strength as a functional parameter.

Body weight had increased significantly after 3 months of supplementation with either placebo or n-3 fatty acids plus antioxidants. This increased body weight was explained by a significant increase in body fat in these patients. The total fat intake of patients supplemented with the antioxidant formula had decreased after 3 months, compared with an increase in total fat intake in patients receiving placebo or $\mathrm{n}-3$ fatty acids/antioxidants. This difference could explain the stable body weight in patients supplemented with only antioxidants. Nutritional status had improved in patients supplemented with antioxidants despite no change in body weight. This indicates that body weight is not a sensitive indicator of nutritional status in this group of patients.

Malnutrition is associated with reduced muscle strength ${ }^{12,52}$. Lopes et al showed that skeletal muscle function is a sensitive indicator of the nutritional status of patients ${ }^{53}$. It was shown that exercise capacity in CD patients who had undergone proctocolectomy and small bowel resection was significantly reduced $^{54}$. In the present study, muscle strength as a functional parameter of 
nutritional status was restored after 3 months of supplementation with either extra antioxidants or with $\mathrm{n}-3$ fatty acids plus antioxidants. Macronutrient supplementation (placebo) alone did not change muscle strength in CD patients compared with controls. These results support the idea that immunomodulating nutrients may have beneficial effects on the nutritional status of $C D$ patients.

Quality of life as measured by the IBDQ was not affected by either treatment, indicating that the nutritional supplements were well tolerable and did not negatively affect the patients' daily life. The improved nutritional status did not improve their quality of life. It should be noted however, that IBDQ baseline scores already were comparable with scores in a control population ${ }^{55}$.

The present study was not designed to study the effects on disease activity, as the patients were already in remission at the start of the study. Nevertheless, after supplementation with $\mathrm{n}-3$ fatty acids plus antioxidants, the CDAI significantly decreased within the normal range. This was explained by the improvement in some of the parameters used to calculate CDAl: less abdominal pain, improved well-being and increased body weight. It should be noted however, that the CDAl decreased to about the same extent in the other treatment groups, however, this did not reach significance.

In summary, this study showed that both the antioxidant formula and the $n-3$ fatty acids plus antioxidants formula were well absorbed in patients with longstanding $C D$ clinically in remission; fatty acids were incorporated into adipose tissue. After 3 months of supplementation with either antioxidants or antioxidants plus n-3 fatty acids in addition to the regular diet, several measures of nutritional status and the antioxidant status were significantly improved in these patients. Furthermore, supplementation with $n-3$ fatty acids plus antioxidants significantly decreased the CDAl and changed the eicosanoid precursors profile, which may lead to the production of eicosanoids with attenuated proinflammatory activity. The nutritional supplement did not affect the patients' daily life which was indicated by the absence of a negative impact on quality of life. This study thus indicates that the administration of an oral formula containing immunomodulating nutrients such as $n-3$ fatty acids and antioxidants, in addition to the regular diet, may have a role in the treatment of CD. Long-term supplementation studies in large groups of patients will be required to investigate the effects of these nutrients on achieving remission or preventing relapse in Crohn's disease. 


\section{References}

1. Harries AD, Heatley RV. Nutritional disturbances in Crohn's disease. Postgraduate Med J 1983; 59:690-6.

2. Fernández-Bañares $F$, Abad-Lacruz A, Xiol X, Gine JJ, Dolz C, Cabré E, et al. Vitamin status in patients with inflammatory bowel disease. Am J Gastroenterol 1989; 84:744-8.

3. Fernández-Bañares $F$, Mingorance $M D$, Esteve $M$, Cabré $E$, Lachica $M$, AbadLacruz A, et al. Serum zinc, copper, and selenium levels in inflammatory bowel disease: effect of total enteral nutrition on trace element status. Am $J$ Gastroenterol 1990; 85:1584-9.

4. Cristie PM, Hill GL. Effect of intravenous nutrition on nutrition and function in acute attacks of inflammatory bowel disease: Gastroenterology 1990; 99:730-6.

5. Janczewska I, Bartnik W, Butruk E, Tomecki R, Kazik E, Ostrowski J. Metabolism of vitamin A in inflammatory bowel disease: Hepatogastroenterol 1991; 38:391-5.

6. Stokes MA. Crohn's disease and nutrition: $\mathrm{Br} J$ Surg 1992; 79:391-4.

7. Kuroki F, lida M, Tominaga M, Matsumoto T, Hirakawa K, Sugiyama S, Fujishima M. Multiple vitamin status in Crohn's disease. Correlation with disease activity. Dig Dis Sci 1993; 38:1614-8.

8. Royall D, Greenberg GR, Allard JP, Baker JP, Jeejeebhoy KN. Total enteral nutrition support improves body composition of patients with active Crohn's disease: J Parenteral Enteral Nutr 1995; 19:95-9.

9. Teahon K, Pearson M, Smith T, Bjarnason I. Alternations in nutritional status and disease activity during treatment of Crohn's disease with elemental diet: Scand $\mathrm{J}$ Gastroenterol 1995; 30:54-60.

10. Zurita VF, Rawls DE, Dyck WP. Nutritional support in inflammatory bowel disease: Dig Dis 1995; 503:92-107.

11. Silk DBA, Payne-James J. Inflammatory bowel disease: nutritional implications and treatment. Proc Nutr Soc 1989; 48:355-361.

12. Geerling BJ, Badart-Smook A, Stockbrügger RW, Brummer R-JM. Comprehensive nutritional status in patients with long-standing Crohn's disease in remission: Am J Clin Nutr 1998; 67:919-26.

13. Grimble RF. Nutrition and cytokine action. Nutr Res Rev 1990; 3:193-210.

14. Wan JMF, Haw MP, Blackburn GL. Nutrition, immune function, and inflammation: an overview. Proc Nutr Soc 1989; 48:315-35.

15. Belluzi A, Brignola C, Campieri M, Pera A, Boschi S, Migliolo M. Effect of an enteric-coated fish-oil preparation on relapses in Crohn's disease. N Eng J Med 1996; 334:1557-60.

16. Skou HA, Christensen JH, Aoroe J. Leukotrienes in chronic renal failure patients after dietary supplementation with $\mathrm{n}-3$ fatty acids: Eur J Clin Invest 1998; 28S:A27.

17. Daly JM, Lieberman MD, Goldfine J. Enteral nutrition with supplemental arginine, RNA, and omega-3 fatty acids in patients after operation: Immunologic, metabolic, and clinical outcome. Surgery 1992; 112:56-67.

18. Kemen M, Senkal M, Homan HH, Mumme A, Dauphin AK, Baier J, et al. Early postoperative enteral nutrition with arginine, n-3 fatty acids and ribonucleic acidsupplemented diet versus placebo in cancer patients: an immunologic evaluation of Impact $^{\oplus}$. Crit Care Med 1995; 23:652-9. 
19. Bower RH, Cerra FB, Bershadsky B, Licari JJ, Hoyt DB, Jensen GL, et al. Early enteral administration of a formula (Impact $\left.{ }^{\circledR}\right)$ supplemented with arginine, nucleotides, and fish oil in intensive care unit patients: Results of a multicenter, prospective, randomized, clinical trial. Crit Care Med 1995; 23:436-49.

20. Shenkal M, Kemen M, Homann HH, Eickhoff U, Baier J, Zumtobel V. Modulation of postoperative immune response by enteral nutrition with a diet enriched with arginine, RNA, and omega-3 fatty acids in patients with upper gastrointestinal cancer. Eur J Surg 1995; 161:115-22.

21. Lorenz-Meyer H, Nicolay C, Schulz B, Purrmann J, Fleig WE, Scheurlen C, et al. Omega-3 fatty acids and low carbohydrate diet for maintenance of remission in Crohn's disease: a randomized controlled multicenter trial. Scand J Gastroenterol 1996; 31:778-85.

22. Millar AD, Rampton DS, Chander CL, Claxson AWD, Blades S, Coumbe A, et al. Evaluating the antioxidant potential of new treatments for inflammatory bowel disease using a rat model of colitis. Gut 1996; 39:407-15.

23. Reimund JM, Allison AC, Muller CD, Dumont S, Kenney JS, Baumont R, Duclos B, Poidron P. Antioxidants inhibit the in vitro production of inflammatory cytokines in Crohn's disease and ulcerative colitis. Eur J Clin Invest 1998; 28:145-50.

24. Jeejeebhoy KN, Detsky AS, Baker JP. Assessment of nutritional status: J Parenteral Enteral Nutr 1990; 14:193S-6S.

25. Lennard-Jones JE. Classification of inflammatory bowel disease. Scand J Gastroenterol 1989; 24:2S-6S.

26. Mazess RB, Barden HS, Bisek JP, Hanson J. Dual-energy X-ray absorptiometry for total-body and regional bone-mineral and soft-tissue composition: Am J Clin Nutr 1990; 51:1106-12.

27. Al MDM, Badart-Smook A, v Houwelingen AC, Hasaart THM, Hornstra G. Fat intake of women during normal pregnancy: relationship with maternal and neonatal essential fatty acid status. J Am Coll Nutr 1996; 15:49-55.

28. NEVO Foundation. Dutch food composition table 1989-1990. Voorlichtingsbureau voor de Voeding. The Hague, The Netherlands (in Dutch).

29. Paglia DE, Valentine WN. Studies on the quantitative and qualitative characterization of erythrocyte glutathione peroxidase. J Lab Clin Med 1967; 70:158.

30. Gleeson NP, Mercer TH. The utility of isokinetic dynamometry in the assessment of human muscle function. Sports Med 1996; 21:18-34.

31. Al MDM, Hornstra G, van der Schouw YT, Bulstra-Ramakers MTEW, Huisjes HJ. Biochemical EFA status of mothers and their neonates after normal pregnancy. Early Human Development 1990; 24:239-48.

32. Best WR, Becktel JM, Singleton W. Rederived values of the eight coefficients of the Crohn's disease activity index (CDAl): Gastroenterology 1979; 77:843-6.

33. Naito C, Kawamura M, Yamamoto Y: Lipid peroxides as the initiating factor of atherosclerosis. Ann N Y Acad Sci 1993; 676:27-45.

34. Russel MGVM, Pastoor CJ, Brandon S, Rijken J Engels LGJB, Heijde van der DMFM, et al. Validation of the Dutch translation of the Inflammatory Bowel Disease Questionnaire (IBDQ): A health-related quality of life questionnaire in Inflammatory Bowel Disease. Digestion 1997; 58:282-8.

35. Caughey GE, Mantzioris E, Gibson RA, Cleland LG, James M. The effect on human tumor necrosis factor $\alpha$ and interleukin-1 $\beta$ production of diets enriched in $\mathrm{n}-3$ fatty acids from vegetables or fish oil. Am J Clin Nutr 1996; 63:112-6.

36. King TS, Woolner JT, Hunter JO. Review article: the dietary management of Crohn's disease. Aliment Pharmacol Ther 1997; 11:17-31. 
37. Grimble RF. Nutritional antioxidants and the modulation of inflammation: Theory and practice. New Horizons $1994 ; 32: 175-85$.

38. Grisham MB. Oxidants and free radicals in inflammatory bowel disease. Lancet 1994; 344:859-61.

39. Conner EM, Grisham MB. Inflammation, free radicals, and antioxidants. Nutrition 1996; 12:274-7.

40. Gross V, Arndt H, Andus T, Palitzsch KD, Scholmerich J. Free radicals in inflammatory bowel diseases pathophysiology and therapeutic implications. Hepatogastroenterol 1994; 41:320-7.

41. Simmonds NJ, Rampton DS. Inflammatory bowel disease, a radical view. Gut 1993; 34:865-8.

42. Buffinton GD, Doe WF. Altered ascorbic acid status in the mucosa from inflammatory bowel patients. Free Rad Res 1995; 22:131-43.

43. Hinks LJ, Inwards KD, Lloyd B, Clayton B. Reduced concentrations of selenium in mild Crohn's disease. J Clin Pathol 1988; 41:198-201.

44. Girelli D, Olivieri O, Stanzial AM. Factors affecting the thiobarbituric acid test as index of red blood cell susceptibility to lipid peroxidation: a multivariate analysis. Clin Chim Acta 1994; 227:45-57.

45. O'Leary MJ, Coakley JH. Nutrition and immunonutrition. Br J Anaest 1996; 77:118-27.

46. Sardesai VM. Role of antioxidants in health maintenance. Nutr Clin Prac 1995; 10:19-25.

47. Diplock AT. Antioxidant nutrients and disease prevention: an overview. Am J Clin Nutr $1991 ; 53: 189 S-93 S$.

48. Andersson H, Bosaeus I, Brummer R-J, Fasth S, Hultén L, Mangusson O, Strauss BI. Nutritional and metabolic consequences of extensive bowel resection. Dig Dis $1986 ; 4: 193-202$.

49. Pereira SP, Cassell TB, Engelman JL, Sladen GE, Murphy GM, Dowling RH. Plasma arachidonic acid-rich phospholipids in Crohn's disease: a response to treatment. Clin Sci 1996; 91:509-12.

50. Geerling BJ, van Houwelingen AC, Badart-Smook A, Stockbrügger RW, Brummer R-JM. Fat intake and fatty acid profile in plasma phospholipids and adipose tissue in patients with Crohn's disease compared with controls. Am J Gastroenterol 1999; 94:410-7.

51. Ling $P$, Boyce $P$, Bistrian BR. Role of arachidonic acid in the regulation of the inflammatory response in TNF- $a$-treated rats. J Parenter Enter Nutr 1998; 22:26875.

52. Nishio ML, Jeejeebhoy KN. Effect of malnutrition on aerobic and anaerobic performance of fast- and slow-twitch muscles of rats. J Parenter Enter Nutr $1992 ; 16: 219-25$.

53. Lopes J, Russell DMCR, Whitwell J, Jeejeebhoy KN. Skeletal muscle function in malnutrition. Am J Clin Nutr 1982; 36:602-10.

54. Brevinge H, Berglund B, Bosaeus I, Tolli J, Nordgren S, Lundholm K. Exercise capacity in patients undergoing proctocolectomy and small bowel resection for Crohn's disease. Br J Surg 1995; 82:1040-5. 


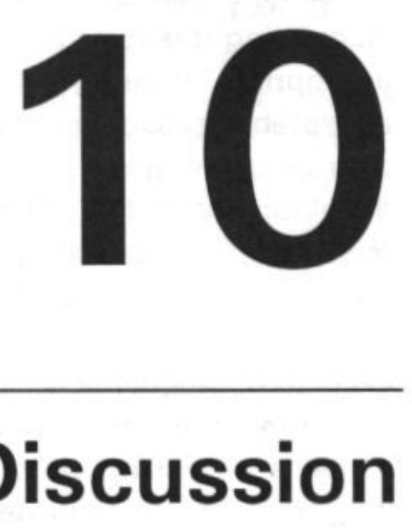




\section{General Discussion}

\section{The role of nutrition in the pathogenesis of Inflammatory Bowel Disease (IBD)}

The increasing incidence of IBD, especially Crohn's disease (CD) over the last fifty years ${ }^{1}$ coincides with profound changes in life-style and dietary patterns. An interaction between food intake and mucosal inflammation along the gastrointestinal tract therefore seems an attractive concept. There are indeed indications that diet may play a role in the etiology of IBD, but the difficulty in elucidating this hypothesis is related to the study design necessary to obtain the appropriate information. The incidence of IBD is too low to perform an acceptable prospective cohort study, hence a case-control study is the most appropriate method to investigate the etiological role of dietary factors in the development of IBD. The nature of this design, however, introduced the risk of recall bias ${ }^{2}$. In an effort to reduce this bias, we included only newly diagnosed patients (within 6 months of diagnosis) in the study described in Chapter 3 .

Objective biochemical indicators of dietary intake may be used to further overcome the problem of recall bias in case-control studies. Adipose tissue biopsies assessing fatty acid composition have been used as a biomarker of long-term polyunsaturated fatty acid intake, reflecting the fat intake over the previous 2-3 years ${ }^{3}$. The increased risk to develop ulcerative colitis (UC) which was associated with high consumption of polyunsaturated fatty acids as assessed by the dietary history method (Chapter 3), was not reflected by the adipose tissue results in that study. In IBD patients, however, especially those with $C D$, duration of disease symptoms before establishing the diagnosis may be months to years. This may influence dietary intake and therefore adipose tissue composition. Furthermore, medication administered in the early postdiagnosis period to achieve remission (especially corticosteroids) may influence the fatty acid pattern in adipose tissue. Adipose tissue biopsies, taken at the time of diagnosis as in our study (Chapter 3), therefore seem to be less useful for assessing pre-illness diet in IBD patients.

Reducing selection and information bias in a case-control study requires adequate controls. Many studies have used hospitalized controls who suffer from other diseases, which may influence dietary intake. The controls in our study were selected from a database of one general practice in the study region. In the Netherlands, almost every resident is registered by a general practitioner and the population database used in the present study is therefore a sample frame of the population within the study region. Subjects with a history of IBD were excluded. However, it cannot be ruled out that patients make a greater effort to remember their previous dietary habits than controls do, leading to differential misclassification. 
The study described in Chapter 3 concluded that a high consumption of monounsaturated and polyunsaturated fatty acids and vitamin B6 was associated with an increased risk of UC. An apparent paradox was found between previously reported beneficial effects of fish oil ( $n-3$ fatty acids) in treating active $\mathrm{UC}^{4-6}$ and the observed increased risk of developing UC following a high consumption of polyunsaturated fat (n-6 + n-3 fatty acids) (Chapter 3). The pre-illness fish consumption was, however, very low, indicating that fish consumption makes a negligible contribution to the total polyunsaturated fat intake. Hence, on the basis of the study presented in Chapter 3, fish consumption cannot be regarded as a risk factor for the development of UC. Furthermore, it is important to realize that dietary factors, which may be involved in the etiology of UC do not necessarily modulate the clinical course of the disease. The study presented in Chapter 3 was not designed to reveal a particular dietary pattern as a risk factor in the development of UC. However, it would be interesting to investigate whether the observed increased UC risk upon high consumption of the specific nutrients mentioned above may reflect a certain dietary pattern. In future studies, the role of specific food items or a particular dietary life-style in the etiology, clinical course or prognosis of UC needs to be investigated.

This thesis did not describe the role of diet in the pathogenesis of CD, because the number of newly-diagnosed $C D$ patients $(n=23)$ included was too small to perform the appropriate analysis (conditional logistic regression). Furthermore, the duration of disease symptoms before diagnosis was much longer than in UC patients. The data obtained were therefore less reliable, as the necessary dietary recall period of the pre-illness diet could exceed five years.

As the etiology of IBD is still unknown, it is possible that IBD is primarily initiated a long time before inflammation and complaints appear. The diet during childhood could be more important than the diet prior to disease complaints in order to identify risk factors in the development of IBD. However, reliable data on this subject are lacking.

\section{Assessment of nutritional status}

The nutritional status in IBD is influenced by several factors, including dietary intake, increased requirements, altered metabolism and disease activity ${ }^{7}$. The pathophysiology of malnutrition is complex and the necessity of assessing a comprehensive nutritional status in IBD patients was confirmed in the study described in Chapter 4. We found no significant associations between the various dimensions (body composition, dietary intake, biochemical parameters of nutrition and muscle strength) determining nutritional status. This implies that the assessment of just one dimension of nutritional status is a poor predictor of the other indices of nutritional status. 


\section{Nutritional status and disease duration}

A deteriorated nutritional status is expected especially in patients with longstanding $C D$ with small bowel involvement, because active inflammation and its sequelae may interfere with nutrient absorption. As our aim was to investigate the relation between $C D$ and malnutrition per se, we assessed the nutritional status in patients with long-standing $C D$ with small bowel involvement, who were currently in remission. We observed several nutritional and functional deficiencies in these patients (Chapter 4).

The next goal was to assess the nutritional status in patients with recently diagnosed IBD to see whether disease duration might be an important determinator of the nutritional status (Chapter 5). It should be noted that these patients recently had gone through an inflammatory process, although the majority of the patients were clinically in remission at time of investigation. We showed that in patients with recently diagnosed IBD (within 6 months of diagnosis), the nutritional status had deteriorated, although not as severely as in patients with long-standing $C D$. This may imply that disease duration and subsequent malnutrition are important factors affecting nutritional status in IBD.

The study described in Chapter 5 stresses the importance of assessing a comprehensive nutritional status in IBD patients at the time of diagnosis. One should be aware of the deteriorated antioxidant status in these patients. Furthermore, the observation that vitamin B12 concentration was already significantly decreased in patients with recently diagnosed $C D$ compared with controls, warrants attention to the vitamin B12 status at an early stage. The subclinical disease may have affected the ileal vitamin B12 uptake during many months or even years before diagnosis.

However, whether nutritional supplementation with eg. antioxidants during an early phase of IBD may be beneficial to the clinical course of the disease needs further investigation.

\section{Biochemical parameters of the nutritional status}

Decreased serum or plasma zinc concentrations have frequently been reported in $C D$, especially in patients with active inflammation ${ }^{8-10}$. We showed in the study presented in Chapter 4 that $50 \%$ of patients with long-standing CD clinically in remission have serum zinc concentrations below the 15 th percentile of controls, indicating a zinc deficiency ${ }^{10}$. Zinc is an essential trace element and has a key role in more than 200 enzymes. It has been shown that zinc deficiency is associated with growth failure, delayed wound healing, decreased protein synthesis, and impaired cell-mediated immunity (impaired antibodymediated responses to both T-cell-dependent and T-cell-independent antigens, and impaired natural killer-cell activity) ${ }^{11}$. This indicates that zinc deficiency may have negative consequences in IBD.

It is important to note, however, that a decreased serum or plasma zinc concentration does not always indicate a true zinc deficiency. Serum zinc is also decreased during inflammatory stress as a result of a decrease in serum 
albumin, enhanced interleukin-1 activity, or redistribution of zinc towards the liver $^{9}$. It seems therefore difficult to assess a reliable zinc status in patients with active disease. Several alternative methods for assessing the true zinc status have been suggested, such as the assessment of serum alkaline phosphatase activity $^{8.12}$, the activity of zincdependent enzymes ${ }^{13}$, zinc concentration in blood cells $^{9}$, hair and urinary zinc concentrations ${ }^{14}$, or in vitro uptake of zinc by blood cells $^{15}$. However, most of these methods are not suitable for clinical practice.

In a patient population with quiescent disease, however, serum zinc concentrations may provide adequate information about the true zinc status because the circulating zinc reflects the metabolizable or exchangeable zinc that is delivered to metabolically active tissues ${ }^{14}$.

Besides serum zinc, serum concentrations of fat-soluble vitamins may also be influenced by the activity of the disease. Fat-soluble vitamins have been found to be closely related to serum lipids, and in addition, hypolipidemia have been reported during active inflammation ${ }^{16}$. We therefore calculated the ratio of these fatsoluble vitamins to serum lipids or cholesterol to accurately assess fat-soluble vitamins status in IBD patients (Chapter $4,5,9$ ).

Selenium is considered an essential element for humans. It is a constituent of the antioxidant enzyme glutathione peroxidase $(\mathrm{GpX})$ which plays an important role against oxidative injury. A reduced $\mathrm{GpX}$ activity is thought to be a sensitive indicator of selenium deficiency ${ }^{17,18}$. This thesis showed that selenium concentrations and $\mathrm{GpX}$ activity were significantly lower in patients with longstanding $C D$ in remission than in controls (Chapter 4). Furthermore, we observed a significant correlation between serum selenium and $\mathrm{GpX}$ activity in patients with recently diagnosed UC, but not in age-and sex-matched controls (Chapter 5). This suggests that the selenium requirement for enzyme activity was met in the majority of the controls but not in the UC patients, indicating real selenium deficiency in the latter.

\section{Assessment of inflammatory activity}

Since one of the aims of this thesis was to investigate the relation between CD and malnutrition per se, we included patients with long-standing $C D$ who were clinically in remission. The criteria used were the absence of a significant acute phase response and stable body weight and no change in medication during the 3 months preceding the study. The Crohn's disease activity index (CDAI) is the most widely used parameter of disease activity, and remission of $C D$ is usually defined as a CDAl score below $150^{19}$. The CDAI includes several components, such as the number of soft/ liquid bowel movements, abdominal pain, sense of general well-being, and ideal body weight. In CD, one or several of these factors may well be negatively affected in the absence of inflammatory activity ${ }^{20}$. For example, a $C D$ patient with ileal dysfunction after extensive small bowel resection, but without histological evidence of active inflammation, may report a very high frequency of liquid stools, no abdominal pain, good general well-being, and a low body weight, resulting in a CDAl of 190. Following the CDAl criteria, 
this patient would have been considered having active disease. According to our criteria, however, this patient would have been clinically in remission due to a low C-reactive protein level ( $<9 \mathrm{mg} / \mathrm{L}$ ), stable body weight and stable medication. In our opinion, indices like the CDAl often reflect the extent or severity of the disease rather than the inflammatory activity.

The use of C-reactive protein has its limitations too. C-reactive protein increases non-specifically in response to inflammation and to an intercurrent common infection. Hence, C-reactive protein levels may increase without the presence of gastrointestinal inflammation, indicating that acute phase response is not a specific disease activity parameter in CD patients.

There is a need for new indices or parameters to accurately assess current inflammatory activity in IBD patients, although it may be wishful thinking that a parameter could be found that is sensitive and specific at the same time.

\section{Energy metabolism}

Increased energy expenditure associated with active inflammation has been suggested as an additional mechanism contributing to malnutrition in IBD. However, the available literature is unequivocal ${ }^{21-24}$. It has been assumed that weight loss in CD patients could be caused by an increased resting metabolic rate. However, Stokes and $\mathrm{Hill}^{22}$ showed that total energy expenditure was not raised in CD patients. In this thesis we assessed energy intake of IBD patients, however measurement of energy expenditure was not performed. To get a complete picture of the nutritional status of IBD patients and of the factors influencing it, energy balance (energy expenditure and energy intake) should be investigated in future studies.

\section{Muscle strength}

In the studies described in Chapters 4, 5, 9, muscle strength of IBD patients was measured by isokinetic dynamometry ${ }^{25}$. Using dynamometry, active torque of different muscle groups spanning one joint can be assessed dynamically. In the studies described in the present thesis muscle torque of the knee extensor (m. quadriceps) and knee flexor (the hamstring muscle group) muscles were determined.

Other devices to study muscle function, like the more commonly used hand-grip test ${ }^{26}$, mostly measure muscle contractile performance under static, isometric conditions, not taken into account the potential bias of muscle length. Dynamic muscle testing provides clear insight in the capability of the muscle to generate work over the entire range of motion and is therefore to be preferred. Furthermore, dynamometry as used in the present study permits testing of both knee flexor and extensor muscle in one experimental set-up. Since knee flexor and extensor differ in fiber typing, potential selective wasting of either muscle fiber type will be reflected in alterations in the flexor/extensor ratio. The flexor/extensor ratio provides information about muscle function and selective reduction of muscle strength in either the extensor or the flexor muscle group, 
and hence may serve as a functional parameter of the nutritional status.

Patients with long-standing CD who were clinically in remission showed a significantly decline in peak torque of the hamstrings muscle group, while the peak torque of the $\mathrm{m}$. quadriceps was preserved (Chapter 4). It is interesting to note that the muscle function (flexor/extensor ratio) did not significantly differ between recently diagnosed IBD patients and controls (Chapter 5). It has been shown that both corticosteroid therapy and malnutrition may induce atrophy of type Ilb muscle fibres ${ }^{27-29}$. The hamstring muscles have a higher percentage of type $\mathrm{llb}$ muscle fibres ${ }^{30}$ than do the $\mathrm{m}$. quadriceps. This may explain the selectively decline in peak torque of the hamstrings muscle group in patients with long-standing CD. Furthermore, a recent study showed that in malnourished patients the phosphocreatine/ ATP-ratio measured in muscles with nuclear magnetic resonance was signficantly lower compared with controls, indicating a reduction in total creatine ${ }^{31}$. The effect of malnutrition on muscle function may also be mediated by altered mitochondrial energetics. The observed abnormalities of muscle function in $C D$ patients with long-standing CD in remission may therefore be attributed to steroid use or malnutrition. Physical activity may also influence muscle function but was not taken into account in the present thesis. However, patients as well as controls were both sedentary with a few of them performing regular physical activity.

The peak torque of both the hamstring muscles and the $\mathrm{m}$. quadriceps were significantly lower in the $C D$ patient population included in the intervention study compared with controls (Chapter 9). The results of the intervention trial suggest that malnutrition is involved in the impaired muscle function, as muscle strength was restored in those patients in whom the nutritional status had improved after nutritional supplementation with n-3 fatty acids and/or antioxidants (Chapter 9). However, the distinct effects of both corticosteroids and malnutrition on muscle contractile performance remains to be elucidated. Muscle fatigue of unknown origin is frequently observed in CD patients and this stresses the importance to gain more insight into the relation between muscle function and IBD.

\section{Nutritional intervention}

We observed a deteriorated nutritional status in patients with long-standing CD who were clinically in remission (Chapters 4,6 ), which prompted us to try and improve their nutritional status. Several nutritional interventions have been considered to achieve this goal. In view of the results presented in this thesis (Chapters 4, 7, 8), we performed a randomized, double-blind, placebo-controlled study to assess the nutritional and metabolic effects of supplementation with energy, n-3 fatty acids and antioxidants for three months in addition to the regular diet in patients with long-standing $C D$, clinically in remission (Chapter 9). This intervention may regarded as nutritional support to improve e.g. the antioxidant status of $C D$ patients, but the supplement also contained potentially immuno-modulating nutrients. These nutrients (antioxidants, arginine, n-3 fatty 
acids and nucleotides) may have interacted with the immune system and may have resulted in immunologic benefits ${ }^{32}$. In order to evaluate the immunomodulating effects of these nutrients on inflammatory activity and the course of the disease in CD patients, it has to be established whether these nutrients are absorbed and utilized. We therefore investigated the effects of the nutritional supplement in patients with long-standing CD who were clinically in remission, to exclude effects of inflammatory activity on the nutritional status.

Antioxidants and fish oil were well absorbed, as was shown by the improved antioxidant status and increased proportions of eicosapentaenoic acid and docosahexaenoic acid in plasma phospholipids and adipose tissue in supplemented CD patients (Chapter 9). However, we do not know the influence of active inflammation on the absorption and metabolism of these nutrients in $C D$ patients. Furthermore, the effect of nutritional supplementation with n-3 fatty acids and antioxidants in UC patients is unknown, however, the intestinal absorption of nutrients will not be affected by disease activity in the latter group.

Fish oil (eicosapentaenoic acid (20:5n-3) and docosahexaenoic acid (22:6n-3)) may have anti-inflammatory activity because $n-3$ fatty acids are thought to compete in the substrate pool of the lipoxygenase pathway, thus reducing the production of eicosanoids with high inflammatory activity ${ }^{33}$. These fatty acids are also able to suppress the synthesis of other inflammatory cytokines, including interleukin- $1 \beta$ and tumor necrosis factor- $a^{34}$. As was shown in Chapter 7, we observed no eicosapentaenoic acid deficiency in plasma phospholipids in patients with long-standing $C D$ who were clinically in remission. On the other hand, patients with active $C D$ tended to have a lower proportion of eicosapentaenoic acid in plasma phospholipids compared with CD patients clinically in remission (borderline significance, $P=0.06$ ). This may support the beneficial role of fish oil in achieving remission in $C D$ patients with active disease and could explain the contradictory results of fish oil supplementation in preventing a relapse ${ }^{35,36}$. The studies presented in this thesis do not give an answer to this hypothesis. However, we reported a significantly decreased arachidonic acid proportion after n-3 supplementation (Chapter 9), which may have an attenuating effect on inflammation.

We found no significant change in quality of life after $n-3$ supplementation in $C D$ patients in remission. Furthermore, the CDAI significantly decreased within the normal range after $n-3$ supplementation. It should be noted, however, that the CDAl decreased to about in the same extent in the other treatment groups (placebo or antioxidant supplementation), however, this did not reach significance. This may underline the earlier mentioned disadvantages of using the CDAl for assessment of inflammatory activity in CD patients.

One of the well-known drawbacks of nutritional intervention is noncompliance $^{37}$. We also found a $30 \%$ patient drop-out rate, which was, however, 
not specifically related to one of the nutritional supplements (Chapter 9). Most patients found it difficult to consume the energy-rich and nutrient-rich supplement in addition to the regular diet. Motivation and compliance of patients will be hard to achieve with long-term nutritional supplementation. We therefore recommend to supplement IBD patients with specific immunomodulating nutrients without a high energy content. The supplement should be refreshing, with an acceptable taste. In a selective group of IBD patients with low body weight, however, an energy-rich supplement may be recommended.

\section{Implications for future research}

Nutrients may be involved in the pathogenesis of IBD, as was shown for UC patients in Chapter 3. However, as we did not study the nutritional pattern which may be responsible for the development of UC, it will be necessary to investigate dietary behavior and life-styles in the etiology of UC patients, as well as in $C D$ patients.

Disease duration was found to influence the nutritional status of CD patients in our studies. Although we found a deteriorated nutritional status in UC patients at the time of diagnosis, the comprehensive nutritional status in patients with long-standing UC is unknown and needs further research.

The selectively reduced muscle function observed in patients with longstanding $C D$ warrants further studies to investigate the specific effects of malnutrition and corticosteroid therapy on muscle function. This can be achieved by assessing muscle function in patients with obvious malnutrition without other concomitant inflammatory disease (e.g. anorexia nervosa) and in patients without obvious signs of malnutrition but with chronic corticosteroid use (a selected group of patients with chronic obstructive pulmonary disease or giant cell arthritis). Furthermore, it should be elucidated whether the selectively decreased muscle function is accompanied by increased muscle fatigue in $C D$ patients.

Studies of energy balance should be performed in order to investigate the effects of energy metabolism on the body composition and metabolism of IBD patients.

Nutritional status was significantly improved after supplementation with n-3 fatty acids and/or antioxidants in addition to the regular diet in $C D$ patients with quiescent disease. It should be investigated whether these nutrients may have an effect on the clinical course of the disease of CD patients as well as UC patients with a view to prolonging the remission phase of the disease. 


\section{References}

1. Sandler RS. Epidemiology of inflammatory bowel disease. In: Targan SR, Shanahan F, eds. Inflammatory bowel disease; from bench to bedside. Baltimore, Maryland: Williams \& Wilkins $1994 ; 5-32$.

2. Sacket DL, Haynes RB, Guyatt GH, Tugwell P. The clinical examination. In: Sacket DL, Haynes RB, Guyatt GH, Tugwell P, eds. Clinical epidemiology; a basic science for clinical medicine. 2nd edition. Toronto, Boston: Little, Brown and Company $1991 ; 19-51$.

3. Lands WEM. Long-term fat intake and biomarkers. Am J Clin Nutr 1995; 61:721S-5S.

4. Stenson WF, Cort D, Rodgers J, Burakoff R, Deschyrverkecskemeti K, Gramlicch TL, Becker W. Dietary supplementation with fish oil in ulcerative colitis. Ann Intern Med 1992; 116:609-14.

5. Aslan A, Triadafilipoulos F. Fish oil fatty acid supplementation in active ulcerative colitis: a double-blind, placebo-controlled, crossover study. Am J Gastroenterol 1992; 87:432-437.

6. Hawthorne AB, Daneshmend TK, Hawkey CJ. Treatment of ulcerative colitis with fish oil supplementation: a prospective 12 month randomized controlled trial. Gut 1992; 33:922-938.

7. Jeejeebhoy, KN, Detsky AS, Baker JP. Assessment of nutritional status. J Parent Enteral Nutr 1990; 14:193S-6S.

8. Hendricks KM, Walker WA. Zinc deficiency in inflammatory bowel disease. Nutr Rev $1988 ; 46: 401-8$.

9. Ainley CC, Cason LK, Carlsson LK, Slavin BM, Thompson RPH. Zinc status in inflammatory bowel disease. Clin Sci 1988; 75:277-83.

10. Fernández-Bañares $F$, Mingorance $M D$, Esteve $M$, Cabré $E$, Lachica $M$, AbadLacruz A, et al. Serum zinc, copper, and selenium levels in inflammatory bowel disease: effect of total enteral nutrition on trace element status. Am J Gastroenterol 1990; 85:1584-9.

11. Wan JMF, Haw MP, Blackburn GL. Nutrition, immune function, and inflammation: an overview. Proc Nutr Soc 1989; 48:315-35.

12. Naber THJ, Baadenhuysen H, Jansen JBMJ, Hamer van den CJA, Broek van den W. Serum alkaline phosphatase activity during zinc deficiency and long-term inflammatory stress. Clin Chim Acta 1996; 249:109-27.

13. Mulder TPJ, Sluys Veer van der A, Verspaget HW, Griffioen G, Pena AS, Janssens AR, et al. Effect of oral zinc supplementation on methallothionein and superoxide dismutase concentrations in patients with inflammatory bowel disease. J Gastroenterol \& Hepatol 1994; 9:472-7.

14. Solomons NW. On the assessment of zinc and copper nutrition in man. Am J Clin Nutr 1979; 32:856-71.

15. Naber THJ, Heymer F, Hamer van den CJA, Broek van den WJM, Jansen JBMJ. The in vitro uptake of zinc by blood cells in rats with long-term inflammatory stress. Clin Nutr 1994; 13:247-55.

16. Horwitt MK, Harvey CC, Dahm CH, Searcy MT. Relationship between tocopherol and serum lipid levels for determination of nutritional adequacy. Ann NY Acad Sci 1972; 203:223-36.

17. Thomas AG, Miller V, Shenkin A, Fell GS, Tayler F. Selenium and glutathione peroxidase status in paediatric health and gastrointestinal disease. J Pediatr Gastroenterol Nutr 1994; 19:213-9.

18. Nève J. Methods in determination of selenium status. J Trace Elem Electrolytes Health Dis $1991 ; 5: 1-17$. 
19. Best WR, Becktel JM, Singleton W. Rederived values of the eight coefficients of the Crohn's disease activity index (CDAl). Gastroenterol 1979;77:843-6.

20. Stenson WF, Alpers DH. Nutritional therapy in inflammatory bowel disease: a historical overview. Curr Opinion Gastroenterol 1997; 13:135-9.

21. Chan ATH, Fleming R, O'Fallon WM, Huizinga KA. Estimated versus measured basal energy requirements in patients with Crohn's disease. Gastroenterology 1986; 91:75-8.

22. Stokes MA, Hill GL. Total energy expenditure in patients with Crohn's disease: measurement by the combined body scan technique. J Parenter Enter Nutr 1993; 17:3-7.

23. Mingrone G, Benedetti G, Capristo E, De Gaetano A, Virgillo Greco A, Tataranni PA, et al. Twenty-four-hour energy balance in Crohn disease patients: metabolic implications of steroid treatment. Am J Clin Nutr 1998; 67:118-123.

24. Capristo E, Mingrone G, Addolorato G, Greco AV, Gasbarrini G. Metabolic features in inflammatory bowel disease in a remission phase of the disease activity. J Int Med 1998; 243:339-347.

25. Gleeson NP, Mercer TH. The utility of isokinetic dynamometry in the assessment of human muscle function. Sports Med 1996; 21:18-34.

26. Klidjian AM, Forster KJ, Kammerling RM. Relation of anthropometric and dynamometric variables to serious postoperative complications. Br J Med J 1980; 281:899-901.

27. van Balkom RHH, van der Heijden HFM, van Herwaarden CLA, Dekhuijzen PNR. Corticosteroid-induced myopathy of the respiratory muscles. Neth J Med 1994; 45:114-22.

28. Russell DMCR, Leiter LA, Whitwell J, Marliss EB, Jeejeebhoy KN. Skeletal muscle function during hypocaloric diets and fasting: a comparison with standard nutritional assessment parameters. Am J Clin Nutr 1983; 37:133-8.

29. Church JM, Choong SY, Hill GL. Abnormalities of muscle metabolism and histology in malnourished patients awaiting surgery: effect of a course of intravenous nutrition. Br J Surg 1984; 71:563-9.

30. Garret WE, Mummen M, Lucareche C. Ultrastructural differences in human skeletal muscle fiber types. Orthop Clin North Am 1983; 14:413-25.

41. Thompson A, Damyanovich A, Madapallimattam A, Mikalus D, Allard J, Jeejeebhoy KN. ${ }^{31} \mathrm{P}$-nuclear magnetic resonance studies of bioenergetic changes in skeletal muscle in malnourished human adults. Am J Clin Nutr 1998; 67:39-43.

42. O'Leary MJ, Coakley JH. Nutrition and immunonutrition. $\mathrm{Br} J$ Anaest 1996; 77:118-127.

43. Rask-Madsen J. Eicosanoids in inflammatory bowel disease: advances, pitfalls and therapeutic consequences. Eur J Gastroenterol Hepatol 1989; 1:133-65.

44. Caughey GE, Mantzioris E, Gibson RA, Cleland LG, James MJ. The effect on human tumor necrosis factor- $\alpha$ and interleukin-1 $\beta$ production of diets enriched in n-3 fatty acids from vegetable oil or fish oil. Am J Clin Nutr 1996; 63:116-22.

45. Lorenz-Meyer H, Nicolay C, Schulz B, Purrmann J, Fleig WE, Scheurlen C, et al. Omega-3 fatty acids and low carbohydrate diet for maintenance of remission in Crohn's disease: a randomized controlled multicenter trial. Scand J Gastroenterol $1996 ; 31: 778-85$.

46. Belluzi A, Brignola C, Campieri M, Pera A, Boschi S, Migliolo M. Effect of an enteric-coated fish-oil preparation on relapses in Crohn's disease. N Eng J Med 1996; 334:1557-60.

47. King TS, Woolner JT, Hunter JO. Review article: the dietary management of Crohn's disease. Aliment Pharmacol Ther 1997; 11:17-31. 



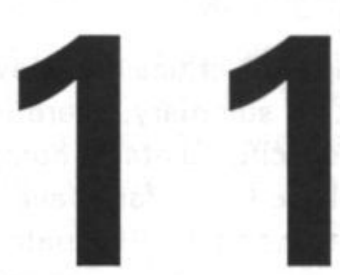

Summary 


\section{Summary}

This thesis describes the role of nutrition in patients with Crohn's disease (CD) and ulcerative colitis (UC), collectively referred to as Inflammatory Bowel Disease (IBD). Three main topics which can be distinguished with regard to the relation between nutrition and IBD are addressed: the role of specific dietary components in the pathogenesis of IBD; the prevalence of malnutrition in the course of the disease; and nutritional therapy to improve nutritional status.

Chapter 2 critically reviews the current knowledge about the role of nutrition in IBD. In summary, there is still very little conclusive evidence regarding the role of specific dietary components in the pathogenesis of IBD. Many studies published so far have been subject to methodological flaws. Nutritional deficiencies in IBD patients, especially in $C D$, have been documented. It is, however, hard to discriminate between disease-induced and malnutritioninduced changes in nutritional parameters. Maintaining an adequate nutritional status has been suggested to be beneficial for the disease course in IBD. Several studies have provided further insights into the possible beneficial effects of nutritional supplementation as an adjunctive therapy in IBD. Polyunsaturated $\mathrm{n}-3$ fatty acids, as in fish oil, may have anti-inflammatory activity because they compete with polyunsaturated $n-6$ fatty acids in the substrate pool of the lipoxygenase pathway, thus reducing the production of leukotrienes with high inflammatory activity.

In Chapter $\mathbf{3}$ the role of dietary factors in the etiology of UC is described using a case-control study. Pre-illness diet of UC patients and population controls was assessed using a cross-check dietary history. It was shown that high intakes of monounsaturated fatty acids and polyunsaturated fatty acids and vitamin B6 were associated with a significantly increased UC risk. This may reflect a particular, as yet unidentified, dietary life-style. It is unclear whether fish consumption, which may be useful in the treatment of inflammation, is involved in the etiology of UC, because both patients and controls reported very low fish intake. This may indicate that fish ( $\mathrm{n}-3$ fatty acids) intake makes a negligible contribution to the total polyunsaturated fatty acid intake (n-6 and n-3 fatty acids).

The association between long-standing ( $>10$ years) $C D$ and malnutrition is reported in Chapter 4. The nutritional status of patients with long-standing $C D$ who were currently in remission, as well as that of age- and sex-matched population controls was comprehensively assessed by 1) dietary intake, 2) body composition, 3) biochemical parameters of nutrition, and 4) muscle strength. This study showed a variety of nutritional and functional deficiencies in patients compared with controls. Serum concentrations of $\beta$-carotene, vitamin $C$, vitamin $E$, selenium and zinc, and activity of glutathione peroxidase were significantly 
lower in $C D$ patients than in controls. Furthermore, a selectively reduced strength of the hamstring muscles was reported in these patients, especially in males. We did not found significant associations between the various dimensions determining nutritional status. This implies that a comprehensive nutritional assessment is superior to the assessment of a single dimension of nutritional status.

A study on the nutritional status of recently diagnosed IBD patients (within 6 months of diagnosis) and age- and sex-matched population controls was performed in order to investigate whether malnutrition was associated with disease duration (Chapter 5). This study revealed that even at the time of diagnosis, IBD patients were at risk of developing several nutritional deficiencies, especially antioxidant deficiency. The decrease in serum antioxidants in UC patients seem to be explained by an increased use of antioxidants by the inflamed tissue rather than by a deficient intake or impaired digestion and absorption of nutrients. The present data support the hypothesis that a reduced antioxidant defense in IBD patients may be important with regard to the pathogenesis of early tissue injury in IBD.

In Chapter 6 the results of a study on body composition in various groups of IBD patients are presented. Measurement of body composition is an essential part of nutritional assessment in IBD, as malnutrition and inflammation may lead to aberrations in the size of body water compartments. However, no data about body water distribution in IBD had been reported. We reported an altered body water distribution and body hydration in female IBD patients. Fluid shifts were most pronounced in female patients with recently diagnosed CD, which suggests that a recent acute inflammatory process, in addition to malnutrition, could be a major factor contributing to the altered body composition. In male IBD patients, no significant changes in body water distribution were observed, but body weight, body fat and fat-free mass were significantly lower than in age- and sex-matched population controls. The mechanism for the observed gender-based differences in body water distribution in IBD is as yet unclear. Our findings illustrate the importance of a comprehensive body composition assessment in IBD patients.

Fatty acid metabolism is involved in the immune response and inflammation processes in $C D$ patients and may be relevant to the clinical course of the disease. A study describing the qualitative and quantitative fat intake as well as the fatty acid profile of plasma phospholipids and adipose tissue in various groups of $C D$ patients and age- and sex-matched population controls is presented in Chapter 7. Although the quatitative or qualitative fat intake did not differ significantly between patients and controls, an aberrant essential fatty acid profile was found in CD patients, especially in patients with long-standing CD. We observed a significantly lower percentage of the sum of the $n-3$ fatty 
acids, with significantly higher levels of clupanodonic acid (22:5n-3) and significantly lower levels of docosahexaenoic (22:6n-3) and arachidonic acid $(20: 4 n-6)$. This aberrant fatty acid profile may be the result of an altered metabolism rather than of malabsorption of essential fatty acids. The reported findings may be important with regard to the pathophysiology of $C D$, and hence, in the choice of fatty acids to be used when therapeutic administration is considered in CD patients.

The relations between the results presented in Chapters 6 and 7 are discussed in Chapter 8. In addition, the fatty acid profile in plasma phospholipids and the antioxidant status were assessed in $C D$ patients during an exacerbation of the disease and subsequent remission. The plasma phospholipid fatty acid profile differed significantly between patients with active compared with inactive disease, as was illustrated by the increased sum of the saturated fatty acids, the decreased sum of the unsaturated fatty acids and the decreased EFA status in the former group. We observed a significantly diminished antioxidant status in patients with active $C D$ compared with inactive $C D$ and controls, respectively. In addition, the antioxidant defence was depleted in patients with inactive CD compared with controls. Furthermore, the fatty acid profile in CD patients was significantly associated with inflammatory activity and serum antioxidant concentrations. This observation, along with the diminished antioxidant defense in patients with active and inactive $C D$, supports the hypothesis that antioxidants should be considered in the therapy of inflammation in CD.

The results of the studies presented in this thesis (Chapters 3-8) led to an intervention study described in Chapter 9. The primary aim of this study was to assess the effects of supplementation with n-3 fatty acids and antioxidants in addition to the regular diet on the nutritional status of $C D$ patients. To eliminate effects of disease activity on the nutritional status, inclusion was restricted to $C D$ patients who were clinically in remission. The randomized, double-blind, placebo-controlled study showed that the antioxidant status and the nutritional status improved significantly after 3 months of supplementation with antioxidants or with n-3 fatty acids plus antioxidants, compared with placebo. Supplementation with $n-3$ fatty acids plus antioxidants significantly changed the eicosanoid precursor profile, which may result in the production of eicosanoids with attenuated proinflammatory activity; the proportions of eicosapentaenoic acid and docosahexaenoic acid in plasma phospholipids and adipose tissue increased significantly and the proportion of arachidonic acid decreased significantly after n-3 fatty acids plus antioxidant supplementation. This study indicates that an immuno-modulating formula containing n-3 fatty acids and/or antioxidants may potentially play a beneficial role in the treatment of CD.

In conclusion, this thesis shows that specific nutrients may play a role in the development of UC, however it remains to be elucidated whether a specific 
dietary pattern is associated with an increased UC risk. It was furthermore shown, that the nutritional status of patients with long-standing CD who were clinically in remission, and that of recently diagnosed (within the previous 6 months) IBD patients was significantly deteriorated. Finally, nutritional supplementation with $\mathrm{n}-3$ fatty acids and/or antioxidants improved the nutritional status of patients with long-standing $C D$, and such immunomodulating formula may potentially play a beneficial role in the treatment of IBD. 



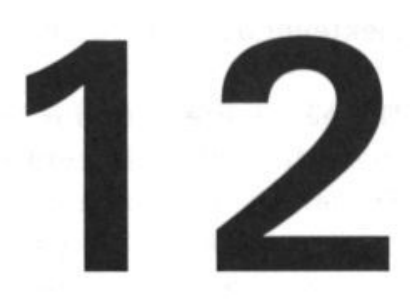

\section{Samenvatting}




\section{Samenvatting}

Dit proefschrift beschrijft de rol van voeding bij patiënten met de ziekte van Crohn (CD) en colitis ulcerosa (UC). Beide ziektebeelden vormen samen het begrip 'Inflammatory Bowel Disease' (IBD, inflammatoire darmziekten). Drie belangrijke gebieden op het terrein van voeding en IBD worden behandeld: de rol van specifieke voedingscomponenten bij het ontstaan (etiologie) van IBD; de prevalentie van een slechte voedingstoestand (malnutritie) tijdens het ziekteverloop; en voedingstherapie om de voedingsstatus te verbeteren.

$\mathrm{Na}$ een korte introduktie in hoofdstuk 1 wordt in hoofdstuk 2 een kritisch overzicht gepresenteerd van de huidige kennis over de rol van voeding bij IBD. Er zijn op dit moment geen duidelijke aanwijzingen dat voedingscomponenten een rol spelen bij de pathogenese van IBD. Veel studies die over dit onderwerp zijn gepubliceerd hebben methodologische zwakheden. Voedingsdeficiënties bij IBD patiënten, speciaal bij de ziekte van Crohn zijn vaak gerapporteerd. Het blijkt echter moeilijk om onderscheid te maken tussen ziekte-geïnduceerde en malnutritie-geïnduceerde veranderingen van voedingsparameters. $\mathrm{Er}$ zijn aanwijzingen dat handhaving van een goede voedingsstatus een gunstige invloed kan hebben op het ziekteproces van IBD. Resultaten van verscheidene studies hebben een beter inzicht gegeven over de mogelijke positieve effecten van voedingssuppletie als aanvullende therapie bij IBD. Meervoudig onverzadigde $n-3$ vetzuren, zoals die voorkomen in visolie, hebben een antiinflammatoire werking o.a. doordat ze het substraat zijn voor de productie van eicosanoiden met een verminderde inflammatoire activiteit. De meervoudig onverzadigde $n-3$ vetzuren concurreren om de enzymen 5-lipoxygenase en cyclooxygenase met de meervoudig onverzadigde $\mathrm{n}-6$ vetzuren welke eicosanoiden produceren met een hoge inflammatoire activiteit.

In hoofdstuk 3 wordt de rol van voeding in het ontstaan (de etiologie) van UC beschreven waarbij gebruik is gemaakt van een case-control design. Een crosscheck dietary history is gebruikt om de voedselconsumptie van 5 jaar tevoren te bepalen in UC patiënten en populatie-gebaseerde controle personen. De resultaten van dit onderzoek toonden aan dat een hoge consumptie van meervoudig- en enkelvoudig onverzadigde vetzuren en vitamine B6 geassocieerd waren met een significant verhoogd risico op het ontwikkelen van UC. Dit kan een afspiegeling zijn van een bepaalde levensstijl, welke tot op heden nog niet is geïdentificeerd. Het is niet duidelijk of de consumptie van visolievetzuren, die een gunstige invloed lijken te hebben bij de behandeling van UC, een rol spelen bij het ontstaan van UC. Zowel patiënten als controle personen aten zulke geringe hoeveelheden vis dat visconsumptie ( $n-3$ vetzuren) een verwaarloosbare bijdrage levert aan de totale consumptie van meervoudig onverzadigde vetzuren ( $n-6+n-3$ vetzuren). 
De relatie tussen langdurige ziekte van Crohn en malnutritie wordt beschreven in hoofdstuk 4. De voedingsstatus werd uitgebreid bepaald bij patiënten die meer dan 10 jaar aan de ziekte van Crohn lijden maar geen recente klinische ziekteactiviteit hadden en bij leeftijd- en geslacht gematchte controle personen door middel van 1) de voedselconsumptie, 2) lichaamssamenstelling, 3) biochemische parameters van voeding, en 4) spierkracht. Bij patiënten met de ziekte van Crohn werden verscheidene voedings- en functionele deficiënties gerapporteerd vergeleken met controle personen: serum concentraties van $\beta$ caroteen, vitamine C, vitamine $E$, selenium en zink en de activiteit van glutathione peroxydase waren significant lager. Bovendien werd in deze patientengroep, vooral bij de mannen, een selectief verminderde spierkracht van de hamstrings spieren gerapporteerd. Er werden geen significante relaties gevonden tussen de verschillende dimensies die de voedingsstatus bepalen. Dit geeft aan dat een uitgebreide bepaling van de voedingsstatus de voorkeur verdient boven de bepaling van een enkele dimensie van de voedingsstatus.

Om vast te stellen of malnutritie geassocieerd is met de ziekteduur is de voedingsstatus van een groep nieuw gediagnostiseerde IBD patiënten (binnen 6 maanden na diagnose) en leeftijd- en geslacht gematchte controle personen bestudeerd in hoofdstuk 5 . Deze studie geeft aan dat IBD patiënten, zelfs op het tijdsstip van diagnose, allerlei voedingsdeficiënties hadden, vooral deficiënties van antioxidanten. Een verminderde consumptie of verstoorde vertering en absorptie van antioxidanten kan niet de verklaring hiervoor zijn. Er werd daarom aangenomen dat een toegenomen verbruik van antioxidanten door het ontstoken weefsel bij UC een oorzaak kan zijn voor de verminderde antioxidant status bij UC patiënten. Deze gegevens ondersteunen de hypothese dat bij IBD patiënten een verminderde antioxidanten verdediging een rol kan spelen bij de pathogenese van vroege weefselbeschadiging.

In Hoofdstuk 6 worden de resultaten gepresenteerd van een studie naar de lichaamssamenstelling van verschillende groepen IBD patiënten en controle personen. Bij het vaststellen van de voedingstoestand bij IBD patiënten is het belangrijk om de lichaamssamenstelling te bepalen, omdat zowel malnutritie als ontsteking kunnen leiden tot veranderingen van de omvang van de lichaamswatercompartimenten. Er zijn echter uit de literatuur weinig gegevens bekend over de lichaamswaterverdeling bij IBD patiënten. In bovengenoemd hoofdstuk hebben wij een veranderde waterverdeling en hydratie in het lichaam beschreven bij vrouwelijke IBD patiënten vergeleken met controle personen. Deze waterverschuivingen waren vooral aantoonbaar bij nieuw gediagnostiseerde vrouwelijke IBD patiënten. Dit suggereert dat met name een recent acuut ontstekingsproces, naast malnutritie, een belangrijke bijdrage levert aan de veranderde lichaamssamenstelling. Bij mannelijke IBD patiënten werden geen veranderingen van lichaamswaterverdeling gerapporteerd. Echter, lichaamsgewicht, lichaamsvet en vetvrije massa waren significant lager dan bij 
leeftijd-en geslacht gematchte controle personen. Het mechanisme achter deze geslacht-gebaseerde verschillen in lichaamssamenstelling is nog onduidelijk en meer onderzoek is noodzakelijk.

Het vetzuurmetabolisme is betrokken bij het ontstekingsproces van patiënten met de ziekte van Crohn en de immuunrespons. In hoofdstuk 7 wordt een studie beschreven waarin zowel de kwalitatieve als kwantitatieve vetzuurconsumptie en het vetzuurprofiel van plasma fosfolipiden en vetweefsel worden bepaald bij verschillende groepen $C D$ patiënten en leeftijd- en geslacht-gematchte controle personen. Alhoewel de kwantitatieve en kwalitatieve vetzuurconsumptie niet verschilde tussen patiënten en controle personen, werd een afwijkend essentieel vetzuurpatroon gevonden bij $C D$ patiënten, vooral bij die patiënten die al langdurig aan de ziekte lijden. Een significant lager percentage van de som van de $n-3$ vetzuren, en een significant lagere concentratie van clupadonzuur $(22: 5 n-3)$, docosahexaeenzuur $(22: 6 n-3)$ en arachidonzuur $(20: 4 n-6)$ werden in bovengenoemde patientengroep geobserveerd. Gezien het feit dat malabsorptie van essentiële vetzuren geen rol lijkt te spelen concluderen wij dat dit afwijkende vetzuurpatroon het resultaat kan zijn van een veranderd vetzuurmetabolisme. Deze bevindingen zijn van belang ten aanzien van de pathofysiologie bij de ziekte van Crohn, maar ook ten aanzien van de keuze van vetzuren als mogelijke therapeutische suppletie.

De relaties tussen de resultaten die gepresenteerd zijn in de hoofdstukken 4,5 en 7 worden besproken in hoofdstuk 8 . Bovendien worden de antioxidant status en het vetzuurpatroon in plasma fosfolipiden bij patiënten met de ziekte van Crohn tijdens een exacerbatie en de daaropvolgende remissie periode beschreven. Het plasma fosfolipiden vetzuurpatroon bij patiënten met een actieve ziekte verschilde van het vetzuurpatroon bij patiënten zonder actieve ziekte en controle personen: in de eerste groep patiënten werden een verhoogde som van de verzadigde vetzuren, een verlaagde som van de onverzadigde vetzuren en een verlaagde essentiële vetzuur status waargenomen vergeleken met patiënten zonder ontstekingsaktiviteit en controle personen. De antioxidant status was significant verslechterd in de patiëntengroep met actieve ziekte vergeleken met de patiënten zonder actieve ziekte en de controle personen. De antioxidanten verdediging was ook verminderd in patiënten met inactieve ziekte vergeleken met controle personen. Bovendien was het vetzuurpatroon significant gecorreleerd met de ontstekingsactiviteit concentraties en de serum antioxidant concentraties. Dit gegeven, samen met de verminderde antioxidanten verdediging, onderstreept de hypothese dat antioxidanten kunnen worden overwogen in de therapie ten aanzien van de ontsteking bij de ziekte van Crohn. 
De resultaten van de studies die in dit proefschrift zijn beschreven (hoofdstuk 3-8) resulteerden in een interventie trial die beschreven is in Hoofdstuk 9. Het primaire doel van deze studie was het bepalen van het effect van een voeding met $n-3$ vetzuren en antioxidanten op de voedingsstatus bij patiënten met de ziekte van Crohn. Dit supplement werd gegeven naast de normale voeding. Om de effecten van ziekteactiviteit op de voedingsstatus uit te sluiten werden alleen patiënten geïncludeerd zonder klinische ziekteactiviteit. Deze gerandomiseerde, dubbel blind placebo gecontroleerde studie toonde aan dat de antioxidant status en de voedingsstatus significant verbeterde na 3 maanden suppletie met antioxidanten alleen of de combinatie van $n-3$ vetzuren en antioxidanten vergeleken met placebo. Het aandeel van eicosapentaeenzuur en docosahexaeenzuur in plasma fosfolipiden en vetweefsel nam significant toe en het aandeel van arachidonzuur nam significant af na suppletie van $n-3$ vetzuren plus antioxidanten. Dit vetzuurpatroon is geassocieerd met een productie van eicosanoiden met een verminderde pro-inflammatoire activiteit. Deze studie laat zien dat een voedingssuppletie met $n-3$ vetzuren en/of antioxidanten met immunologisch modulerende effecten potentieel een nuttige rol kan spelen bij de behandeling van de ziekte van Crohn.

Samenvattend illustreert dit proefschrift dat specifieke nutriënten een rol kunnen spelen bij het ontstaan van colitis ulcerosa, maar dat het nog onduidelijk is of een specifiek voedingspatroon geassocieerd is met een verhoogd risico op het ontwikkelen van colitis ulcerosa. In dit proefschrift is bovendien aangetoond dat de voedingsstatus van patiënten die al meer dan 10 jaar aan de ziekte van Crohn lijden, maar ook van nieuw gediagnostiseerde IBD patiënten (binnen zes maanden na diagnose) significant was verslechterd vergeleken met controle personen. Tevens toonden we aan dat voedingssuppletie met $n-3$ vetzuren en/of antioxidanten de voedingsstatus van patiënten met de ziekte van Crohn significant verbeterde hetgeen van belang kan zijn de behandeling van IBD. 



\section{Dankwoord}

Uit eigen ervaring weet ik dat dit waarschijnlijk het meest gelezen stuk gaat worden uit mijn proefschrift. Dat is misschien wel jammer maar het positieve hiervan is dat ik kan laten zien dat ik met veel mensen en met veel plezier heb gewerkt aan dit proefschrift.

Graag wil ik een aantal mensen in het bijzonder bedanken.

Als eerste wil ik mijn waardering uitspreken voor alle patiënten en controle personen die hebben meegewerkt aan de studies beschreven in dit proefschrift. Zonder dat het misschien direct voor jullie zelf merkbaar was, hebben jullie een bijdrage geleverd aan het verkrijgen van meer kennis over inflammatoire darmziekten. Bedankt allemaal voor jullie medewerking!

Er zijn twee mensen die zeer betrokken zijn geweest bij dit proefschrift, mijn promotor Reinhold Stockbrügger en mijn co-promotor Robert-Jan Brummer. Beste Robert-Jan, zonder te overdrijven kan ik zeggen dat ik door jouw begeleiding al die jaren met heel veel plezier aan dit proefschrift heb gewerkt. Jouw grenzeloos enthousiasme en wetenschappelijke wijsheid heb ik enorm gewaardeerd. Dat ook mijn eigen ideeën voor het onderzoek aandacht kregen en uitgewerkt konden worden heeft mij enorm gesteund en vertrouwen gegeven. Maar misschien heb ik nog wel de meeste waardering voor het feit dat ik altijd bij je kon binnen lopen en dat we naast de wetenschappelijke discussies ook vaak hebben 'geoâwehoerd' over van alles en nog wat.

Beste Reinhold, jouw interesse en kennis op het gebied van Gastroenterologie en verwante kennisgebieden is enorm. Vooral tijdens de laatste 'schrijffase' wanneer ik dacht 'de inhoud van het artikel ziet er prima uit', waren daar altijd weer die kritische en waardevolle opmerkingen die het artikel compleet maakten. Ik heb veel van je geleerd, waarvoor mijn hartelijke dank!

Ik wil alle leden van de beoordelingscommissie, Dr I Bosaeus, Prof dr MP van Dieijen-Visser, Prof dr SGM Meuwissen, Prof dr ir WHM Saris, Prof dr HP Sauerwein en Prof dr EHM Wouters bedanken voor hun bereidheid dit proefschrift te lezen en de beoordelen.

Anita Badart heeft een enorme hoeveelheid werk verzet door aan alle patiënten en controle personen (en dat waren er heel wat) te vragen wat ze nu precies eten. Beste Anita, ontzettend bedankt voor je enthousiaste inzet en fijne samenwerking, maar ook voor de gezellige gesprekken die er meestal voor zorgden dat we allebei weer wat meer Twents gingen praten.

Bij Humane Biologie heb ik met een groot aantal mensen prettig samengewerkt. Rian van Houwelingen, jij bent nauw betrokken geweest bij 'alle vetzuren-data' in dit proefschrift. Bedankt voor onze goede samenwerking en jouw kritische en praktische opmerkingen. Gerard Hornstra, ook bedankt voor jouw heldere blik op onze vetzuur-data. Hasibe Aydeniz en Marianne Simonis bedankt voor de hulp bij de vetzuur-analyses. 
Van de 'lichaamssamenstelling-mensen' wil ik als eerste Wouter van Marken Lichtenbelt noemen. Wouter, je zette me vaak aan het denken met je vragen, maar nu weet ik, dat ik juist hierdoor wijzer ben geworden. Bedankt voor je enthousiasme en kritisch advies. Adje, bedankt voor de hulp bij de broomanalyses maar ook voor je altijd vrolijke humeur. Loek Wouters en Klaas Westerterp wil ik bedanken voor hun hulp bij de deuterium-analyses.

Hans Keizer en Harm Kuipers van de vakgroep Bewegingswetenschappen hebben een bijdrage geleverd aan het spierkracht onderzoek. Ik wil Matthijs Hesselink vooral bedanken voor zijn geduldige uitleg over de Cybex en zijn heldere visie op de spierkracht data.

Bij de afdeling Nucleaire Geneeskunde kon ik altijd rekenen op Lia, Florence en Sandra. Zij zorgden ervoor dat iedere patiënt en controle persoon van top tot teen werden gescand. Reuze bedankt voor jullie enthousiaste inzet.

Op het Klinisch Chemisch Lab zijn bijna alle biochemische bepalingen van mijn onderzoek uitgevoerd. Er waren heel wat buisjes bloed die elke dag weer bij jullie terecht kwamen. ledereen bedankt, maar met name Lou Donselaar wil ik bedanken voor de fijne samenwerking.

Van het Lab Endocrinologie wil ik Geertje en Gabriëlle bedanken voor de bepaling van de TBARs. Gabriëlle, ik denk nog wel eens terug aan ons gedenkwaardige bezoek naar Maagdenburg. Bedankt dat je erbij was, want we hebben achteraf toch veel gelachen.

Petra Koken wil ik bedanken voor de statistische ondersteuning tijdens de laatste fase van mijn onderzoek maar vooral voor de relaxte lunchpauzes.

Van de afdeling Epidemiologie wil ik Pieter Dagnelie en Maurice Zeegers bedanken. Pieter, jij hebt een belangrijke bijdrage geleverd aan het schrijfwerk van het epidemiologische artikel. Bedankt voor jouw zeer kritische inzet. Maurice, bedankt dat je af en toe je computer afstond zodat ik met STATA kon werken.

Christine Hermans, bedankt voor het verzamelen van voedingsgegevens tijdens de vier maanden afwezigheid van Anita Badart.

Jan Klerkx, bedankt voor de altijd zeer snelle Engelse correcties van dit proefschrift.

Dr L Engels, Dr L Bos van het Maasland Ziekenhuis in Sittard en Dr C van Deursen van het Atrium ziekenhuis in Brunssum wil ik bedanken voor het includeren van patiënten in dit onderzoek. Door de enthousiaste medewerking van Cees van Deursen konden we met een relatief grote groep patiënten het voedingssuppletie-onderzoek uitvoeren. Bedankt!

Mireille Spanjers en Judith Numan zijn als stagiaires betrokken geweest bij dit proefschrift. Bedankt voor jullie goede inzet.

I would like to thank Adrian Heini and Heinz Schneider from Novartis Nutrition in Switzerland for the valuble scientific discussions and the genuine interest in our project. 
Binnen de werkgroep Gastroenterologie heb ik met veel plezier gewerkt. Ik wil dan ook graag Erik Schoon, Maurice Russel, Wim Hameeteman, Ingrid Pladdet, Robert Bragelman, Ton Vrij en Ger Koek bedanken voor hun gezelligheid maar ook voor het altijd weer vragen aan de patiënten of ze mee wilden doen met mijn onderzoek. Erik, ik kijk met veel plezier terug op de congressen die we samen hebben bezocht, bedankt! Gaby, in de periode dat je bij ons werkte ging ik altijd met plezier 'naar boven'. Bedankt voor de aangename werksfeer en ook voor alle hulp. Ook wil ik Edith Maes en Lilian Wishaupt bedanken voor alle behulpzaamheid en betrokkenheid bij mijn onderzoek. ledereen van de Endoscopie afdeling, bedankt dat ik kamer 1 kon gebruiken maar ook voor jullie interesse in mijn onderzoek. Elvira Dautzenberg en Andrea Boers, bedankt voor jullie enthousiasme op de Functiekamer.

Een speciaal plekje krijgt toch Anita Ruijgers. Anita, wij hebben vanaf het begin bij elkaar op de Functiekamer gezeten. Zonder jouw hulp had ik heel wat jongens naar de eerste hulp moeten dragen omdat ze waren flauw gevallen. Jij wist veel storingen te voorkomen, maar ik wil je vooral bedanken voor je gezelligheid tijdens onze 'leut-uurtjes' op de Functiekamer.

Ook wil ik een speciaal woord van dank richten tot mijn 'collega-AlOs', Ardi, Silvia, Daisy Michiel, Martine en Ingrid. Bedankt voor jullie medeleven, gezelligheid, steun en de prettige werksfeer. Met name aan Martine, Ingrid en Michiel ben ik veel dank verschuldigd. Bedankt voor jullie luisterend oor. Wat had ik gemoeten zonder jullie! Ik ben dan ook heel blij dat Martine en Michiel mijn paranimfen wilden zijn.

Tiny Wouters heeft er voor gezorgd dat de binnenkant (de lay-out) van dit proefschrift er zo mooi uit ziet. Bedankt! De buitenkant van dit boekje is gemaakt door Ineke Brummer. Het is prachtig geworden en ik ben er erg blij mee. Bedankt, ook voor de gastvrijheid bij mijn werkbezoeken bij jullie thuis.

Voor de broodnodige ontspanning in het weekend zorgden vele vrienden en familie. Allen hartelijk dank.

Lieve Papa en Mama, ook al snapten jullie niet altijd waarmee ik bezig was, ik kon altijd op jullie rekenen. Jullie hebben mij destijds het vertrouwen gegeven om helemaal in Maastricht te gaan studeren en ook te gaan werken. Als dank voor jullie onvoorwaardelijke steun en liefde draag ik dit proefschrift op aan jullie.

Ook Edwin en Maud, pa en ma Philipsen, Marly en Jos wil ik bedanken voor hun gezelligheid, interesse en betrokkenheid bij mijn onderzoek.

Lieve Ronald, jij was mijn uitlaatklep voor alles. Geduldig luisterde je naar mijn verhalen van elke dag in Maastricht, die gelukkig al wat waren genuanceerd door de lange trein/auto reis. Soms gaf je voorzichtig een advies, maar altijd wist je weer het positieve naar boven te halen. Bedankt voor jouw vertrouwen en, ... dat je er altijd was! 


\section{Publicaties}




\section{Artikelen}

1. BJ Geerling, MS Alles, PR Murgatroyd, GR Goldberg, M Harding, AM Prentice. Fatness in relation to substrate oxidation during exercise. Int J Obs 1994; 18:453-9.

2. R-JM Brummer, BJ Geerling, RW Stockbrügger. Initial and chronic gastric acid inhibition by lansoprazole and omeprazole in relation to meal administration. Dig Dis Sci 1997; 42:2132-7.

3. BJ Geerling, A Badart-Smook, RW Stockbrügger, R-JM Brummer. Comprehensive nutritional status in patients with long-standing Crohn's disease in remission. Am J Clin Nutr 1998; 67:919-26.

4. BJ Geerling, AC v. Houwelingen, A Badart- Smook, RW Stockbrügger, R-JM Brummer. Fat intake and fatty acid pattern in plasma phospholipids and adipose tissue in patients with Crohn's disease compared with controls. Am J Gastroenterol $1999 ; 94: 410-7$.

5. MA van Nieuwenhoven, BJ Geerling, NEP Deutz, F Brouns, R-JM Brummer. The sensitivity of the lactulose rhamnose gut permeability test. Eur J Clin Invest 1999; 29:160-5.

6. BJ Geerling, RW Stockbrügger, R-JM Brummer. Nutrition and Inflammatory Bowel Disease: an update. Scand J Gastroenterol (in press).

7. BJ Geerling, WD van Marken Lichtenbelt, RW Stockbrügger, R-JM Brummer. Gender specific alterations of body composition in patients with Inflammatory bowel disease compared with controls. Eur J Clin Nutr (in press).

\section{Abstracts}

1. BJ Geerling, WD van Marken-Lichtenbelt, RW Stockbrügger, R-JM Brummer. Body water compartments of patients with inflammatory bowel disease compared to controls. Clinical Nutrition 1996; 15:070:19.

2. BJ Geerling, WD van Marken Lichtenbelt, RW Stockbrügger, R-JM Brummer. Validation of multiple-frequency bio-electrical impedance in patients with inflammatory bowel disease to estimate total body water and extra-cellular water. Clinical Nutrition 1996; 15:P77:44.

3. BJ Geerling, MA van Nieuwenhoven, R-JM Brummer, RW Stockbrügger. Intestinal permeability is not increased in patients with inflammatory bowel disease. European Journal of Gastroenterology and Hepatology 1996; 8 (No 12): A49.

4. BJ Geerling, WD van Marken Lichtenbelt, RW Stockbrügger, R-JM. Brummer. A comparative study on body water distribution in patients with inflammatory bowel disease. European Journal of Gastroenterology and Hepatology 1996; 8 (No 12):A51.

5. BJ Geerling, R-JM Brummer, RW Stockbrügger. Decreased antioxidant status in patients with inflammatory bowel disease. European Journal of Gastroenterology and Hepatology 1996; 8 (No 12):A51.

6. EJ Schoon, AB van Nunen, G Heidendal, BJ Geerling, MGVM Russel, RW Stockbrügger, R-JM Brummer. Low body fat and risk for osteoporosis in Crohn's disease. Gut 1996; 39:A168.

7. MA van Nieuwenhoven, BJ Geerling, NEP Deutz, F Brouns, R-JM Brummer. Gut permeability test in subjects with and without exercise-induced gastrointestinal symptoms. Gut 1996; 39:A247. 
8. BJ Geerling, AC van Houwelingen, A Badart-Smook, RW Stockbrügger, R-JM Brummer. Altered fatty acid pattern of plasma phospholipids and adipose tissue in patients with long-standing Crohn's disease compared with controls. Gastroenterology 1997; 112:A980.

9. BJ Geerling, A Badart-Smook, RW Stockbrügger, R-JM Brummer. Fat and antioxidant intake in patients with Inflammatory Bowel Disease compared to controls. Gastroenterology 1997: 112:A875.

10. BJ Geerling, R W Stockbrügger, R-JM Brummer. Isokinetic upper leg muscle strength as a functional parameter of nutritional status in patients with inflammatory bowel disease. Clinical Nutrition 1997; 16:012:4.

11. BJ Geerling, RW Stockbrügger, R-JM Brummer. Muscle strength as a functional parameter of nutritional status in patients with inflammatory bowel disease. European Journal of Gastroenterology and Hepatology 1997; 9 (No 12):A55.

12. BJ Geerling, AC van Houwelingen, RW Stockbrügger, R-JM Brummer. The effect of antioxidants $/ \mathrm{n}-3$ fatty acids supplementation on the plasma phospholipid fatty acid pattern and disease activity in patients with Crohn's disease in a double blind placebo controlled study. European Journal of Gastroenterology and Hepatology 1998; 10 (No 12):A24.

13. BJ Geerling, C van Deursen, RW Stockbrügger, R-JM Brummer. Improved antioxidant status after supplementation with $\mathrm{n}-3$ fatty acids and/or antioxidants in addition to a regular diet in patients with Crohn's disease in a double blind placebo controlled study. European Journal of Gastroenterology and Hepatology 1998; 10 (No 12):A23.

14. MA van Nieuwenhoven, BJ Geerling, NEP Deutz, F Brouns, R-JM Brummer. The effect of strenuous exercise on gut permeability. J Sport Sci 1998; 16:503-4.

15. MA van Nieuwenhoven, BJ Geerling, NEP Deutz, E Thys, F Brouns, R-JM Brummer. The sensitivity of the lactulose/rhamnose gut permeability test is influenced by the dosage of lac/rham when the permeability is increased. Gastroenterology 1998; 114:G1741.

16. EJ Schoon, BJ Geerling, L Schurgers, C Vermeer, RW Stockbrügger, R-JM Brummer. Bone formation is suppressed and bone resorption is normal in longstanding quiescent Crohn's disease. Gastroenterology 1998; 114:G4421.

17. EJ Schoon, BM Blok, BJ Geerling, MG Russel, RW Stockbrügger, R-JM Brummer. Is bone mineral density in patients with inflammatory bowel disease low at diagnosis? A case-control study. Bone 1998; 23:T364.

18. EJ Schoon, BJ Geerling, L Schurgers, C Vermeer, MGVM Russel, RW Stockbrügger, R-JM Brummer. Serum and bone vitamin K depletion in patients with long-standing Crohn's disease. Bone 1998; 23:S607.

19. BJ Geerling, C van Deursen RW Stockbrügger, R-JM Brummer. Restoration of muscle strength after nutritional supplementation in patients with Crohn's disease in a double blind placebo controlled study. Gastroenterology 1998; 114:G4032.

20. BJ Geerling, PC Dagnelie, RW Stockbrügger, R-JM Brummer. Polyunsaturated and monounsaturated fatty acids and vitamin B6 are risk factors for the development of ulcerative colitis. Gastroenterology 1999 (in press). 



\section{Curriculum vitae}





\section{Curriculum Vitae}

Bertine Geerling werd geboren op 14 augustus 1969 te Zwolle. In 1986 behaalde zij het HAVO diploma en in 1988 het VWO diploma aan het Meander College te Zwolle. In 1988 startte zij met de studie Gezondheidwetenschappen aan de Universiteit Maastricht, met als afstudeerrichting Biologische Gezondheidskunde. Na een stage op het Dunn Clinical Nutrition Centre in Cambridge, Engeland werd het doctoraal examen behaald in april 1994. Op 1 mei 1994 begon zij als assistent in opleiding (AIO) bij de vakgroep Interne Geneeskunde van de Universiteit Maastricht onder leiding van Prof Dr RW Stockbrügger en Dr R-JM Brummer. In dit proefschrift staat het uitgevoerde onderzoek beschreven. Sinds 1 mei 1999 is zij werkzaam als post-doc bij de vakgroep Interne Geneeskunde van de Universiteit Maastricht. 
